Portland State University

PDXScholar

\title{
Secondary stresses in bowstring timber trusses
}

John F. Bradford

Portland State University

Follow this and additional works at: https://pdxscholar.library.pdx.edu/open_access_etds

Part of the Civil Engineering Commons, and the Structural Engineering Commons Let us know how access to this document benefits you.

Recommended Citation

Bradford, John F., "Secondary stresses in bowstring timber trusses" (1983). Dissertations and Theses. Paper 3252.

https://doi.org/10.15760/etd.3242

This Thesis is brought to you for free and open access. It has been accepted for inclusion in Dissertations and Theses by an authorized administrator of PDXScholar. Please contact us if we can make this document more accessible: pdxscholar@pdx.edu. 
AN ABSTRACT OF THE THESIS OF John F. Bradford for the Degree of Master of Science in Applied Science (Structural Engineering) presented February $21,1983$.

Title: Secondary Stresses in Bowstring Timber Trusses.

APPROVED BY MEMBERS OF THE THESIS COMMITTEE:

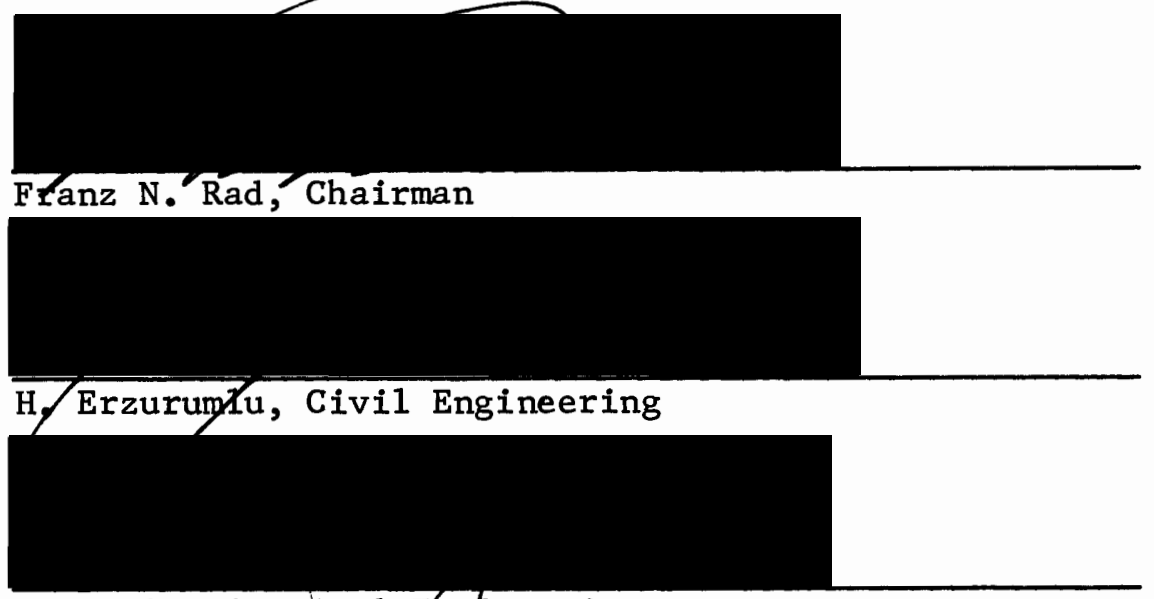

M. M. Gorji, Civil Engineering

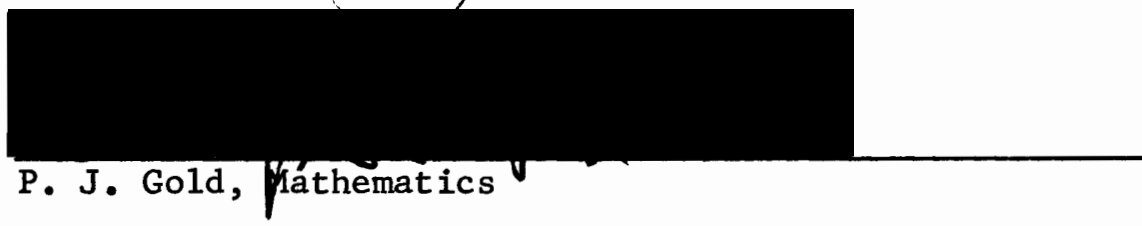

This study was undertaken in order to determine analytically the magnitude of the secondary (i.e., joint deflection induced) moments in the continuous glued-laminated chords of bowstring timber trusses. Traditionally, these moments have been assumed to be small and therefore neglected. The American Institute of Timber Construction makes no mention of these moments in their recommended design procedure. 
The results of the investigation show, however, that these moments are theoretically very large--considerably larger than the primary moment. In a typical design problem, a truss designed neglecting the secondary moments was found to be $36 \%$ overstressed when these moments were considered.

Proposed design charts and characteristic equations which represent the secondary moments are presented for three truss configurations.

A byproduct of the investigation was the development of a method to produce general characteristic equations for a specific structural configuration. These equations allow the designer to quickly determine the maximum moments, shears, deflections or other variables which may be affected by changing a parameter such as the moment of inertia of one of the members. The effect on the structure of changing a parameter can be determined immediately by the use of the characteristic equations as opposed to the significant time and effort involved in running a complete frame analysis. The technique is primarily intended for standard structures, such as trusses, but might also be useful for structures which require a large number of iterations before obtaining the final design.

A computer program for the technique which can be implemented on a sma11 microcomputer is presented. 


\title{
SECONDARY STRESSES
}

IN BOWSTRING TIMBER TRUSSES

by

JOHN F. BRADFORD

A thesis submitted in partial fulfillment of the requirements for the degree of

\author{
MASTER OF SCIENCE
}

in

APPLIED SCIENCE

(STRUCTURAL ENGINEERING)

Portland State University

1983 
TO THE OFFICE OF GRADUATE STUDIES AND RESEARCH:

The members of the Committee approve the thesis of John F. Bradford presented February 21, 1983.

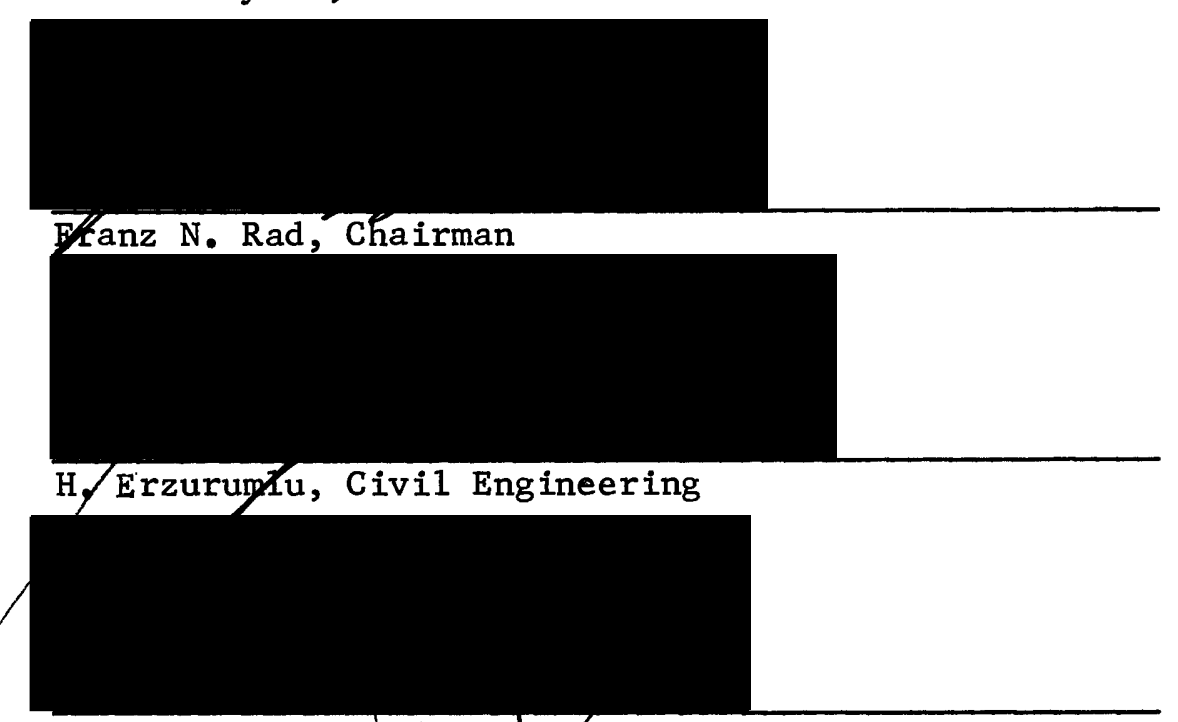

M. M. Gorji, Civil Englineering
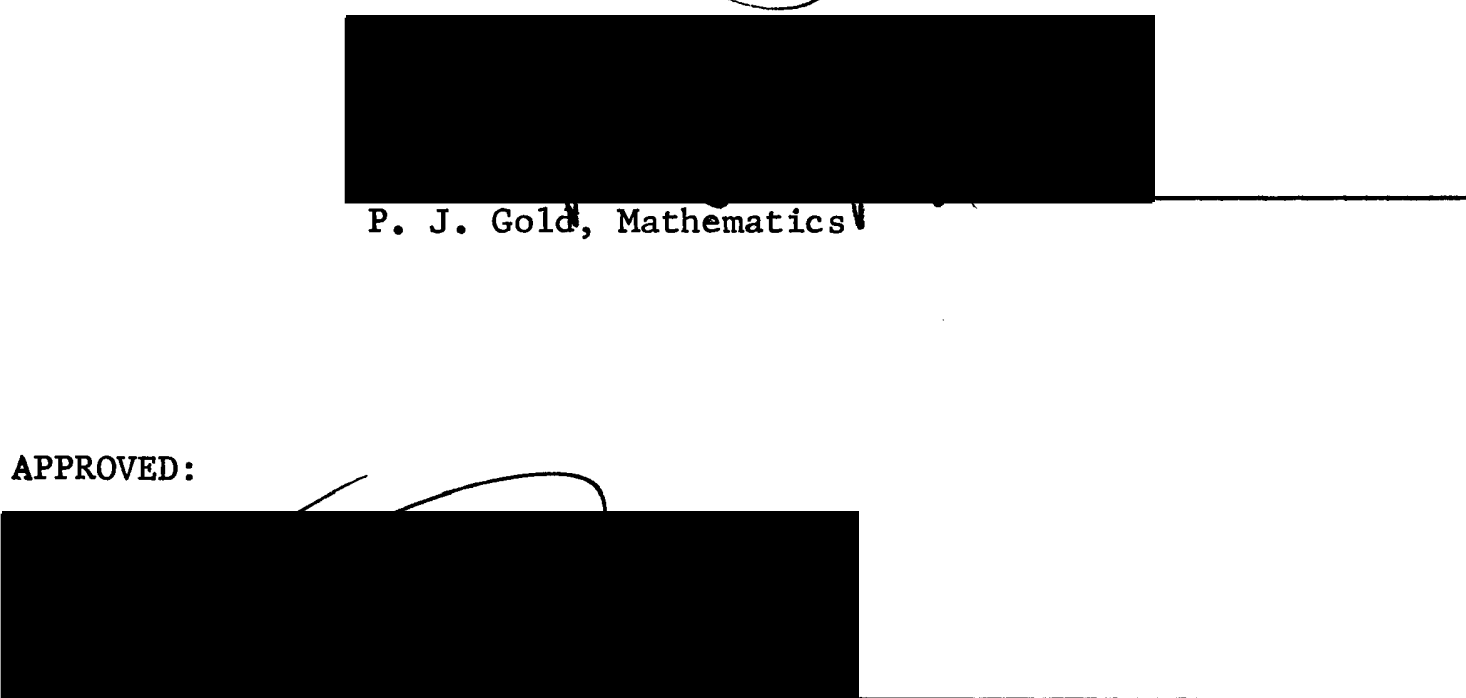

Franz N. Rad, Department of Civil Engineering

Stanley E. Rauch, Dean of Graduate Studies and Research 
TO MY LOVING WIFE

DONETA

and

MY FOUR CHILDREN

JOSHUA

KAYLA

LARISSA

MEGAN 


\section{ACKNOWLEDGEMENTS}

This investigation was carried out under the supervision of Dr. Franz N. Rad. The author is indebted to Dr. Rad for his help and advice throughout this work.

The author would also like to thank the other members of his thesis committee, Dr. Hacik Erzurumlu, Dr. M. M. Gorji, and Dr. Phil J. Gold for their helpful comments and suggestions.

The author would like to thank Mr. Dick W. Ebeling for his valuable input and for allowing the author to devote a considerable number of office hours to this work.

Thanks are also due to Dr. Wendelin H. Mueller for his assistance in the application of the frame analysis program, "RIGID", which he authored; also to Leon Kempner for his assistance in the application of the SAPIV program.

The author would like to extend his thanks to Mrs. Sharon U11rich for the excellent typing of this thesis.

I am especially indebted to my dear and loving wife and to my four children for their understanding, encouragement and patience throughout the author's graduate work. 
TABIE OF CONTENTS

PAGE

ACKNOWLEDGEMENTS. .................. iv

LIST OF TABLES. ................... ix

LIST OF FIGURES ................... xii

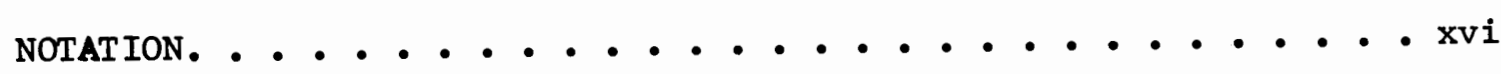

CHAPTER

I INTRODUCTION ..................... 1

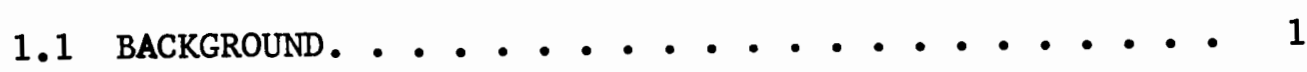

1.2 DESIGN METHODS. . . . . . . . . . 2

1.2.1 Traditional Method ........... 2

1.2.2 Computer Frame Analysis. ........ 3

1.3 DESIGN PROBLEMS ..................... 4

1.4 SCOPE OF THIS INVESTIGATION .......... 5

II STRUCTURAL CHARACTERISTICS AND CONSTRUCTION DETAILS

OF GLUED-LAMINATED BOWSTRING TRUSSES . . . . . . . 7

2.1 STRUCTURAL CHARACTERISTICS. . . . . . . . 7

2.2 COMMON CONSTRUCTION DETAILS . . . . . . 8

2.2.1 Geometry ............ 8

2.2 .2 Details............ 10

III COMPUTER MODELS. . . . . . . . . . . . . 16

3.1 GENERAL INFORMATION ................. 16

3.2 EIGHT PANEL TRUSS ............... 16 
PAGE

3.2 .1 Model I. . . . . . . . . . 16

3.2.2 Model II . . . . . . . . . 17

3.2.3 Model III. . . . . . . . . . 17

3.2 .4 Loading. . . . . . . . . 20

3.2 .5 Variations ........... 20

3.2.5.1 Web Connection Bolt Slippage. . . 20

3.2.5.2 Heel Joint Slippage ....... 22

3.2.5.3 Heel Joint Fixity . . . . . . 22

3.2.5.4 Bottom Chord Splice Bolt S1ippage • . 22

3.2.5.5 Bottom Chord Splice Fixity. . . . 23

3.2.5.6 Heel Plate Fixity, Chord Rotation

Permitted at Bolts....... 23

3.2.5.7 Combinations of Effects ..... 23

3.2.6 Member Properties............ 23

3.3 TEN PANEL TRUSS . . . . . . . . . . . 27

3.4 TWELVE PANEL TRUSS. . . . . . . . . . . 27

IV PRIMARY MOMENTS IN THE TOP CHORD . . ....... 30

4.1 METHODS OF ANALYSIS .............. 30

4.1.1 AITC Method........... 30

4.1.2 Moment Distribution.......... 31

4.1.2.1 FEM due to "Pe" ........ 31

4.1.2.2 FEM due to External Member Loads. . 31

4.1.2.3 Moment Distribution ....... 32

V SECONDARY MOMENTS IN THE BOTTOM CHORD. . . . . . . 46 
5.1 PARAMETERS AFFECTING THE SECONDARY MOMENT IN

THE BOTTOM CHORD. . . . . . . . . . 46

$5.2 \mathrm{M}_{\mathrm{BC}}$ AS A FUNCTION OF $\mathrm{A}_{\mathrm{BC}} \ldots \ldots \ldots 2$

5.3 THE EFFECT OF $\mathrm{I}_{\mathrm{BC}} \mathrm{ON} \mathrm{M}_{\mathrm{BC}} \cdots \ldots . . \ldots 54$

$5.4 \mathrm{M}_{\mathrm{BC}}$ AS A FUNCTION OF $A_{\mathrm{TC}} \mathrm{AND} \mathrm{I}_{\mathrm{TC}} \cdots \cdots 60$

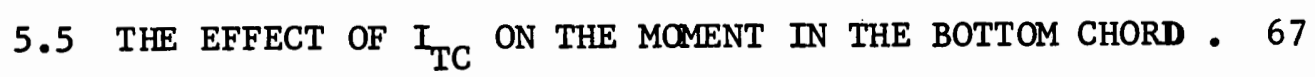

5.6 INFLUENCE OF TRUSS SPAN (L) ON $\mathrm{M}_{\mathrm{BC}} \cdots \cdots 71$

5.7 THE INFLUENCE OF LOADING ON $\mathrm{M}_{\mathrm{BC}} \ldots \ldots 75$

5.8 THE INFLUENCE OF THE NUMBER OF PANELS ON M $\mathrm{BC} \cdots 75$

5.9 SUMMARY . . . . . . . . . . . . 79

VI SECONDARY MOMENTS IN THE TOP CHORD .......... 83

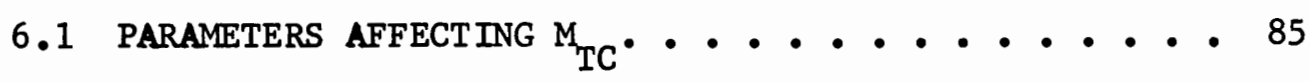

6.2 DEVELOPMENT OF EQUATIONS. . . . . . . . 85

VII VERIFICATION OF EQUATIONS DEVELOPED IN CHAPTERS V AND VI • 98

VIII OTHER FACTORS AFFECTING THE SECONDARY MOMENTS IN THE

CHORDS ......................... 102

8.1 BOLT SLIPPAGE IN THE WEB CONNECTIONS. . . . . 102

8.2 HEEL FIXITY ...................... 103

8.3 BOLT SLIPPAGE IN THE HEEL CONNECTION. ...... 104

8.4 BOTTOM CHORD SPLICE ................. 108

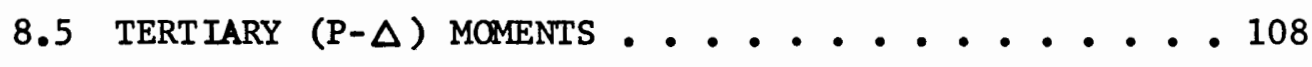

IX DEVELOPMENT OF A SYSTEMATIC APPROACH TO THE DESIGN

OF STANDARD STRUCTURES ............................. 110

9.1 INTRODUCTION. . . . . . . . . . . . 110

9.2 GENERAL CHARACTERISTIC EQUATION CONCEPT . . . . 110 
9.3 PARAMETERS TO BE VARIED . . . . . . . . 114

9.4 DEVELOPMENT OF A GENERAL CHARACTERISTIC EQUATION. • 115 9.4.1 Summary. . . . . . . . . . 119

9.5 COMPUTER IMPLEMENTATION OF THE PROCEDURE. • • • . 122

9.6 EXAMPLE PROBLEM . . . . . . . . . . 123

9.6.1 I. Data Base Preparation. . . . . . 123

9.6.2 II. Development of the Characteristic

Equations. . . . . . . . 124

9.6.3 III.A. Verification of Equations. . . . 127

9.6.4 III.B. Design Procedure . . . . . . 131

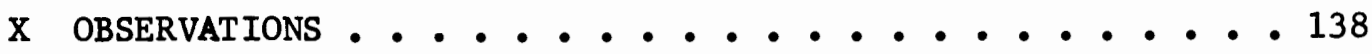

10.1 EXAMPLE PROBLEM . . . . . . . . . 138

10.2 DESIGN OPTIMIZATION . . . . . . . . 143

10.3 THE EFFECT OF THE SECONDARY MOMENTS ON THE WEBS . . 144

XI SUMMARY, CONCLUSIONS AND RECOMMENDATIONS . . . . . 145

11.1 SUMMARY . . . . . . . . . . . . 145

11.2 CONCLUSIONS . . . . . . . . . . 146

11.3 RECOMMENDATIONS . . . . . . . . . 147

APPENDIX 1 DERIVATION AND JUSTIFICATION OF FIXED END MOMENT

EQUATIONS FOR THE PRIMARY MOMENT ANALYSIS . . . . 148

APPENDIX 2 SUMMARY OF THE FRAME ANALYSIS COMPUTER DATA . . . 163

APPENDIX 3 "PINNED MEMBER" DESIGN METHOD . . . . . . . 169

APPENDIX 4 "GENERAL CHARACTERISTIC EQUATION" METHOD COMPUTER

PROGRAMS. ................ 171

REFERENCES. . . . . . . . . . . . . 178 


\section{LIST OF TABLES}

TABLE

PAGE

3.1 Design Values for Structural Glued Laminated Timber

Combination No. 3. ATTC 117-79............. 25

3.2 Section Properties of Chord Members . . . . . . . . 26

4.1 Moment Distribution for the 8 Panel Truss . . . . . . 37

4.2 Primary Moments in the Top Chord of a 100 Ft., 8 Pane1

Truss with $1 \mathrm{~K} / \mathrm{Ft}$. Loading (Obtained from Eq. 4.6 and 4.7) 38

4.3 8 Panel Truss - Primary Moments in the Top Chord Obtained

from Computer Results . . . . . . . . . . . 38

4.4 Moment Distribution for the 10 Panel Truss. . . . . . 40

4.5 Primary Moments in the Top Chord of a 100 Ft., 10 Pane1

Truss with $1 \mathrm{~K} / \mathrm{Ft}$. Loading (Obtained from Eq. 4.6 and 4.7) 41

4.6 Moment Distribution for the 12 Pane1 Truss. . . . . 43

4.7 Primary Moments in the Top Chord of a 100 Ft., 12 Panel

Truss with $1 \mathrm{~K} / \mathrm{Ft}$. Loading (Obtained from Eq. 4.6 and 4.7) 44

5.1 Principal Parameters Affecting the Secondary Moments in the Bottom Chord.............. 47

5.2 Computation of $k_{B}$ and $C_{B}$ for the Eight, Ten and Twelve

Panel Trusses using Eq. 5.4 and 5.5 . . . . . . 53

5.3 Computation of N. . . . . . . . . . . . . 56

$5.4 \quad$ Computation of $\mathrm{M}_{\mathrm{BC}}$ using Eq. 5.11 . . . . . . . . 61

5.5 Computation of $\mathrm{k}_{\mathrm{B} 1}$ and $\mathrm{C}_{\mathrm{B} 1}$ using $\mathrm{Eq} \cdot 5.14$ and 5.15.. .65 
5.6 Computation of $\mathrm{K}_{\mathrm{B} 1}$ using Eq. 5.16 . . . . . . . 65

5.7 Computation of $k_{B 2}, C_{B 2}$ and $g_{B 2}$ using Eq. 5.19, 5.20 and 5.21......... ............ 72

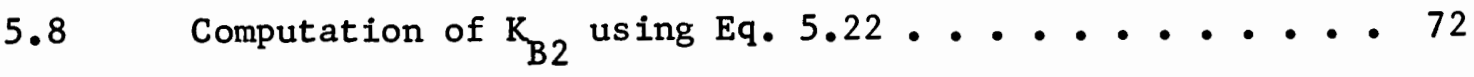

5.9 Data for Fig. 5.9 and Computation of $\mathrm{k}_{\mathrm{B} 5}, \mathrm{C}_{\mathrm{B} 5}$ and $\mathrm{g}_{\mathrm{B} 5} \cdot{ } \cdot 77$

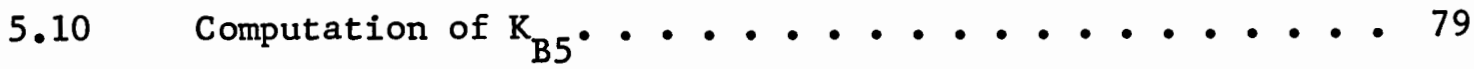

5.11 Summary of General Equations for the Bottom Chord Secondary Moments . . . . . . . . . . . . . 80

5.12 Summary of Explicit Equations for the Bottom Chord Secondary Moments. . . . . . . . . . . . . 82

6.1 General Equations for the Top Chord Secondary Moment. . 87

6.2 Computation of $\mathrm{k}_{\mathrm{T}}$ and $\mathrm{C}_{\mathrm{T}}$ for an 8 Panel Truss using Eq.

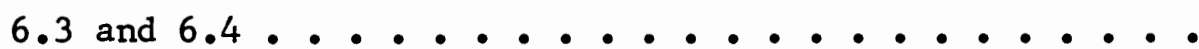

6.3 Computation of $\mathrm{k}_{\mathrm{TO}}, \mathrm{C}_{\mathrm{TO}}$ and $\mathrm{g}_{\mathrm{TO}}$ for an 8 Panel Truss using Eq. 6.6,6.7,6.8 and 6.9...........

6.4 Computation of $\mathrm{k}_{\mathrm{T} 1}$ and $\mathrm{C}_{\mathrm{T} 1}$ for an 8 Panel Truss using Eq.

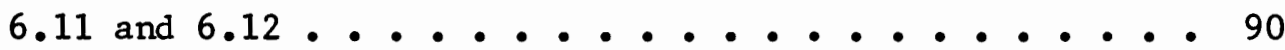

6.5 Computation of $k_{\mathrm{T} 2}, \mathrm{C}_{\mathrm{T} 2}$ and $\mathrm{g}_{\mathrm{T} 2}$ for an 8 Panel Truss using Eq. 6.14,6.15,6.16 and 6.17 ......... 90 6.6 Computation of $\mathrm{k}_{\mathrm{T} 5}, \mathrm{C}_{\mathrm{T} 5}$ and $\mathrm{g}_{\mathrm{T} 5}$ for an 8 Pane1 Truss using Eq. 6.21, 6.22, 6.23 and 6.24 ......... 90 6.7 Explicit Equations for the Secondary Moment in the Top Chord . . . . . . . . . . . . . . . 91 6.8 Calculated Data for Curve of Fig. 6.1 using Equations from Table 6.7. . . . . . . . . . . . . 91 
6.9 Calculated Data for Fig. 6.2 Based on the Equations from Table 6.7. . . . . . . . . . . . . 92

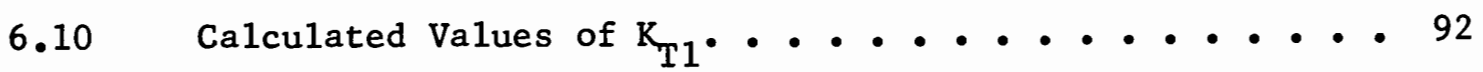

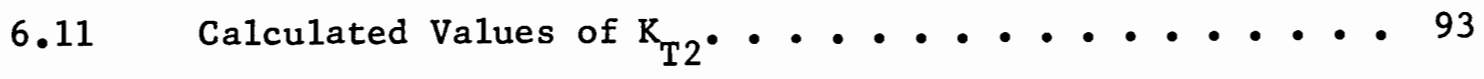

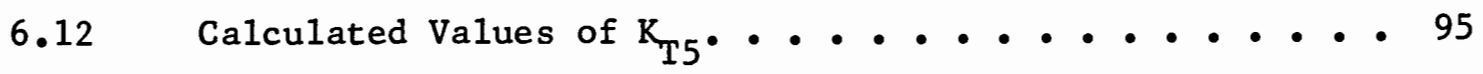

7.1a Verification Data . . . . . . . . . . . 100

7.1b Verification Data . . . . . . . . . . . . 101

8.1 Effect of Bolt Slippage in the Web Connections. . . . 103

9.1 Parameter Data for Example Problem. . . . . . . . 123

9.2 Output Data for the Chosen Variables (Obtained from the Computer Frame Analysis). . . . . . . . . . 125

9.3 Constants for the "General Characteristic Equations" for the Bowstring Truss Example Problem . . . . . . . . 128

9.4 General Characteristic Equation Verification Data . • . 130 A2.1 Data for Figure 5.1 . . . . . . . . . . . 164 A2.2 Computer Frame Analysis Data. . . . . . . . . 165 A2.3a Computer Frame Analysis Data Used to P1ot Fig. 6.1a • . 167 A2.3b Computer Frame Analysis Data Used to Plot Fig. 6.1b . . 168 


\section{LIST OF FIGURES}

F IGURE

PAGE

2.1 Truss configurations considered . . . . . . . . . . 9

2.2 Alternate web configuration . . . . . . . . . . 9

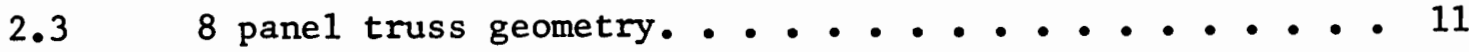

2.410 panel truss geometry . . . . . . . . . . . 12

2.512 panel truss geometry . . . . . . . . . . . 13

2.6 Concentric heel connection. . . . . . . . . 14

2.7 Eccentric heel connection . . . . . . . . . 14

2.8 Typical web connection. . . . . . . . . . . . 15

2.9 Typical bottom chord splice . . . . . . . . . . 15

3.18 pane1 - Mode1 I ("RIGID") • • • • • • • • • • 18

3.2 8 pane1 - Mode1 II (SAP IV) . . . . . . . . . 19

3.3 8 pane1 truss - Mode1 III ("RIGID" - Ful1 Truss). • • • 21

3.4 Fixed heel with rotation of bottom chord at bolts . . .24

3.5 10 pane1 - Mode1 I ("RIGI") • • • . • . • • • • • 28

3.612 pane1 - Model I ("RIGID") . . . . . . . . . . 29

4.1 Fixed end forces on a top chord panel due to ' $\mathrm{P} x \mathrm{e}$ '. . 33

4.2 Fixed end forces on a top chord panel due to a concentrated load. . . . . . . . . . . . . . . 33

4.3 Free-body forces on a top chord segment . . . . . . . 34

4.4 8 panel truss - primary moment data .......... 39

4.5 Primary moment diagram for a $100 \mathrm{ft}$. span 8 pane 1 truss one kip per foot. . . . . . . . . . . . . 39 
4.6 10 panel truss - primary moment data. . . . . . . . 42

4.7 Primary moment diagram for a $100 \mathrm{ft}$. span 10 panel truss one kip per ft. . . . . . . . . . . . . 42

4.8 12 panel truss - primary moment data. . . . . . . 45

4.9 Primary moment diagram for a $100 \mathrm{ft}$. span 12 panel trus one kip per ft. . . . . . . . . . . . . 45

5.1 Typical bottom chord secondary moment diagrams. . . . 48

5.2a 8 panel truss - secondary moment in the bottom chord as a function of $A_{B C}$ and $I_{B C}$. . . . . . . . . . 49

5. $2 \mathrm{~b} 10$ panel truss - secondary moment in the bottom chord as a function of $\mathrm{A}_{\mathrm{BC}}$ and $\mathrm{I}_{\mathrm{BC}}$. . . . . . . . . 50 5.2c 12 pane1 truss - secondary moment in the bottom chord as a function of $\mathrm{A}_{\mathrm{BC}}$ and $\mathrm{I}_{\mathrm{BC}} \cdot$...$\cdot \cdot \cdot \cdot \cdot \cdot \cdot \cdot 51$

5.3a 8 panel truss - secondary moment and bending stress in the bottom chord as computed from Equation 5.11 . . . . 57

5.3b 10 panel truss - secondary moment and bending stress in the bottom chord as computed from Equation 5.11 . . . 58

5.3c 12 pane1 truss - secondary moment and bending stress in the bottom chord as computed from Equation 5.11 . . . 59

5.4a 8 panel truss - secondary moment in the bottom chord as a function of $A_{T C}$ and $\mathrm{I}_{\mathrm{TC}} \cdot$. . . . . . . . . . 62 5.4b 10 pane1 truss - secondary moment in the bottom chord as a function of $A_{T C}$ and $\mathrm{I}_{\mathrm{TC}} \cdot$. . . . . . . . . 63 5.4c 12 pane1 truss - secondary moment in the bottom chord as a function of $A_{T C}$ and $I_{T C} \cdot$. . . . . . . . . 64 
5.5 $\mathrm{K}_{\mathrm{B} 1}$ - Adjustment factor to $\mathrm{M}_{\mathrm{BC}}$ for variation in $\mathrm{A}_{\mathrm{TC}} \cdots 66$

5.6 Secondary moment in the bottom chord as a function of $\mathrm{I}_{\mathrm{TC}} 68$

5.7 Effect of secondary moment in the chords on the axial

forces in the members ................ 69

5.8 $\mathrm{K}_{\mathrm{B} 2}$ - Adjustment factor to $\mathrm{M}_{\mathrm{BC}}$ to account for variations

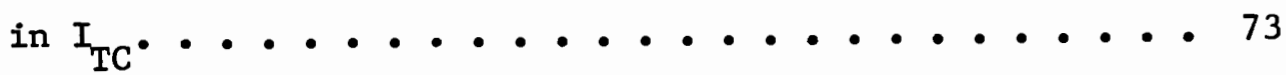

5.9 Secondary moment in the bottom chord as a function of the number of panels in the truss ......... 76

5.10 $\mathrm{K}_{\mathrm{B} 5}$ - Adjustment factor to $\mathrm{M}_{\mathrm{BC}}$ to account for a varying number of panels in the truss ......... 78 6.1 Top chord moment diagrams for typical cases ..... 84 6.2 8 panel truss - secondary moment in the top chord as a

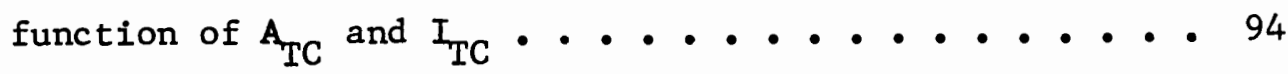

6.3 8 panel truss - secondary moment and bending stress in the top chord as computed from Equations 6.2 and 6.5. . 95 $6.4 \quad \mathrm{~K}_{\mathrm{T} 1}$ - Adjustment factor to $\mathrm{M}_{\mathrm{TC}}$ to account for variation in $\mathrm{A}_{\mathrm{BC}}$. . . . . . . . . . . . 96

$6.5 \mathrm{~K}_{\mathrm{T} 2}$ - Adjustment factor to $\mathrm{M}_{\mathrm{TC}}$ to account for variation in $\mathrm{I}_{\mathrm{BC}}$. . . . . . . . . . . . 96 6.6 $\mathrm{K}_{\mathrm{T} 5}$ - Adjustment factor to $\mathrm{M}_{\mathrm{TC}}$ to account for a variation in the number of panels in the truss. . . . . . 97 8.1 Probable stress distribution in an eccentric heel . . 105 8.2 Amplification of moment in the bottom chord due to an eccentric hee1............... 105 
PAGE

8.3 Effect of a fully fixed heel on the bottom chord moment in an 8 pane1 truss with bolt slippage permitted in the web connections .................. 106 A1.1 Fixed end forces in a top chord pane1 . . . . . . 149 A1.2 Free-body forces on a top chord segment under fixed end conditions. . . . . . . . . . . . . . 149 A1.3 Mode1 and nomenclature used by Roark and Young. . . . 153 A1.4 Data for Example A1.1 . . . . . . . . 160 A1.5 Load components for Example A1.1. ......... 160 


\section{NOTATION}

a - . - . Reference dimension for locating a concentrated load on a chord segment.

$a^{\prime}$ - . - . Intermediate coefficient used in the development of primary moments.

b. - . - Reference dimension for locating a concentrated load on a chord segment.

$b^{\prime}$. - . . - Intermediate coefficient used in the development of primary moments.

c...... $\operatorname{Cos} \theta$.

e. - . - Eccentricity of the top chord between panel points, Ft.

$f($ ).....A function of ... (expression).

$\mathrm{g}_{\mathrm{B}} \cdot$ - . - Constant used in equation to define $\mathrm{M}_{\mathrm{BC}} 0^{\circ}$

$g_{B i}$ - - - . Constant used in equation to define $\mathrm{K}_{\mathrm{Bi}}$, an adjustment factor for the characteristic equation for the bottom chord as developed in Chapter V.

$\mathrm{g}_{\mathrm{Ti}}$ - . - . Constant used in equation to define $\mathrm{K}_{\mathrm{T} i}$, an adjustment factor for the characteristic equation for the top chord as developed in Chapter VI.

$g_{i j l}$ - . - Constant used in the general characteristic equation to define an adjustment factor to account for the effect of the ith parameter on the $j$ th variable under 
load case $l$.

j...... Subscript to represent the jth variable (i.e., maximum bottom chord moment, etc.).

$k_{B}$...... Constant used in equation to define $M_{B C 0^{*}}$

$\mathrm{k}_{\mathrm{Bi}}$.... Constant used in equation to define $\mathrm{K}_{\mathrm{Bi}}$, an adjustment factor for the characteristic equation for the bottom chord as developed in Chapter $\mathrm{V}$.

$\mathrm{k}_{\mathrm{Ti}}$..... Constant used in equation to define $\mathrm{K}_{\mathrm{Ti}}$, an adjustment factor for the characteristic equation for the top chord as developed in Chapter VI.

$k_{i j l}$.... Constant used in the general characteristic equation to define an adjustment factor to account for the effect of the ith parameter on the $j$ th variable under load case $\ell$.

l..... Subscript to represent the $\ell$ th load case.

n ...... The total number of parameters (i.e., area of bottom chord, etc.).

p...... Virtual load.

$\mathrm{q}_{\mathrm{Bi}}$.... Intermediate factor used to develop $\mathrm{g}_{\mathrm{Bi}}$.

s...... $\sin \theta$.

w..... Uniform load on the top chord.

$w^{B}$..... Base value of $w$ used to compute $k_{B 0}$ and $C_{B 0^{\circ}} \quad(=1 K / f t)$.

x..... The value of a parameter (such as $A_{B C}$ ).

$x_{i}$.... The value of the ith parameter.

$x_{i 1}$.... The lower limit of the $i$ th parameter used to develop the general characteristic equation. 
$x_{i 2}$ - . - The base value of the ith parameter used to develop the general characteristic equation.

$\mathbf{x}_{i 3}$ - - - . The upper limit of the ith parameter used to develop the general characteristic equation.

y - - . - The value of a variable (such as $\mathrm{M}_{\mathrm{BC}}$ ).

$y_{j} \cdot$ - *. The value of the $j$ th variable.

A -..... Area of a member, sq. in.

$A_{B C}$ - - - Area of the bottom chord, sq. in.

$A_{B C}^{B} \cdot \cdots \cdot$. Base value of $A_{B C}$.

AC - - - Area of the top chord, sq. in.

$\mathrm{A}_{\mathrm{TC}}^{\mathrm{B}} \cdot$ - . - Base value of $\mathrm{A}_{\mathrm{TC}}$

B . - . - Intermediate coefficient used to define $g$.

$B_{i j l} \cdot$ - - Value of B for case ijl.

$B_{1}$ - - - Intermediate coefficient used in the development of primary moments.

$\mathrm{B}_{\mathrm{HH}}$ - - - - Intermediate coefficient used in the development of primary moments.

$\mathrm{B}_{\mathrm{HM}}$ - - - - Intermediate coefficient used in the development of primary moments.

$\mathrm{B}_{\mathrm{HV}}$ - - - - Intermediate coefficient used in the development of primary moments.

$\mathrm{B}_{\mathrm{MH}}$ - - . - Intermediate coefficient used in the development of primary moments.

$B_{M M}$ - - - Intermediate coefficient used in the development of 
primary moments.

$\mathrm{B}_{\mathrm{MV}}$ - - - Intermediate coefficient used in the development of primary moments.

${ }_{\mathrm{VH}}$ - - - . Intermediate coefficient used in the development of primary moments.

${ }_{\mathrm{VM}}$ - - - - Intermediate coefficient used in the development of primary moments.

${ }_{\mathrm{BV}}$ - - - - Intermediate coefficient used in the development of primary moments.

BC. - - - - Bottom chord of the truss - used as a subscript.

$C_{B}$ - . - Constant used in equation to define $\mathrm{M}_{\mathrm{BC}} 0^{\circ}$

$\mathrm{C}_{\mathrm{Bi}}$ - - - . Constant used in equation to define $\mathrm{K}_{\mathrm{B} i}$, an adjustment factor for the characteristic equation for the bottom chord as developed in Chapter V.

$\mathrm{C}_{\mathrm{T}}$ - - . - Constant used in equation to define $\mathrm{M}_{\mathrm{TC}} 0^{\circ}$

$\mathrm{C}_{\mathrm{Ti}}$ - - . - Constant used in equation to define $\mathrm{K}_{\mathrm{Ti}}$, an adjustment factor for the characteristic equation for the top chord as developed in Chapter VI.

$c_{i j l}$ - - - Constant used in the general characteristic equation to define an adjustment factor to account for the effect of the ith parameter on the $j$ th variable under load case $\ell$.

Co. - - - . Carry over factor for moment distribution method. DF. - - - Distribution factor for moment distribution method. DFL - - . . Douglas Fir/Larch. E - . - . Modulus of elasticity, psi. 
$\mathrm{Fb}_{\mathrm{x}-\mathrm{x}}$ - - - Allowable bending stress about the $\mathrm{x}-\mathrm{x}$ axis.

Fc. - . - Allowable compression stress.

Ft. - - . Allowable tension stress.

FEM - - - . Fixed end moment.

$\mathrm{FEM}_{A}(\mathrm{Pe})$. - - Fixed end moment at point $A$ produced by an axial load acting on a curved member.

I...... Moment of inertia, in ${ }^{4}$.

$\mathrm{I}_{\mathrm{BC}} \cdot \cdots \cdot$ Moment of inertia of the bottom chord, in ${ }^{4}$.

$\mathrm{I}_{\mathrm{BC}}^{\mathrm{B}}$ - . - . Base value of $\mathrm{I}_{\mathrm{BC}}$.

$\mathrm{I}_{\mathrm{TC}}$ - .... Moment of inertia of the top chord, in ${ }^{4}$.

$\mathrm{I}_{\mathrm{TC}}^{\mathrm{B}}$ ・. - . Base value of $\mathrm{I}_{\mathrm{TC}}$.

K - - . - Member stiffness factor used in the moment distribution method of analysis.

$\mathrm{K}_{\mathrm{Bi}}$ - - - Adjustment factor to the moment in the bottom chord to account for variation in parameter $i$.

$\mathrm{K}_{\mathrm{Ti}}$ - - - Adjustment factor to the moment in the top chord to account for variation in parameter $i$.

I . - . . Span length of truss, ft.

L2. - - - - Material grade for Lam stock.

L2D - - - - Dense grade of L2 Lam stock.

$\mathrm{LF}_{\mathrm{H}}$ - - - . Load factors used in developing the primary moment equations--as defined by Roark and Young, Formulas for Stress and Strain, Fifth Edition.

$L F_{M}$ - - - . Load factors used in developing the primary moment equations--as defined by Roark and Young, Formulas 
for Stress and Strain, Fifth Edition.

$\mathrm{LF}_{\mathrm{V}}$ - . - . Load factors used in developing the primary moment equations--as defined by Roark and Young, Formulas for Stress and Strain, Fifth Edition.

$M_{i}$ - - . - Moment at point $i$.

$M_{B C}$-... Maximum moment in the bottom chord, located at the first panel point from the end of the truss.

$\mathrm{M}_{\mathrm{BC} 0} \cdot$ - . Value of $\mathrm{M}_{\mathrm{BC}}$ when all parameters are at base values except $A_{B C} \cdot$

$\mathrm{M}_{\mathrm{BC}}^{\mathrm{B}} \cdot$ - . - Base value of $\mathrm{M}_{\mathrm{BC}}$.

$M_{T C}$ - . - Maximum moment in the top chord, located at the first panel point from the end of the truss.

$\mathrm{M}_{\mathrm{TC} 0^{*}} \cdot$. . Values of $\mathrm{M}_{\mathrm{TC}}$ when all parameters are at base values except $\mathrm{ATC}_{\mathrm{TC}}$

N - . - . Power coefficient used in Chapter V to correlate the effect of $I_{B C}$ on $M_{B C}$.

NP. - - . . Number of panels in the truss.

P... - Axial force in a member.

$Q_{i} \cdot$ - . - Intermediate coefficients used in the development of primary moments.

R - - - . Radius of the top chord (center 1ine), ft. $\mathrm{V}_{\mathbf{A}} \cdot$ - - . - Shear at point A. W1. - . - . Web number 1 .

$\mathrm{Y}_{j}$ - - - . Final value of the $\mathrm{jth}$ variable (such as $\mathrm{M}_{\mathrm{BC}}$ ), accounting for the chosen values of all parameters. $\mathrm{Y}_{\mathrm{j}}^{\mathrm{B}}$ - . . . Value of $\mathrm{Y}_{\mathrm{j}}$ using base values for a11 parameters. 
$\mathrm{Y}_{\mathrm{j} \ell}$.... Value of $\mathrm{Y}_{\mathrm{j}}$ for load case $\ell$.

$\delta_{I} \cdot \cdots \cdot($. (DELTA) Tangential deflection of the roller support of an arch section (see Fig. Al.3).

...... (ETA) Angle measured from the vertical line through the centroid of the top chord radius of the truss to the center of the top chord segment being considered.

A..... (LAMBDA) Horizontal projection of a top chord panel length, ft.

P...... (RHO) Radius of curvature of a member subjected to bending.

$\emptyset \ldots . .$. (PHI) Angle measured from the upper end of a top chord segment to the point $i$ on the top chord.

4...... (PSI) Vertical projection of a top chord panel length, ft.

$\triangle$...... (DELTA) Joint deflection.

-...... (THETA) One half of the included angle formed by the arc of a top chord panel.

П...... (PI) Sequential Product operator.

$\Sigma$..... (SIGMA) Sequential Summation operator.

8P. ..... Eight pane1 truss.

10P ..... Ten pane1 truss.

12P . . . . Twelve pane1 truss.

01TC23. . . Designation assigned to the frame analysis computer runs were the 0 indicates that $A_{B C}=A_{0}$ (see Table 3.2), the 1 indicates $I_{B C}=I_{1}, T C 2$ indicates $A_{T C}=A_{2}$, and 3 
indicates that $\mathrm{I}_{\mathrm{TC}}=I_{3}$. 


\section{CHAPTER I}

\section{INTRODUCTION}

\subsection{BACKGROUND}

The bowstring truss is a truss with a curved top chord, located so that it follows the force Iine of an arch with the bottom chord acting as the tie. The webs of the truss are required only to provide stability and to distribute concentrated and unbalanced loads which impart substantial bending into an arch. The webs carry very small forces which results in a very efficient truss, particularly for uniform loads such as roof loads.

The early designs, used for many years, used three basic methods to form the top chord. One method used dimension lumber resawn on one edge to the curved shape. The pieces were lapped approximately one half of their length which resulted in a semi-continuous segmented top chord--thus the term "segmental chord" bowstring was used to describe these trusses.

A second method used small dimension lumber ( $2 \times 4$ or $2 \times 6^{\prime} s$ ) nail laminated into a continuous curved chord with staggered butt splices between pieces. They were sometimes built with one or two wider laminations to provide a ledger for the roof joists. The most common name for this type of truss was the "Summerbe11" truss. 
The third method used large members resawn to a radius and butt spliced at web joints. They were usually called "monochord" trusses.

With the advent of glued laminated timber (glu-lam), engineers began designing the trusses using truly continuous curved glu-lams for the chords. The analysis of these trusses continued to assume "pinjointed" members, recognizing the continuity of the chords only to redistribute the already small primary bending moments.

\subsection{DESIGN METHODS}

Currently, two methods are known to be used in the industry to analyze these trusses: the method mentioned above which will be referred to as the traditional method; and by the use of a relatively large capacity computer to perform a "frame analysis".

\subsubsection{Traditional Method}

Traditionally, the most common method involves modeling the truss assuming pinned joints and straight top chord segments between panel points. A graphical technique known as the Maxwell diagram (1) is normally used to compute member forces. Small microcomputers or even programmable calculators may also be used to compute member forces using matrix or joint analysis techniques.

The moments in the to $\mathrm{p}$ chord are computed using semi-empirical equations such as those found in the AITC Timber Construction Manual.(2) These equations use superposition to combine continuous beam moments with moments induced by the eccentricity of the curved chord (' $\mathrm{Pe}$ ' effects). This moment is assumed to be distributed in the same manner 
as the moment produced by the vertical loads.

Traditionally, secondary bending stresses induced by the deflection of the truss have been ignored. Thus, the bottom chord has been designed for pure tension (except when ceiling or other loads are applied directly to the bottom chord). The top chords are designed using the axial load and moments as described above.

The assumption has been that the secondary stresses are relatively small and therefore not worth the fairly large effort required to compute them. As will be demonstrated in this study, however, the secondary stresses may indeed be quite large. In a few cases investigated, the top chord moment at the critical location was found to be several times larger than the primary moment, with the total bending stress exceeding $60 \%$ of the stress allowed for pure bending. Previous1y they were usually computed to be less than $10 \%$ when neglecting the secondary stress. The result is that trusses designed by this method may actually be overstressed by as much as $50 \%$ in some cases.

\subsubsection{Computer Frame Analysis}

The second method utilizes relatively large computers to analyze the truss using a conventional matrix displacement frame analysis, or a finite element analysis program. This method, therefore, does take into account the effects of the "secondary" moments.

The "secondary" moments as referred to here are actually pri-

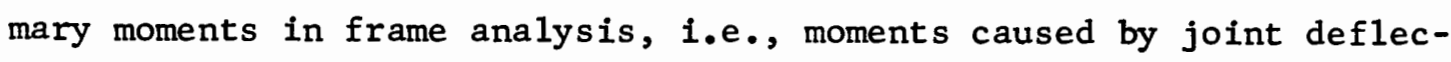
tion. What would be called "secondary" moments in frame amalysis terminology (i.e., P- $\Delta$ effect) will be denoted as "tertiary" moments here. 


\subsection{DES IGN PROBLEMS}

To accurately model the curved chord of the truss the chord must be broken up into several segments between each panel point. As a result, a typical truss will have over 100 members in the model. This poses several problems. Extensive time is required for model development and data input. The coordinates of the top chord segments must be accurately computed and correctly entered. This is a tedious task which lends itself to errors. A minor error in coordinate input can have drastic effects on the top chord moments.

The input of the loads is also a laborious task. Due to the curvature, the horizontal projection of the members is different for each member. Every joint in the top chord must therefore have the load computed and input separately. The task of considering multiple load cases, such as unbalanced loading which is critical for the design of the webs in bowstring trusses, increases the task considerably.

These problems can be reduced by the use of a sophisticated program which has cylindrical coordinate and load generation capabilities.

Use of a small 8-bit microprocessor for such a task would be unduly cumbersome, time consuming, and indeed impossible without a sophisticated program utilizing a mass storage device for storing the large matrices. Matrix partitioning techniques would be required to manipulate these large matrices. Programs of this sophistication are not readily available for 8-bit machines. Even if a program were available, the accuracy would be highly suspect for a structure with such small member offsets. 
Programs with these capabilities do exist for use on several minicomputers. However, these machines (and the software) are much more expensive than the smaller machines and are not found in most small design firms. Even with such a system, or a large inhouse timeshared system, the time element and its associated cost is restrictive, especially if the job has only a few trusses of a specific design.

In addition to design office practicality problems of the computer analysis method, the analysis itself can be misleading and the degree of accuracy may be unjustified. As will be seen later in the study, several factors such as bolt slippage can have a major effect on the induced moments. With the type of web connection normally used in these trusses (strap and pin), bolt slippage is highly probable. A small amount of bolt slippage in the web connections can reduce the moments in the chords by as much as $50 \%$.

In light of this and the highly unpredictable nature of loading and strength of the member, it seems unnecessary and indeed undesirable to require an analysis of such "precision". As mentioned previously, however, the secondary moments are substantial and should be accounted for by some method of reasonable accuracy, even if the method results in "overly precise" answers.

\subsection{SCOPE OF THIS INVESTIGATION}

Three major areas of study which will affect the design of these and other types of trusses are needed. The first of these, which this paper addresses, is to establish a method of computing the primary and secondary moments in continuous chords of bowstring timber trusses. 
Charts which enable the secondary moments to be determined are proposed for a specific set of truss configurations. These moments can then be superimposed on the primary moments computed using the traditional method or using a more refined method presented in Chapter IV. An additional study is needed to quantify the beneficial effect of bolt slippage in the web connections in reducing the secondary moments. This effect is introduced, but not fully investigated in this paper.

The third area of study would deal with the interaction equations for combined tension or compression plus bending. The author of this paper feels that the equations currently being used in the major design codes have several shortcomings which could have a significant affect on the sizing of the chords. This area of study is beyond the scope of this paper, however.

A new design method is proposed in which "characteristic equations" for a given structural configuration are systematically developed. Intended primarily for "standard" structures such as trusses, the results of a series of frame analyses are used to establish the influence of various parameters on the structure. The resulting equations can be utilized to quickly generate designs for an unlimited number of parameter combinations, using design charts, programmable calculators, or small microcomputers. A simple computer program is presented for this procedure. The data from which the design charts of Chapters $V$ and VI were developed was utilized to verify the reliability and demonstrate the use of this method. 


\section{CHAPTER II}

\section{STRUCTURAL CHARACTERISTICS AND CONSTRUCTION \\ DETAILS OF GLUED-IAMINATED \\ BOWSTRING TRUSSES}

\subsection{STRUCTURAL CHARACTERISTICS}

A bowstring truss essentially performs as a tied arch. Under balanced uniformly distributed load the webs will have very little force in them. The top chord carries the loads like an arch to the bearings with the bottom chord providing a tension tie. The webs are used to distribute unbalanced and concentrated loads, as well as to reduce the buckling length of the top chord. Tied arches, of course, are designed to carry these unbalanced loads also. This is achieved by greatly increasing the size of the arch member to give it substantial bending capability. By introducing webs, the requirement for large bending capacity is reduced.

The web members restrict the deformations that the arch would otherwise undergo, even under uniform load. This is reflected somewhat by a pin-jointed truss analysis which results in small forces in the webs. The webs near the ends of the truss greatly interfere with these deformations and as a result impart substantial secondary moments into both top and bottom chords. This problem which is not reflected by a pin-joint analysis, and has traditionally been ignored, is the focal point of this study. 


\subsection{COMMON CONSTRUCTION DETAILS}

\subsubsection{Geometry}

A bowstring truss is a truss in which the top chord is a curved member. This curve normally is a circular arc with the radius equal to the span of the truss. Some designs utilize larger radii in order to reduce the depth of the truss. This results in larger chord size and therefore increased cost. Parabolic curves have also been used in an attempt to more closely obtain pure arch action. The difference in shape between a parabolic and circular curve is so slight that the refinement is norma11y not warranted.

Various web configurations have been used. The most commonly used configurations are shown in Figure 2.1. The configuration shown in Fig. 2.2 was used a great deal for the old segmental chord trusses. Truss configurations shown in Fig. 2.1 are investigated here. The number of web members in the truss is normally selected so as to keep the top chord panel lengths between 8 to $12 \mathrm{ft}$. Keeping the panel lengths short reduces the primary moments thus minimizing the size of the top chord required. However, it will be shown later that the secondary moments can be much larger than the primary moments. In addition, the secondary moments increase as the number of web members increases. This suggests then that fewer webs may actually provide a stronger, more efficient truss. This point will be discussed further in later chapters.

The trusses considered herein have a $100 \mathrm{ft}$. span with the center line radius equal to the span. The geometry is as shown in Figures 


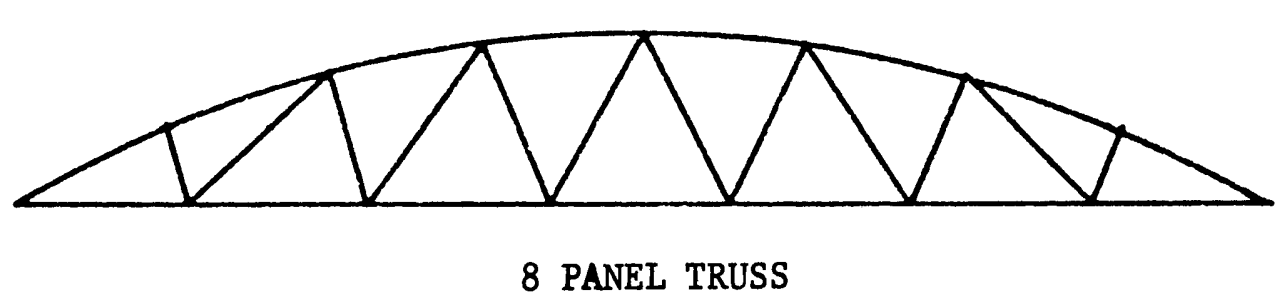

9
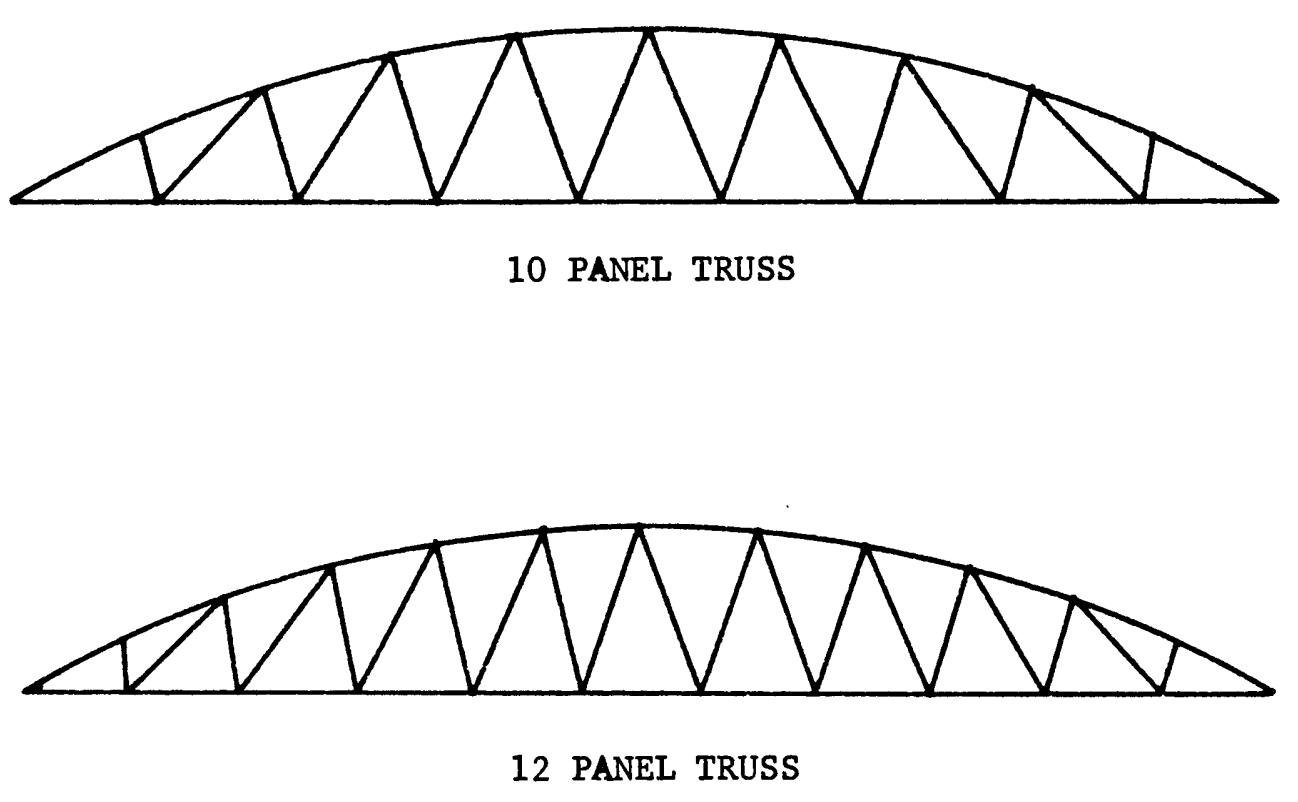

Figure 2.1 Truss configurations considered.

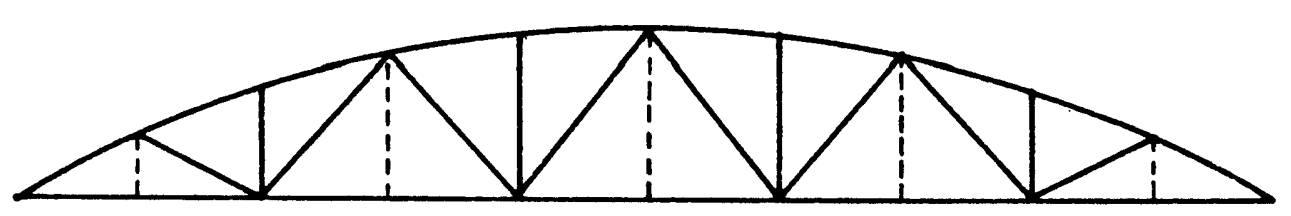

Figure 2.2 Alternate web configuration. 
2.3, 2.4 and 2.5. All dimensions are to the center line of the members.

\section{$\underline{2.2 .2 \text { Details }}$}

Figure 2.6 shows one type of heel connection being used. Another similar type, shown in Fig. 2.7 has been commonly used. This heel has the problem of inducing partial fixity into the bottom chord as a result of the eccentric bearing. The effect of eccentric bearing is studied in Chapter VIII.

Figure 2.8 shows a typical "strap and pin" web connection commonly used. As can be seen, some joint slip in this connection would be unavoidable. Fortunately, this will actually help relieve some of the secondary moments by allowing the deflected shape to change to a smoother curve.

Figure 2.9 shows a typical center line splice detail. Very 1ittle curvature is found to exist at the center of the truss when deflected. As a result, fixity or lack of fixity induced by the large side plates is found to have negligible effect on the bending moments in the bottom chord. 


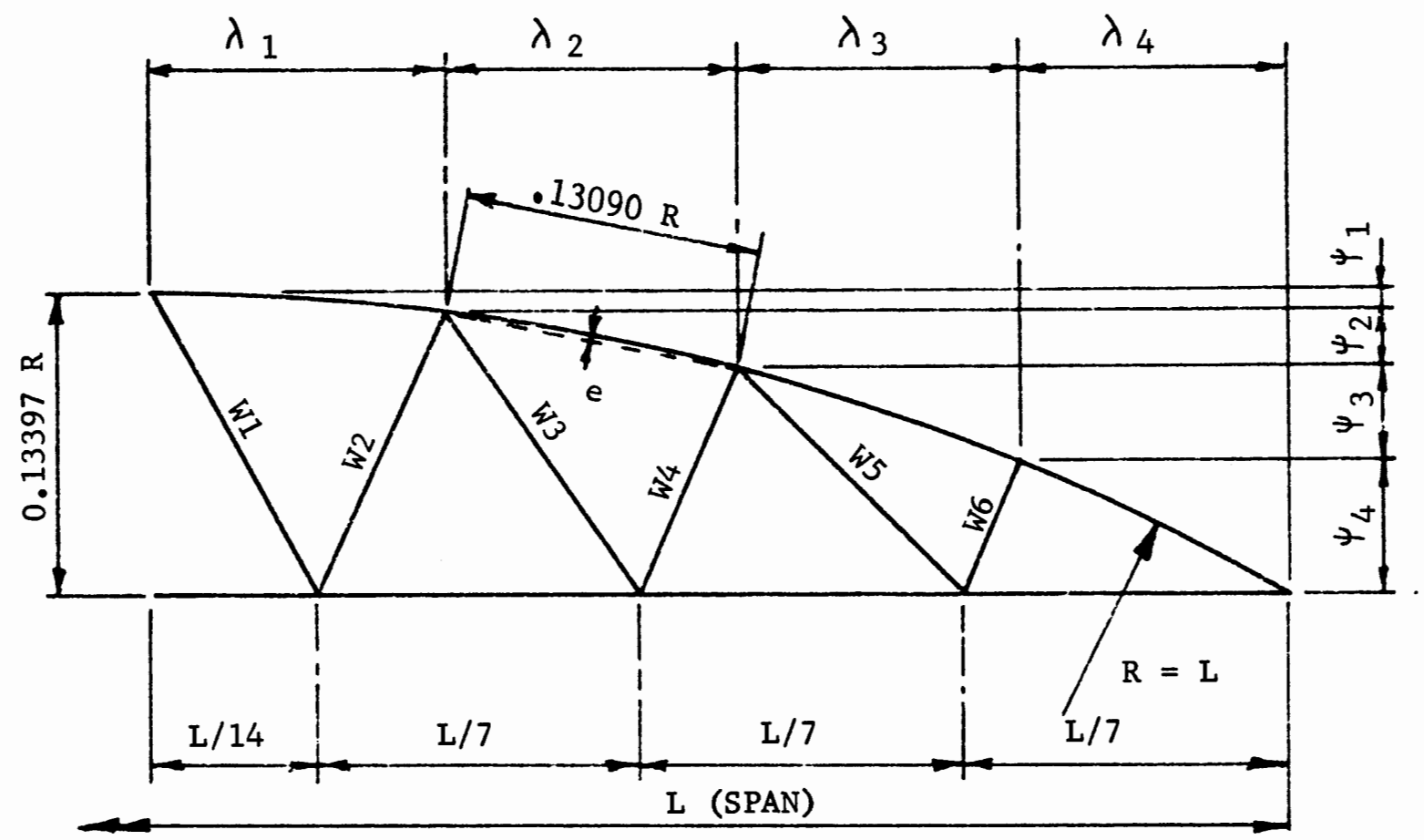

$$
\begin{array}{ll}
\lambda_{1}=0.130525 \mathrm{R} & \psi_{1}=0.00856 \mathrm{R} \\
\lambda_{2}=0.128295 \mathrm{R} & \psi_{2}=0.02551 \mathrm{R} \\
\lambda_{3}=0.123865 \mathrm{R} & \psi_{3}=0.04205 \mathrm{R} \\
\lambda_{4}=0.117315 \mathrm{R} & \psi_{4}=0.05785 \mathrm{R} \\
\mathrm{e}=0.00214 \mathrm{R} &
\end{array}
$$

Figure 2.3 8 pane1 truss geometry. 


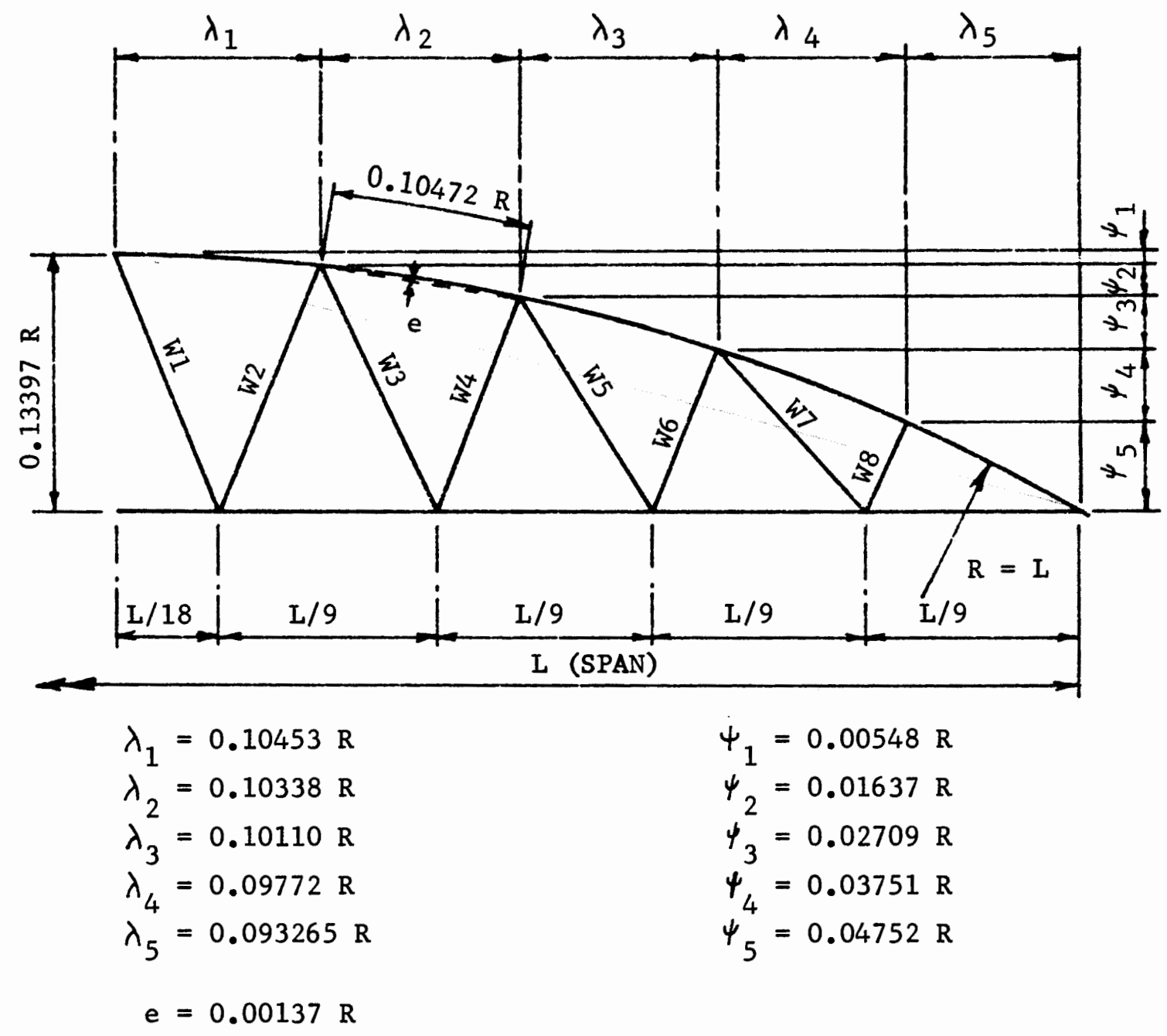

Figure 2.4 10 panel truss geometry. 


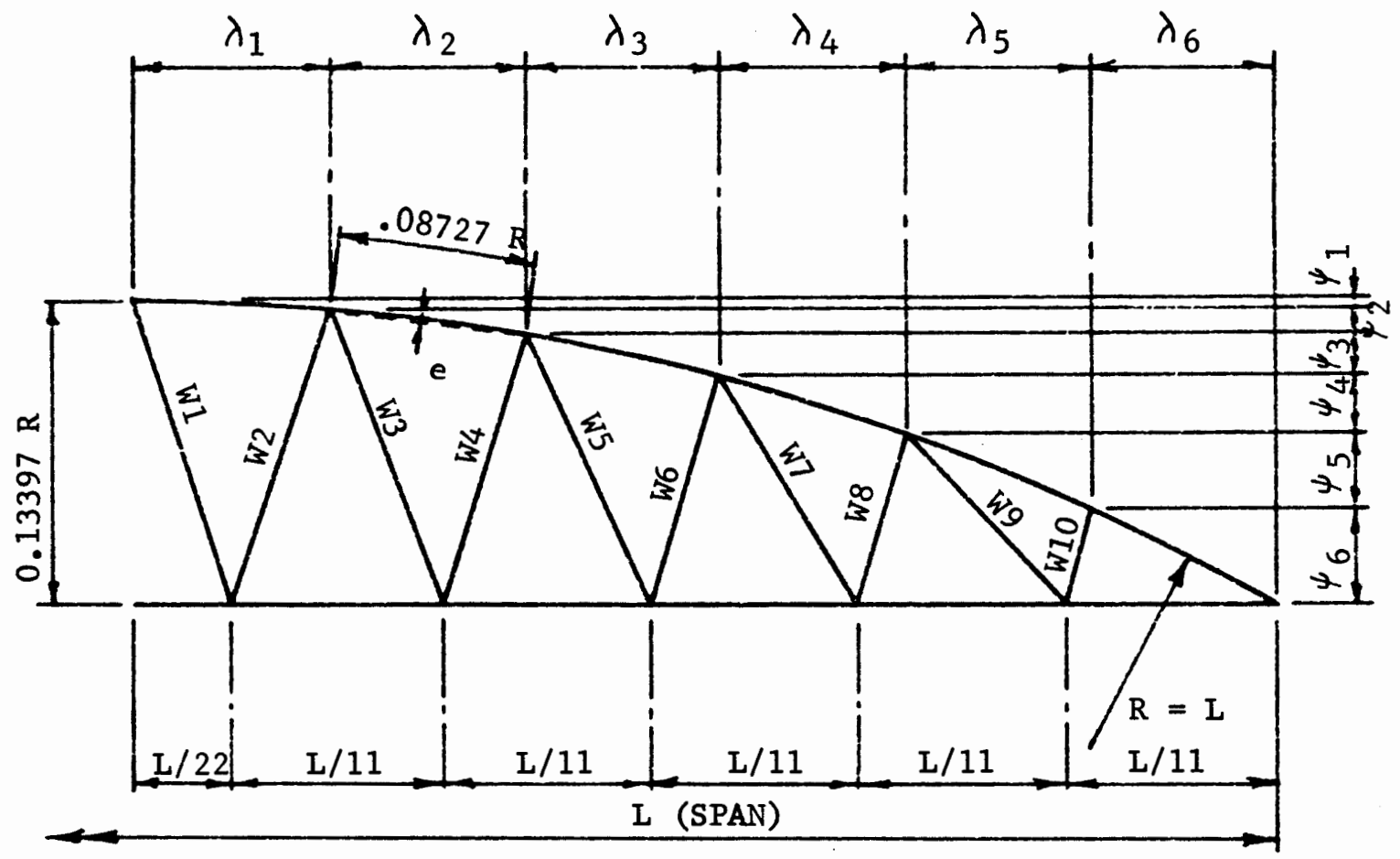

$\lambda_{1}=0.087155 \mathrm{R}$

$\psi_{1}=0.00381 \mathrm{R}$

$\lambda_{2}=0.086495 \mathrm{R}$

$\psi_{2}=0.01138 \mathrm{R}$

$\lambda_{3}=0.08517 \mathrm{R}$

$\psi_{3}=0.01888 \mathrm{R}$

$\lambda_{4}=0.0832 \mathrm{R}$

$\Psi_{4}=0.02624 \mathrm{R}$

$\lambda_{5}=0.0806 \mathrm{R}$

$\psi_{5}=0.03338 \mathrm{R}$

$\lambda_{6}=0.07738 \mathrm{R}$

$\psi_{6}=0.04028 \mathrm{R}$

$e=0.00095 R$

Figure 2.5 12 pane1 truss geometry. 


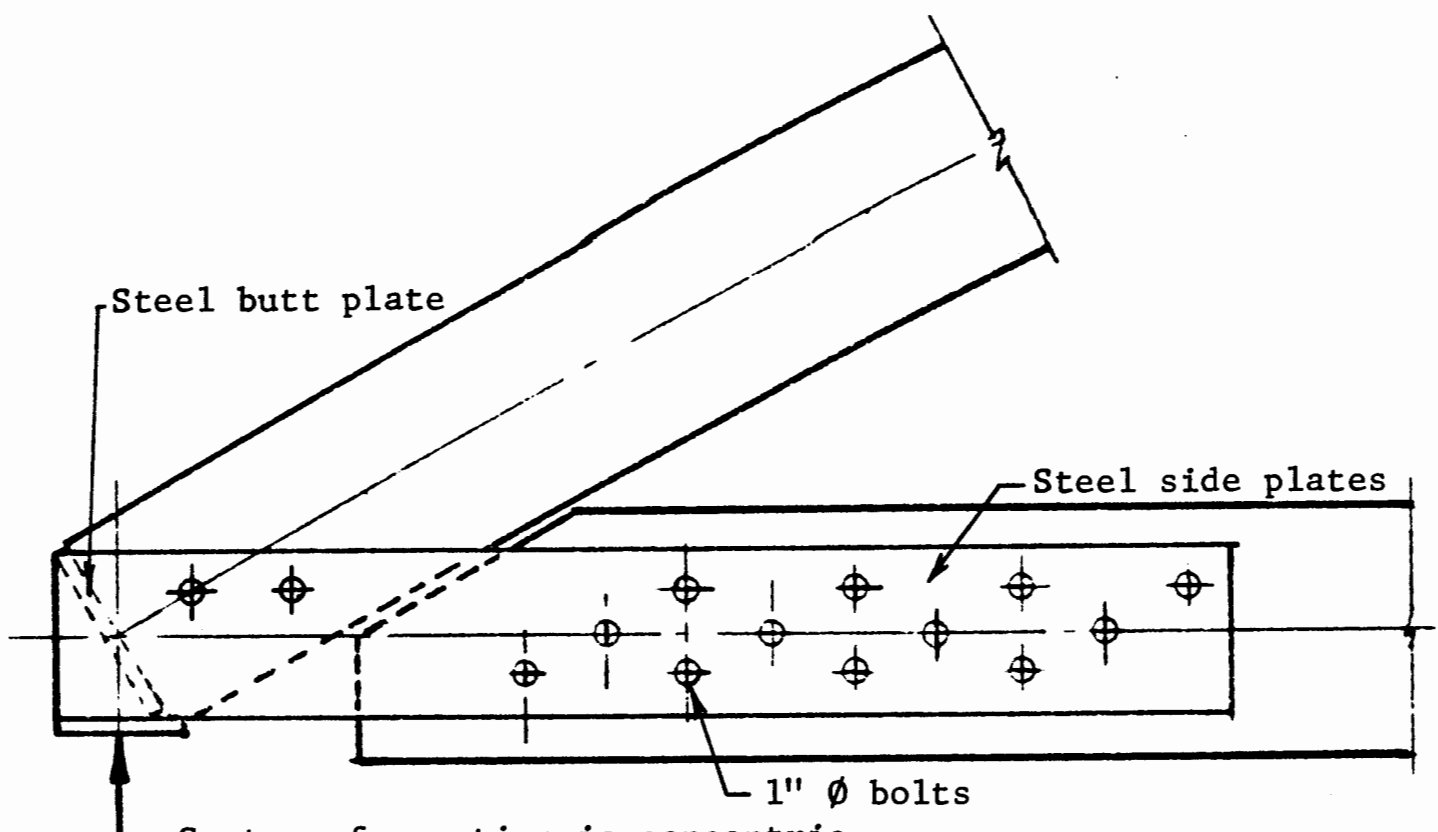

Center of reaction is concentric

with intersection of chord center lines.

Figure 2.6 Concentric heel connection.

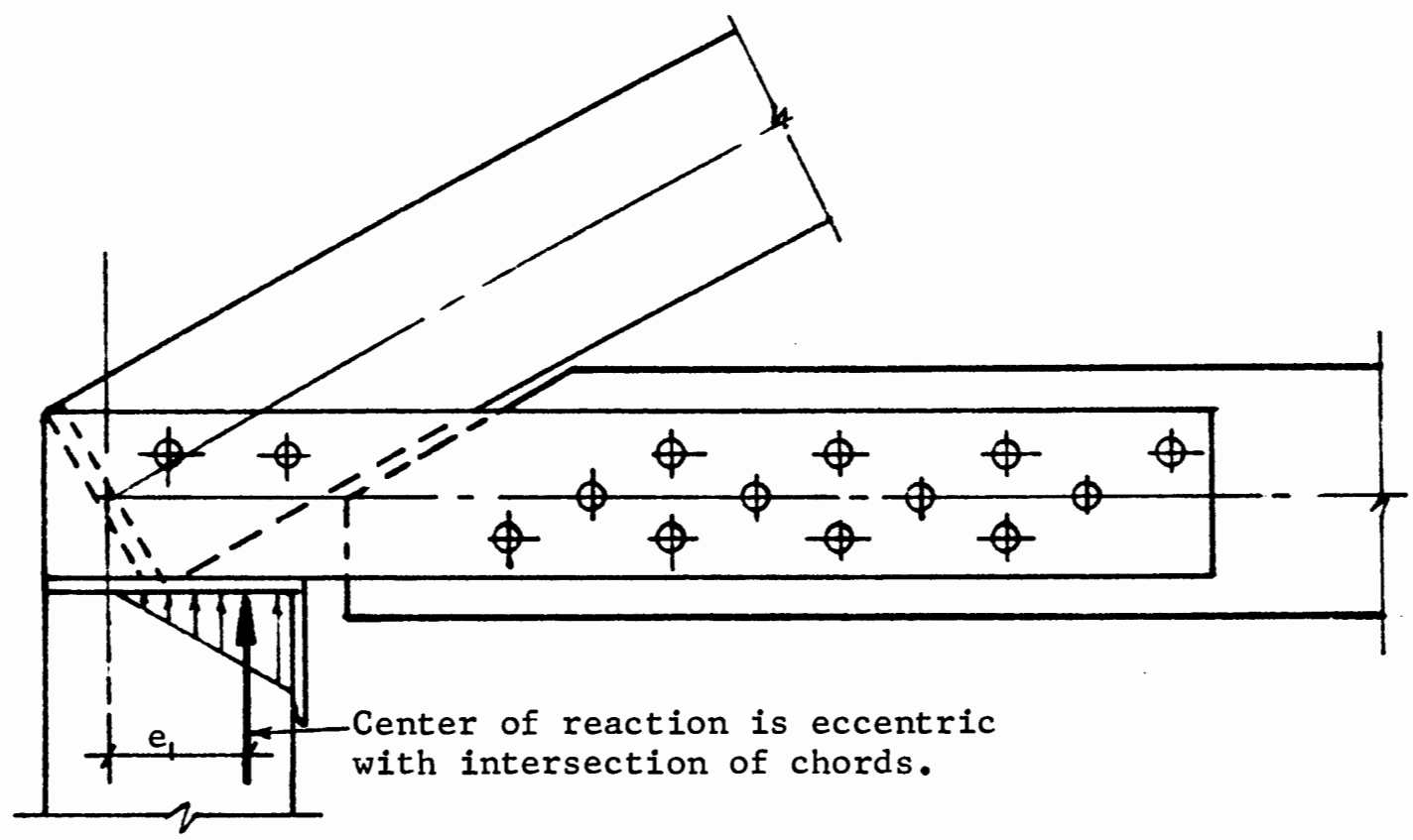

Figure 2.7 Eccentric heel connection. 


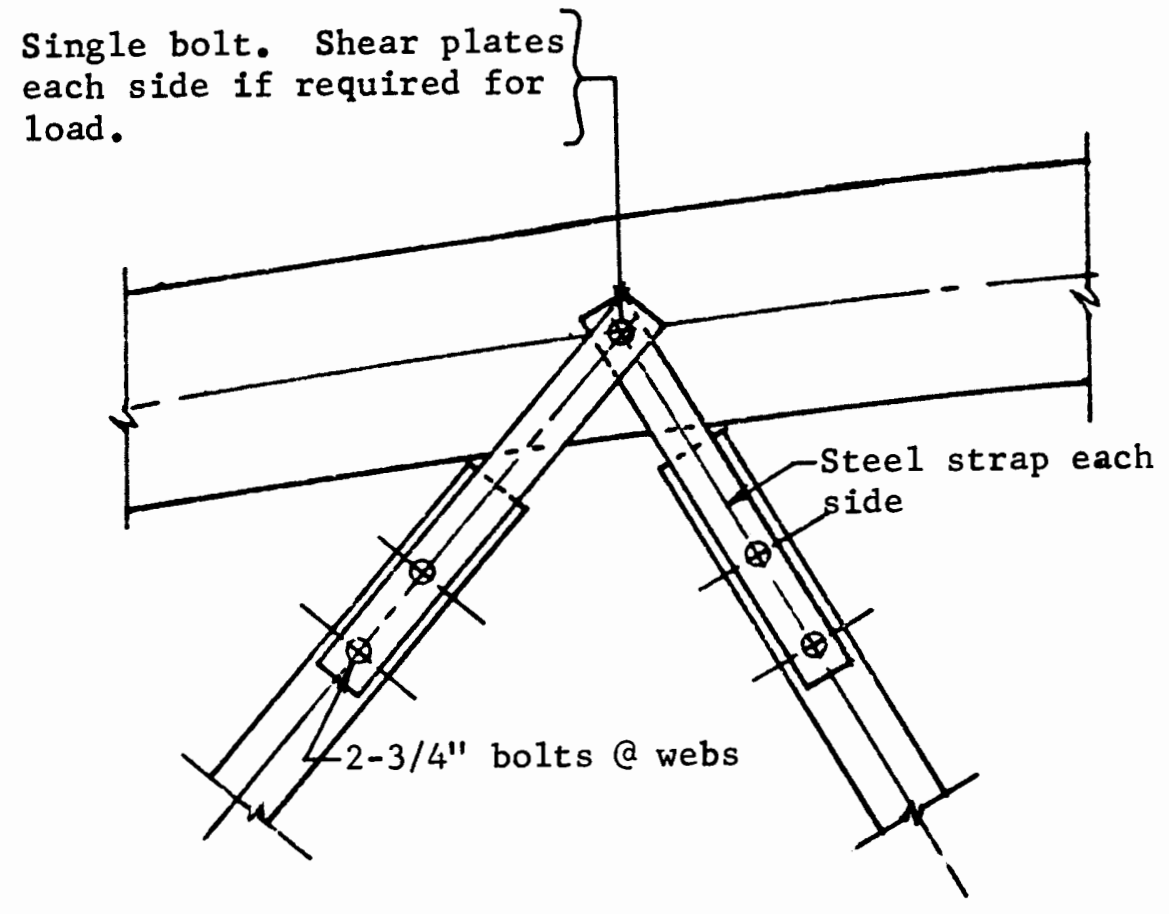

Figure 2.8 Typica1 web connection.

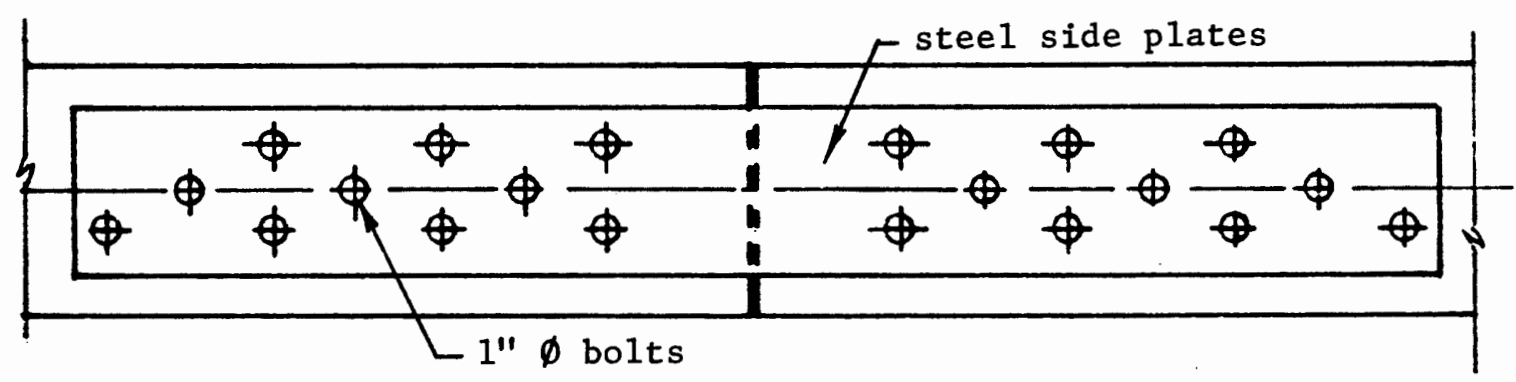

Figure 2.9 Typica1 bottom chord splice. 
CHAPTER III

COMPUTER MODELS

\subsection{GENERAL INFORMATION}

Computer models were developed for the three configurations shown in Figure 2.1. These will be referred to as 8 pane1, 10 pane1 and 12 panel trusses in respect to the number of top chord sections or "pane1s" they contain.

A basic $100 \mathrm{ft}$. span truss with the radius of the top chord equal to the span was used for each configuration. In order to model the curved top chord, each top chord panel was divided into four equal straight segments. Al1 loads were applied at the nodes.

The bottom chord panels were divided into two segments in order to allow evaluation of tertiary $(P-\triangle)$ moments.

\subsection{EIGHT PANEL TRUSS}

The eight panel truss was modeled in three different ways, using two computer programs.

\subsubsection{Mode1 I}

A truss and frame analysis program entitled "RIGID" (3) was utilized for this model. One half of the truss was modeled, with vertical roller supports provided at the truss center line. A horizontal roller support was used to model the column bearing support at the end of the 
truss. The model is shown in Fig. 3.1 .

The chords are modeled with beam elements to reflect the continuous nature of the chords. A double roller support with a rigid truss link between them was used at the heel to artificially provide the member end releases. As can be seen from Fig. 2.6, the top chord is essentially free to rotate in the connection. An internal hinge would therefore seem appropriate. This technique provided the ability to model heel joint slippage and joint fixity.

The peak connection was also modeled as a pinned joint. The top chord of these trusses is normally spliced at the peak to facilitate fabrication and shipping. The connection is normally not substantial enough to be considered capable of transferring moment.

A11 webs are modeled as truss elements i.e., no bending capacity $(I=0)$. Therefore, all web to chord connections are in essence pinned, which is obviously the case in the real truss. (See Fig. 2.8.)

\section{$\underline{3.2 .2 \text { Mode1 II }}$}

The second model considered was very similar to the first model, except that it was developed using "SAP IV"(4) finite element program. The same half truss was modeled with similar supports. This was used as an independent check on the input/output information that was gathered from the first model. Fig. 3.2 shows the model which was used.

\subsubsection{Mode1 III}

This mode1, using the program "RIGID", modeled the entire truss. The purpose for this model was to observe unbalanced conditions, which was not possible with the half truss of the first model. The diffi- 

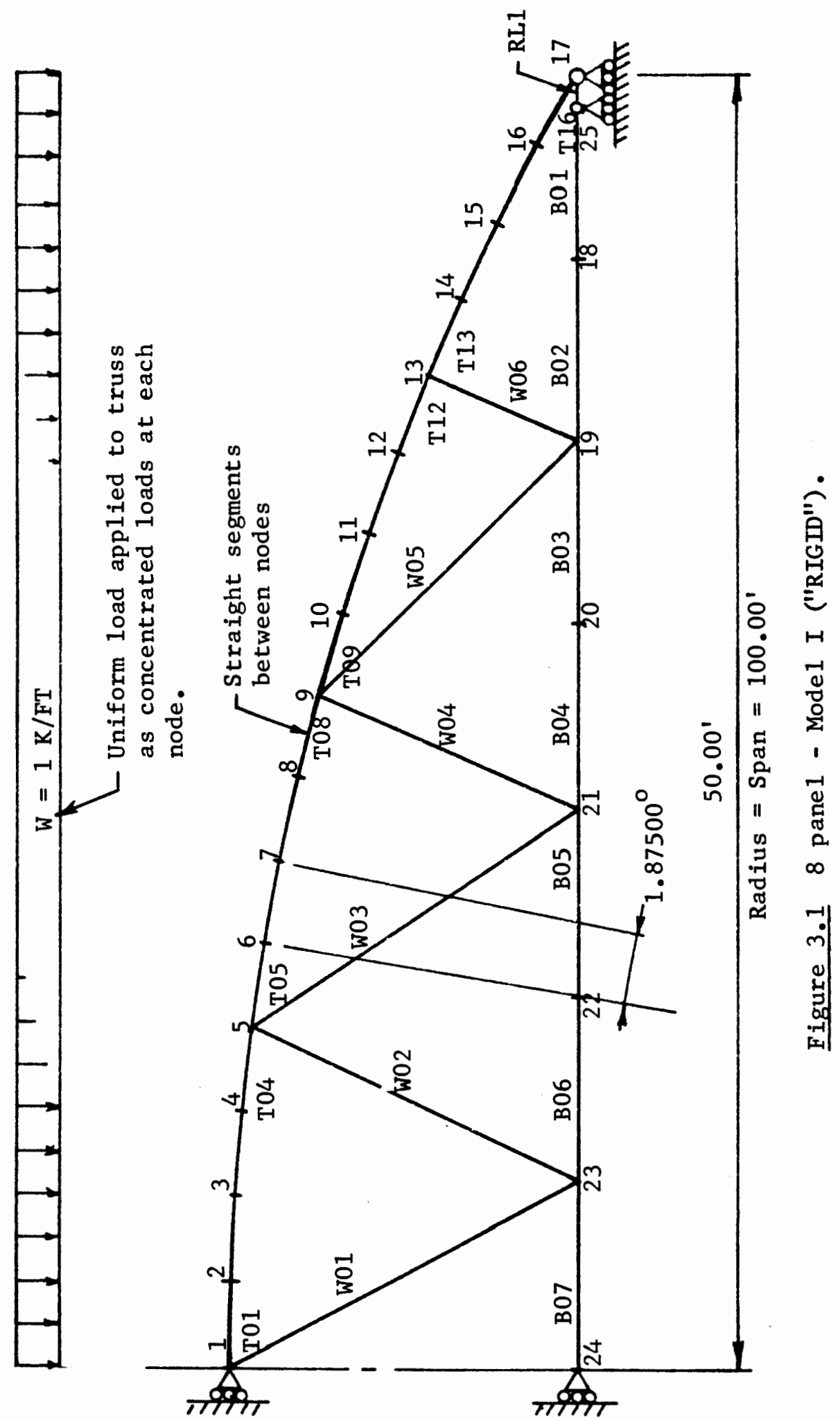

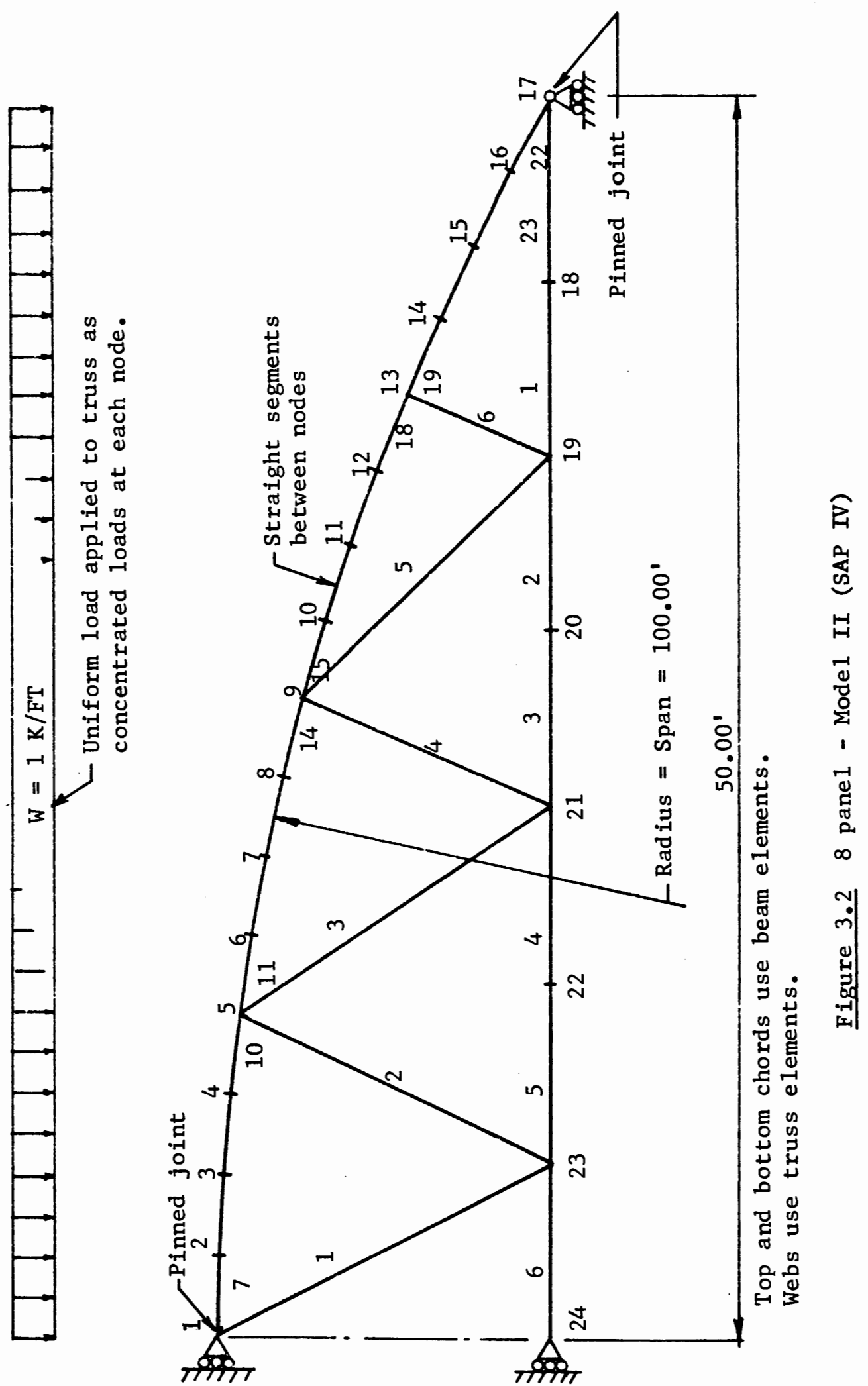
culty encountered here was created by the fact that the current version of the program does not provide for member end releases. Therefore, modeling the internal hinge at the center of the top chord proved cumbersome. The member release was obtained by installing a short rigid link at the center. In order to transfer shear across the joint, two artificial web members were included in the model, as shown in Fig. 3.3.

This provided reasonable results when using the actual web areas (no joint slippage). When providing for joint slip, however, the artificial webs disrupted the deflections of the truss substantially. This data is therefore not considered valid.

\section{$\underline{3.2 .4 \quad \text { Loading }}$}

The loading assumed a one kip per foot uniform load on the top chord, under fully balanced conditions. This load was converted to concentrated loads to be applied to the truss at the node points.

The bottom chord of the truss was assumed to have no external loading.

\section{$\underline{3.2 .5 \quad \text { Variations }}$}

Several variations were made using Model I, to briefly study the effects of several potential physical variations from the "ideal" model. Effects of joint slippage, heel and bottom chord splice fixity were considered.

3.2.5.1 Web Connection Bolt S1ippage. As mentioned previously, the type of connection shown in Figure 2.8 will be subject to joint slippage, both at the pin bolt and also in the double bolt connection 

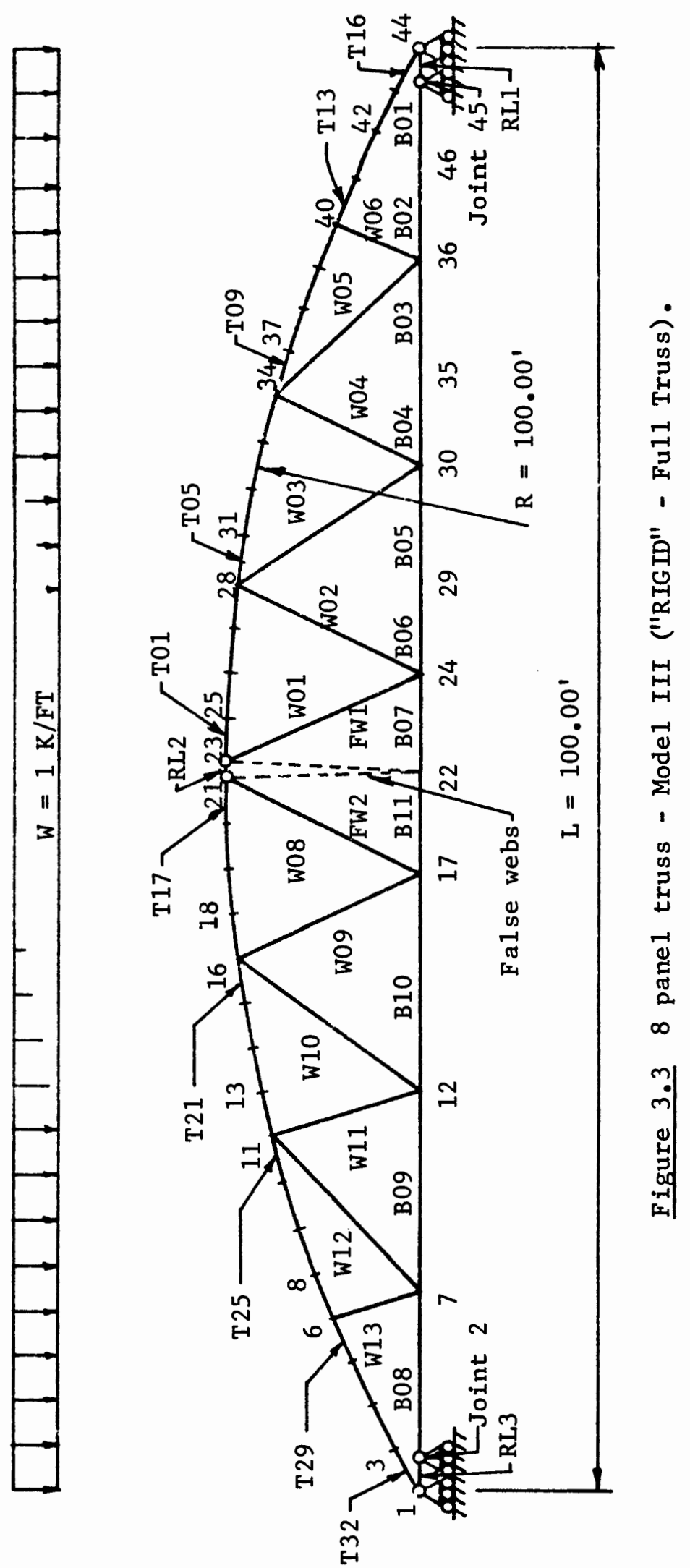
to the web itself. This effect was modeled by "softening" the web (reducing the area) to provide an additional $1 / 16 \mathrm{in.} \mathrm{to} 1 / 8 \mathrm{in}$. member shortening or elongation. No attempt was made to establish an exact, uniform amount of slip in all joints. The required area was back calculated from the member loads obtained from the first series of runs using actual member areas. The resulting elongation did not exactly yield the slip assumed due to redistribution of forces changing the member forces. Further refinement seems unjustified in light of the highly unpredictable nature of the slippage. Member misfit during fabrication, hole size and straightness, temperature, moisture content and residual stresses in the chords during fabrication will all affect the amount of slip actually occurring in the real structure. This general influence and its potential magnitude is what is of importance.

3.2.5.2 Heel Joint Slippage. The effect of joint slippage in the heel connection was modeled by "softening" the rigid link connecting the two support rollers at the heel location.

3.2.5.3 Heel Joint Fixity. Some heel designs have the potential of inducing full or partial fixity into the bottom chord at the heel connection. This was modeled by fully fixing the roller connecting the bottom chord member. This therefore would simulate the warst condition, providing an upper bound to examine the effect of fixity in the hee1.

\subsubsection{Bottom Chord Splice Bolt Slippage. Joint slippage in} the center splice joint was modeled by specifying a specific horizontal support displacement $(.006 \mathrm{ft}$.$) at the vertical roller at the bottom$ chord. 
3.2.5.5 Bottom Chord Splice Fixity. The normal model assumes the bottom chord to be pinned at the center. The effect of fixity which may we11 be the case in the real truss was modeled by providing rotational fixity to the roller joint.

\subsubsection{Heel Plate Fixity, Chord Rotation Permitted at Bolts.}

The possible, but unlikely, occurrance of the heel assembly being fixed on the column, while the chord rotates at the bolted connection was considered. The physical condition is shown in Fig. 3.4. This was modeled by extending the length of the "rigid" link from .001 ft. to $2.5 \mathrm{ft}$. The area of the link was then reduced to simulate joint slip in addition to the rotation.

3.2.5.7 Combinations of Effects. Web slippage combined with heel slippage plus fixity was examined by combining the techniques used above. Similar combinations were used for the center splice.

\subsubsection{Member Properties}

The chords of the truss were taken as Douglas Fir/Larch combination no. 3 as defined under the AITC 117-79 Specifications.

The design values given are shown in Table 3.1. 


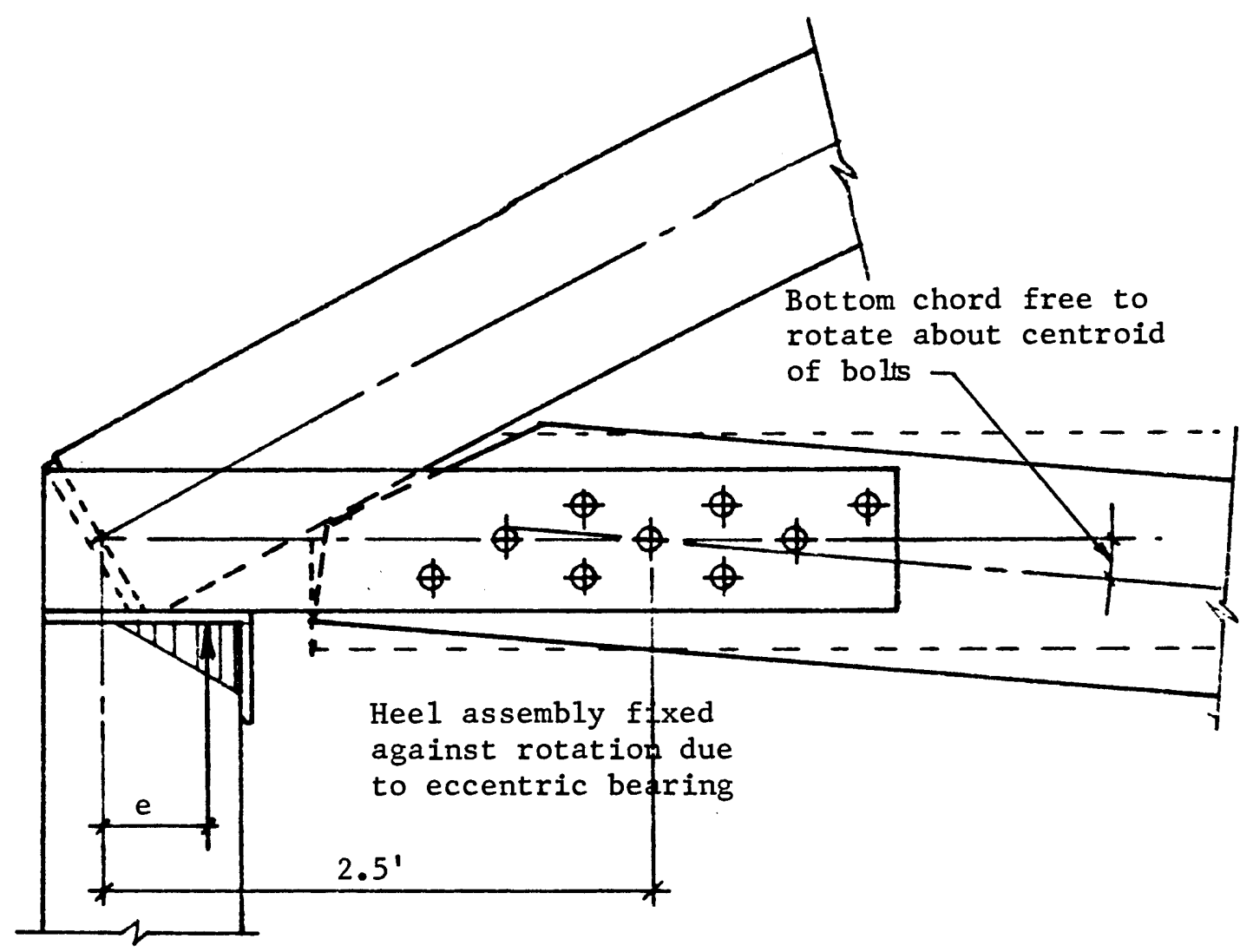

Figure 3.4a Physical condition.

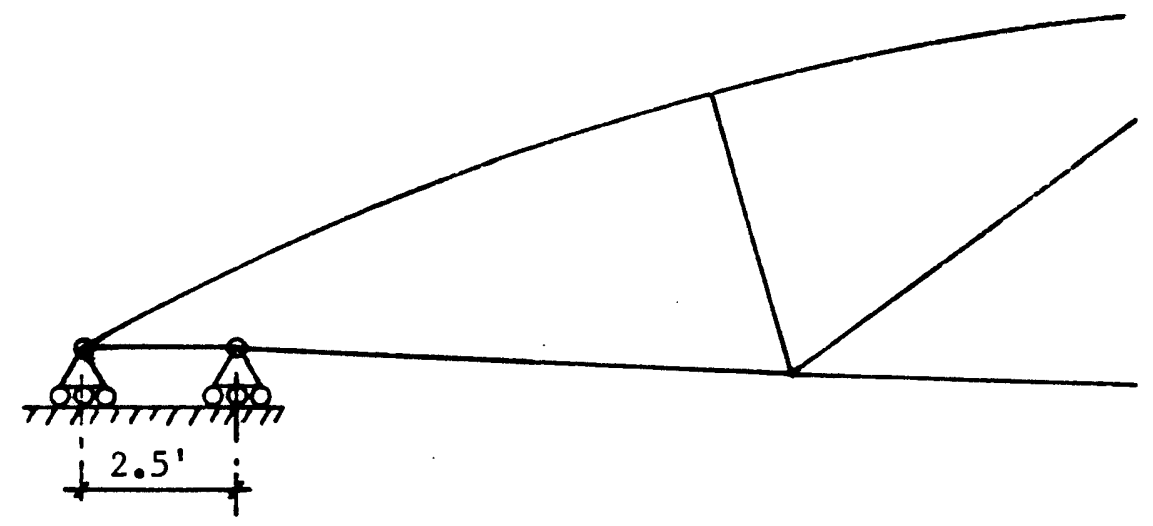

Figure 3.4b Computer mode1.

Figure 3.4 Fixed heel with rotation of bottom chord at bolts. 
TABLE 3.1

DESIGN VALUES FOR STRUCTURAL

GLUED LAMINATED TTMBER

COMBINATION NO. 3

AITC $117-79$

\begin{tabular}{|l|l|}
\hline Species & DFL \\
Grade & L2D \\
E & $1.8\left(10^{6}\right)$ psi \\
Ft & 1450 psi \\
Fc & 2300 psi \\
Fb & 2000 psi \\
\hline
\end{tabular}

Combination no. 3 is commonly used in trusses built in the Pacific Northwest because it combines several desirable properties. Douglas Fir/Larch is the most readily available high strength material in this region. Of the DFL combinations, only combination no. 5 has higher design values for tension, compression and bending. The advantage of combination no. 3 is that in addition to high strength, L2D laminating stock (which is used in this grade) is a dense grained material which permits the use of higher allowable connector loads. L2D stock can be extracted from commonly supplied L2 stock, since a considerable amount of the $\mathrm{L} 2$ stock meets the dense grade requirement. The web members were assumed to have an $\mathrm{E}$ value of $1.6\left(10^{6}\right)$ psi.

The chord member areas and moments of inertia (I values) were the principal parameters varied in developing the data. The areas and I values were varied independently in order to produce correlations 
based on the four parameters. This was the approach taken on all three truss configurations. The values of these four parameters were varied as shown in Table 3.2

TABLE 3.2

SECTION PROPERTIES OF CHORD MEMBERS

(VARIED INDEPENDENTLY)

\begin{tabular}{|l|l|}
\hline Area $\left(\right.$ in $\left.^{2}\right)$ & $\underline{I\left(\text { in }^{4}\right)}$ \\
$A_{0}=50$ & $I_{0}=250$ \\
$A_{1}=75$ & $I_{1}=800$ \\
$A_{2}=100$ & $I_{2}=1800$ \\
$A_{3}=125$ & $I_{3}=3600$ \\
$A_{4}=99999$ & \\
\hline
\end{tabular}

The computer runs were labeled as follows:

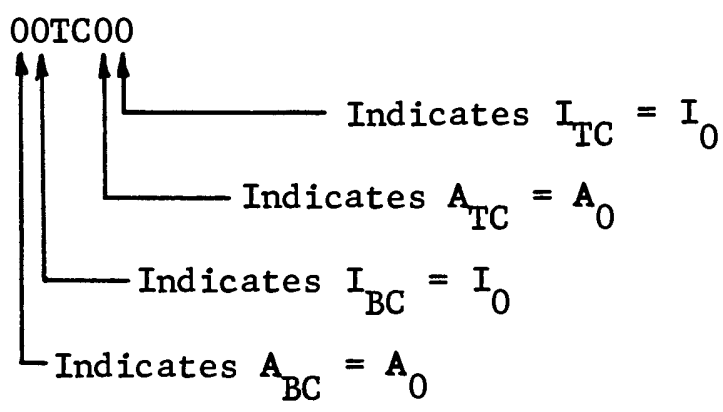

The TC simply indicates that the second two numbers refer to the top chord.

These properties are not indicative of any specific member sizes, but were selected to represent the range of sizes used in practice. The extremely large area was used in order to verify the primary moments in the top chord by providing very small deflections, which 
results in very small secondary moments.

\subsection{TEN PANEL TRUSS}

The 10 panel truss was modeled as a half truss similar to the 8 panel Model I, using the RIGID program. See Fig. 3.5 for the model description.

The same member properties and parameter variations were made for the 10 panel as for the 8 panel Model I.

\subsection{TWELVE PANEL TRUSS}

A half truss was modeled using RIGID, similar to the 8 panel Model I. See Fig. 3.6 for the model description. The same member

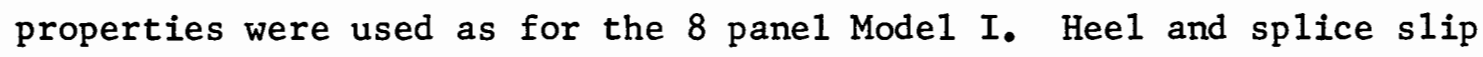
and fixity were not considered in this model. 

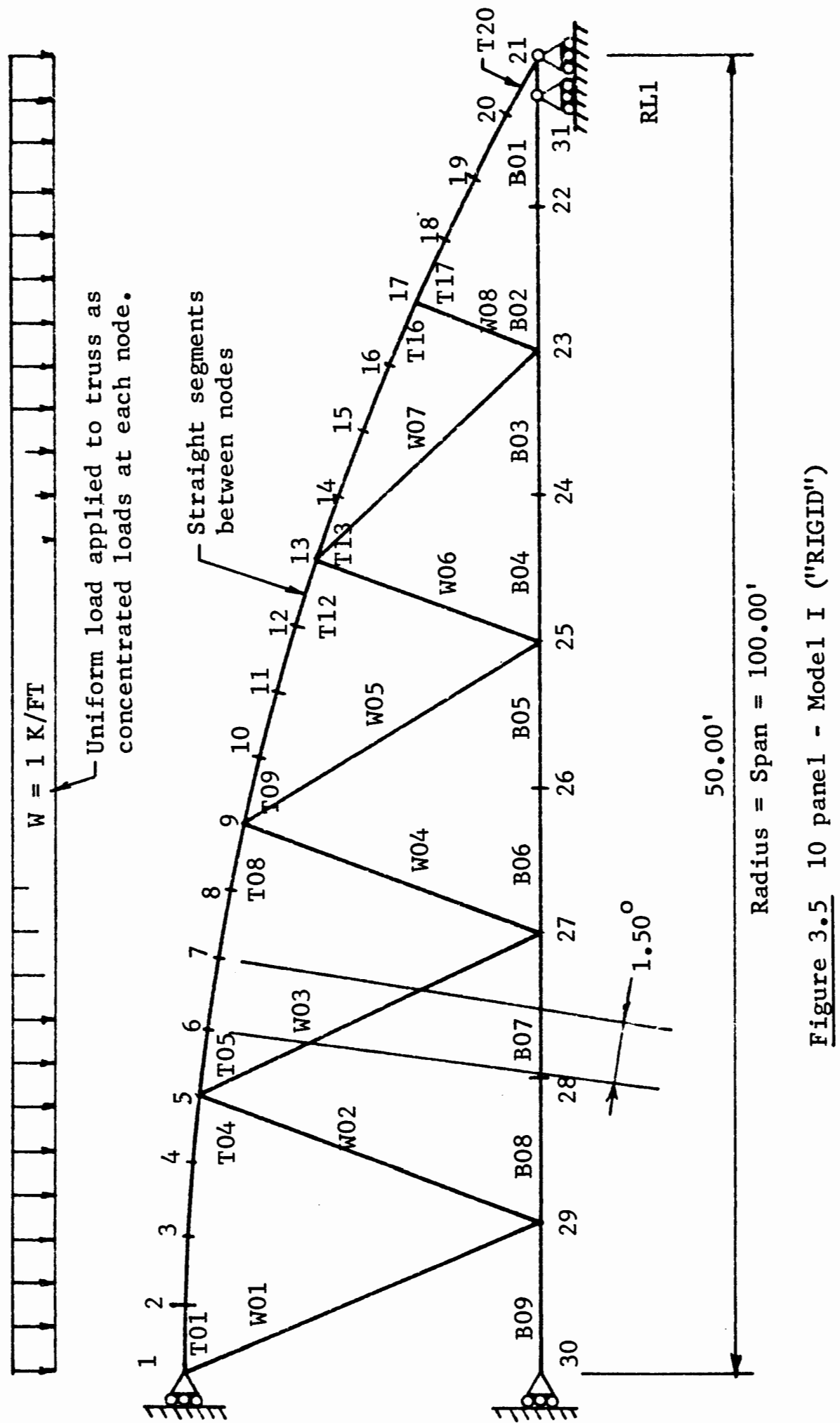

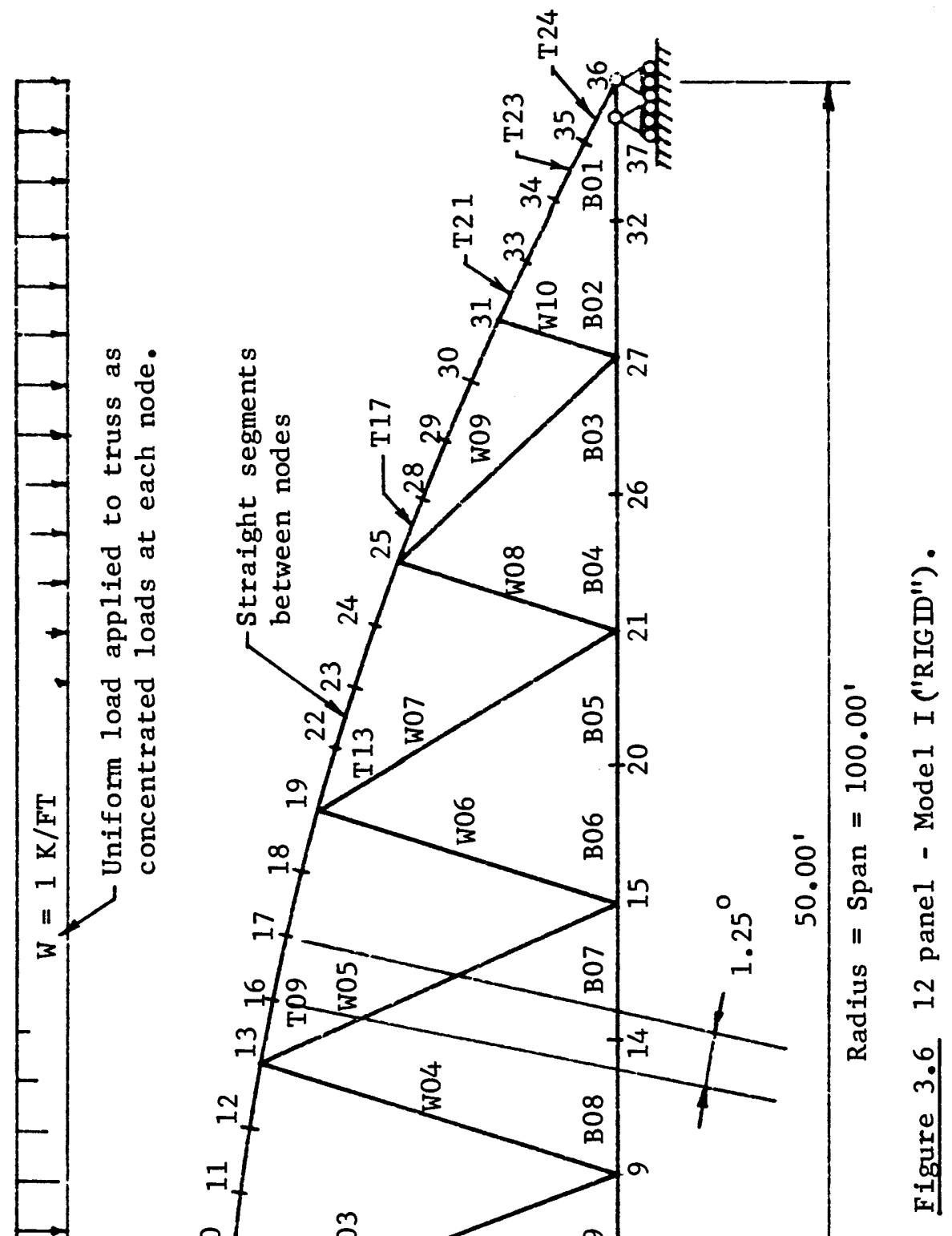
CHAPTER IV

PRTMARY MOMENTS IN THE TOP CHORD

\subsection{METHODS OF ANALYSIS}

In order to assess the secondary moments in the top chord, we must first determine the primary moments which exist as part of the moments computed by the computer analysis.

\subsubsection{AITC Method}

The existing design methodology as outlined in the AITC Timber Construction Manual $^{(2)}$ uses the method of superposition when computing the top chord bending moments. The moments for a continuous, straight beam are added algebraically to the "Pe" moments, assuming that the "Pe" moments are distributed in the same manner as the uniform load moments. The "Pe" moment is the moment induced by the axial force, $P$, in the chord acting through the eccentricity, e, of the curved member. Secondary moments (i.e., those caused by joint displacement) are neglected.

For example, for an 8 panel truss, the beam moment at the first panel point would be computed as

$$
\mathrm{M}_{\text {Beam }}=-.1071 \mathrm{w} \lambda^{2}
$$

which is $85.68 \%$ of the simple span moment $\left(.8568 \times 1 / 8 w \lambda^{2}\right)$. The .1071 factor is the moment coefficient for a four span continuous beam with uniform load on all spans. 
Thus,

$$
\begin{aligned}
M & =.8568\left[\frac{w \lambda^{2}}{8}\right]-.8568 \mathrm{Pe} \\
& =.1071 \mathrm{w} \lambda^{2}-.8568 \mathrm{Pe}
\end{aligned}
$$

This method is expected to give reasonably accurate results, however a more accurate analysis is necessary here in order to accurately separate the primary from the secondary moments (i.e., from joint deflection induced moments).

The following method has been used for this purpose, and is proposed for general use.

\subsubsection{Moment Distribution}

The moment distribution method requires that "fixed end" moments be determined for each "span" of the continuous curved chord. These "fixed end" moments (FEM) will consist of the moments induced by the external loads applied to the member acting as a continuous beam, plus the moments induced by the "Pe" effect. The equations for these FEM's are as follows. The derivation of the equations is provided in Appendix 1.

4.1.2.1 FEM due to "Pe". Referring to Figure 4.1,

$$
\mathrm{FEM}_{A}(\mathrm{Pe})=-\mathrm{FEM}_{B}(\mathrm{Pe})=\mathrm{P}_{A} \mathrm{R}\left[\frac{\tan \theta}{\theta}-1\right]
$$

4.1.2.2 FEM due to External Member Loads. The FEM due to the loads on the member can be calculated assuming the beam to be a straight beam with its length equal to the projected distance between the two end points, $A$ and $B$, measured perpendicular to the axis of the load. 
For example, for a vertical load, the length used to compute the FEM's would be the horizontal distance from $A$ to $B$. This is the same technique used to compute FEM's on a straight sloped beam. For a uniform vertical load, $w$, the total FEM's will be,

$$
\begin{aligned}
\mathrm{FEM}_{A}=\mathrm{P}_{A} \mathrm{R}\left(\frac{\tan \theta}{\theta}-1\right) & -\frac{\mathrm{w}}{3}(\mathrm{R} \sin \theta \sin \eta)^{2} \\
\mathrm{FEM}_{B} & =-\mathrm{FEM}_{\mathrm{A}}
\end{aligned}
$$

For a concentrated vertical load, such as in Figure 4.2 , the FEM's will be,

$$
\begin{aligned}
{ }_{A B M} & =P_{A} R\left(\frac{\tan \theta}{\theta}-1\right)-\left[\frac{\mathrm{Pa}^{2} \mathrm{~b}}{4(\mathrm{R} \sin \theta \sin \eta)^{2}}\right] \\
\text { FEM }_{B} & =P_{A} R\left(\frac{\tan \theta}{\theta}-1\right)+\left[\frac{\mathrm{Pab}^{2}}{4(\mathrm{R} \sin \theta \sin \eta)^{2}}\right]
\end{aligned}
$$

Any other loading can be computed in a similar manner.

4.1.2.3 Moment Distribution. Once the fixed end moments have been computed, a conventional moment distribution is performed. The actual arc length of the members should be used when computing distribution factors.

Once the end moments are computed, the moment of any point on the member can be found by summing moments on the free-body diagram about the point in question. Referring to Fig. 4.3 and including the member loads,

$$
M_{i}=\sum\left(M_{i} \text { of external loads }\right)-M_{A}-P_{A} R(1-\cos \phi)-V_{A} R \sin \phi
$$

The shear, $\mathrm{V}_{\mathrm{A}}$, can be found by summing moments about point $\mathrm{B}$. 


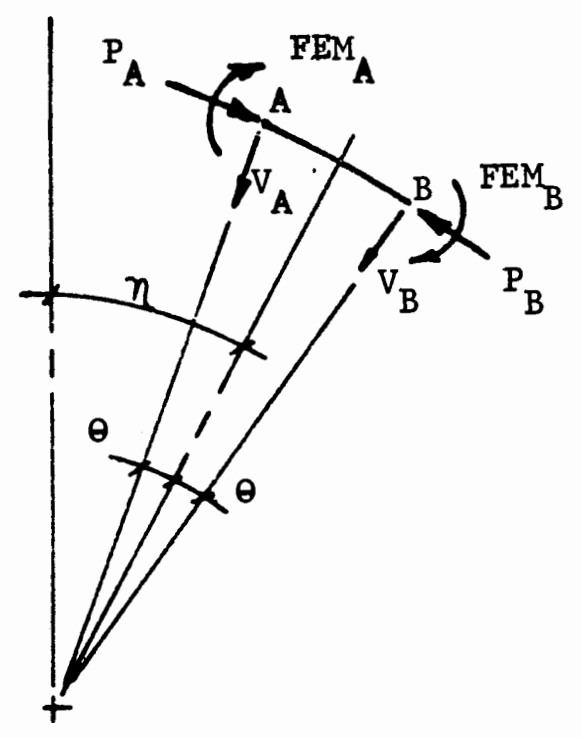

Figure 4.1 Fixed end forces on a top chord panel due to ' $\mathrm{P} \times \mathrm{e}^{\prime}$.

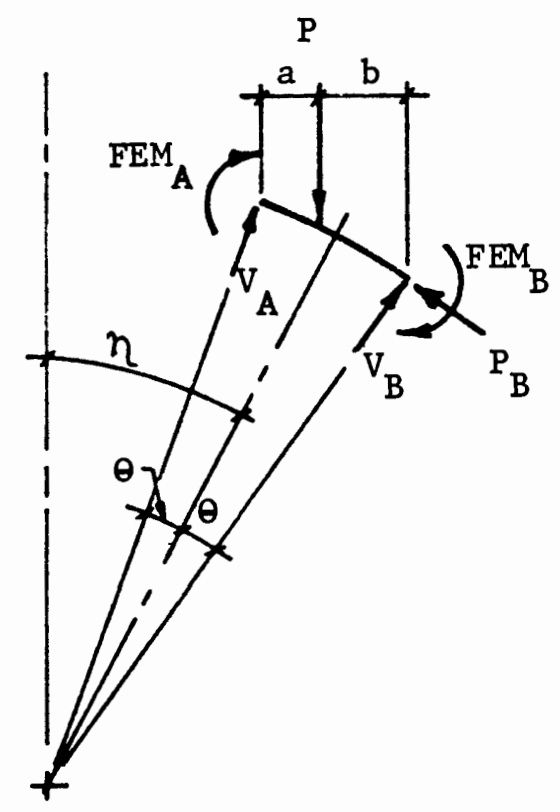

Figure 4.2 Fixed end forces on a top chord panel due to a concentrated load. 


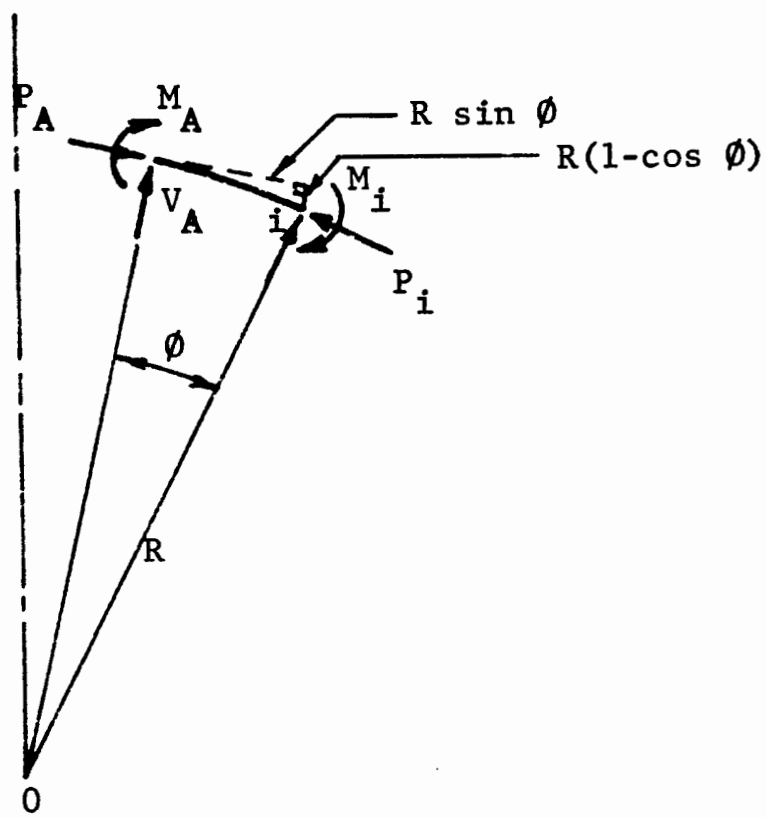

Figure 4.3 Free-body forces on a top chord segment. 
Thus,

$$
\mathrm{V}_{\mathrm{A}}=\frac{\sum\left(\mathrm{M}_{\mathrm{B}} \text { external loads }\right)-\mathrm{M}_{A}-\mathrm{M}_{B}-\mathrm{P}_{A} R(1-\cos 2 \theta)}{\mathrm{R} \sin 2 \theta}
$$

The procedure is demonstrated on the following pages where the primary moments in the 8,10 and 12 panel trusses subjected to a uniform vertical load are computed.

Figure 4.4 provides the loading and geometrical data required for determining the primary moments in the top chord of an 8 panel truss. The axial forces listed in the figure are those in the chords as obtained from a pin jointed analysis assuming straight line segments between panel points.

Table 4.1 shows the moment distribution calculations for the top chord of the 8 panel truss. The fixed end moments listed are computed from Equations 4.2 and 4.3. For clarity, the fixed end moments due to "Pe" and due to the external loads are calculated and listed separately.

The moment at intermediate points along the top chord of the 8 panel truss were computed using Equations 4.6 and 4.7. These values are listed in Table 4.2, and plotted by a solid line in Fig. 4.5. Data obtained from a computer frame analysis (Model I) in which very large member areas were used is plotted as a dashed line in Fig. 4.5. As discussed in Chapter III, the use of large member areas nearly eliminates the secondary moments induced from the deflection of the truss joints. Some slight deflection still occurs, owing to both the axial deformation of the members and to the moments acting on the curved top 
chord. Therefore some small amount of secondary moment will exist in the computer data. As will be seen in later chapters, the secondary moments are positive along the entire length of the top chord. From this, it would be expected that the moments obtained from the computer analysis would be slightly greater (more positive) than the actual primary moment.

As can be seen from Fig. 4.5, the computer produced moments do plot slightly higher than, but very close to the moments computed using the method proposed in this chapter.

Figure 4.6 together with Tables 4.4 and 4.5 provide the data required to produce the primary moment diagram for the 10 pane1 truss which is plotted in Fig. 4.7. This data is computed in the same manner as for the 8 panel truss.

The procedure is repeated for the 12 panel truss. Fig. 4.8 and Tables 4.6 and 4.7 provide the necessary data. The diagram for the primary moment in the top chord of the 12 pane1 truss is plotted in Fig. 4.9.

The data produced in this chapter will be used in Chapter VI to separate the primary moment out of the total moments in the top chord obtained from the computer analyses. This will be done in order to study the magnitude of the secondary (joint movement induced) moments. 


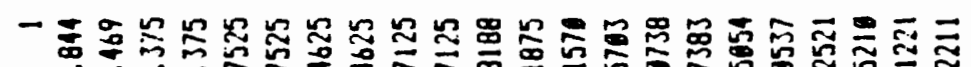

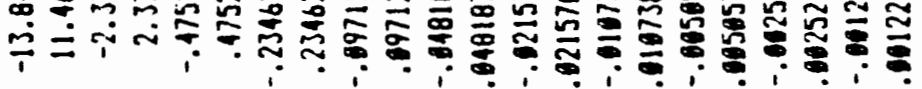

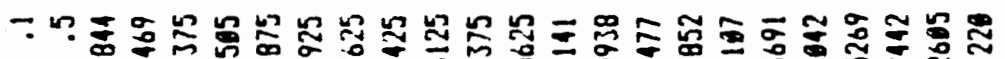

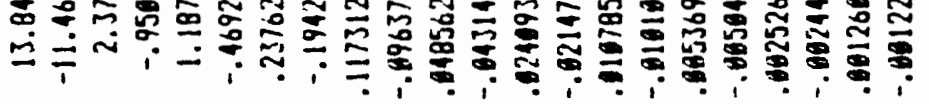

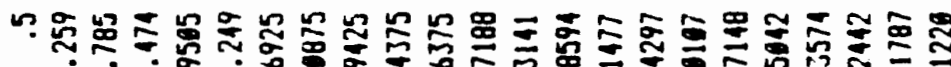

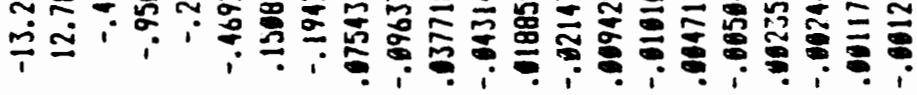

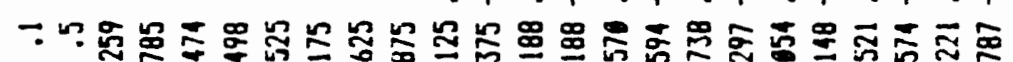
ڤัง

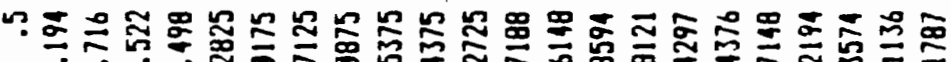

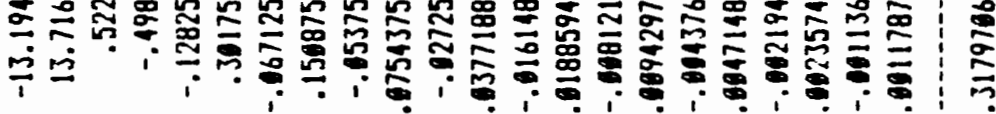

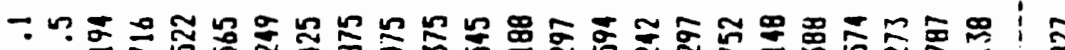

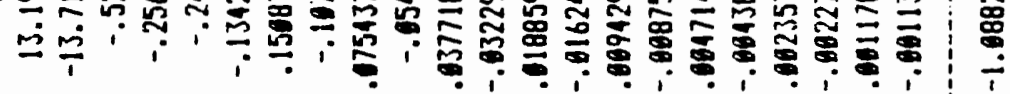

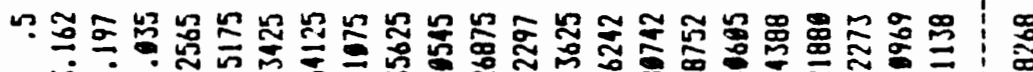

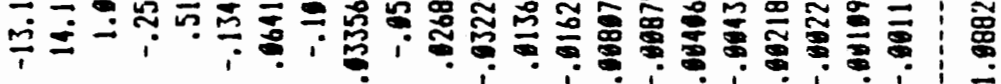

4

產

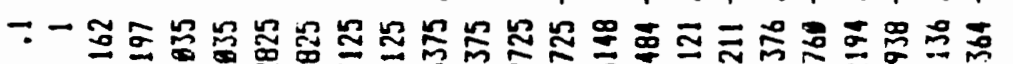

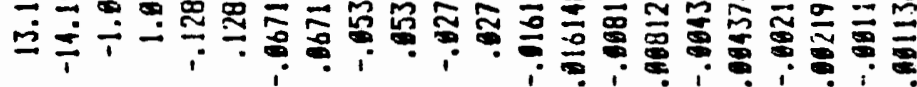

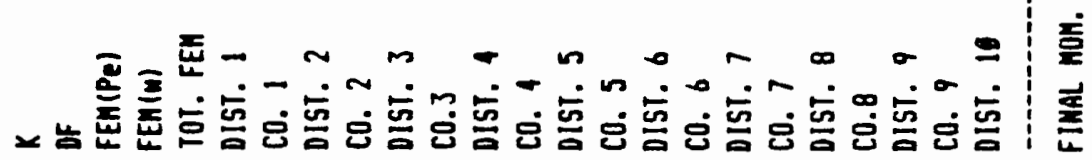


TABLE 4.2

PRTMARY MOMENTS IN TOP CHORD OF 100 FT. EIGHT PANEL TRUSS WITH $1 \mathrm{~K} / \mathrm{FT}$ LOADING OBTAINED FROM EQUATIONS 4.6 AND 4.7

\begin{tabular}{|c|c|c|c|c|}
\hline$\emptyset$ & $\begin{array}{r}\eta=3.75 \\
\text { 1st Pane1 }\end{array}$ & $\begin{array}{c}\eta=11.25 \\
\text { 2nd Pane1 }\end{array}$ & $\begin{array}{r}\eta=18.75 \\
\text { 3rd Pane1 }\end{array}$ & $\begin{array}{r}\eta=26.25 \\
\text { 4th Pane1 }\end{array}$ \\
\hline 0.00 & 0.00 & -1.09 & -0.32 & 2.21 \\
1.25 & 0.71 & -0.53 & -0.33 & -0.21 \\
2.50 & 1.04 & -0.22 & -0.29 & -1.96 \\
3.75 & 1.01 & -0.10 & -0.11 & -2.95 \\
5.00 & 0.63 & -0.12 & 0.30 & -3.03 \\
6.25 & -0.08 & -0.21 & 1.04 & -2.09 \\
7.50 & -1.09 & -0.32 & 2.21 & 0.00 \\
\hline
\end{tabular}

TABLE 4.3

PRTMARY MOMENTS IN THE TOP CHORD OBTAINED FROM COMPUTER RESULTS

FOR AN EIGHT PANEL TRUSS

\begin{tabular}{|l|c|c|c|c|}
\hline \multicolumn{1}{|c|}{$\emptyset$} & 1st Panel & 2nd Panel & 3rd Panel & 4th Pane1 \\
\hline 0.00 & 0.00 & -1.01 & -0.20 & 2.39 \\
1.875 & 0.97 & -0.25 & -0.11 & -0.92 \\
3.75 & 1.11 & 0.04 & 0.14 & -2.73 \\
5.625 & 0.39 & -0.02 & 0.82 & -2.59 \\
7.50 & -1.01 & -0.20 & 2.39 & 0.00 \\
\hline
\end{tabular}



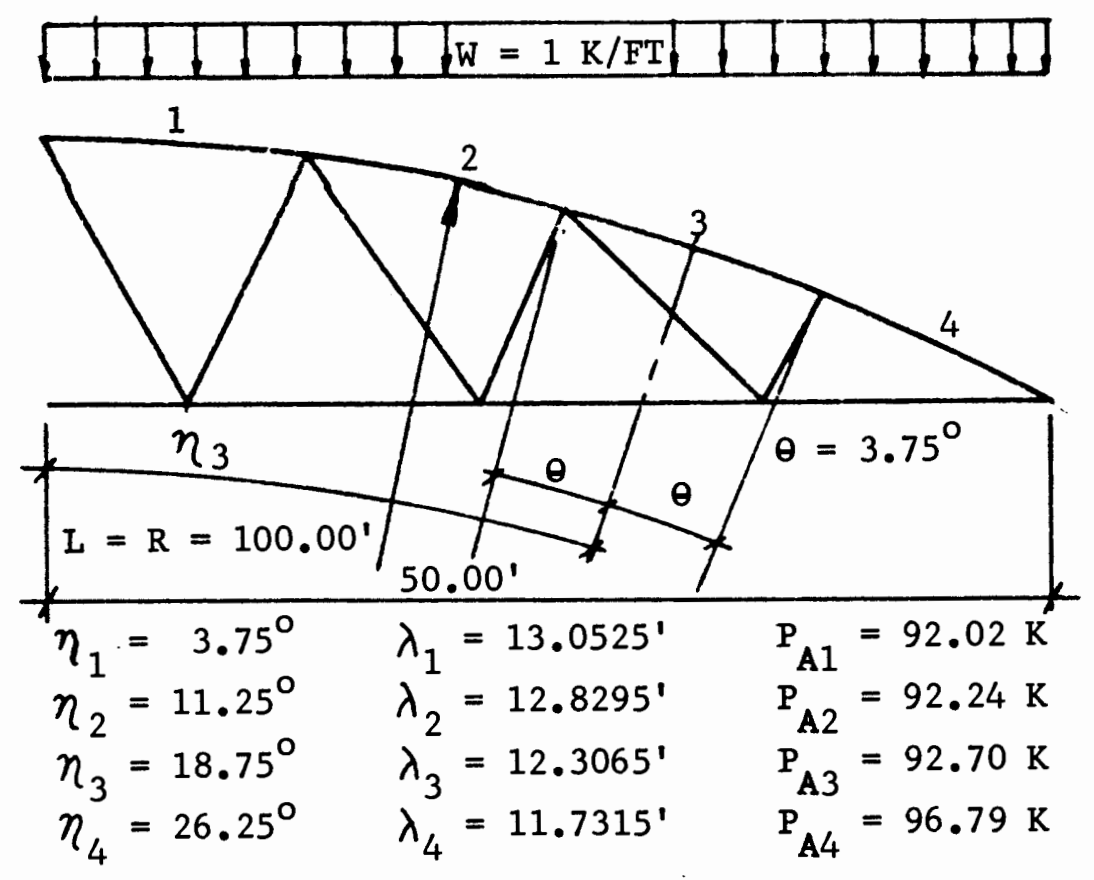

Figure 4.48 panel truss - primary moment data.

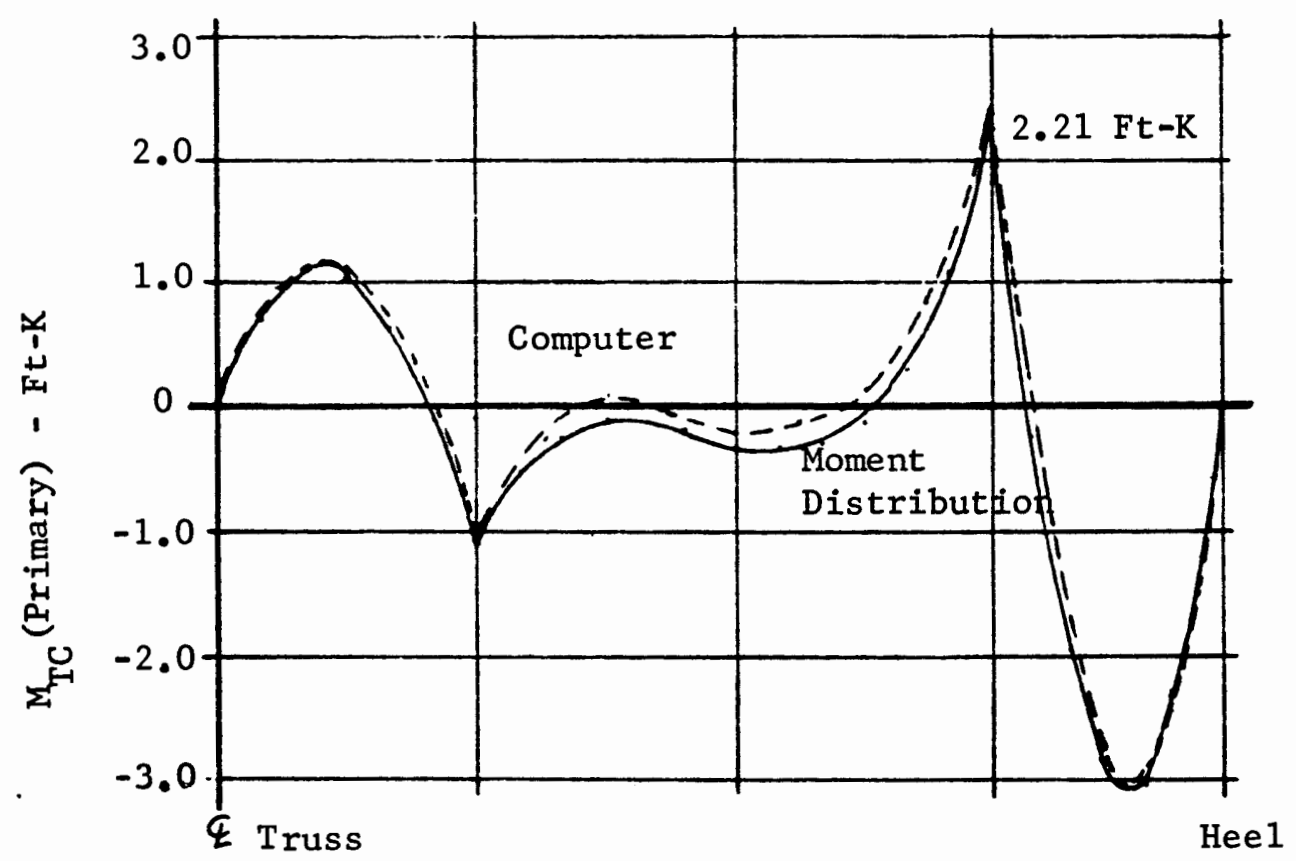

Figure 4.5 Primary moment diagram for a $100 \mathrm{ft}$. span 8 panel truss - one kip per ft. 


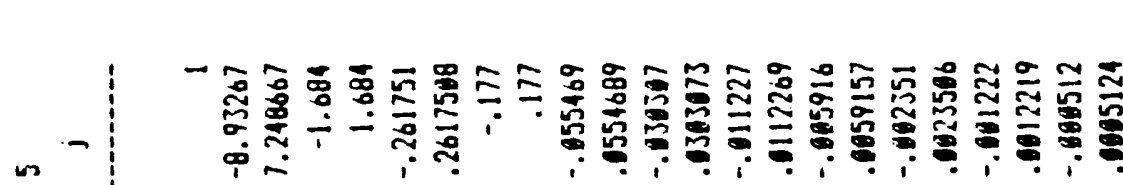

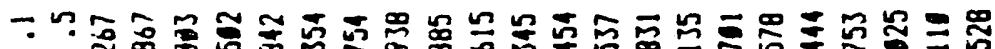

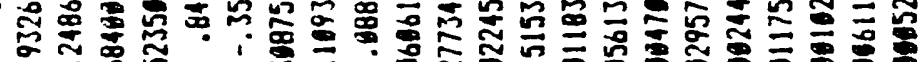
$\infty \uparrow \stackrel{1}{\infty}$

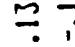

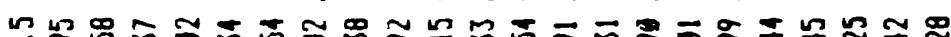

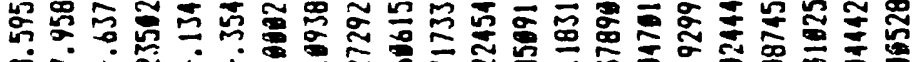

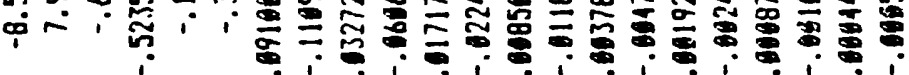

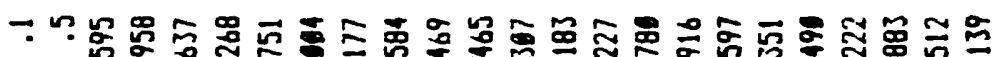

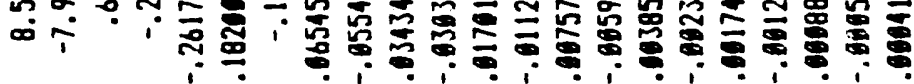

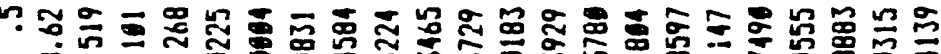

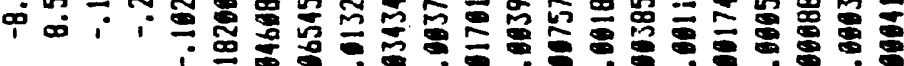

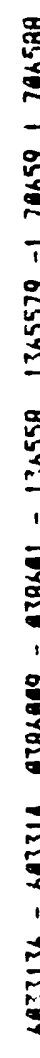
m

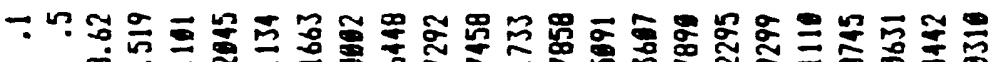

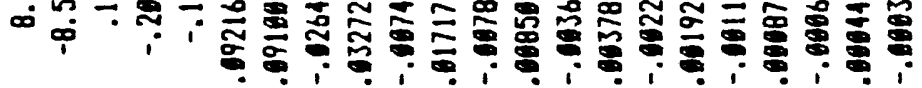

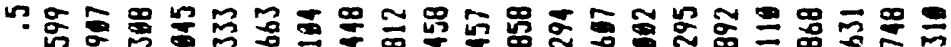

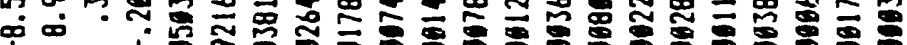
一几。

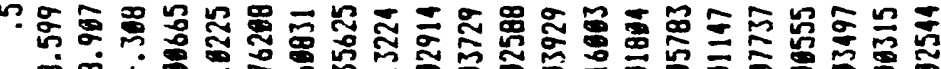

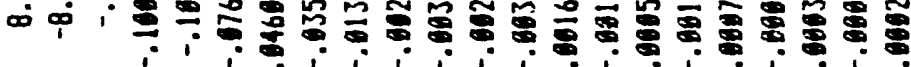

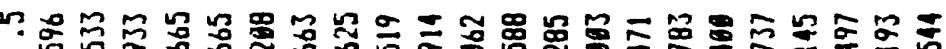

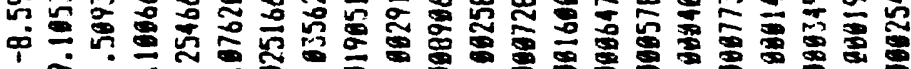

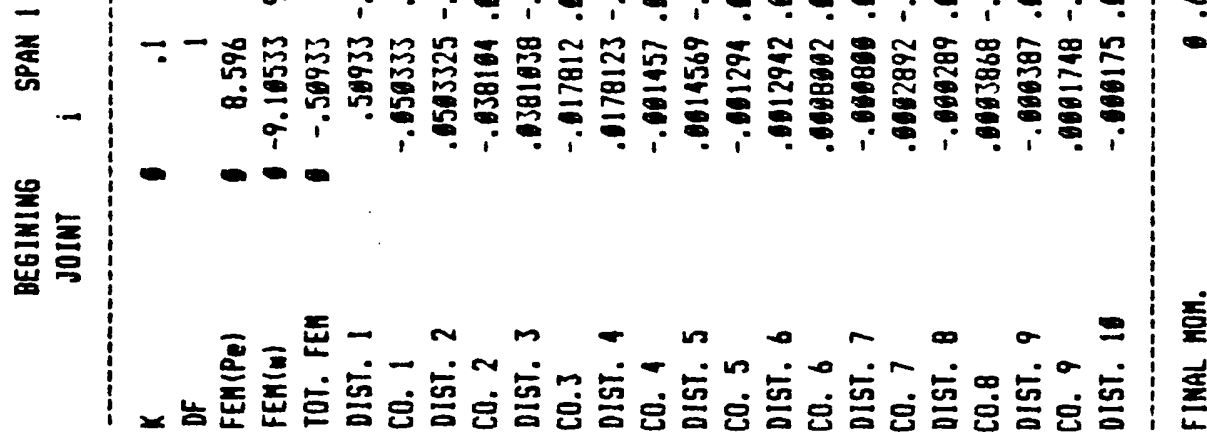


TABLE 4.5

PRIMARY MOMENTS IN TOP CHORD OF 100 FT TEN PANEL TRUSS WITH $1 \mathrm{~K} / \mathrm{FT}$ LOADING OBTAINED FROM EQUATIONS 4.6 AND 4.7

\begin{tabular}{|c|c|c|c|r|r|}
\hline$\emptyset$ & $\begin{array}{r}\eta=3.0 \\
\text { First } \\
\text { Pane1 }\end{array}$ & $\begin{array}{r}\eta=9.0 \\
\text { Second } \\
\text { Pane1 }\end{array}$ & $\begin{array}{r}\eta=15.0 \\
\text { Third } \\
\text { Pane1 }\end{array}$ & $\begin{array}{r}\eta=21.0 \\
\text { Fourth } \\
\text { Pane1 }\end{array}$ & $\begin{array}{r}\eta=27.0 \\
\text { Fifth } \\
\text { Pane1 }\end{array}$ \\
\hline 0.50 & 0.00 & -0.60 & -0.04 & 0.14 & 1.71 \\
0.75 & 0.27 & -0.33 & -0.09 & -0.10 & 0.37 \\
1.50 & 0.43 & -0.13 & -0.15 & -0.26 & -0.70 \\
2.25 & 0.50 & -0.002 & -0.21 & -0.31 & -1.48 \\
3.00 & 0.46 & 0.07 & -0.25 & -0.24 & -1.94 \\
3.75 & 0.33 & 0.09 & -0.25 & -0.03 & -2.04 \\
4.50 & 0.10 & 0.07 & -0.20 & 0.35 & -1.78 \\
5.25 & -0.21 & 0.02 & -0.08 & 0.92 & -1.10 \\
6.00 & -0.60 & -0.04 & 0.14 & 1.71 & 0.00 \\
\hline
\end{tabular}




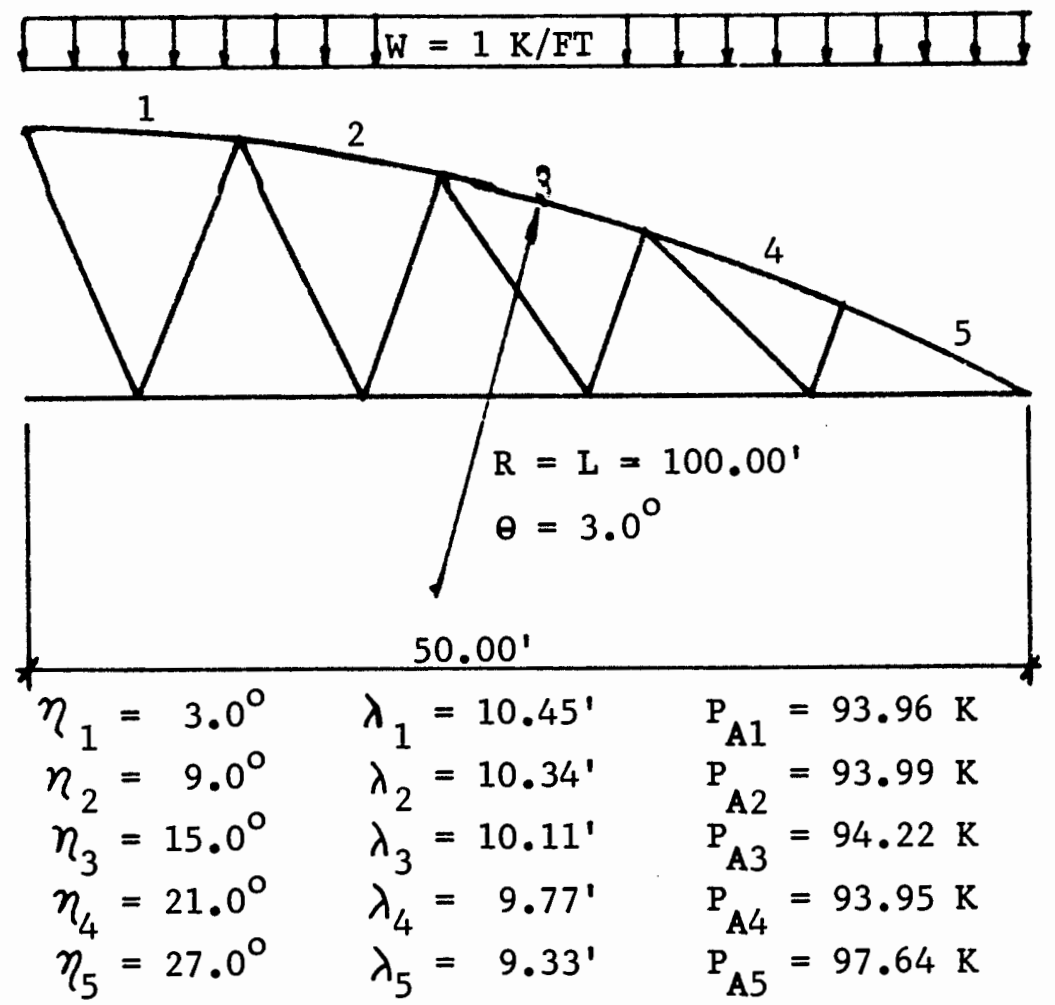

Figure 4.610 panel truss - primary moment data.

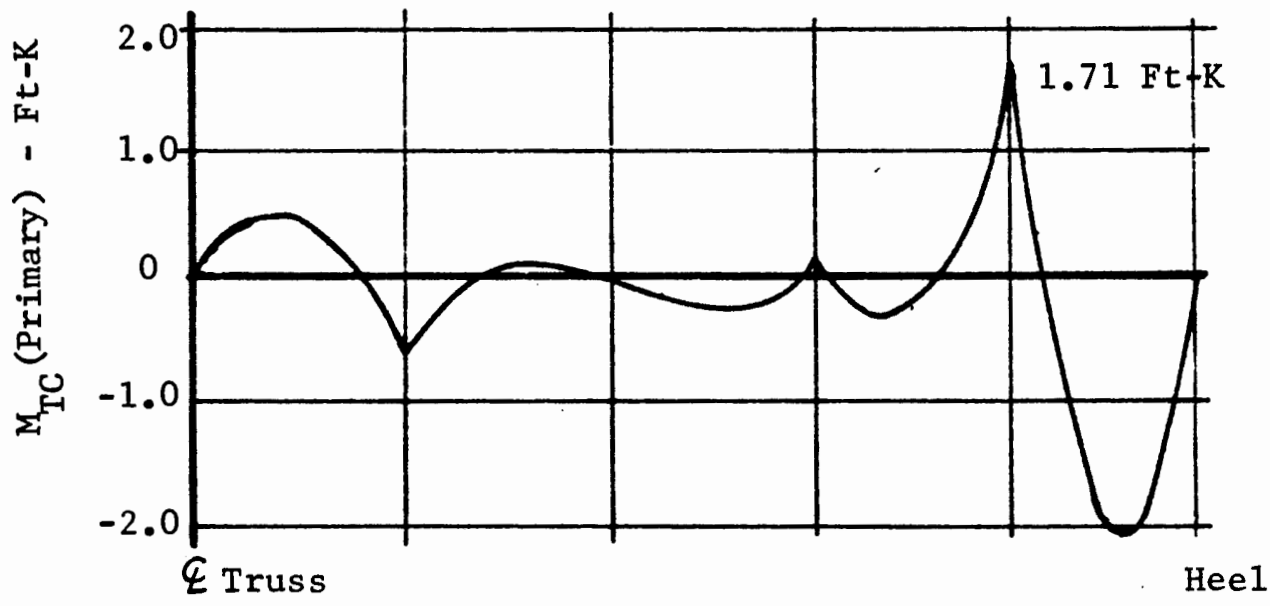

Figure 4.7 Primary moment diagram for a $100 \mathrm{ft}$ span 10 panel truss - one kip per foot. 


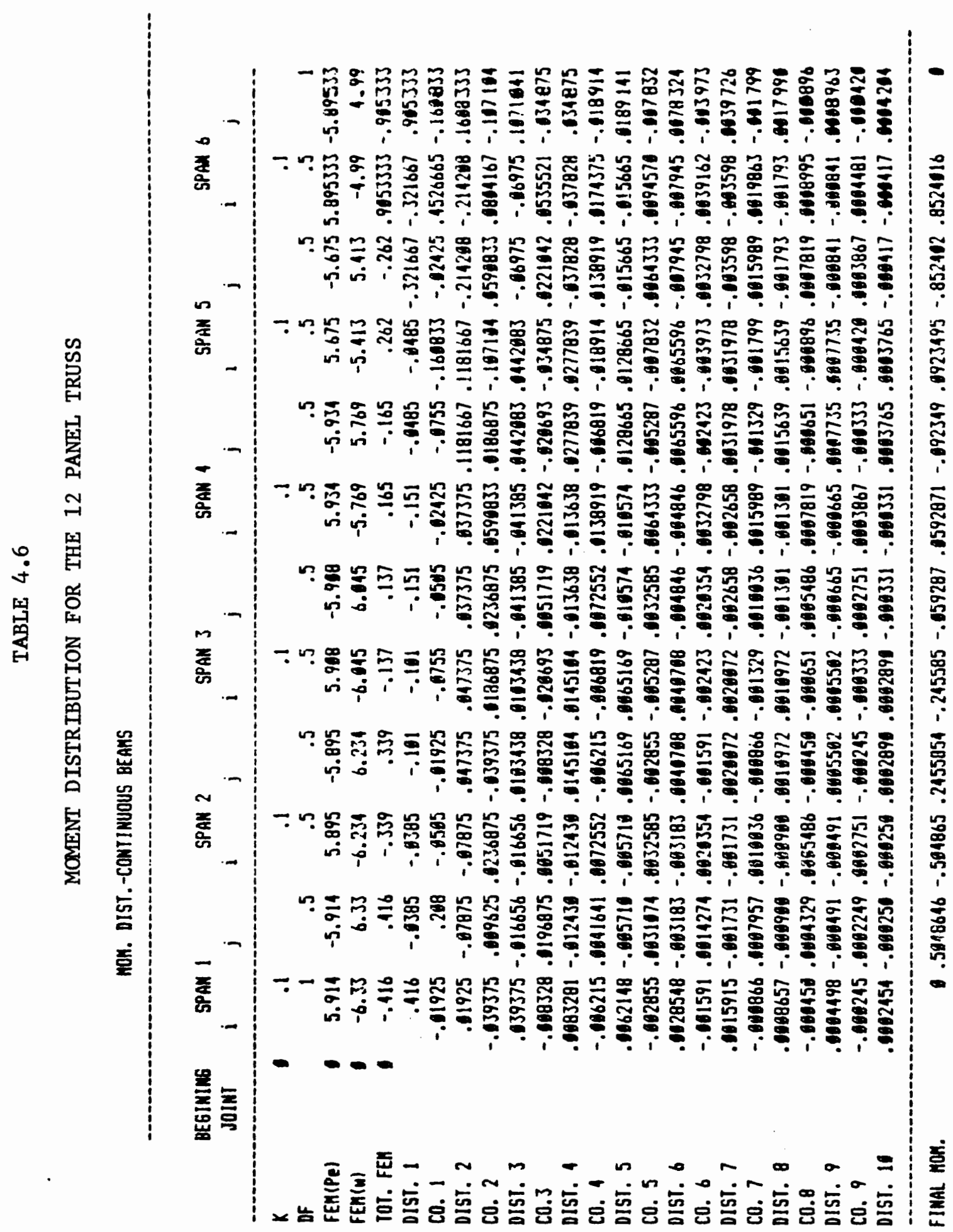


TABLE 4.7

PRIMARY MOMENTS IN TOP CHORD OF 100 FT.

TWELVE PANEL TRUSS WITH $1 \mathrm{~K} / \mathrm{FT}$ LOADING

OBTAINED FROM EQUATIONS 4.6 AND 4.7

\begin{tabular}{|c|r|r|r|r|r|r|}
\hline$\emptyset$ & $\begin{array}{r}\eta=2.5 \\
\text { First } \\
\text { Pane1 }\end{array}$ & $\begin{array}{r}\eta=7.5 \\
\text { Second } \\
\text { Pane1 }\end{array}$ & $\begin{array}{r}\eta=12.5 \\
\text { Third } \\
\text { Pane1 }\end{array}$ & $\begin{array}{r}\eta=17.5 \\
\text { Fourth } \\
\text { Pane1 }\end{array}$ & $\begin{array}{r}\eta=22.5 \\
\text { Fifth } \\
\text { Pane1 }\end{array}$ & $\begin{array}{r}\eta=27.5 \\
\text { Sixth } \\
\text { Pane1 }\end{array}$ \\
\hline 0.00 & 0.00 & -0.50 & -0.25 & 0.06 & 0.09 & 0.85 \\
0.63 & 0.21 & -0.25 & -0.12 & -0.05 & 0.01 & 0.14 \\
1.25 & 0.35 & -0.06 & -0.04 & -0.15 & -0.06 & -0.43 \\
1.88 & 0.40 & 0.05 & 0.02 & -0.23 & -0.08 & -0.85 \\
2.50 & 0.37 & 0.10 & 0.04 & -0.28 & -0.05 & -1.09 \\
3.13 & 0.27 & 0.09 & 0.05 & -0.28 & 0.04 & -1.14 \\
3.75 & 0.08 & 0.02 & 0.05 & -0.22 & 0.21 & -0.99 \\
4.38 & -0.17 & -0.09 & 0.05 & -0.11 & 0.48 & -0.61 \\
5.00 & -0.50 & -0.25 & 0.06 & 0.09 & 0.85 & 0.00 \\
\hline
\end{tabular}




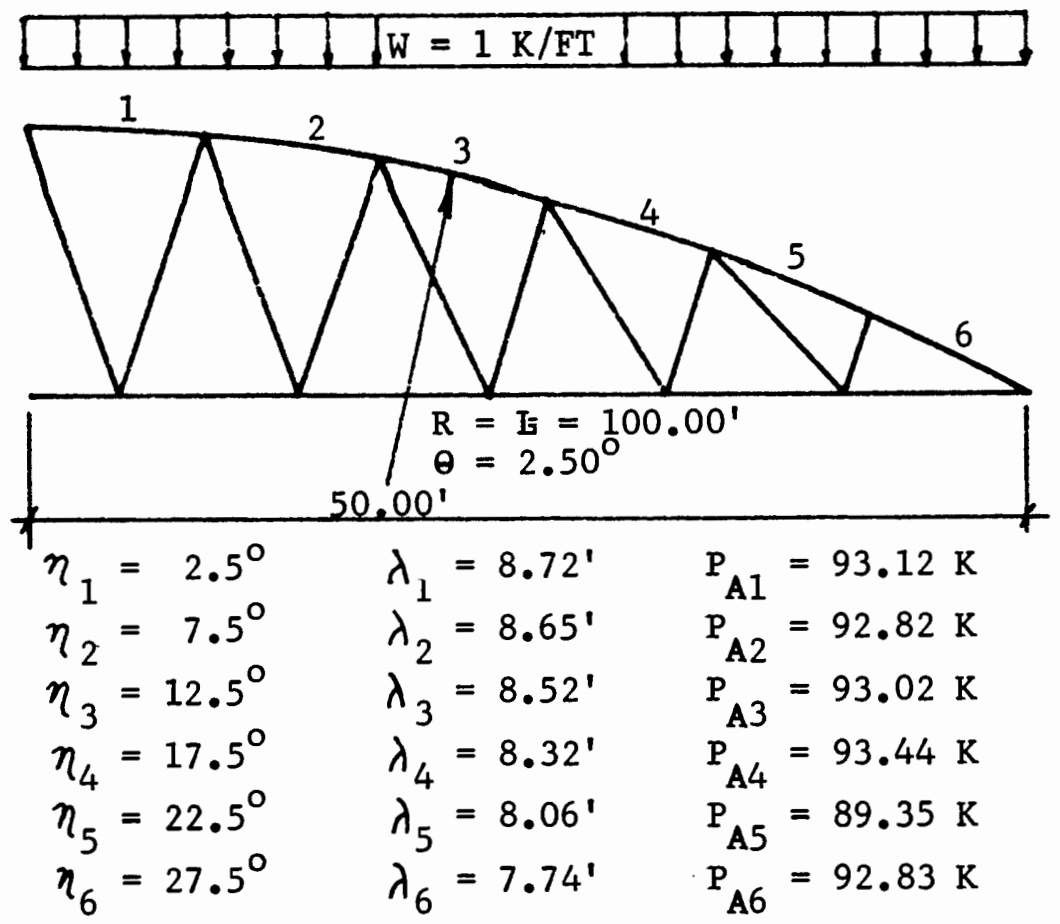

Figure 4.812 panel truss - primary moment data.

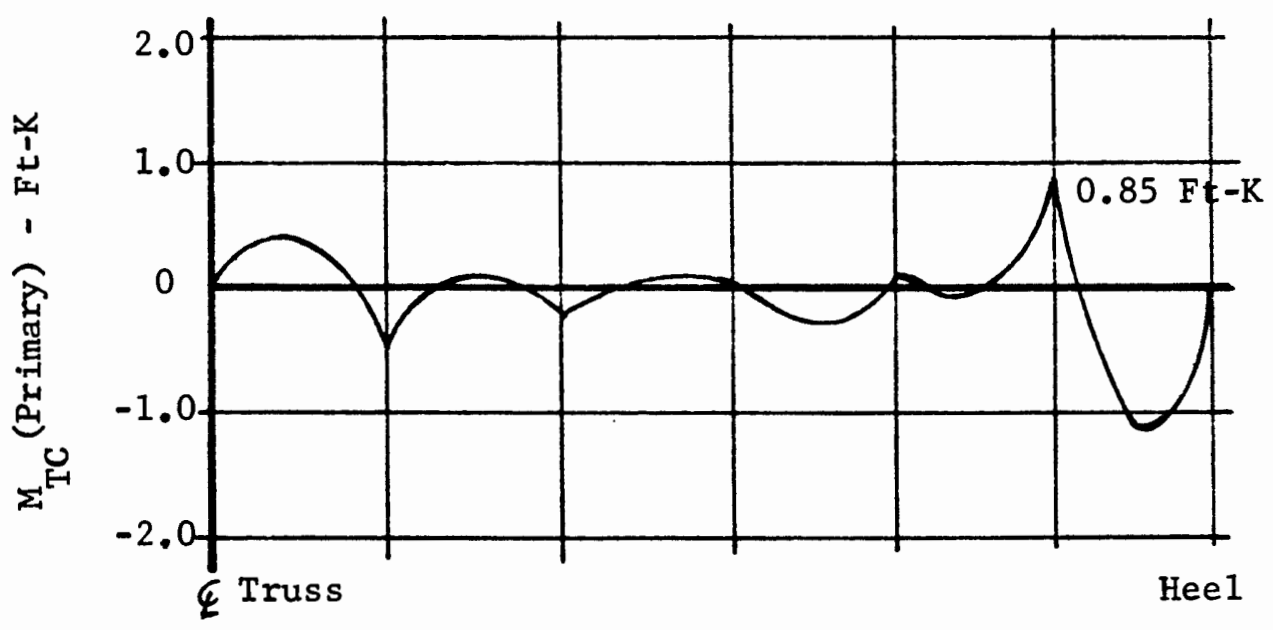

Figure 4.9 Primary moment diagram for a $100 \mathrm{ft}$. span 12 panel truss - one kip per foot. 


\section{CHAPTER V}

\section{SECONDARY MOMENTS IN THE BOTTOM CHORD}

As defined earlier, the secondary moments are "support settlement" type moments induced into the continuous chord as the truss deflects under load. In this case, the secondary moment in the bottom chord will be equal to the total moment since we have assumed a straight bottom chord with no direct loading on the bottom chord members.

\subsection{PARAMETERS AFFECTING THE SECONDARY MOMENT IN THE BOTTOM CHORD}

The principal parameters affecting the secondary moments in the bottom chord are the values of the area and moment of inertia of both the top and bottom chords, the load intensity, truss span and the number of panels.

These parameters are designated as shown in Table 5.1. As indicated in Chapter III, the $A$ and I values were varied independently over a range of values encompassing the normal range of member sizes used in practice. This range was 1 isted in Table 3.2 . 
TABLE 5.1

PRINCIPAL PARAMETERS AFFECTING THE SECONDARY MOMENTS IN THE BOTTOM CHORD

\begin{tabular}{|c|c|}
\hline Parameter & Designation \\
\hline Area of Bottom Chord & $A_{\mathrm{BC}}$ \\
Area of Top Chord & $A_{\mathrm{TC}}$ \\
I of Bottom Chord & $\mathrm{I}_{\mathrm{BC}}$ \\
I of Top Chord & $\mathrm{I}_{\mathrm{TC}}$ \\
Truss Span & $\mathrm{I}$ \\
Load Intensity & $\mathrm{w}$ \\
Number of Panels & $\mathrm{NP}$ \\
\hline
\end{tabular}

Additional parameters affecting the moment in the bottom chord are joint slippage and heel and splice fixity. These effects will be discussed in Chapter 8.

The influence of $A_{B C}, I_{B C}, A_{T C}$ and $I_{T C}$ on the moment in the bottom chord are studied independently in a series of plots for each truss configuration (8, 10 and 12 pane1). The data for these plots can be found in Appendix 2.

Figure 5.1 shows plots of the moment in the bottom chord for several combinations of $A_{B C}$ and $I_{B C}$. As can be seen, the critical section for designing the bottom chord occurs at the first panel point from the heel in all cases.

The moment at this location will be designated $\mathrm{M}_{\mathrm{BC}}$ and is plotted as a function of $A_{B C}$ and $I_{B C}$ in Figures $5.2 a, b$, and $c$. 


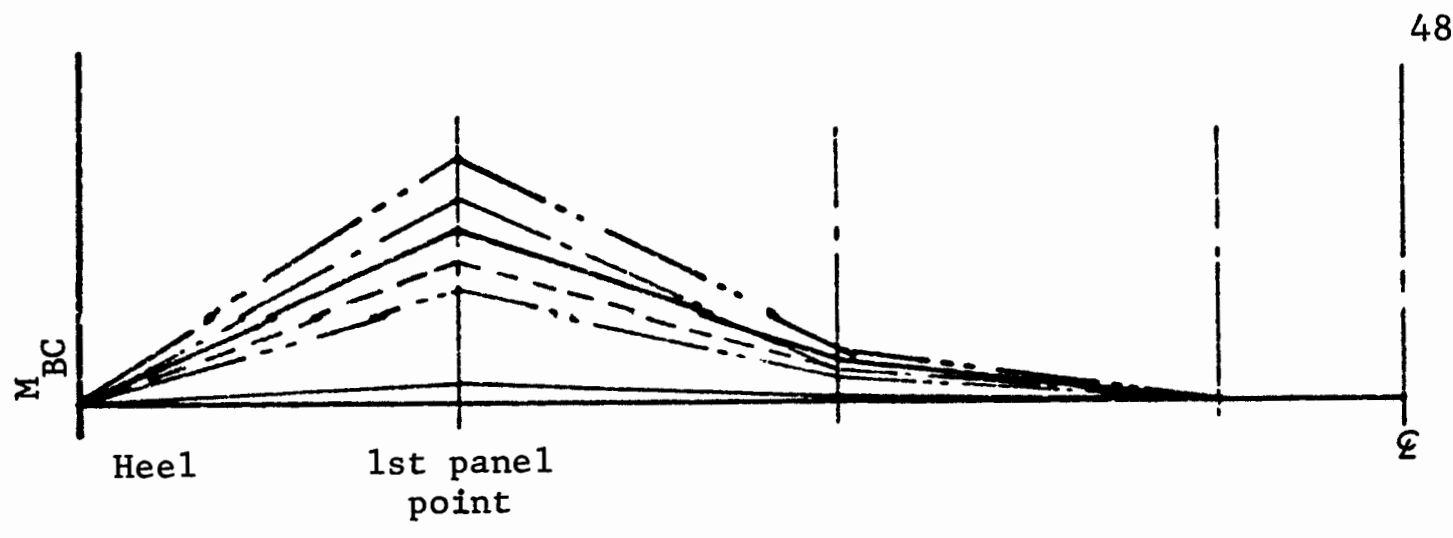

8 Pane1

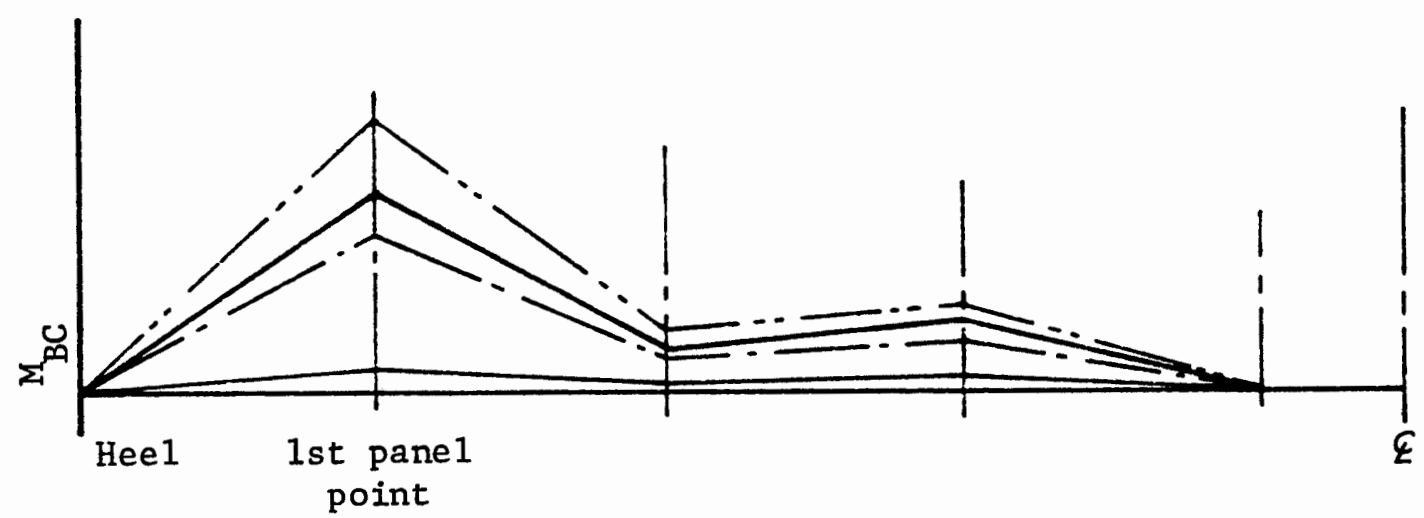

10 Pane1

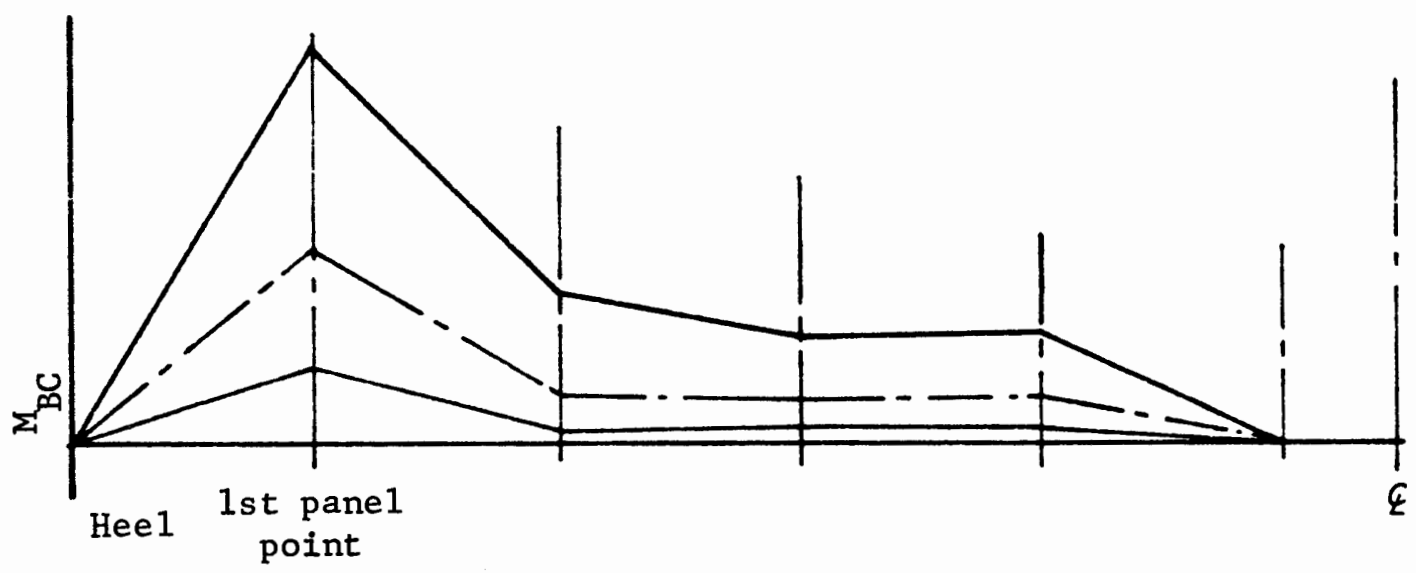

12 Pane1

Figure 5.1 Typical bottom chord secondary moment diagrams. 


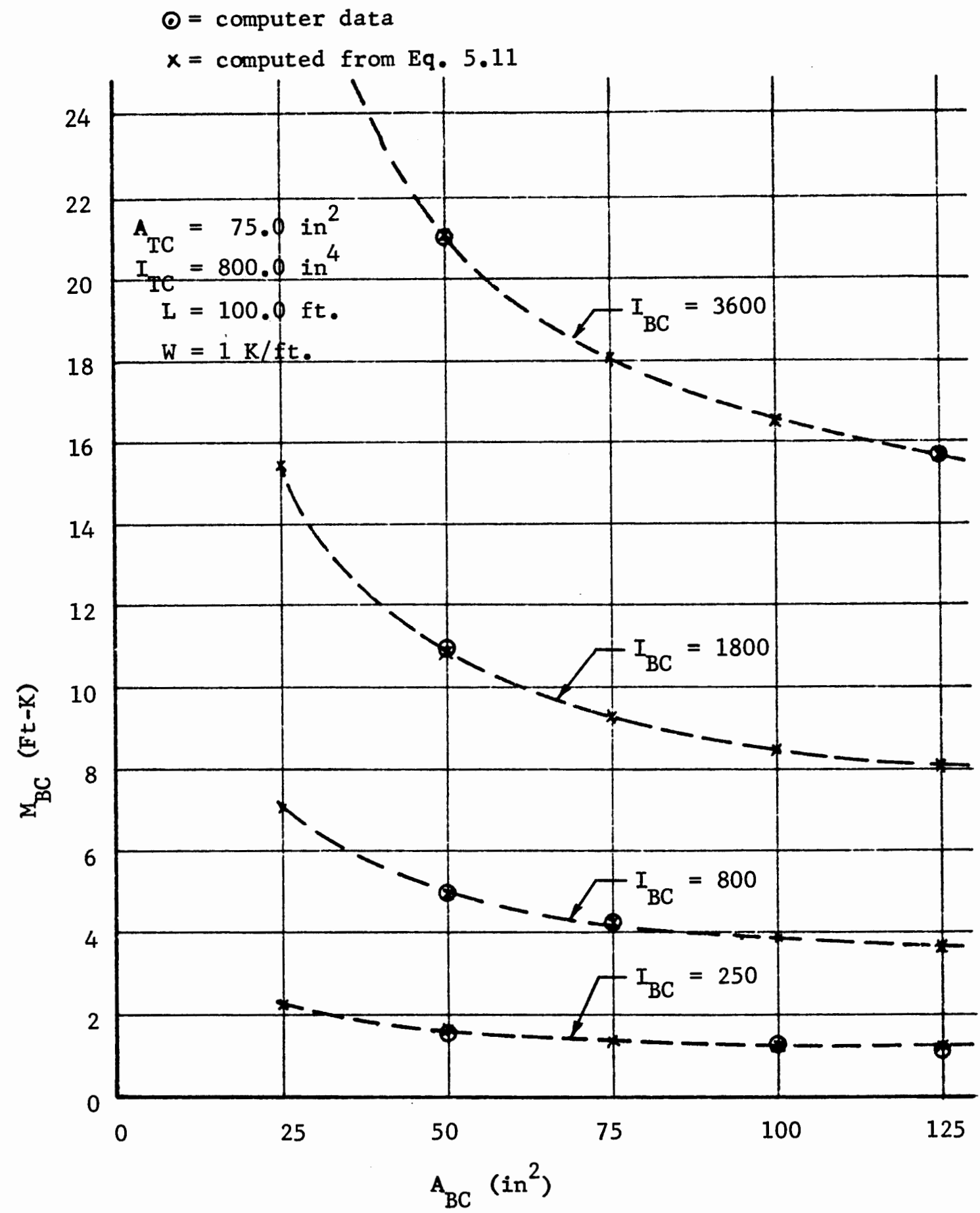

Figure 5.2a 8 panel truss - secondary moment in the bottom chord as a function of $A_{B C}$ and $I_{B C} \cdot$ 


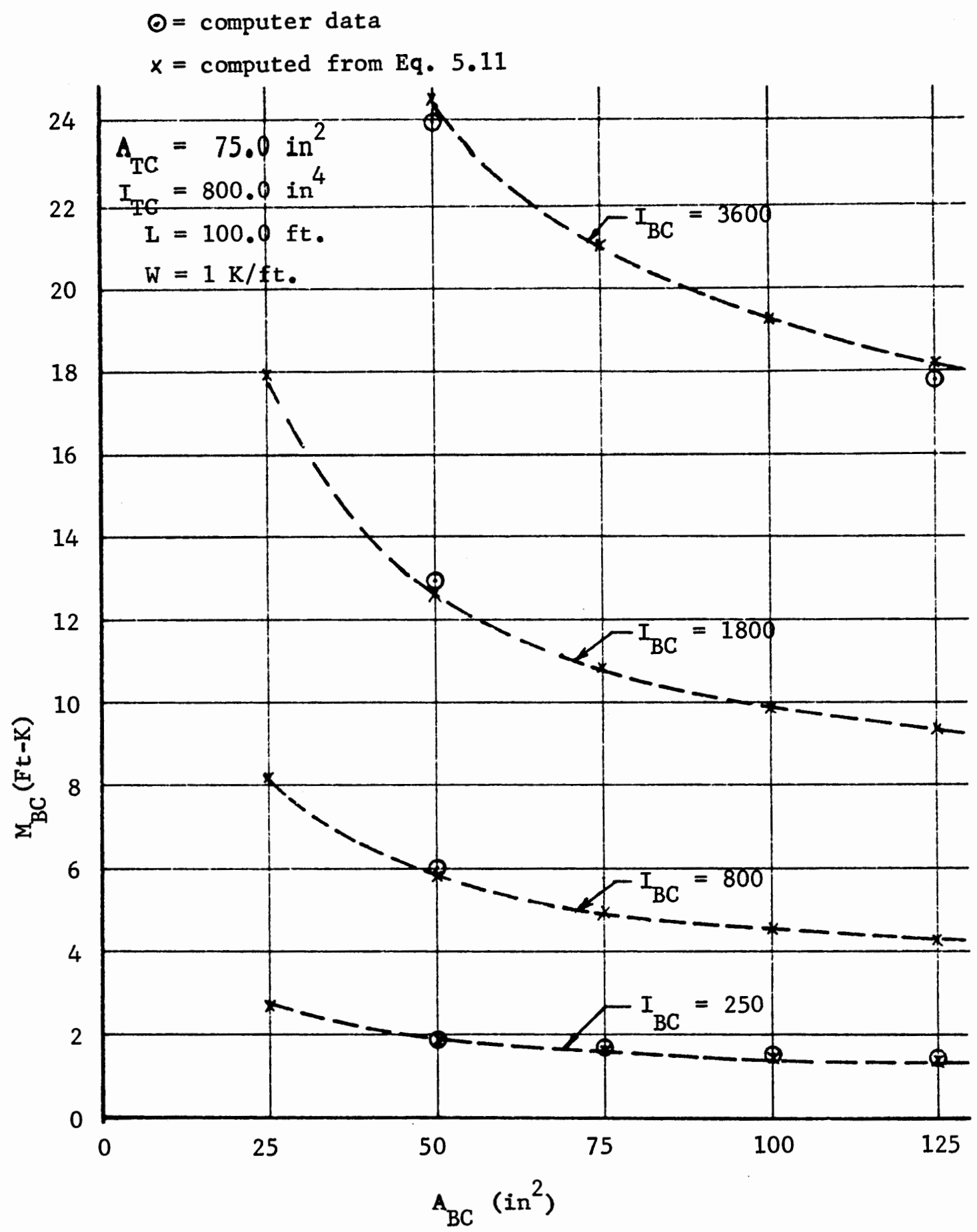

Figure 5.2b 10 panel truss - secondary moment in the bottom chord as a function of $A_{B C}$ and $I_{B C} \cdot$ 


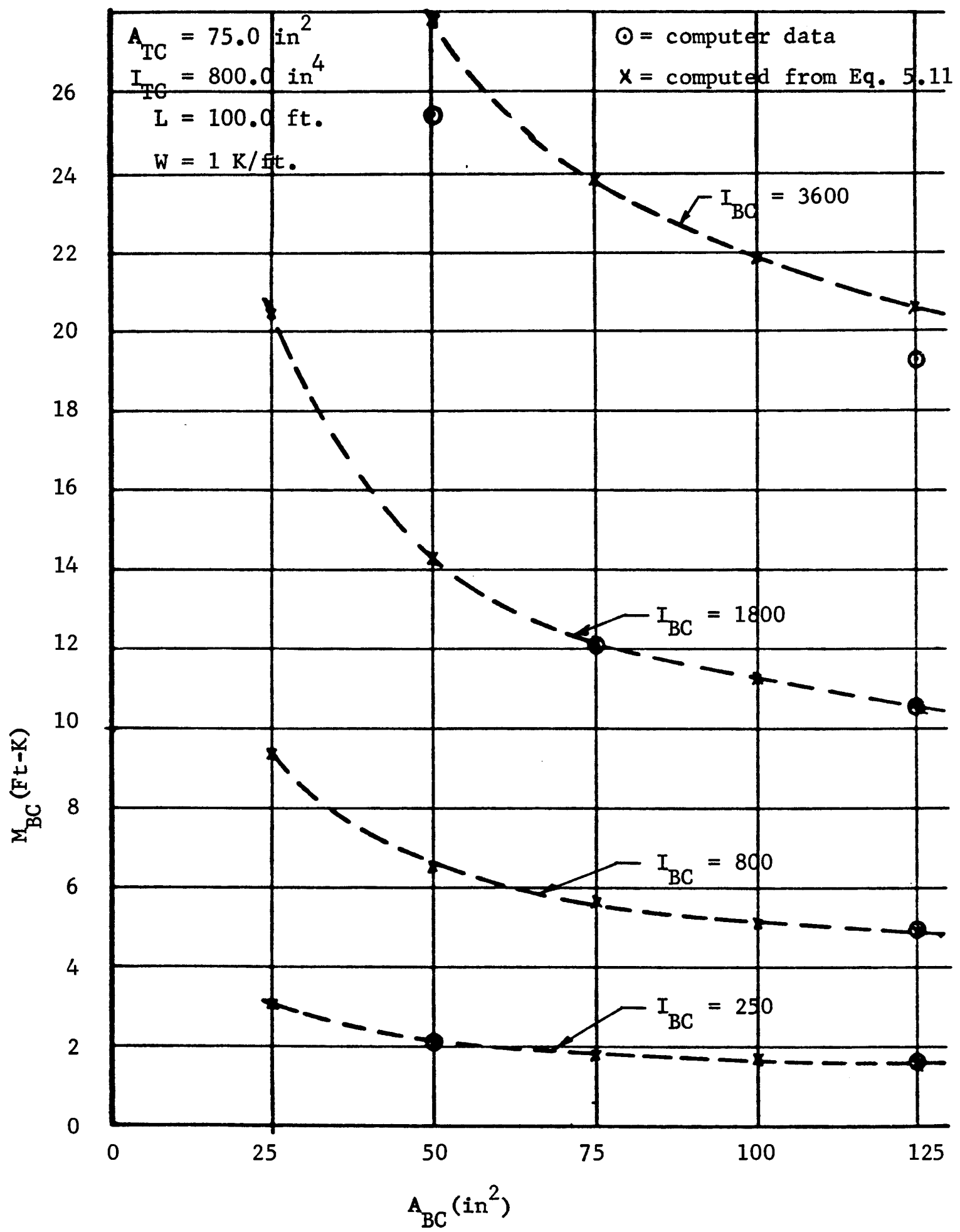

Figure 5.2c 12 pane1 truss - secondary moment in the bottom chord as a function of $A_{B C}$ and $I_{B C}$. 
As would be expected, the value of $I_{B C}$ has a much more pronounced effect on the induced moment than does the area, $A_{B C}$.

\section{$5.2 M_{B C}$ AS A FUNCTION OF $A_{B C}$}

The area of the bottom chord affects the net deflection of the truss according to the virtual. work expression

$$
\triangle=\sum \frac{\mathrm{pPL}}{\mathrm{AE}}
$$

The resulting change in deflection caused by varying $A_{B C}$ affects a change in the curvature of the deflected continuous chord member. The change in curvature results in a change in moment due to the flexural deflection, that is

$$
\begin{aligned}
& \text { Curvature }=\frac{1}{\rho}=\frac{M}{E I} \\
& \text { or } \quad M=\frac{E I}{\rho}
\end{aligned}
$$

As $A_{B C}$ is increased with all other parameters remaining constant, the secondary moments will decrease. This can be seen in Figure 5.2. The moment will not approach zero as $\mathrm{A}_{\mathrm{BC}}$ goes to infinity, however. The deformations of the top chord and the webs also contribute to the deflection of the truss. The moment, therefore, approaches asymptotically a value greater than zero, which is dependent on the other parameters.

The curves of Figure 5.2, which relate $A_{B C}$ to $M_{B C}$, can be approximated by an equation of the form:

$$
\mathrm{M}_{\mathrm{BC} 0}=\frac{k_{B}}{\mathrm{~A}_{\mathrm{BC}}}+\mathrm{C}_{\mathrm{B}}
$$

The " 0 " subscript on $M_{B C}$ indicates that this is the moment 
obtained when all parameters except $\mathrm{A}_{\mathrm{BC}}$ are fixed at "base" values. This "base" value of $M_{B C}$ will subsequently be adjusted to account for variation in the other parameters.

Equation 5.3 suggests that $M_{B C 0}$ would approach infinity as $A_{B C}$ approaches zero, which seems reasonable since zero area would produce infinite deflections.

The values of $M_{B C}$ obtained from a series of computer frame analyses in which all parameters are held constant except $A_{B C}$ are utilized to compute the constants $k_{B}$ and $C_{B}$ of Equation 5.3. Since there are two unknowns, two analyses will be required. Designating the two analyses as case 1 and 2 and subscripting $A_{B C}$ and the resulting $M_{B C}$ accordingly, the following expressions are obtained by substituting the known values into Equation 5.3 and solving for the constant:

$$
C_{B}=\frac{A_{B C 1} M_{B C 1}-A_{B C 2} M_{B C 2}}{A_{B C 1}-A_{B C 2}}
$$

and

$$
k_{B}=\left(M_{B C 1}-C_{B}\right) A_{B C 1}
$$

These constants will vary as $I_{B C}$ varies. The computed values of $k_{B}$ and $C_{B}$ and the data from which they were computed are listed in Table 5.2.

\section{TABLE 5.2}

COMPUTATION OF $k_{B}$ AND $C_{B}$ FOR THE EIGHT, TEN AND TWELVE PANEL TRUSSES USING EQUATIONS 5.4 AND 5.5

\begin{tabular}{|r|c|c|c|c|c|c|c|}
\hline Truss & $I_{B C 0}$ & $A_{B C 1}$ & $A_{B C 2}$ & $M_{B C 1}$ & $M_{B C 2}$ & $C_{B}$ & $k_{B}$ \\
\hline $8 P$ & 3600 & 50.0 & 125.0 & 21.07 & 15.67 & 12.0700 & 450.0000 \\
$10 P$ & 3600 & 50.0 & 125.0 & 23.98 & 17.79 & 13.6633 & 515.8333 \\
$12 P$ & 3600 & 50.0 & 125.0 & 25.43 & 19.25 & 15.1300 & 515.0000 \\
\hline
\end{tabular}


It should be noted that although Equation 5.3 very closely predicts $\mathrm{M}_{\mathrm{BC}}$ ' it is not exact, and care should be taken if extrapolation beyond the existing data is attempted. The accuracy within the range of data appears well within normal engineering tolerances however.

Equation 5.3 provides a relationship between $\mathrm{M}_{\mathrm{BC}}$ and $\mathrm{A}_{\mathrm{BC}}$, with all other parameters constant. $\mathrm{M}_{\mathrm{BC}}$ will be affected by the other parameters as we11. In order to account for these effects, an adjustment factor, $\mathrm{K}_{\mathrm{Bi}}$, for each parameter will be developed, resulting in an equation as follows:

$$
\mathrm{M}_{\mathrm{BC}}=\left(\mathrm{K}_{\mathrm{B} O} \mathrm{~K}_{\mathrm{B} 1} \ldots \mathrm{K}_{\mathrm{Bi}} \ldots \mathrm{K}_{\mathrm{Bn}}\right)\left(\frac{\mathrm{k}_{\mathrm{B}}}{\mathrm{A}_{\mathrm{BC}}}+\mathrm{C}_{\mathrm{B}}\right)
$$

The following parameters will be considered here:

$$
\begin{array}{rlrl}
K_{B 0} & =f\left(I_{B C}\right) & & (I \text { of Bottom Chord) } \\
K_{B 1} & =f\left(A_{T C}\right) & & (\text { Area of Top Chord) } \\
K_{B 2} & =f\left(I_{T C}\right) & & (I \text { of Top Chords) } \\
K_{B 3} & =f(L) & & \text { (Truss Span) } \\
K_{B 4} & =f(w) & & \text { (Load Intensity) } \\
K_{B 5} & =f(\text { number of pane1s) } & (8 \text { pane1, 10 pane1 or 12 pane1) }
\end{array}
$$

5.3 THE EFFECT OF $I_{B C}$ ON $M_{B C}$

The effect of the moment of inertia, $I_{B C}$, has a much more pronounced effect than does the area, as was anticipated. Equation 5.2 would suggest a linear relationship between $I_{B C}$ and $M_{B C} \cdot$ The computer results confirmed this to be nearly true. A slight nonlinearity results from the axial forces in the members being changed slightly as $I_{B C}$ varies. The deflections of the truss are therefore not a linear 
function of $I_{B C}$, which results in $M_{B C}$ being slightly nonlinear.

Various approaches to representing the variation of $M_{B C}$ with $I_{B C}$ were considered, including a power curve fit of the form

$$
\mathrm{K}_{\mathrm{BO}}=\left(\frac{\mathrm{I}_{\mathrm{BC}}}{\mathrm{I}_{\mathrm{BCO}}}\right)^{\mathrm{N}}
$$

As mentioned above, the relationship is nearly linear over the range of normal chord sizes. Thus $\mathrm{N}$ will be very nearly equal to one.

The value of $\mathrm{N}$ can be determined by considering the following equation

$$
\begin{gathered}
M_{B C}=m I_{B C}^{N} \\
\text { or } \quad m=\frac{M_{B C}}{I_{B C}^{N}}
\end{gathered}
$$

Using two values of $I_{B C}$, we obtain

$$
\frac{M_{B C 1}}{I_{B C 1}^{N}}=\frac{M_{B C 2}}{I_{B C 2}^{N}}
$$

or

$$
\left(\frac{I_{B C 2}}{I_{B C 1}}\right)^{N}=\frac{M_{B C 2}}{M_{B C 1}}
$$

Thus

$$
\mathrm{N}=\frac{\ln \left(\mathrm{M}_{\mathrm{BC} 2} / \mathrm{M}_{\mathrm{BC1} 1}\right)}{\ln \left(\mathrm{I}_{\mathrm{BC} 2} / \mathrm{I}_{\mathrm{BC1}}\right)}
$$

The calculations for $\mathrm{N}$ are found in Table 5.3.

At this point we have the following: 
TABLE 5.3

COMPUTATION OF $\mathrm{N}$

\begin{tabular}{|l|l|l|c|}
\hline & 8 Pane 1 & 10 Pane1 & 12 Pane1 \\
\hline $\begin{array}{l}\text { Designation 1 } \\
\text { Designation 2 }\end{array}$ & $01 \mathrm{TC} 11$ & $01 \mathrm{TC} 11$ & $00 \mathrm{TC} 12$ \\
$\mathrm{I}_{\mathrm{BC} 1}$ & 800 & $03 \mathrm{TC} 11$ & $03 \mathrm{TC} 12$ \\
$\mathrm{I}_{\mathrm{BC} 2}$ & 3600 & 800 & 250 \\
$\mathrm{M}_{\mathrm{BC} 1}$ & 4.97 & 6.01 & 3600 \\
$\mathrm{M}_{\mathrm{BC} 2}$ & 21.07 & 23.98 & 2.13 \\
$\mathrm{~N}$ & .960343 & .920029 & .929732 \\
\hline
\end{tabular}

$$
\mathrm{M}_{\mathrm{BC}}=\mathrm{K}_{\mathrm{BO}}\left(\frac{\mathrm{k}_{\mathrm{B}}}{\mathrm{A}_{\mathrm{BC}}}+\mathrm{C}_{\mathrm{B}}\right)
$$

Equation 5.11 yields the variation of $M_{B C}$ with $I_{B C}$ and $A_{B C}$ for a specific value of $w, L$, number of panels, $I_{T C}$ and $A_{T C}$ Figures 5.3a, $b$, and $c$ show $M_{B C}$ as a function of actual chord sizes using Equation 5.11. The values of $k_{B}$ and $C_{B}$ are computed from the data on Figures 5.2a,b, and $c$, using Equations 5.4 and 5.5. The computed values are 1isted in Table 5.2; computed values of $\mathrm{N}$ are found in Table 5.3; and computed values of $\mathrm{M}_{\mathrm{BC}}$ using Eq. 5.11 are listed in Table 5.4 .

For a rectangular member, we can compute the bending stress as:

$$
f b(p s i)=\frac{72000 M_{B C}(F t-K)}{b(i n)(d(i n))^{2}}
$$

$\mathrm{fb}$ is also plotted in Figures $5.3 \mathrm{a}, \mathrm{b}$, and $\mathrm{c}$. 


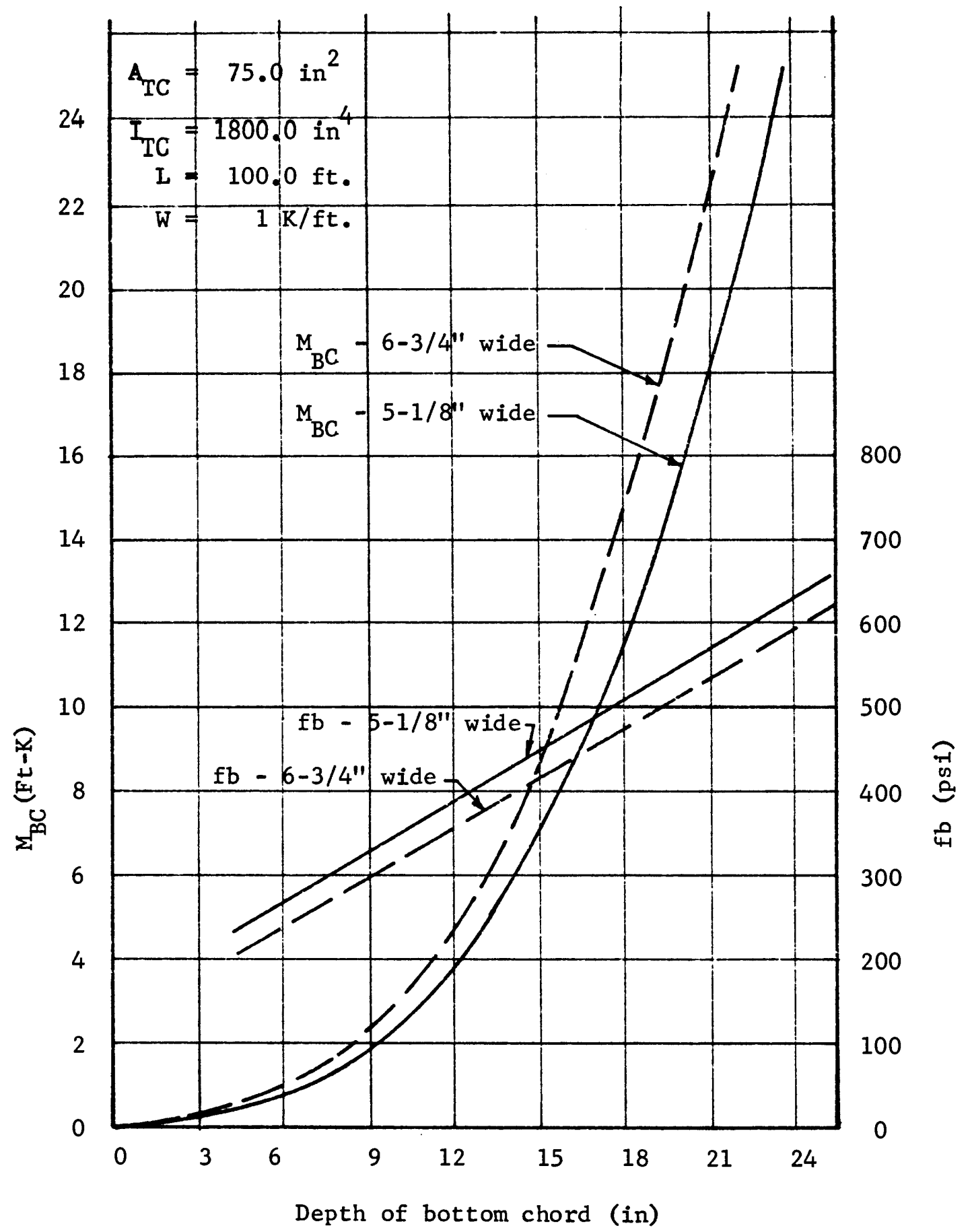

Figure 5.3a 8 panel truss - secondary moment and bending stress in the bottom chord as computed from Equation 5.11. 


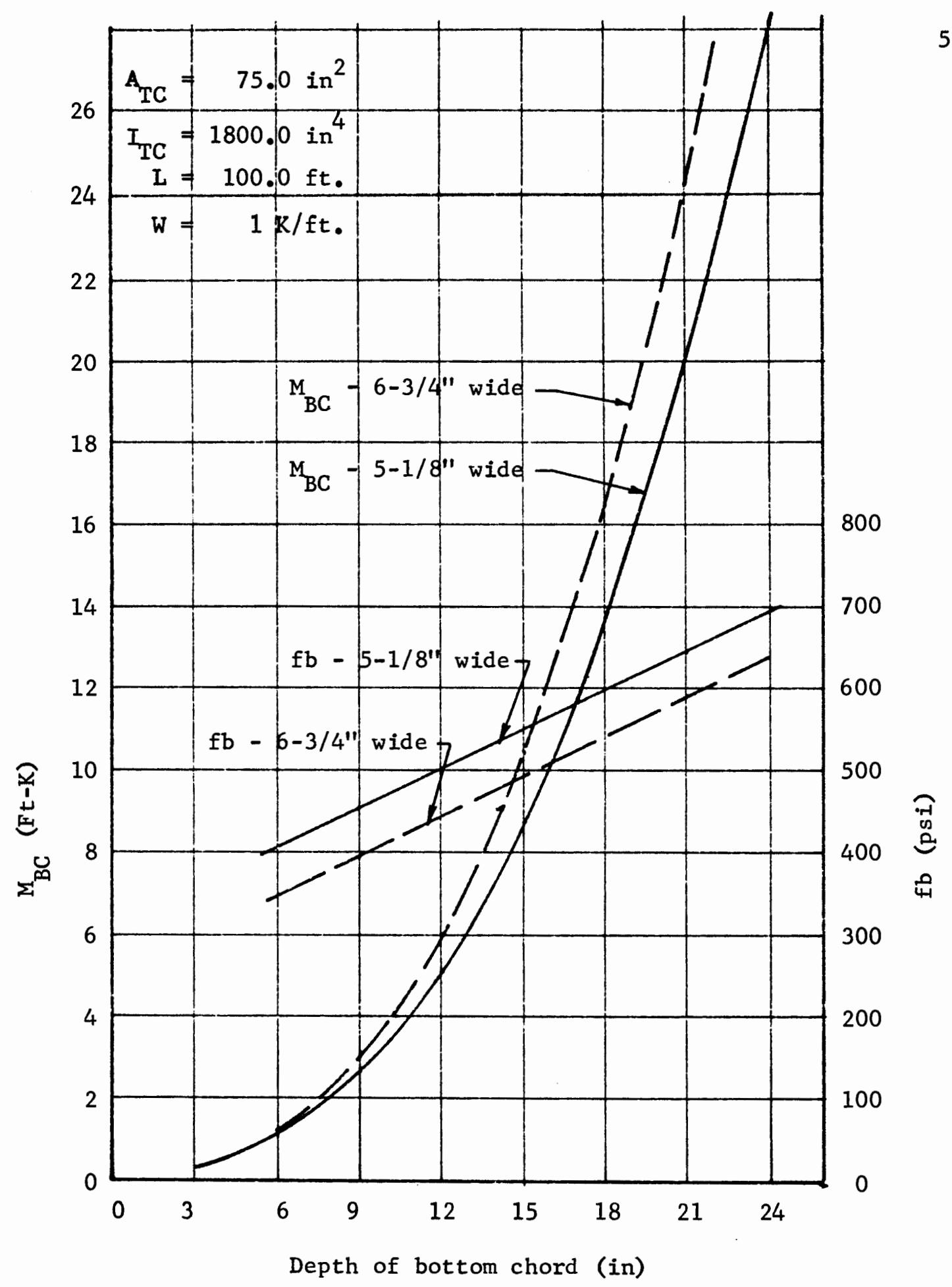

Figure 5.3b 10 pane 1 truss - secondary moment and bending stress in the bottom chord as computed from Equation 5.11. 


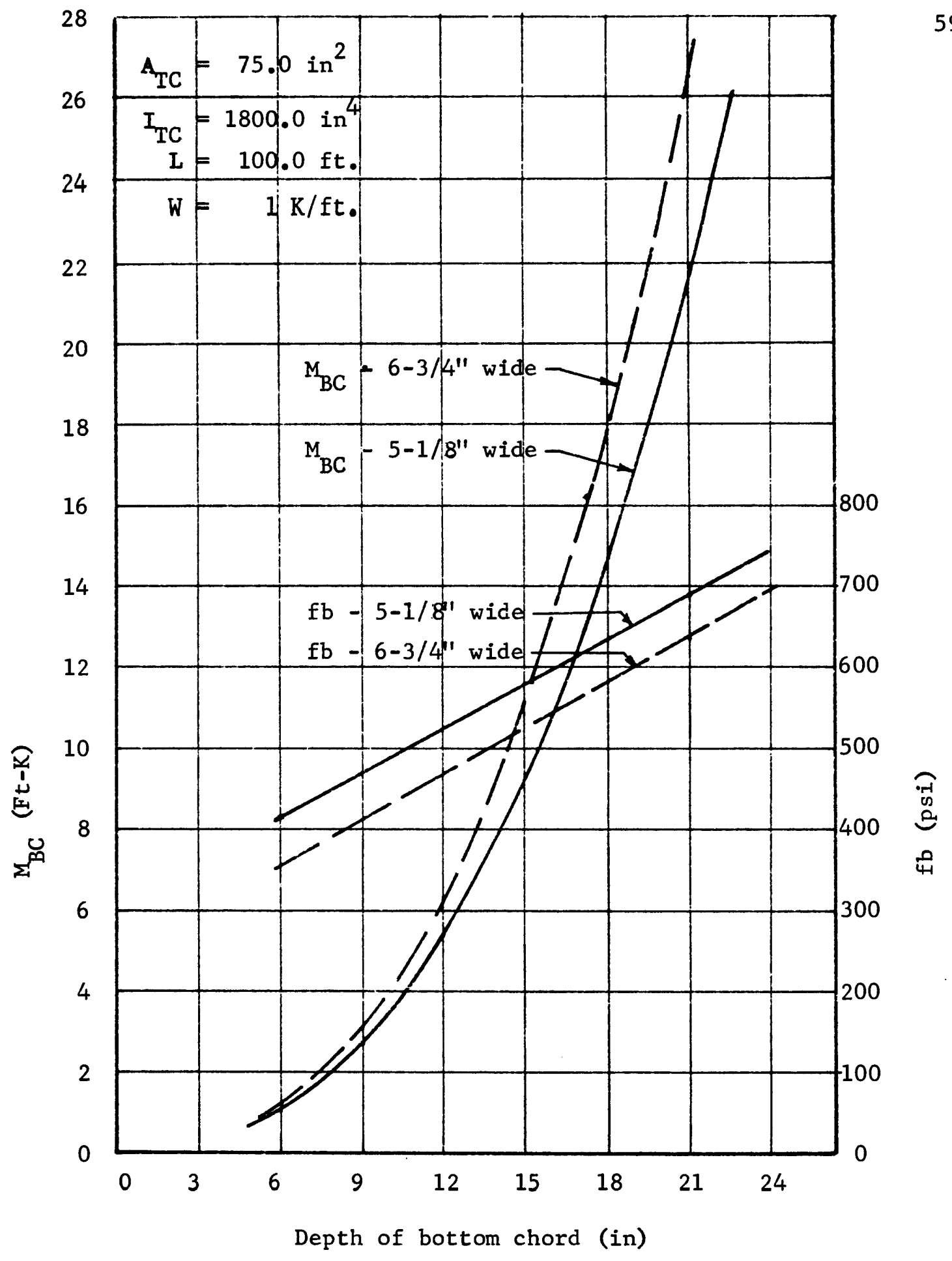

Figure 5.3c 12 panel truss - secondary moment and bending stress in the bottom chord as computed from Equation 5.11. 
The moments computed in Table 5.4 are based on the specific top chord parameters noted on Figures $5.3 \mathrm{a}, \mathrm{b}$ and $\mathrm{c}$. To account for other values of $A_{T C}$ and $I_{T C}$, another set of correlations will be developed to relate the size of the top chord to $\mathrm{M}_{\mathrm{BC}}$.

$$
5.4 \mathrm{M}_{\mathrm{BC}} \text { AS A FUNCTION OF } A_{\mathrm{TC}} \text { AND } \mathrm{I}_{\mathrm{TC}}
$$

Figures 5.4a,b and $c$ relate $\mathrm{M}_{\mathrm{BC}}$ as a function of $\mathrm{A}_{\mathrm{TC}}$ and $\mathrm{I}_{\mathrm{TC}}$, in a manner similar to Figures $5.2 a, b$ and $c$. In this case, the bottom chord is held constant.

The influence of $I_{T C}$ is quite small. Doubling $I_{T C}$ decreases $\mathrm{M}_{\mathrm{BC}}$ only about $3 \%$. The area, $\mathrm{A}_{\mathrm{TC}}$, however, has essentially the same influence on $\mathrm{M}_{\mathrm{BC}}$ as did $\mathrm{A}_{\mathrm{BC}}$. This is to be expected since the area of the top chord affects the deflections of the truss nearly the same as the area of the bottom chord.

As before, we can relate $\mathrm{M}_{\mathrm{BC}}$ to $\mathrm{A}_{\mathrm{TC}}$ as follows:

$$
M_{B C}=\frac{k_{B 1}}{A_{T C}}+C_{B 1}
$$

where

$$
C_{B 1}=\frac{A_{T C 1} M_{B C 1}-A_{T C 2} M_{B C 2}}{A_{T C 1}-A_{T C 2}}
$$

and

$$
\mathrm{k}_{\mathrm{B} 1}=\left(\mathrm{M}_{\mathrm{BC} 1}-\mathrm{C}_{\mathrm{B} 1}\right) \mathrm{A}_{\mathrm{TC} 1}
$$

The computed values of $C_{B I}$ and $k_{B 1}$ along with the data used to compute them are listed in Table 5.5. Letting $A_{\text {TC }}^{B}$ be defined as the value of $A_{T C}$ used when developing the coefficients of Equation 5.11, an adjustment factor to adjust Equation 5.11 for a variable $A_{\text {TC }}$ can be developed as follows: 
TABLE 5.4

COMPUTATION OF $\mathrm{M}_{\mathrm{BC}}$ USING EQUATION 5.11

\begin{tabular}{|c|c|c|}
\hline Depth & $\mathrm{b}=5.125$ & $b=6.75$ \\
\hline $\begin{array}{l}6 \\
7.5 \\
9 \\
10.5 \\
12 \\
13.5 \\
15 \\
16.5 \\
18 \\
19.5 \\
21 \\
22.5 \\
24\end{array}$ & $\begin{array}{r}.791317 \\
1.340090 \\
2.080040 \\
3.035920 \\
4.232140 \\
5.692810 \\
7.441750 \\
9.502520 \\
11.898500 \\
14.652700 \\
17.788200 \\
21.327700 \\
25.293700\end{array}$ & $\begin{array}{r}.894895 \\
1.538890 \\
2.418210 \\
3.565400 \\
5.012530 \\
6.791200 \\
8.932620 \\
11.467700 \\
14.426900 \\
17.840500 \\
21.738500 \\
26.150700 \\
31.106500\end{array}$ \\
\hline Depth & $\frac{10 \text { Pane } 1}{\mathrm{~b}=5.125}$ & $b=6.75$ \\
\hline $\begin{array}{l}6 \\
7.5 \\
9 \\
10.5 \\
12 \\
13.5 \\
15 \\
16.5 \\
18 \\
19.5 \\
21 \\
22.5 \\
24\end{array}$ & $\begin{array}{r}1.045550 \\
1.722290 \\
2.613490 \\
3.742280 \\
5.131200 \\
6.802210 \\
8.776790 \\
11.076000 \\
13.720300 \\
16.730100 \\
20.125300 \\
23.925300 \\
28.149600\end{array}$ & $\begin{array}{r}1.168350 \\
1.954270 \\
3.002310 \\
4.342910 \\
6.005570 \\
8.019020 \\
10.411300 \\
13.209700 \\
16.441200 \\
20.132000 \\
24.308000 \\
28.994600 \\
34.217000\end{array}$ \\
\hline Depth & $\frac{12 \text { Panel }}{\mathrm{b}=5.125}$ & $b=6.75$ \\
\hline $\begin{array}{l}6 \\
7.5 \\
9 \\
10.5 \\
12 \\
13.5 \\
15 \\
16.5 \\
18 \\
19.5 \\
21 \\
22.5 \\
24\end{array}$ & $\begin{array}{r}1.056760 \\
1.762230 \\
2.700940 \\
3.900020 \\
5.385880 \\
7.184390 \\
9.320820 \\
11.820000 \\
14.706300 \\
18.003800 \\
21.736000 \\
25.926300 \\
30.597600\end{array}$ & $\begin{array}{r}1.192480 \\
2.019110 \\
3.132490 \\
4.568210 \\
6.360880 \\
8.544250 \\
11.151300 \\
14.214400 \\
17.765400 \\
21.835300 \\
26.455000 \\
31.654700 \\
37.464300\end{array}$ \\
\hline
\end{tabular}




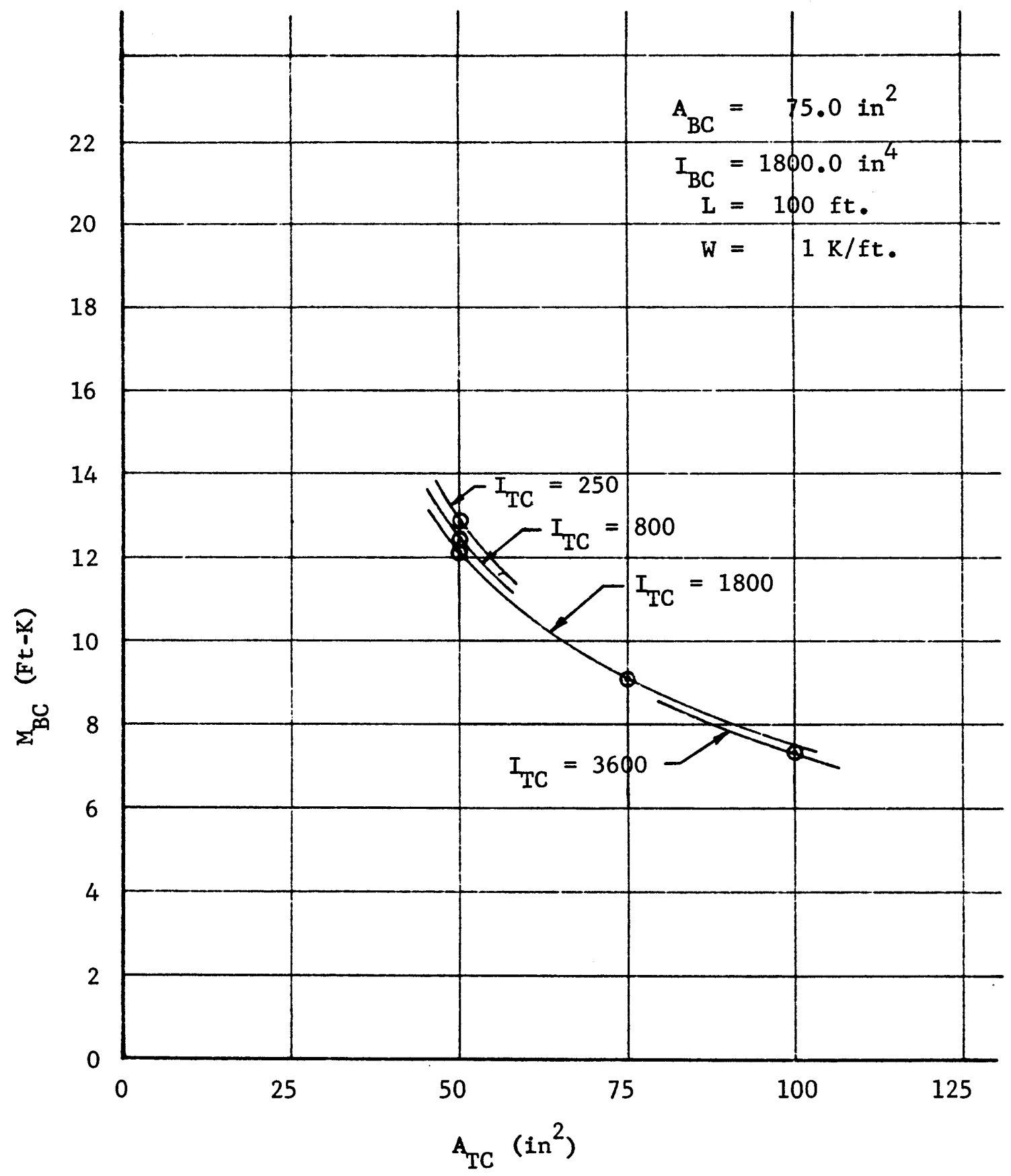

Figure 5.4a 8 panel truss - secondary moment in the bottom chord as a function of $A_{\mathrm{TC}}$ and $\mathrm{I}_{\mathrm{TC}}$. 


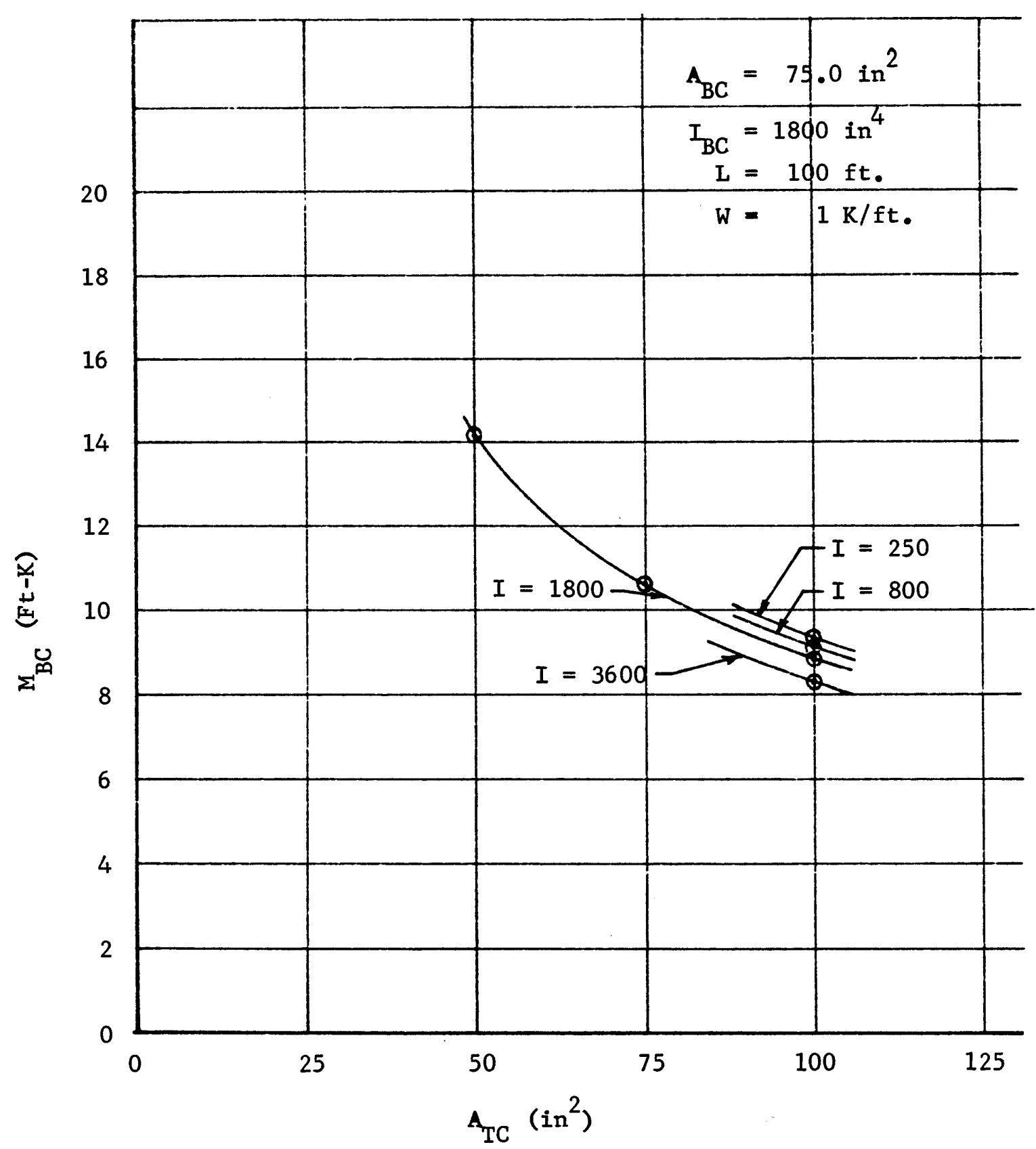

Figure 5.4b 10 panel truss - secondary moment in the bottom chord as a function of $A_{T C}$ and $I_{T C}$. 


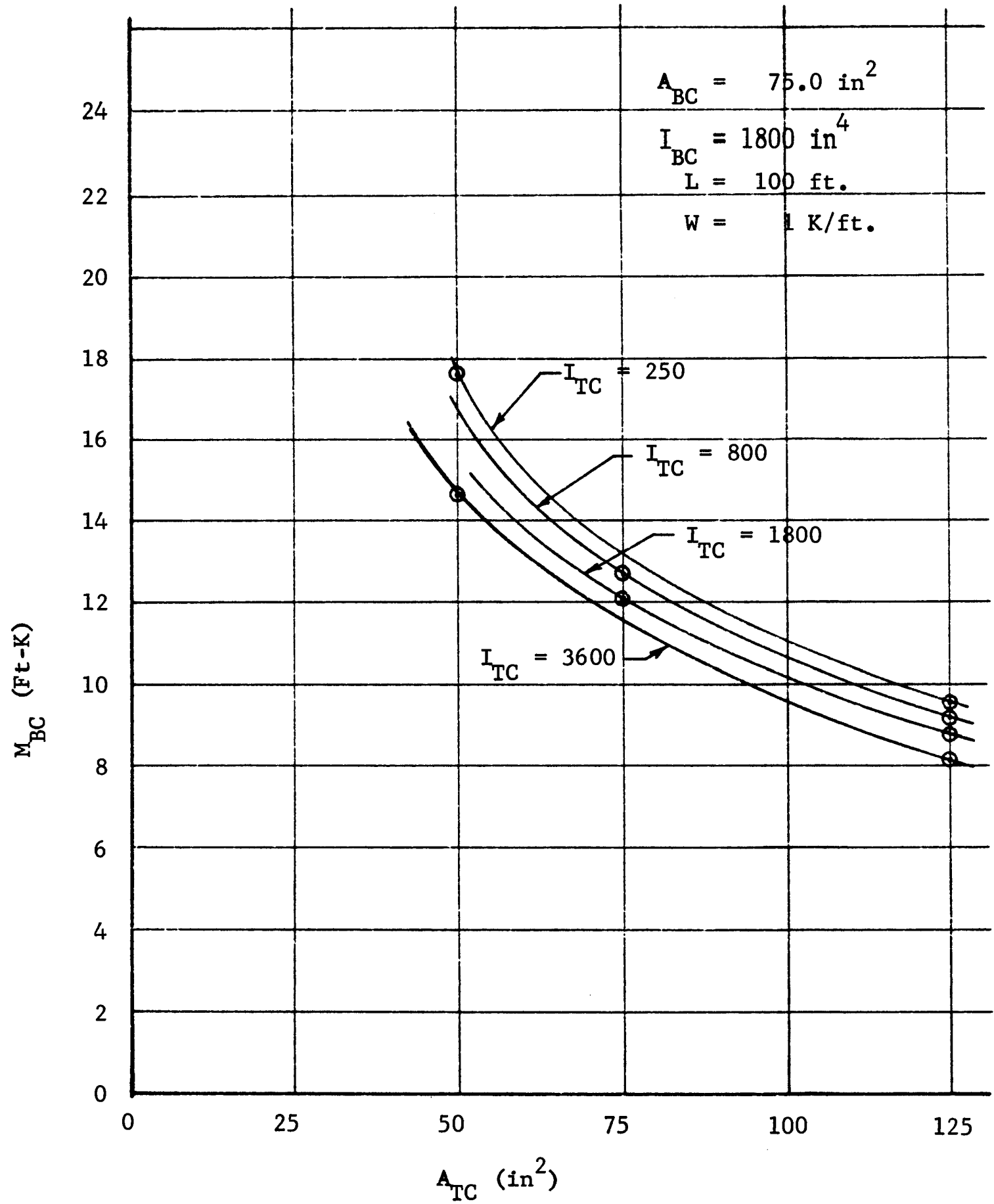

Figure $5.4 \mathrm{c} 12$ panel truss - secondary moment in the bottom chord as a function of $\mathrm{A}_{\mathrm{TC}}$ and $\mathrm{I}_{\mathrm{TC}}{ }^{\circ}$ 


$$
\mathrm{K}_{\mathrm{B} 1}=\frac{\left(\frac{\mathrm{k}_{\mathrm{B} 1}}{\mathrm{~A}_{\mathrm{TC}}}+\mathrm{C}_{\mathrm{B} 1}\right)}{\left(\frac{\mathrm{k}_{\mathrm{B} 1}}{\mathrm{~A}_{\mathrm{TC}}}+\mathrm{C}_{\mathrm{B} 1}\right)}
$$

This is simply a ratio of $M_{B C}$ found from Figure 5.4 to the "base" value of $M_{B C}$ when $A_{T C}$ equals $A_{T C}^{B}$. Figure 5.5 is a plot of $K_{B 1}$ as a function of $A_{T C}$. The computed values are listed in Table 5.6.

TABLE 5.5

COMPUTATION OF $k_{B 1}$ AND $C_{B 1}$ USING EQUATIONS 5.14 AND 5.15

\begin{tabular}{|r|c|c|c|c|c|c|c|}
\hline Truss & $I_{T C 1}$ & $A_{T C 1}$ & $A_{T C 2}$ & $M_{B C 1}$ & $M_{B C 2}$ & $C_{B 1}$ & $k_{B 1}$ \\
\hline $8 P$ & 1800 & 50 & 75 & 12.12 & 9.13 & 3.1500 & 448.50 \\
$10 P$ & 1800 & 50 & 100 & 14.20 & 8.80 & 3.4000 & 540.00 \\
$12 P$ & 1800 & 75 & 125 & 12.08 & 8.78 & 3.8300 & 618.75 \\
\hline
\end{tabular}

TABLE 5.6

COMPUTATION OF $\mathrm{K}_{\mathrm{B} 1}$ USING

EQUATION 5.16

\begin{tabular}{|c|c|c|c|}
\hline$A_{T C}$ & 8 Pane1 & 10 Pane1 & 12 Pane 1 \\
\hline$A_{\text {TC }}^{\mathrm{B}}=75.0$ & 9.130 & 10.600 & 12.080 \\
25 & 2.130 & 2.358 & 2.366 \\
50 & 1.327 & 1.340 & 1.341 \\
75 & 1.000 & 1.000 & 1.000 \\
100 & 0.836 & 0.830 & 0.829 \\
125 & 0.738 & 0.728 & 0.727 \\
\hline
\end{tabular}




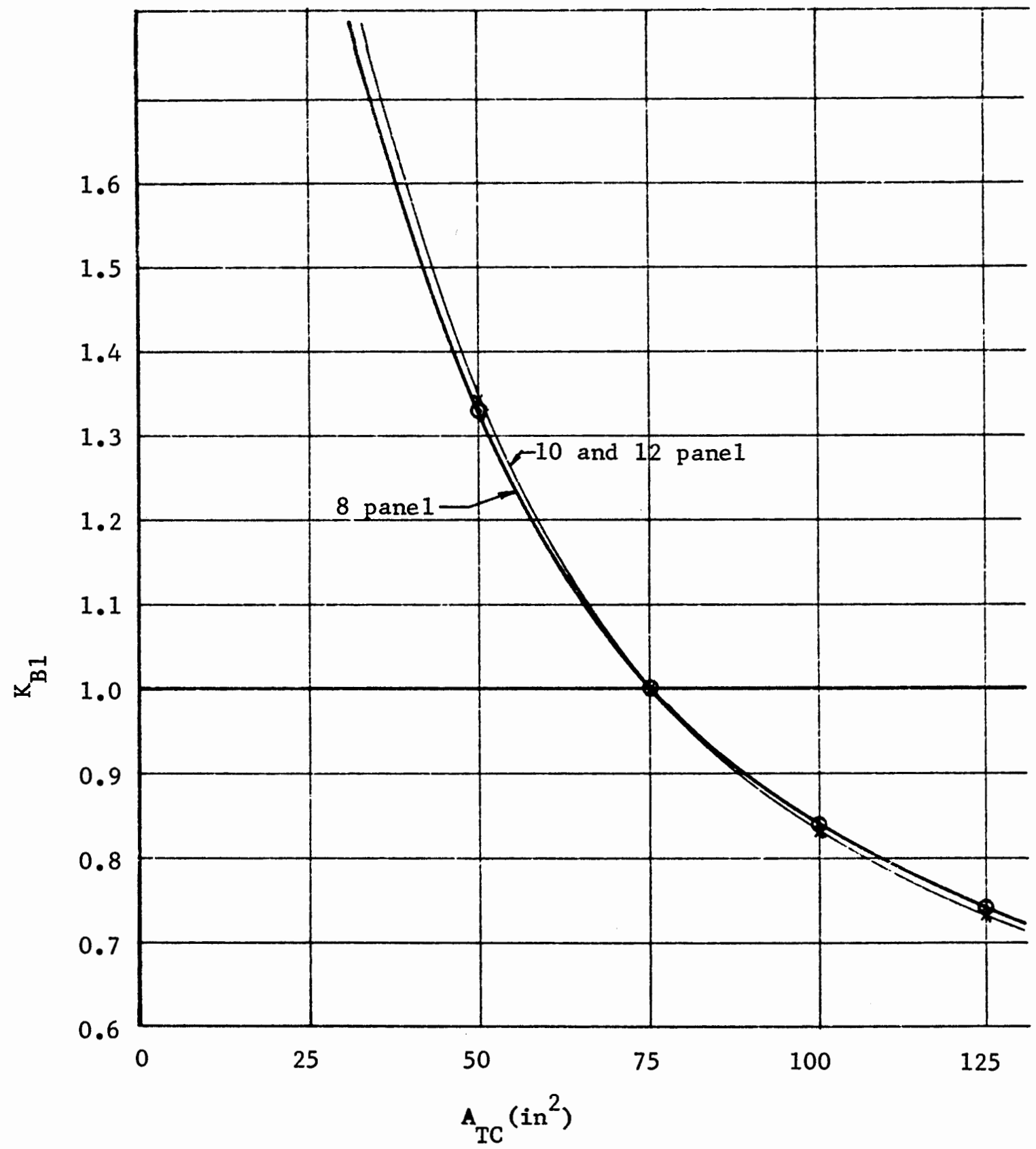

Figure 5.5 $\mathrm{K}_{\mathrm{BI}}$ - Adjustment factor to $M_{B C}$ for variation in $A_{T C}$. 


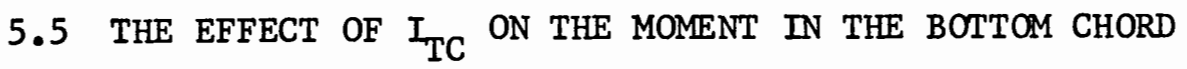

Though the effect is sma11, a variation of $I_{T C}$ does influence $M_{B C}$. Figure 5.6 shows the variation of $M_{B C}$ as a function of $I_{T C}$. Note that the curves for each truss are based on different areas. The variation of $M_{B C}$ between trusses is not of concern at this point. The variation of $M_{B C}$ with $I_{T C}$ is what is being considered here.

The curves of Figure 5.6 appear to intersect the $M$ axis at finite values. The principal influence of the continuity of the top chord is to pull some of the load "off" of the truss--that is, it attempts to act as a beam, carrying some of the load by shear. As will be shown in the next chapter, the entire top chord of the truss ends up with positive moments. As can be seen in Figure 5.7, positive moment at the first top chord joint results in a positive shear in the end pane1. In effect, an upward load equal to the shear is applied to the truss at the first joint, reducing the axial forces in the members, thus reducing deflections.

From this it would be expected that the deflection and therefore the secondary moments will decrease as the stiffness of the top chord increases. This is indeed the case as was seen in Figure 5.6. Therefore, the bottom chord secondary moment will be at a maximum but finite value when $I_{\text {TC }}$ equals zero. The same effect will occur in other types of trusses, even if a net negative moment exists at the joint. The deflection would still tend to make the moment increase in the positive direction.

Several types of curves can be passed through the points of 


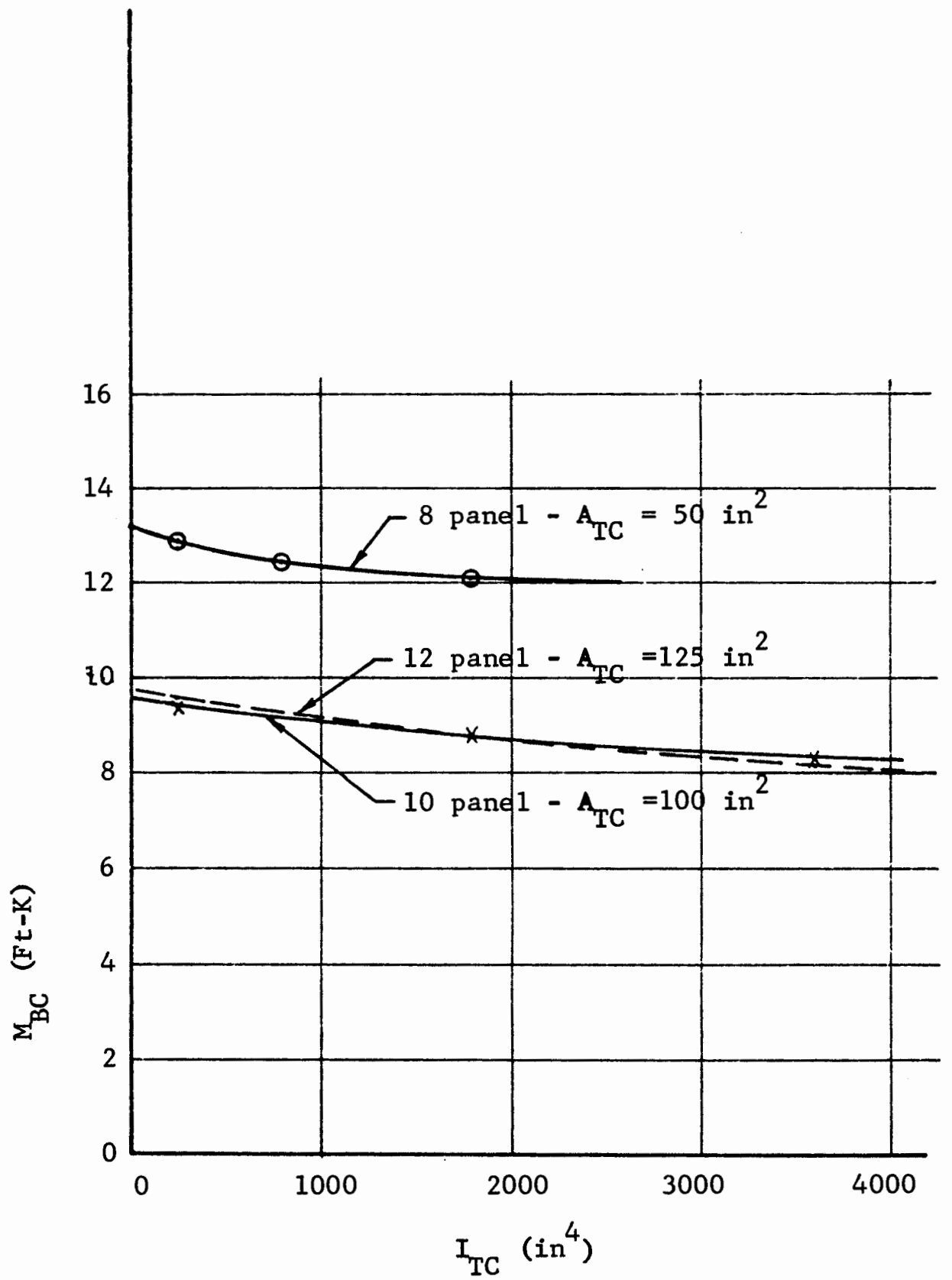

Figure 5.6 Secondary moment in the bottom chord as a function of $\mathrm{ITC}^{\cdot}$ 


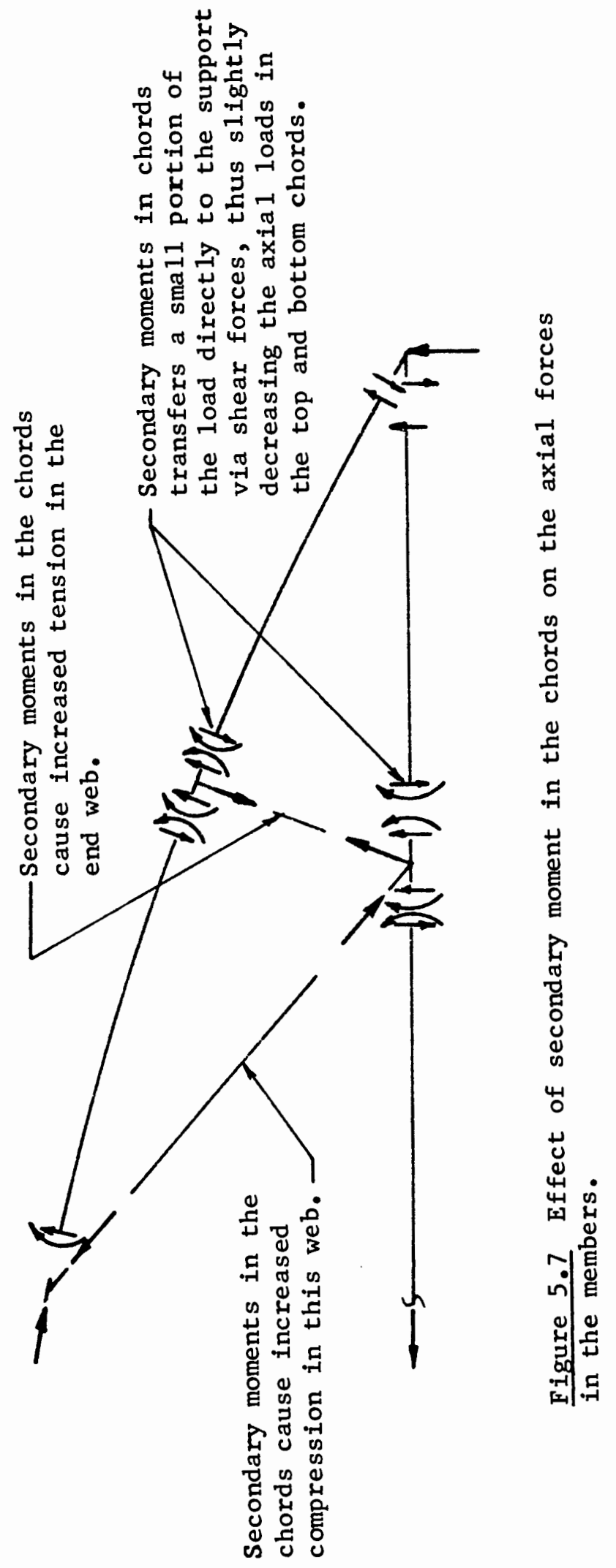


Figure 5.6. A logarithmic curve of the form

$$
M=k \ln I+C
$$

can be made to fit quite well over a reasonable bound of $I$, however extrapolation could be unreliable since this curve approaches infinity as I approaches zero, as well as eventually going negative at very large values of $I$.

An inverse equation of the form

$$
M=\frac{k}{I}+C
$$

as used before could also be made to fit fairly well, however this also approaches infinity as I approaches zero. A variation of this curve, requiring three points to establish, could be written as follows:

$$
M=\frac{k_{B 2}}{\left(I_{T C}+g_{B 2}\right)}+C_{B 2}
$$

This type of curve is plotted in Figure 5.6.

This form of equation meets the requirements of the boundary conditions and fits the data quite well. Therefore, this form of equation will be proposed for development of a top chord stiffness adjustment factor, $\mathrm{K}_{\mathrm{B} 2}$.

Three points are required to establish this equation, due to the presence of the three unknown constants.

Three equations can be written:

$$
\begin{aligned}
& C_{B 2}=\frac{\left(I_{T C 1}+g_{B 2}\right) M_{B C 1}-\left(I_{T C 2}+g_{B 2}\right) M_{B C 2}}{I_{T C 1}-I_{T C 2}} \\
& C_{B 2}=\frac{\left(I_{T C 2}+g_{B 2}\right) M_{B C 2}-\left(I_{T C 3}+g_{B 2}\right) M_{B C 3}}{I_{T C 2}-I_{T C 3}}
\end{aligned}
$$




$$
\mathrm{k}_{\mathrm{B} 2}=\left(\mathrm{M}_{\mathrm{BC} 1}-\mathrm{C}_{\mathrm{B} 2}\right)\left(\mathrm{I}_{\mathrm{TC} 1}+\mathrm{g}_{\mathrm{B} 2}\right)
$$

Setting Equation 5.18 equal to 5.19 , and separating variables, we obtain:

$$
g_{B 2}=-\left[\frac{\left(M_{B C 1} I_{T C 1}-M_{B C 2} I_{T C 2}\right)-q_{B 2}\left(M_{B C 2} I_{T C 2}-M_{B C 3} I_{T C 3}\right)}{\left(M_{B C 1}-M_{B C 2}\right)-q_{B 2}\left(M_{B C 2}-M_{B C 3}\right)}\right]
$$

where

$$
q_{B 2}=\frac{I_{T C 1}-I_{T C 2}}{I_{T C 2}-I_{T C 3}}
$$

$\mathrm{C}_{\mathrm{B} 2}$ and $\mathrm{k}_{\mathrm{B} 2}$ are obtained by substituting $\mathrm{g}_{\mathrm{B} 2}$ as computed in Equation 3.21 into Equations 5.18 and 5.20.

Using the value of $I_{T C}$ used in computing $k_{B}$ and $C_{B}$ of Equation 5.11 as a base value, the following adjustment factor can be proposed:

$$
K_{B 2}=\frac{\left[\frac{k_{B 2}}{\left(I_{T C}+g_{B 2}\right)}+C_{B 2}\right]}{\left[\frac{k_{B 2}}{\left(I_{T C}^{B}+g_{B 2}\right)}+C_{B 2}\right]}
$$

where $g_{B 2}$ can be obtained from Equation 5.21, $k_{B 2}$ from Equation 5.20 and $\mathrm{C}_{\mathrm{B} 2}$ from Equation 5.19.

Using data from Figure 5.6, $\mathrm{k}_{\mathrm{B} 2}, \mathrm{~g}_{\mathrm{B} 2}$ and $\mathrm{C}_{\mathrm{B} 2}$ are computed in Table 5.7. Computed values of $\mathrm{K}_{\mathrm{B} 2}$ are 1 isted in Table 5.8 and plotted in Figure 5.8 .

\subsection{INFLUENCE OF TRUSS SPAN (L) ON $M_{B C}$}

Assuming the same loading intensity per lineal foot, the secondary moments will not be affected appreciably. That is, an $80 \mathrm{ft}$. truss with $1 \mathrm{k} / \mathrm{ft}$ loading will have nearly identical secondary moments to a $100 \mathrm{ft}$. truss with the same chord sizes and carrying $1 \mathrm{~K} / \mathrm{ft}$ of 1 oad. 
TABLE 5.7

COMPUTATION OF $k_{B 2}, C_{B 2}$ AND $g_{B 2}$ USING

EQUATIONS $5.19,5.20$ AND 5.21

\begin{tabular}{|c|c|c|c|}
\hline Truss & 8 Pane1 & 10 Pane1 & 12 Pane1 \\
\hline$A_{\text {TC0 }}$ & 50 & 100 & 125 \\
$I_{\text {TC1 }}$ & 250 & 250 & 250 \\
$I_{\text {TC2 }}$ & 800 & 1800 & 1800 \\
$I_{\text {TC3 }}$ & 1800 & 3600 & 3600 \\
$M_{\text {BC1 }}$ & 12.88 & 9.39 & 9.55 \\
$M_{B C 2}$ & 12.46 & 8.80 & 8.78 \\
$M_{B C 3}$ & 12.12 & 8.30 & 8.14 \\
$g_{\text {B2 }}$ & 993.9914 & 8796.167 & 4.589949 \\
$C_{\text {B2 }}$ & 11.51004 & 5.356620 & 41835.64 \\
$k_{\text {B2 }}$ & 1704.215 & 36486.63 & \\
\hline
\end{tabular}

TABLE 5.8

COMPUTED VALUES OF $\mathrm{K}_{\mathrm{B} 2}$ USING

EQUATION 5.22

\begin{tabular}{|c|c|c|c|}
\hline & 8 Pane 1 & 10 Pane1 & 12 Pane1 \\
\hline$I_{\mathrm{TC}}^{\mathrm{B}}$ & 800 & 800 & 1800 \\
\hline $\mathrm{I}=0$ & 1.061361 & 1.037757 & 1.104955 \\
250 & 1.033708 & 1.025240 & 1.087699 \\
500 & 1.015309 & 1.013397 & 1.071437 \\
800 & 1.000000 & 1.000000 & 1.053117 \\
1000 & 0.992353 & 0.991520 & 1.041568 \\
1500 & 0.978601 & 0.971776 & 1.014783 \\
2000 & 0.969443 & 0.953857 & 0.9906284 \\
3000 & 0.958005 & 0.922576 & 0.9487978 \\
4000 & 0.951147 & 0.896184 & 0.9138334 \\
\hline
\end{tabular}




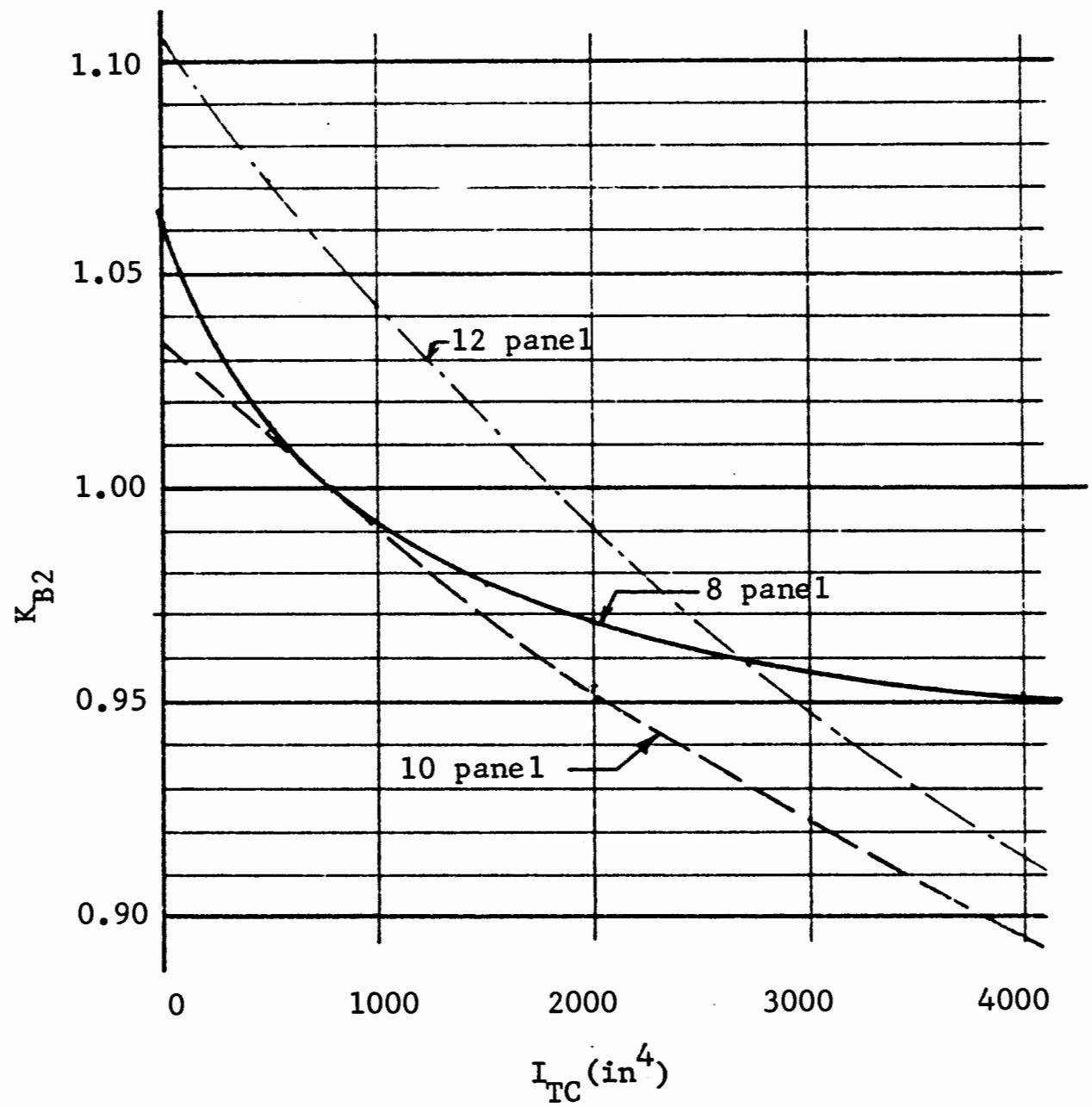

Figure $5.8 \quad K_{B 2}$ - Adjustment factor to $M_{B C}$ to account for variations in ${ }^{\mathrm{B} 2} \mathrm{I}_{\mathrm{TC}}$. 
This can be shown by considering the primary factors involved. As noted earlier, the secondary moments are due to the deflection of the truss forcing the continuous chords to bend. This deflection is a function of span, loading, member areas, modulus of elasticity, and to a small extent the moment of inertia of the chords. Neglecting the influence of $I$,

$$
\Delta=\mathrm{f}\left(\sum \frac{\mathrm{PL}}{\mathrm{AE}}\right)
$$

since

$$
P=f(w L)
$$

we have

$$
\Delta=f\left(\sum \frac{\mathrm{wL}}{\mathrm{AE}}\right)
$$

or, assuming all other parameters constant,

$$
\Delta=\frac{W}{A E} f\left(L^{2}\right)
$$

The moment in the continuous chord is given by the slope deflection equation as

$$
M=f\left(\frac{E I \Delta}{L^{2}}\right)
$$

Substituting Equation 5.24 into 5.25, we obtain

$$
M=f\left(\frac{E I}{L^{2}}\right)\left(\frac{W L^{2}}{E A}\right)
$$

which reduces to

$$
M=f\left(\frac{w I}{A}\right)
$$

The moment is therefore neither a function of $\mathrm{E}$ nor of $\mathrm{L}$.

It $c a n$ be seen from Figure 5.7 that if $M$ were to remain unchanged when $\mathrm{L}$ is varied, then the shear in the member would be affected, thus redistributing the axial forces slightly. Therefore, if the 
influence of $I_{T C}$ and $I_{B C}$ are not neglected, the moment will be slightly influenced by varying $L$. This effect will be quite small and will be neglected in this chapter.

Therefore, the span adjustment factor will be defined in this chapter as:

$$
\mathrm{K}_{\mathrm{B} 3}=1
$$

\subsection{THE INFLUENCE OF LOADING ON $M_{B C}$}

The structure has been modeled as a linearly elastic structure; the effect of changing the magnitude of the uniform load will simply be linear proportional. Thus, for a uniform load on the top chord,

$$
\mathrm{K}_{\mathrm{B} 4}=\frac{\mathrm{w}}{\mathrm{w}}
$$

Changing the loading pattern, however, will change the deflected shape of the truss which would have a direct effect on the secondary moments. Therefore, Equation 5.6 will only be valid for the loading pattern considered. A separate set of coefficients for Equation 5.6 will need to be developed for each loading pattern desired.

\subsection{THE INFLUENCE OF THE NUMBER OF PANELS ON M}

Changing the number of panels in the truss changes the structural configuration, whereas the parameters studied to this point only changed the member properties. Due to the structural similarity, however, this parameter can be treated in the same manner as the other parameters.

Plotting $M_{B C}$ versus the number of panels results in the curve of Figure 5.9. An equation of the form 


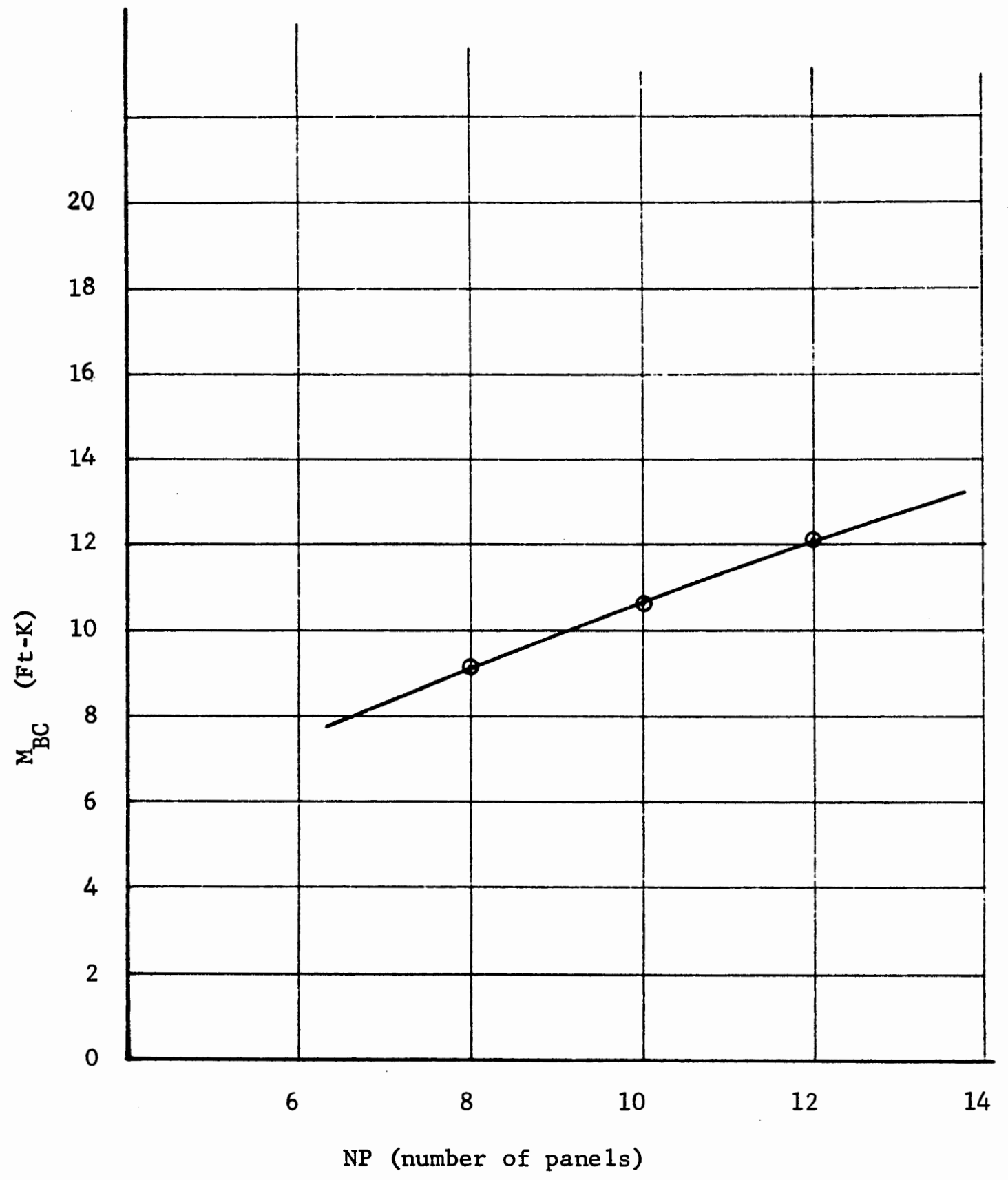

Figure 5.9 Secondary moments in the bottom chord as a function of the number of panels in the truss. 


$$
M_{B C}=\frac{k_{B 5}}{N P+g_{B 5}}+C_{B 5}
$$

seems appropriate.

The adjustment factor thus becomes

$$
\mathrm{K}_{\mathrm{B} 5}=\frac{\left[\frac{\mathrm{k}_{\mathrm{B} 5}}{\mathrm{NP}+\mathrm{g}_{\mathrm{B} 5}}+\mathrm{C}_{B 5}\right]}{\left[\frac{\mathrm{k}_{\mathrm{B} 5}}{\mathrm{NP}^{\mathrm{B}}+\mathrm{g}_{\mathrm{B} 5}}+\mathrm{C}_{\mathrm{B} 5}\right]}
$$

The factors for this equation are computed by use of equations similar to Equations 5.18 through 5.21, replacing $I_{T C}$ with NP. These computations are summarized in Table 5.9. Values of $\mathrm{K}_{B 5}$ are computed from Equation 5.31, summarized in Table 5.10 and plotted in Figure 5.10. Note that these values plot as a near straight line function. A simplified equation for $\mathrm{K}_{\mathrm{B} 5}$ can be written to fit this line. Thus, from Figure 5.10,

$$
\mathrm{K}_{\mathrm{B} 5}=.33+.081 \mathrm{NP}
$$

TABLE 5.9

DATA FOR FIGURE 5.9 AND COMPUTATION OF

$$
\mathrm{k}_{\mathrm{B} 5}, \mathrm{C}_{\mathrm{B} 5} \text { AND } \mathrm{g}_{\mathrm{B} 5}
$$

Parameter Data

$A_{\mathrm{BC}}=75$

$I_{B C}=1800$

$A_{\mathrm{TC}}=75$

$I_{T C}=1800$

Computed Values of the Constants

$k_{B 5}=-10266.0 \quad g_{B 5}=108.0$

$C_{B 5}=97.63$ 


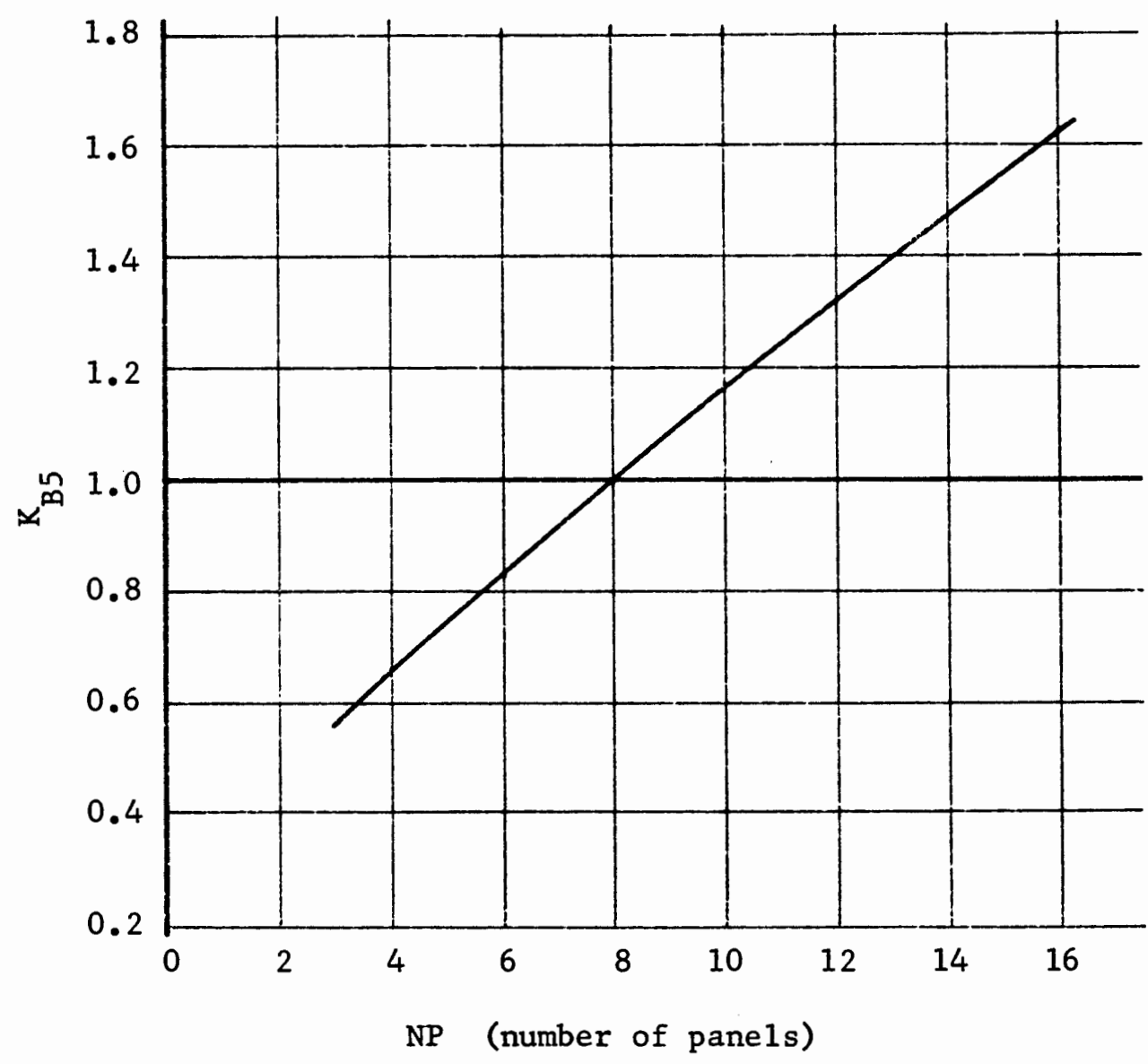

Figure 5.10 $\mathrm{K}_{\mathrm{B} 5}$ - Adjustment factor to $\mathrm{M}_{\mathrm{BC}}$ to account for a varying number of panels in the truss. 
TABLE 5.10

COMPUTATION OF $\mathrm{K}_{\mathrm{B} 5}$

\begin{tabular}{|c|c|}
\hline $\mathrm{NP}$ & $\mathrm{K}_{5}$ \\
\hline 4 & 0.6540 \\
6 & 0.8299 \\
8 & 1.0000 \\
10 & 1.1643 \\
12 & 1.3231 \\
14 & 1.4767 \\
16 & 1.6254 \\
\hline
\end{tabular}

5.9 SUMMARY

The moment in the bottom chord of a bowstring truss with a web configuration of the types considered in this paper can be computed from the following equation:

$$
M_{B C}=K_{B 0} K_{B 1} K_{B 2} K_{B 3} K_{B 4} K_{B 5}\left(\frac{k_{B}}{A_{B C}}+C_{B}\right)
$$

where;

$K_{B 0}\left(\frac{k_{B}}{A_{B C}}+C_{B}\right)$ is computed for the 8 panel truss or found from
Figure $5.2 a$ and $5.3 a$.

$\mathrm{K}_{\mathrm{B} 1}$ is the top chord area adjustment factor which can be computed from Equation 5.16 using data from Table 5.5 for an 8 panel truss, or taken from Figure 5.5.

$\mathrm{K}_{\mathrm{B} 2}$ is the top chord moment of inertia adjustment factor from Equation 5.22 using data from Table 5.7 for an 8 panel truss, or taken from Figure 5.8. 
$\mathrm{K}_{\mathrm{B} 3}$ is the truss span adjustment factor, and is taken as 1.0 . $\mathrm{K}_{\mathrm{B} 4}$ is the load intensity factor,

$$
\mathrm{K}_{\mathrm{B} 4}=\frac{\mathrm{w}}{1}=\mathrm{w}
$$

$\mathrm{K}_{\mathrm{B} 5}$ is the adjustment factor for the number of panels in the truss, computed from Equation 5.31 using Table 5.9 or using the simplified Equation 5.32 or Figure 5.10 .

Table 5.11 provides an easy to use summary of the above information. Using the data from Tables 5.2 through 5.10, explicit equations for each factor were computed. These equations are presented in Table 5.12. Verification of the equations is provided in Chapter VII.

\section{TABLE 5.11}

SUMMARY OF GENERAL EQUATIONS

FOR THE BOTTOM CHORD

SECONDARY MOMENTS

\begin{tabular}{|l|c|c|}
\hline Coef. & Genera1 Equation & Eq. No \\
\hline$M_{B C}$ & $M_{B C 0}\left(K_{B 0} K_{B 1} K_{B 2} K_{B 3} K_{B 4} K_{B 5}\right)$ & 5.6 \\
$M_{B C 0}$ & $\frac{k_{B}}{A_{B C}}+C_{B}$ & 5.3 \\
$\mathrm{C}_{B}$ & $A_{B C 1}\left(M_{B C 1}-C_{B}\right)$ & 5.5 \\
$K_{B 0}$ & $\frac{A_{B C 1} M_{B C 1}-A_{B C 2}{ }_{B C 2}}{A_{B C 1}-A_{B C 2}}$ & 5.4 \\
$N$ & $\left(\frac{I_{B C}}{I_{B C 0}}\right)^{N}$ & 5.7 \\
& $\frac{\ln \left(M_{B C 2} / M_{B C 1}\right)}{\ln \left(I_{B C 2}{ }^{I}{ }_{B C 1}\right)}$ & 5.10 \\
\hline
\end{tabular}


TABLE 5.11 continued

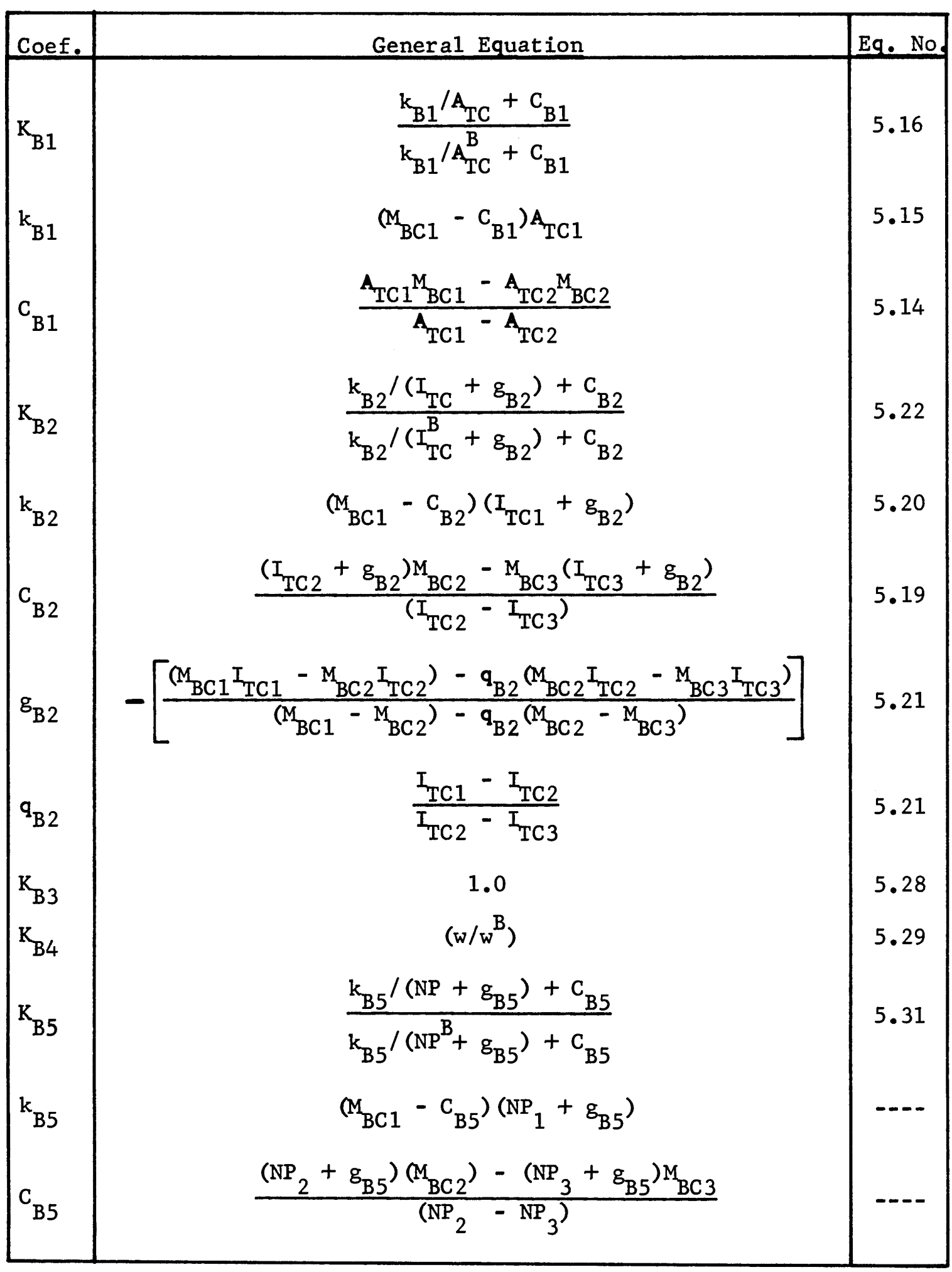


TABLE 5.11 continued

\begin{tabular}{|c|c|c|}
\hline Coef. & Genera1 Equation & Eq. No \\
\hline$g_{B 5}$ & $-\left[\frac{\left(M_{B C 1}{ }_{1}-M_{B C 2}{ }_{2}\right)-q_{B 5}\left(M_{B C 2} N_{2}-M_{B C 3} N P_{3}\right)}{\left(M_{B C 1}-M_{B C 2}\right)-q_{B 5}\left(M_{B C 2}-M_{B C 3}\right)}\right]$ & \\
$q_{B 5}$ & $\frac{N P_{1}-N_{2}}{N_{2}-N_{3}}$ & \\
\hline
\end{tabular}

TABLE 5.12

SUMMARY OF EXPLICIT EQUATIONS

FOR THE BOTTOM CHORD

SECONDARY MOMENTS

(BASED ON 8 PANEL TRUSS)

\begin{tabular}{|l|c|c|}
\hline Coef. & Equation \\
\hline$M_{B C}$ & $M_{B C 0}\left(K_{B 0} K_{B 1} K_{B 2} K_{B 3} K_{B 4} K_{B 5}\right)$ & \\
$M_{B C 0}$ & $\left((450.00) / A_{B C}+(12.070)\right)$ & \\
$K_{B 0}$ & $\left(I_{B C} /(3600)\right)(.960343)$ & \\
$K_{B 1}$ & $\left((49.124) / A_{T C}+(0.3450)\right)$ & \\
$K_{B 2}$ & $\left((136.78) /\left(I_{T C}+(993.99)\right)+(.9238)\right.$ & \\
$K_{B 3}$ & 1.0 & \\
$K_{B 4}$ & $((-1124.4) /(N P+(108))+(10.693)$ & \\
$K_{B 5}$ & & \\
\hline
\end{tabular}




\section{CHAPTER VI}

SECONDARY MOMENTS IN THE TOP CHORD

The secondary moments in the top chord i.e., the "support settlement" type moment resulting from the displacement of the joints, have the potential of being quite large depending on the values of the parameters involved. Figure 6.1 shows the moment diagram of the top chord for an 8 and 12 panel truss for two combinations of parameters. These diagrams are plotted from data obtained from the computer frame analyses. For each case, the primary moment has been subtracted out of the total moment to provide a plot of the secondary moment for the respective cases as well.

As can be seen from Figure 6.1 , the critical location for the design of the top chord will be at the first panel point from the end of the truss, as was the case for the bottom chord. The secondary moment at this location will be designated as $\mathrm{M}_{\mathrm{TC}}$.

It should also be noted that the primary moments are generally small as compared to the secondary moments. The traditional assumption that the secondary moments are small enough to be neglected, as implied by the AITC manual, is obviously incorrect. As will be shown by an example in Chapter $X$, this assumption can lead to a substantially underdesigned structure. 


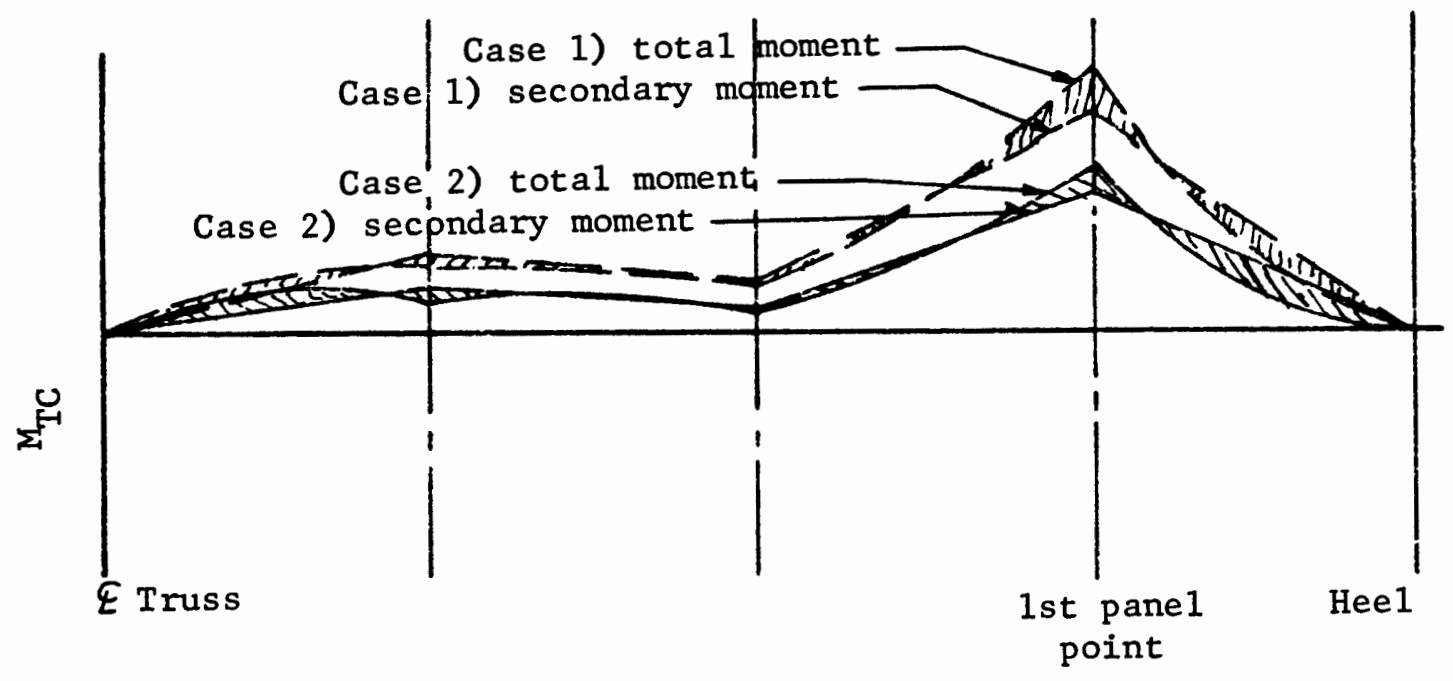

Figure 6.1 a 8 panel truss

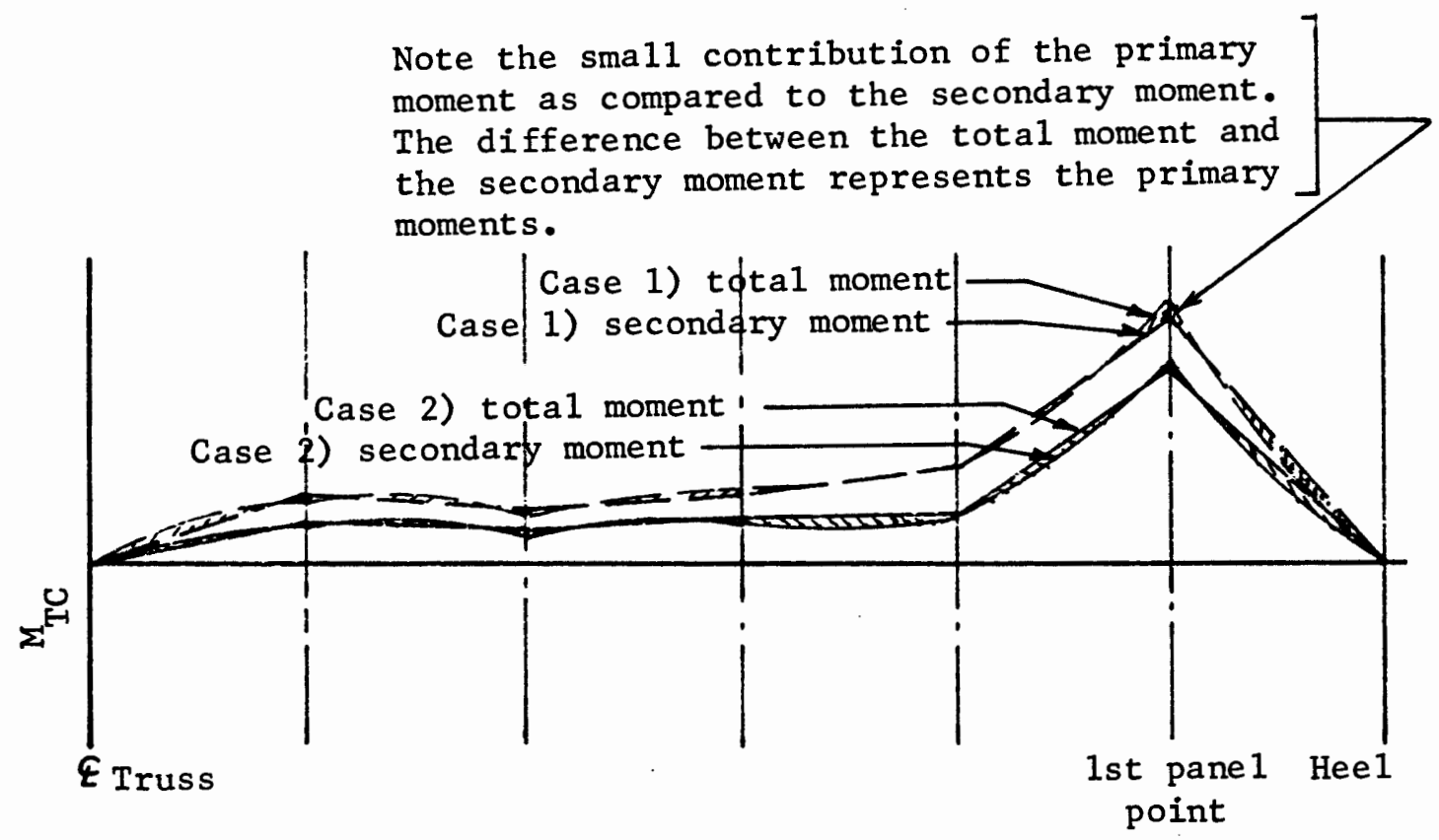

Figure $6.1 \mathrm{~b} 12$ pane 1 truss

Figure 6.1 Top chord moment diagrams for typical cases. 


\subsection{PARAMETERS AFFECTING $\mathrm{M}_{\text {TC }}$}

The principal parameters affecting the secondary moments in the top chord are the same as those affecting the bottom chord, as listed in Table 5.1 .

An additional step must be taken prior to developing the characteristic equations and figures if the secondary moments are to be investigated alone. The "primary" moments must first be separated from the computer generated moments. This is done in Appendix A2, Table A2.2, using the values of the primary moment computed in Chapter IV.

The ability to predict the moments in the bottom chord in the 10 and 12 panel trusses from the 8 panel datum by use of $\mathrm{K}_{\mathrm{B} 5}$ (Equation 5.31) was demonstrated in Chapter V. Therefore, only the 8 pane1 data will be developed in this chapter, except when developing the $\mathrm{K}_{\mathrm{T} 5}$ adjustment factor.

\subsection{DEVELOPMENT OF EQUATIONS}

Based on the reasoning in Chapter $V$, the following equation is proposed.

$$
\mathrm{M}_{\mathrm{TC}}=\mathrm{K}_{\mathrm{T} 0} \mathrm{~K}_{\mathrm{T} 1} \mathrm{~K}_{\mathrm{T} 2} \mathrm{~K}_{\mathrm{T} 3} \mathrm{~K}_{\mathrm{T} 4} \mathrm{~K}_{\mathrm{T} 5}\left(\mathrm{M}_{\mathrm{TC} 0}\right)
$$

The general equations for the individual parameters are presented in Table 6.1. The coefficients are calculated in Tables 6.2 through 6.6 .

Explicit equations are developed by inserting the coefficients into the general equations of Table 6.1. These explicit equations are presented in Table 6.7. Tables 6.8 through 6.12 develop the data re- 
quired for Figures 6.2 through 6.6 .

We thus have the means, by either Table 6.7 or Figures 6.2 through 6.6, for determining the secondary moment in the top chord of a bowstring truss of 8,10 or 12 panels with a uniform load on the top chord.

Figure 6.2, which is analagous to Figure 5.2 for the bottom chord, represents $M_{T C}$ as a function of $A_{T C}$ and $I_{T C}$ with all other parameters held constant at the values listed in the figure. Fig. 6.3 transforms this data to represent actual chord sizes and also plots the bending stress produced by the calculated moment acting on the given section.

Figure 6.4 provides an adjustment factor to modify the values of $M_{T C}$ and $\mathrm{fb}$ obtained from Fig 6.2 or 6.3 to account for a variation in $A_{B C}$. Figure 6.5 adjusts $\mathrm{M}_{\mathrm{TC}}$ for $\mathrm{I}_{\mathrm{BC}}$, and $\mathrm{Fig} \cdot 6.6$ adjusts $\mathrm{M}_{\mathrm{TC}}$ for trusses with other than 8 panels. Figure 6.6 should be considered valid only for 8,10 and 12 panel trusses since other values would require extrapolation beyond the available data. Since NP is not a continuous function, $K_{T 5}$ would more appropriately be taken from Table 6.12 . Figure 6.6 makes it clear however, that increasing the number of panels in the truss significantly increases the secondary moments which are induced into the chord. 
TABLE 6.1

GENERAL EQUATIONS FOR TOP CHORD SECONDARY MOMENT

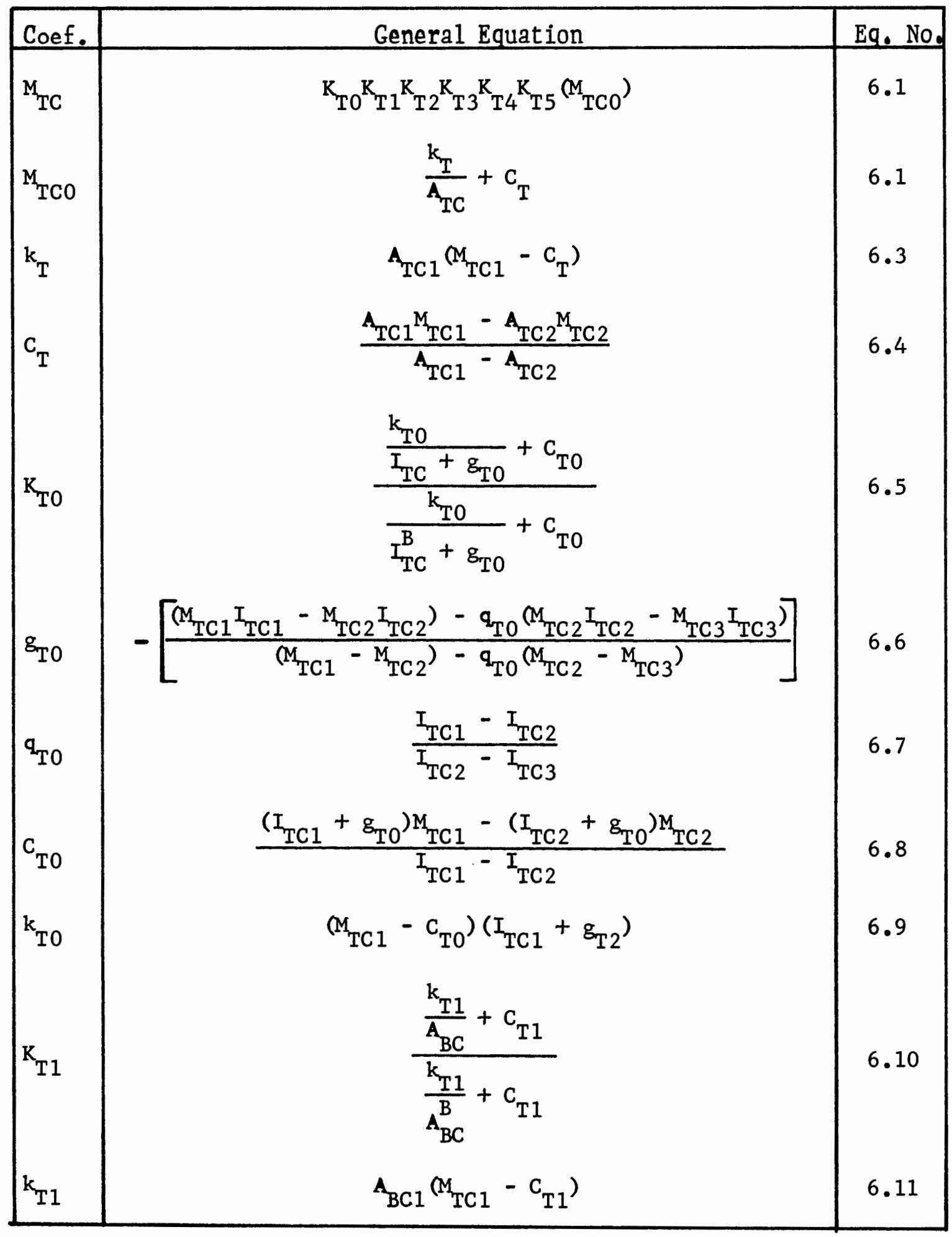


TABLE 6.1 continued

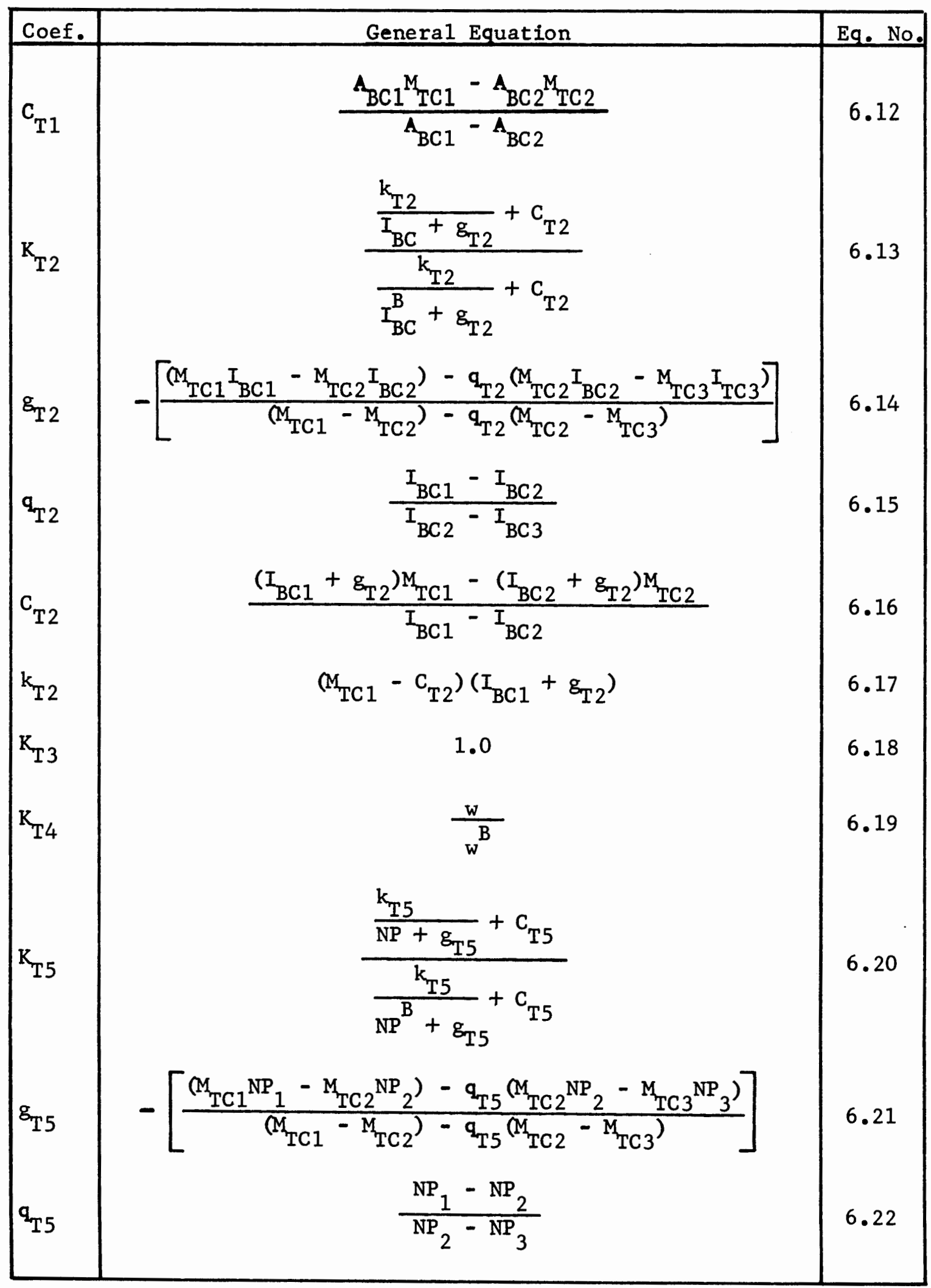


TABLE 6.1 continued

\begin{tabular}{|l|c|c|}
\hline Coef. & Genera1 Equation & Eq. No \\
\hline $\mathrm{C}_{\mathrm{T} 5}$ & $\frac{\left(\mathrm{NP}_{1}+\mathrm{g}_{\mathrm{T} 5}\right) \mathrm{M}_{\mathrm{TC} 1}-\left(\mathrm{NP}_{2}+\mathrm{g}_{\mathrm{T} 5}\right) \mathrm{M}_{\mathrm{TC} 2}}{\mathrm{NP}_{1}-\mathrm{NP}_{2}}$ & 6.23 \\
$\mathrm{k}_{\mathrm{T} 5}$ & $\left(\mathrm{M}_{\mathrm{TC} 1}-\mathrm{C}_{\mathrm{T} 5}\right)\left(\mathrm{NP}_{1}+\mathrm{g}_{\mathrm{T} 5}\right)$ & 6.24 \\
\hline
\end{tabular}

TABLE 6.2

COMPUTATION OF $k_{T}$ AND $C_{T}$ FOR

AN 8 PANEL TRUSS USING EQUATIONS 6.3 AND 6.4

\begin{tabular}{|c|}
\hline 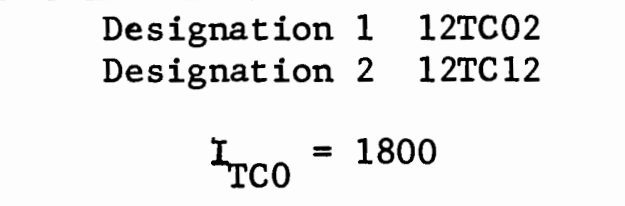 \\
\hline $\begin{aligned} \mathrm{A}_{\mathrm{TC} 1} & =50 & \mathrm{M}_{\mathrm{TC} 1}=12.80 \\
\mathrm{~A}_{\mathrm{TC} 2} & =75 & \mathrm{M}_{\mathrm{TC} 2}=9.78 \\
\mathrm{C}_{\mathrm{T}} & =3.7400 & \mathrm{k}_{\mathrm{T}}=453.00\end{aligned}$ \\
\hline
\end{tabular}

TABLE 6.3

COMPUTATION OF $k_{T 0}, C_{T 0}$ AND $g_{T 0}$ FOR

AN 8 PANEL TRUSS USING EQUATIONS

$6.6,6.7,6.8$ AND 6.9

Designation 1 12TC00

Designation 2 12TC01

Designation $3 \quad 12 \mathrm{TC} 02$

$$
\begin{aligned}
& I_{\mathrm{TC} 1}=250 \quad \mathrm{M}_{\mathrm{TC} 1}=2.10 \\
& I_{\mathrm{TC} 2}=800 \quad \mathrm{M}_{\mathrm{TC} 2}=6.02 \\
& \mathrm{I}_{\mathrm{TC} 3}=1800 \quad \mathrm{M}_{\mathrm{TC} 3}=12.80 \\
& g_{T 0}=30,011.5 \quad C_{T 0}=221.70 \quad k_{T 0}=-6,645,492.8
\end{aligned}
$$


TABIE 6.4

COMPUTATION OF $k_{T 1}$ AND $C_{T 1}$ FOR

AN 8 PANEL TRUSS USING

EQUATIONS 6.11 AND 6.12

\begin{tabular}{|c|}
\hline 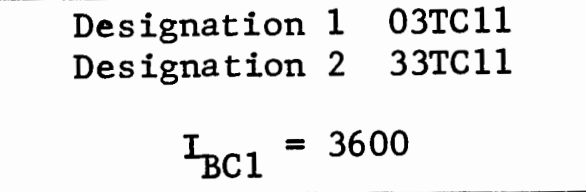 \\
\hline $\begin{array}{l}M_{T C 1}=4.93 \\
M_{T C 2}=3.77\end{array}$ \\
\hline $\mathrm{C}_{\mathrm{T} 1}=2.9967 \quad \mathrm{k}_{\mathrm{T} 1}=96.6667$ \\
\hline
\end{tabular}

TABLE 6.5

COMPUTATION OF $k_{T 2}, C_{T 2}$ AND $g_{T 2}$ FOR AN

8 PANEL TRUSS USING EQUATIONS

$6.14,6.15,6.16$ AND 6.17

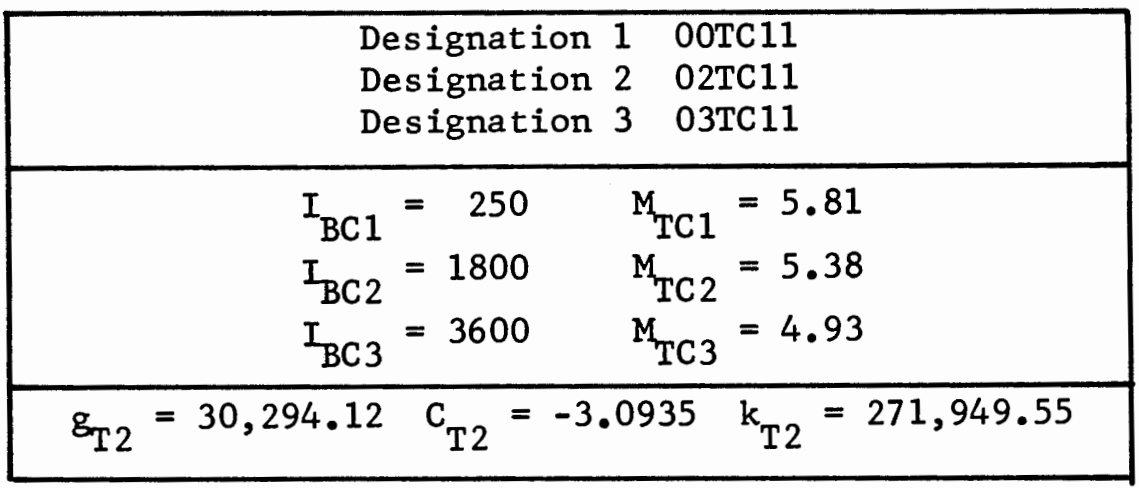

TABLE 6.6

COMPUTATION OF $k_{\mathrm{T} 5}, \mathrm{C}_{\mathrm{T} 5}$ AND $\mathrm{g}_{\mathrm{T} 5}$ USING

EQUATIONS $6.21,6.22,6.23$ AND 6.24

\begin{tabular}{|l|ll|}
\hline \multicolumn{4}{|c|}{ Designation $12 \mathrm{TC} 12$} \\
\hline $\mathrm{A}_{\mathrm{TC}}=75$ & $\mathrm{NP}_{1}=8$ & $\mathrm{M}_{\mathrm{TC} 1}=9.78$ \\
$\mathrm{I}_{\mathrm{TC}}=1800$ & $\mathrm{NP}_{2}=10$ & $\mathrm{M}_{\mathrm{TC} 2}=10.34$ \\
$\mathrm{~A}_{\mathrm{BC}}=75$ & $\mathrm{NP}_{3}=12$ & $\mathrm{M}_{\mathrm{TC} 3}=12.15$ \\
$\mathrm{I}_{\mathrm{BC}}=1800$ & & \\
\hline $\mathrm{g}_{\mathrm{T} 5}=-13.7920$ & $\mathrm{C}_{\mathrm{T} 5}=8.7182$ & $\mathrm{k}_{\mathrm{T} 5}=-6.1497$ \\
\hline
\end{tabular}


TABLE 6.7

EXPLICIT EQUATIONS FOR THE SECONDARY MOMENT IN THE TOP CHORD

\begin{tabular}{|c|c|c|}
\hline Coef. & Explicit Equation & Figure \\
\hline $\mathrm{M}_{\text {TCO }}$ & $\frac{(453.0)}{A_{T C}}+(3.74)$ & $\begin{array}{l}6.1 \mathrm{a} * \\
6.1 \mathrm{~b} \\
6.1 \mathrm{c}\end{array}$ \\
\hline $\mathrm{K}_{\mathrm{TO}}$ & $\frac{-519,179}{I_{T C}+30,011.5}+17.3233$ & \\
\hline $\mathrm{K}_{\mathrm{T} 1}$ & $\frac{(22.555)}{A_{B C}}+(.6992)$ & 6.2 \\
\hline $\mathrm{K}_{\mathrm{T} 2}$ & $\frac{(50,548.2)}{I_{B C}+(30,294.12)}+(-0.5750)$ & 6.3 \\
\hline $\mathrm{K}_{\mathrm{T} 3}$ & 1.0 & \\
\hline $\mathrm{K}_{\mathrm{T} 4}$ & w & \\
\hline $\mathrm{K}_{\mathrm{T} 5}$ & $\frac{(-.6288)}{\mathrm{NP}+(-13.792)}+(.8912)$ & 6.4 \\
\hline${ }^{\mathrm{T}} \mathrm{TC}$ & $\mathrm{K}_{\mathrm{T} 0} \mathrm{~K}_{\mathrm{T} 1} \mathrm{~K}_{\mathrm{T} 2} \mathrm{~K}_{\mathrm{T} 3} \mathrm{~K}_{\mathrm{T} 4} \mathrm{~K}_{\mathrm{T} 5}{ }_{\mathrm{TC} 0}^{\mathrm{M}}$ & \\
\hline
\end{tabular}

*Figures $6.1 \mathrm{a}, \mathrm{b}$ and $\mathrm{c}$ represent $\mathrm{K}_{\mathrm{T} 0} \mathrm{~K}_{\mathrm{T} 5} \mathrm{M}_{\mathrm{TC}}$

TABLE 6.8

CALCULATED DATA FOR CURVE OF F IGURE 6.1 US ING EQUAT IONS FROM TABLE 6.7

\begin{tabular}{|c|c|c|c|c|}
\hline$A_{\mathrm{TC}}$ & $\mathrm{I}_{\mathrm{TC}}=250$ & $I_{\mathrm{TC}}=800$ & $I_{\mathrm{TC}}=1800$ & $I_{\mathrm{TC}}=3600$ \\
\hline $25 *$ & 3.651 & 10.340 & 21.860 & 86.747 \\
50 & 2.138 & 6.054 & 12.800 & 24.03 \\
75 & 1.633 & 4.626 & 9.780 & 18.357 \\
100 & 1.381 & 3.912 & 8.270 & 15.523 \\
125 & 1.230 & 3.483 & 7.364 & 13.822 \\
\hline
\end{tabular}

*Extrapolated 
TABLE 6.9

CAICULATED DATA FOR FIGURE 6.2 BASED ON THE EQUATIONS FROM TABLE 6.7

\begin{tabular}{|l|l|l|l|l|}
\hline & \multicolumn{2}{|c|}{5.125 Wide } & \multicolumn{2}{c|}{6.75 Wide } \\
\hline Depth & $\mathrm{M}_{\mathrm{TC}}$ & $\mathrm{fb}$ & $\mathrm{M}_{\mathrm{TC}}$ & $\mathrm{fb}$ \\
\hline 6 & 1.07831 & 420.804 & 1.12114 & 332.189 \\
7.5 & 1.68606 & 421.105 & 1.79003 & 339.443 \\
9 & 2.48152 & 430.398 & 2.67095 & 351.731 \\
10.5 & 3.47394 & 442.673 & 3.77643 & 365.369 \\
12 & 4.67062 & 455.671 & 5.11492 & 378.883 \\
13.5 & 6.07545 & 468.327 & 6.68973 & 391.534 \\
15 & 7.6883 & 480.05 & 8.49798 & 402.867 \\
16.5 & 9.50446 & 490.454 & 10.5303 & 412.575 \\
18 & 11.5145 & 499.273 & 12.7709 & 420.441 \\
19.5 & 13.7042 & 506.319 & 15.1977 & 426.321 \\
21 & 16.0552 & 511.466 & 17.7834 & 430.135 \\
22.5 & 18.5452 & 514.643 & 20.4967 & 431.865 \\
24 & 21.1489 & 515.826 & 23.3036 & 431.548 \\
\hline
\end{tabular}

TABLE 6.10

CALCULATEd VALUES OF $\mathrm{K}_{\mathrm{T} 1}$

\begin{tabular}{|r|l|}
\hline \multicolumn{2}{|c|}{$\mathrm{I}_{\mathrm{TC}}=1800$} \\
$\mathrm{~A}_{\mathrm{TC}}=75$ \\
$\mathrm{I}_{\mathrm{BC}}=1800$ \\
\hline $\mathrm{A}_{\mathrm{BC}}$ & $\mathrm{K}_{\mathrm{T} 1}$ \\
\hline 25 & 1.601 \\
50 & 1.15 \\
75 & 1.00 \\
100 & 0.925 \\
125 & 0.880 \\
\hline
\end{tabular}


TABLE 6.11

CALCULATED VALUE OF $\mathrm{K}_{\mathrm{T} 2}$

\begin{tabular}{|c|c|}
\hline \multicolumn{2}{|c|}{$I_{\mathrm{TC}}=1800$} \\
$A_{\mathrm{TC}}=75$ \\
$A_{\mathrm{BC}}=75$ \\
\hline$I_{\mathrm{BC}}$ & $\mathrm{K}_{\mathrm{T} 2}$ \\
\hline 200 & 1.083 \\
400 & 1.072 \\
800 & 1.051 \\
1200 & 1.030 \\
1600 & 1.010 \\
1800 & 1.000 \\
2000 & 0.9903 \\
2400 & 0.9711 \\
2800 & 0.9525 \\
3200 & 0.9342 \\
3600 & 0.9134 \\
\hline
\end{tabular}

TABLE 6.12

CALCULATED VALUES OF $\mathrm{K}_{\mathrm{T} 5}$

\begin{tabular}{|r|l|}
\hline$N P$ & $K_{T 5}$ \\
\hline 8 & 1.000 \\
10 & 1.057 \\
12 & 1.242 \\
\hline
\end{tabular}




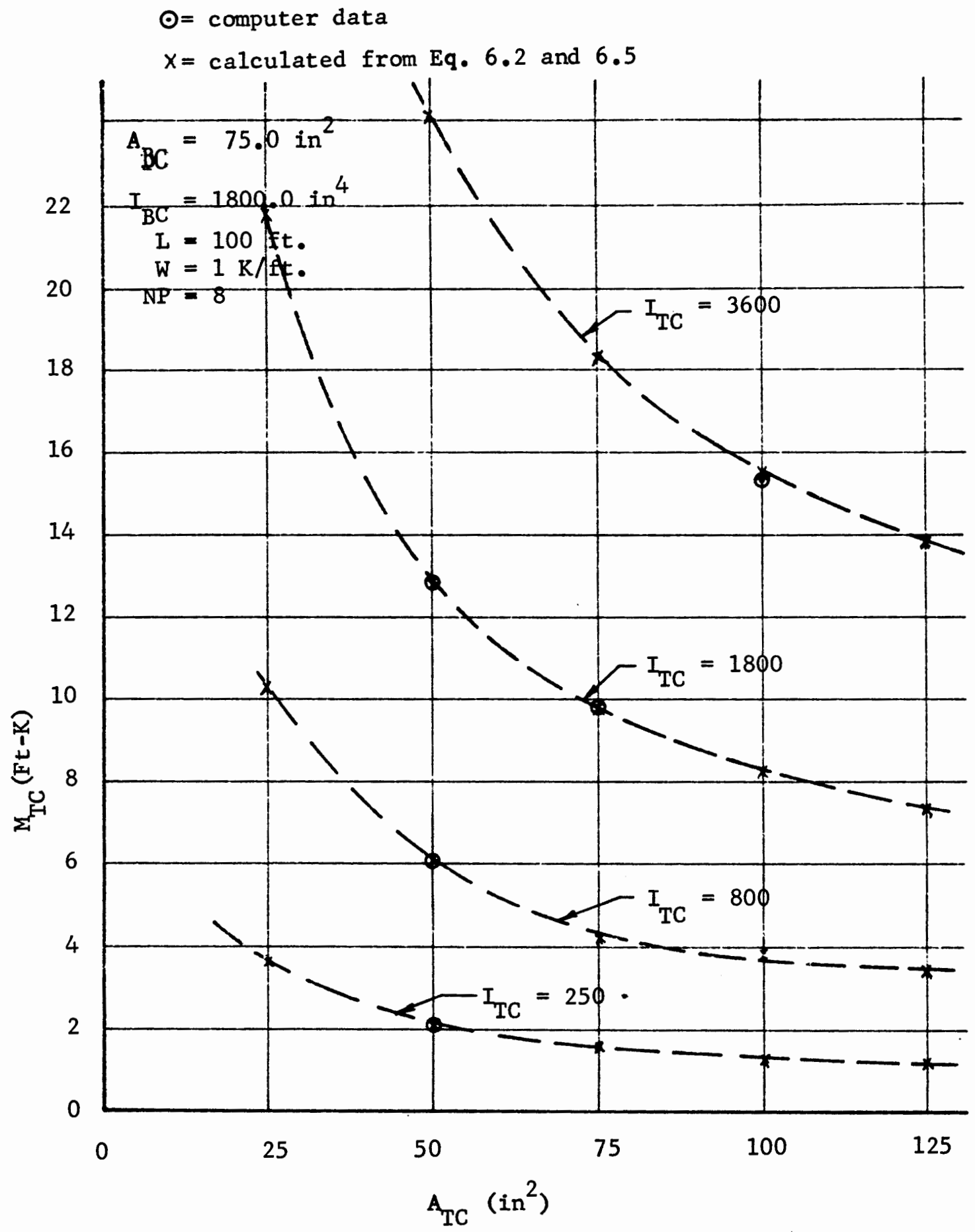

Figure 6.2 8 panel truss - secondary moment in the top chord as a function of $A_{T C}$ and $I_{T C} \cdot$ 


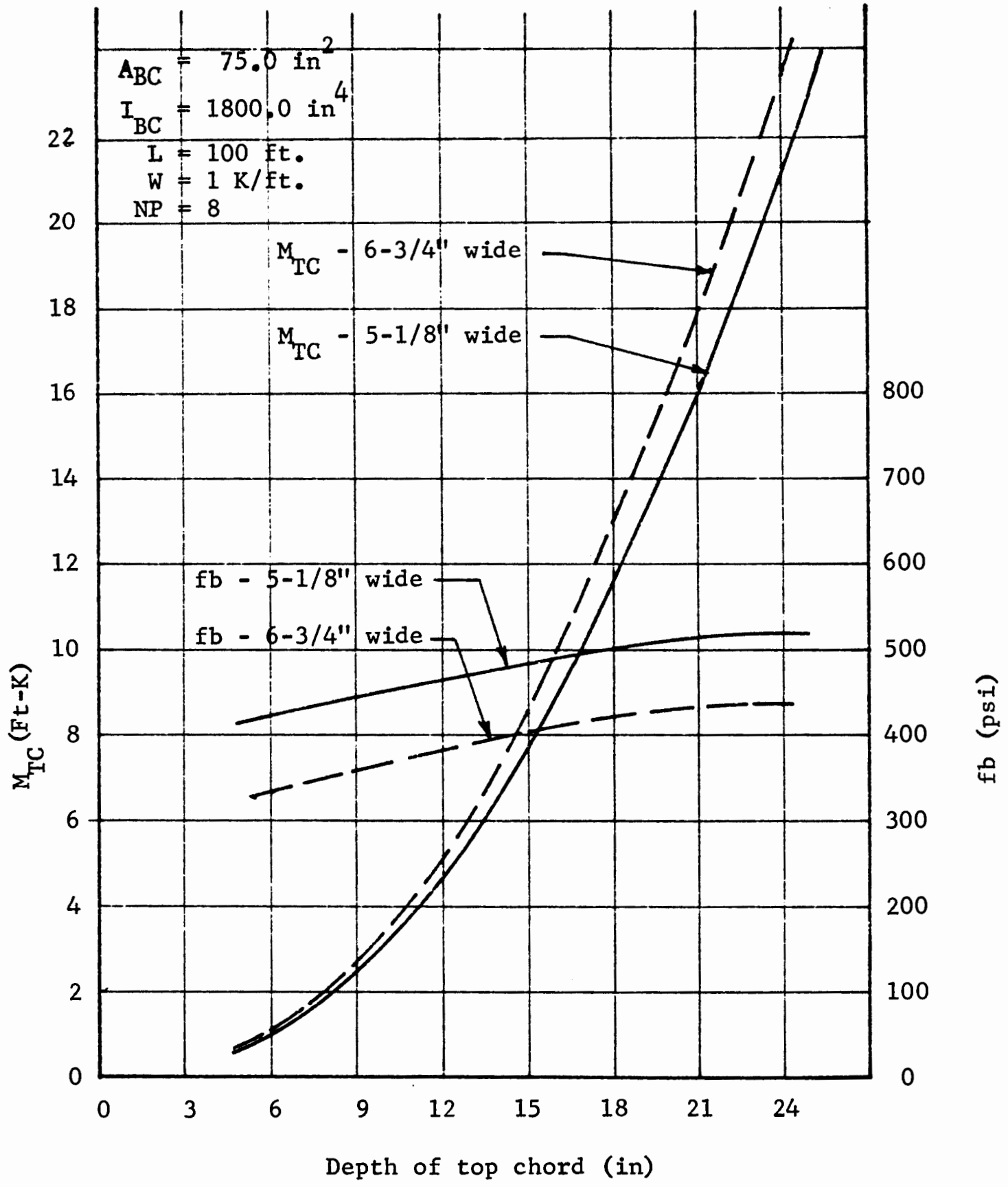

Figure 6.3 8 panel truss - secondary moment and bending stress in the topchord as computed from Equations 6.2 and 6.5 . 


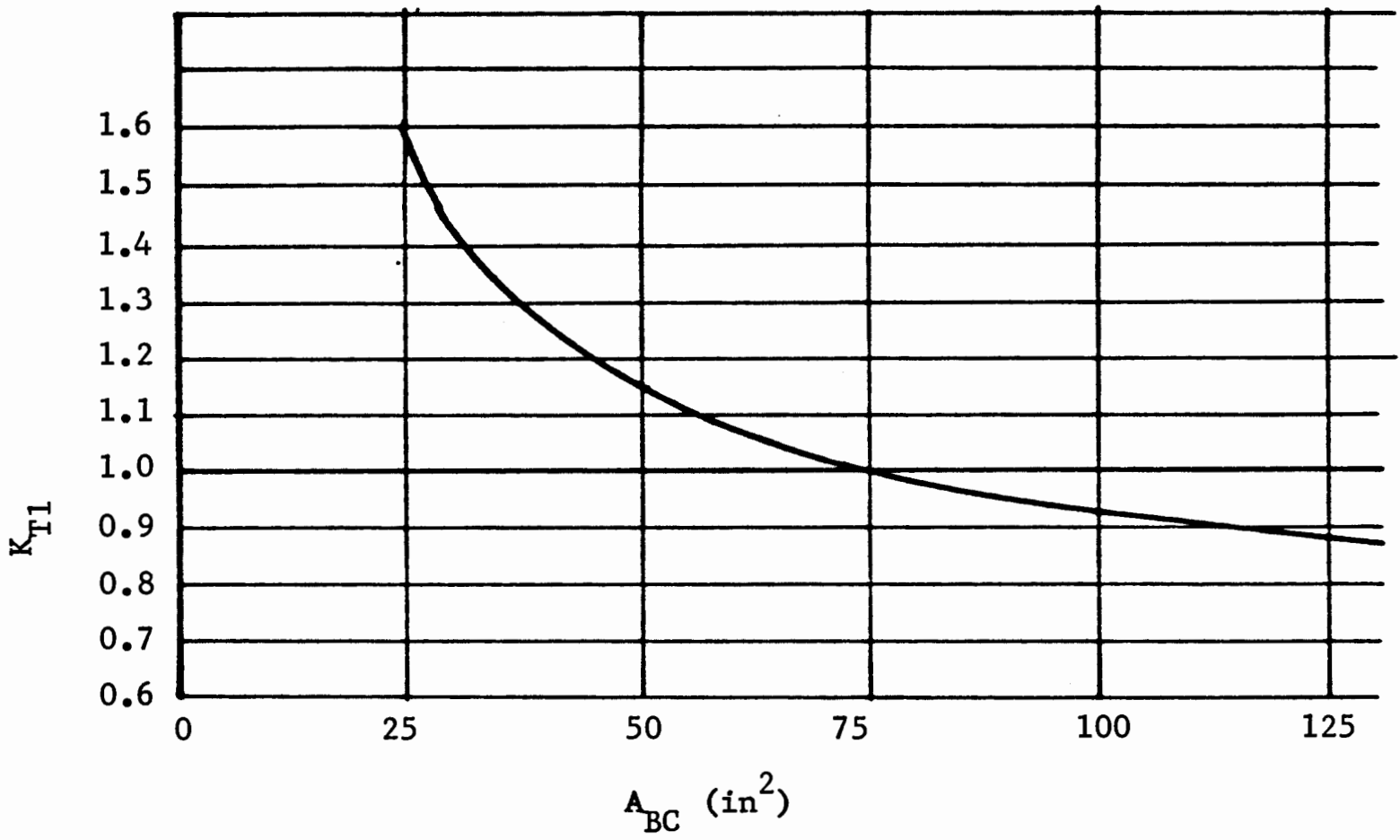

Figure 6.4 $\mathrm{K}_{\mathrm{T} 1}$ - Adjustment factor to $\mathrm{M}_{\mathrm{TC}}$ to account for variation in $\mathrm{A}_{\mathrm{BC}}$.

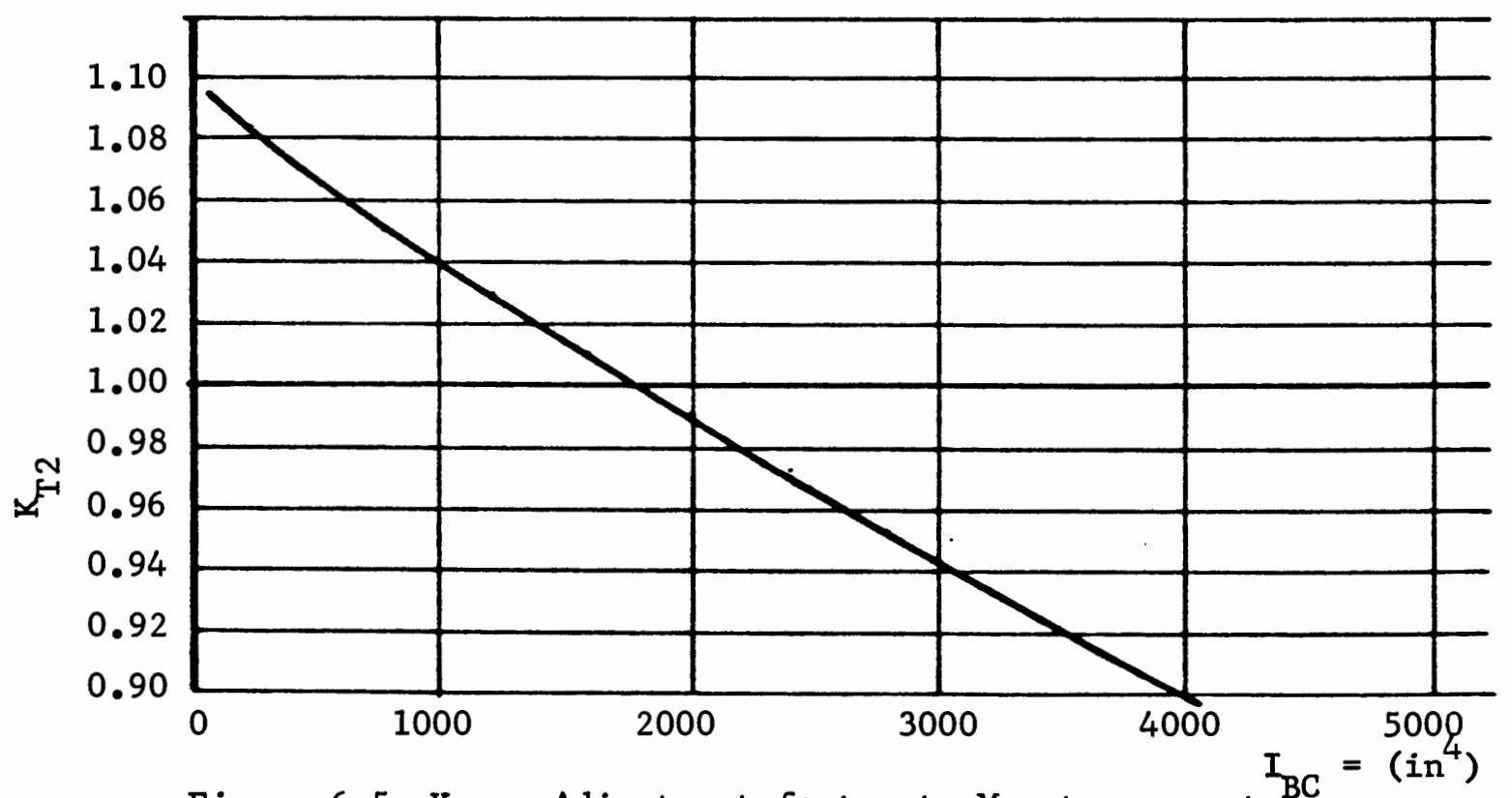

Figure 6.5 $\mathrm{K}_{\mathrm{T} 2}$ - Adjustment factor to $\mathrm{M}_{\mathrm{TC}}$ to account $\mathrm{I}_{\mathrm{BC}}=\left(\mathrm{in}^{4}\right)$ for variation in $I_{B C}$. 


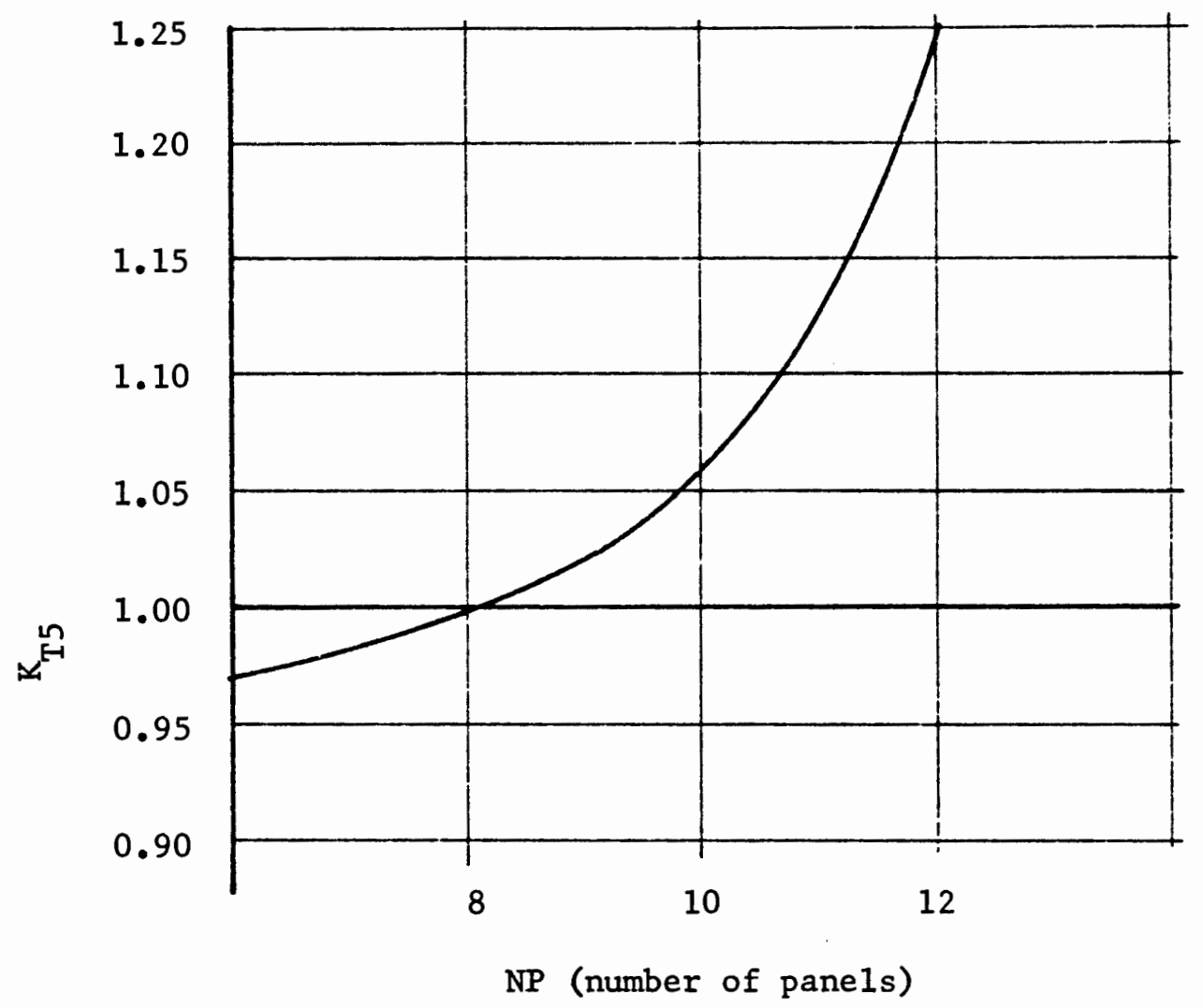

Figure 6.6 $\mathrm{K}_{\mathrm{T} 5}$ - Adjustment factor to $\mathrm{M}_{\mathrm{TC}}$ to account for a variation in the number of panels in the truss. 


\section{VERIFICATION OF EQUATIONS DEVELOPED IN CHAPTERS V AND VI}

In order to check the equations developed in Chapters V and VI, the equations of Tables 5.12 and 6.7 were written into a small computer program. Computation of $\mathrm{M}_{\mathrm{BC}}$ and $\mathrm{M}_{\mathrm{TC}}$ were made for each combination of . parameters for which a frame analysis had been run. The results were compared with the values of $M_{B C}$ and $M_{T C}$ obtained from the frame analysis runs.

Table $7.1 \mathrm{a}$ compares the moment in the bottom chord as computed by the equations developed in Chapter $V$ (Table 5.12) denoted by " $M_{B C}$ equation" against the moment obtained from the frame analysis denoted by "M ${ }_{B C}$ computer". The column labeled "Ratio" lists the ratio of the two, that is

$$
\text { Ratio }=\frac{\mathrm{M}_{\mathrm{BC}} \text { equation }}{\mathrm{M}_{\mathrm{BC}} \text { computer }}
$$

Table $7.1 b$ compares the secondary moment in the top chord in a similar fashion.

It can be seen that the equations generally predict the moments with $1 \%$ or $2 \%$. A few cases have up to nearly a $10 \%$ discrepancy.

This range of accuracy is considered quite acceptable. The bending stress resulting from the secondary moments is generally in the range of $20 \%$ of the allowable bending stress. Therefore, a $10 \%$ error 
in computing the moment will result in only a $2 \%$ error in the combined stress equation which is well within accepted engineering accuracy. In addition, it will be seen in Chapter VIII that bolt slippage in the web to chord joints can reduce the secondary moments by as much as $60 \%$ in some cases, which further justifies the acceptability of the accuracy obtained.

The cases which showed the greatest discrepancy were in the most part unlikely combinations of parameters, such as case $12 \mathrm{TC} 30$ which has the following parameters:

$$
\begin{array}{ll}
A_{B C}=75 & I_{B C}=1800 \\
A_{T C}=125 & I_{T C}=250
\end{array}
$$

Greater accuracy would likely have been obtained if the parameters used to develop the various constants had "bounded" the range of data. This was not always done which results in some extrapolation being required.

Chapter IX will present a systematic approach to choosing parameters and developing characteristic equations which greatly simplifies and improves reliability over the techniques used to develop the equations of Chapters $\mathrm{V}$ and VI. 
TABLE $7.1 \mathrm{a}$

VERIFICATION DATA

\begin{tabular}{|c|c|c|c|c|}
\hline & Designation & $\begin{array}{c}\text { MBC } \\
\text { Equation }\end{array}$ & $\begin{array}{c}\text { MBC } \\
\text { Computer }\end{array}$ & Ratio \\
\hline $8 \mathrm{P}$ & $\begin{array}{l}\text { 00TC11 } \\
20 \mathrm{TC} 11 \\
30 \mathrm{TC} 11 \\
01 \mathrm{TC} 11 \\
02 \mathrm{TC} 11 \\
03 \mathrm{TC} 11 \\
33 \mathrm{TC} 11 \\
11 \mathrm{TC} 11 \\
12 \mathrm{TC} 00 \\
12 \mathrm{TC} 01 \\
12 \mathrm{TC} 02 \\
12 \mathrm{TC} 12 \\
12 \mathrm{TC} 23\end{array}$ & $\begin{array}{r}1.62633 \\
1.27899 \\
1.20952 \\
4.96964 \\
10.82780 \\
21.06850 \\
15.66890 \\
4.26205 \\
12.74280 \\
12.32730 \\
11.99090 \\
9.03273 \\
7.40468\end{array}$ & $\begin{array}{r}1.57 \\
1.23 \\
1.16 \\
4.97 \\
10.94 \\
21.07 \\
15.67 \\
4.26 \\
12.88 \\
12.46 \\
12.12 \\
9.13 \\
7.36\end{array}$ & $\begin{array}{l}1.035880 \\
1.039830 \\
1.042690 \\
0.999927 \\
0.989745 \\
0.999927 \\
0.999927 \\
1.000480 \\
0.989351 \\
0.989351 \\
0.989351 \\
0.989346 \\
1.006070\end{array}$ \\
\hline $10 \mathrm{P}$ & $\begin{array}{l}00 T C 11 \\
10 T C 11 \\
20 \mathrm{TC} 11 \\
30 \mathrm{TC} 11 \\
01 \mathrm{TC} 11 \\
02 \mathrm{TC} 11 \\
03 \mathrm{TC} 11 \\
33 \mathrm{TC} 11 \\
12 \mathrm{TC} 02 \\
12 \mathrm{TC} 12 \\
12 \mathrm{TC} 20 \\
12 \mathrm{TC} 21 \\
12 \mathrm{TC} 22 \\
12 \mathrm{TC} 23\end{array}$ & $\begin{array}{r}1.89354 \\
1.62394 \\
1.48913 \\
1.40825 \\
5.78619 \\
12.60690 \\
24.53020 \\
18.24340 \\
13.96110 \\
10.51690 \\
9.34623 \\
9.04147 \\
8.79475 \\
8.62133\end{array}$ & $\begin{array}{r}1.93 \\
1.65 \\
1.51 \\
1.42 \\
6.01 \\
12.91 \\
23.98 \\
17.79 \\
14.20 \\
10.63 \\
9.39 \\
9.13 \\
8.80 \\
8.30\end{array}$ & $\begin{array}{l}0.981111 \\
0.984203 \\
0.986180 \\
0.991725 \\
0.962760 \\
0.976522 \\
1.022940 \\
1.025480 \\
0.983178 \\
0.989358 \\
0.995339 \\
0.990303 \\
0.999403 \\
1.038710\end{array}$ \\
\hline $12 \mathrm{P}$ & $\begin{array}{l}00 \mathrm{TC} 12 \\
30 \mathrm{TC} 12 \\
03 \mathrm{TC} 12 \\
12 \mathrm{TC} 12 \\
31 \mathrm{TC} 12 \\
32 \mathrm{TC} 12 \\
33 \mathrm{TC} 12 \\
12 \mathrm{TC} 00 \\
12 \mathrm{TC} 03 \\
12 \mathrm{TC} 11 \\
12 \mathrm{TC} 12 \\
12 \mathrm{TC} 30 \\
12 \mathrm{TC} 31 \\
12 \mathrm{TC} 32 \\
12 \mathrm{TC} 33\end{array}$ & $\begin{array}{r}2.09313 \\
1.55669 \\
27.11580 \\
11.95150 \\
4.75684 \\
10.36420 \\
20.16630 \\
16.86050 \\
15.55280 \\
12.28680 \\
11.95150 \\
9.37334 \\
9.06769 \\
8.82026 \\
8.64634\end{array}$ & $\begin{array}{r}2.13 \\
1.61 \\
25.43 \\
12.08 \\
4.96 \\
10.54 \\
19.25 \\
17.68 \\
14.68 \\
12.74 \\
12.08 \\
9.55 \\
9.22 \\
8.78 \\
8.14\end{array}$ & $\begin{array}{l}0.982692 \\
0.966887 \\
1.066290 \\
0.989366 \\
0.959041 \\
0.983319 \\
1.047600 \\
0.953649 \\
1.059450 \\
0.964428 \\
0.989366 \\
0.981502 \\
0.983481 \\
1.004590 \\
1.062200\end{array}$ \\
\hline
\end{tabular}


TABLE $7.1 \mathrm{~b}$

VERIFICATION DATA

\begin{tabular}{|c|c|c|c|c|}
\hline & Designation & $\begin{array}{c}\text { MTC } \\
\text { Equation }\end{array}$ & $\begin{array}{c}\text { MTC } \\
\text { Computer }\end{array}$ & Ratio \\
\hline $8 \mathrm{P}$ & $\begin{array}{l}00 \mathrm{TC} 11 \\
20 \mathrm{TC} 11 \\
30 \mathrm{TC} 11 \\
01 \mathrm{TC} 11 \\
02 \mathrm{TC} 11 \\
03 \mathrm{TC} 11 \\
33 \mathrm{TC} 11 \\
11 \mathrm{TC} 11 \\
12 \mathrm{TC} 00 \\
12 \mathrm{TC} 01 \\
12 \mathrm{TC} 02 \\
12 \mathrm{TC} 12 \\
12 \mathrm{TC} 23 \\
\end{array}$ & $\begin{array}{r}5.59679 \\
4.46999 \\
4.24463 \\
5.44508 \\
5.18257 \\
4.74908 \\
3.60172 \\
4.71424 \\
2.07127 \\
5.87251 \\
12.44710 \\
9.51037 \\
15.05110 \\
\end{array}$ & $\begin{array}{r}5.810 \\
4.640 \\
4.400 \\
5.650 \\
5.380 \\
4.930 \\
3.770 \\
4.900 \\
2.100 \\
6.020 \\
12.800 \\
9.780 \\
15.400 \\
\end{array}$ & $\begin{array}{l}0.963303 \\
0.963359 \\
0.964688 \\
0.963731 \\
0.963303 \\
0.963303 \\
0.955364 \\
0.962090 \\
0.986321 \\
0.975500 \\
0.972430 \\
0.972430 \\
0.977344\end{array}$ \\
\hline $10 \mathrm{P}$ & $\begin{array}{l}00 \mathrm{TC} 11 \\
10 \mathrm{TC} 11 \\
20 \mathrm{TC} 11 \\
30 \mathrm{TC} 11 \\
01 \mathrm{TC} 11 \\
02 \mathrm{TC} 11 \\
03 \mathrm{TC} 11 \\
33 \mathrm{TC} 11 \\
12 \mathrm{TC} 02 \\
12 \mathrm{TC} 12 \\
12 \mathrm{TC} 20 \\
12 \mathrm{TC} 21 \\
12 \mathrm{TC} 22 \\
12 \mathrm{TC} 23 \\
\end{array}$ & $\begin{array}{r}5.91733 \\
5.12311 \\
4.72599 \\
4.48773 \\
5.75693 \\
5.47939 \\
5.02108 \\
3.80800 \\
13.16000 \\
10.05510 \\
1.41488 \\
4.01150 \\
8.50259 \\
15.91310 \\
\end{array}$ & $\begin{array}{r}6.160 \\
5.250 \\
4.790 \\
4.510 \\
5.910 \\
5.510 \\
4.890 \\
3.610 \\
13.820 \\
10.340 \\
1.130 \\
3.890 \\
8.560 \\
16.060 \\
\end{array}$ & $\begin{array}{l}0.960606 \\
0.975830 \\
0.986638 \\
0.995062 \\
0.974101 \\
0.994444 \\
1.026800 \\
1.054850 \\
0.952242 \\
0.972442 \\
1.252110 \\
1.031230 \\
0.993293 \\
0.990854\end{array}$ \\
\hline $12 \mathrm{P}$ & $\begin{array}{l}00 \mathrm{TC} 12 \\
30 \mathrm{TC} 12 \\
03 \mathrm{TC} 12 \\
12 \mathrm{TC} 12 \\
31 \mathrm{TC} 12 \\
32 \mathrm{TC} 12 \\
33 \mathrm{TC} 12 \\
12 \mathrm{TC} 00 \\
12 \mathrm{TC} 03 \\
12 \mathrm{TC} 11 \\
12 \mathrm{TC} 12 \\
12 \mathrm{TC} 30 \\
12 \mathrm{TC} 31 \\
12 \mathrm{TC} 32 \\
12 \mathrm{TC} 33\end{array}$ & $\begin{array}{r}14.73810 \\
11.17740 \\
12.50580 \\
11.81560 \\
10.87440 \\
10.35020 \\
9.48444 \\
2.57332 \\
28.94210 \\
5.57455 \\
11.81560 \\
1.48047 \\
4.19744 \\
8.89670 \\
16.65070\end{array}$ & $\begin{array}{r}15.467 \\
11.670 \\
12.700 \\
12.150 \\
11.270 \\
10.630 \\
10.080 \\
2.610 \\
28.460 \\
5.900 \\
12.150 \\
1.630 \\
4.400 \\
8.970 \\
16.070\end{array}$ & $\begin{array}{l}0.952871 \\
0.957790 \\
0.984708 \\
0.972474 \\
0.964900 \\
0.973675 \\
0.940917 \\
0.985948 \\
1.016940 \\
0.944838 \\
0.972474 \\
0.908261 \\
0.953963 \\
0.991829 \\
1.036140\end{array}$ \\
\hline
\end{tabular}




\section{CHAPTER VIII}

\section{OTHER FACTORS AFFECTING THE SECONDARY MOMENTS IN THE CHORDS}

In addition to the primary factors listed in Table 5.1 which affect the secondary moments in the chords, there are several other influencing factors. These factors, though not treated as "primary" factors, can have significant effect. Some of these factors include:

1. Web joint slippage

2. Heel fixity of the bottom chord

3. Heel bolt slippage

4. Center line bottom chord splice fixity/slippage

The effects of these parameters are briefly treated in the following sections.

\subsection{BOLT SLIPPAGE IN THE WEB CONNECTIONS}

Bolt slippage in the web to chord connection allows significant relief of the induced moments. The effect of bolt slippage was simulated by reducing the area of the webs in a single step iteration in order to approximate a $1 / 16 \mathrm{in.}$ to $1 / 8 \mathrm{in.} \mathrm{slip} \mathrm{displacement.} \mathrm{This}$ procedure was discussed in section 3.2.5.1. Table 8.1 provides a comparison of the maximum moment in the top and bottom chord for a few cases with and without the simulated joint slippage. The columns labeled \% represent the ratio

$$
\frac{\text { with slip }}{\text { without slip }} * 100 \%
$$


As can be seen, for the range of parameters considered, the bottom chord moment is reduced from $30 \%$ to $60 \%$, with the average reduction being approximately 44\%. The top chord moment is likewise reduced from $40 \%$ to $60 \%$ with the average reduction about $50 \%$.

This is a very brief study, so no conclusive recommendations can be made at this time. It does appear, however, that a $30 \%$ reduction could be safely assumed for the bottom chord and a $40 \%$ reduction for the top chord.

In genera1, the combinations which result in large moments generally appear to have the greater reduction when joint slippage is permitted.

\section{TABLE 8.1}

EFFECT OF BOLT SLIPPAGE IN

WEB CONNECTIONS

\begin{tabular}{|c|c|c|c|c|c|c|}
\hline Designation & $\begin{array}{c}\mathrm{M}_{\mathrm{BC}} \\
\text { No Slip } \\
\end{array}$ & $\begin{array}{c}\quad \mathrm{M}_{\mathrm{BC}} \\
\text { With S1ip }\end{array}$ & $\%$ & $\begin{array}{c}M_{T C} \\
\text { No Slip } \\
\end{array}$ & $\begin{array}{c}\mathrm{M}_{\mathrm{TC}} \\
\text { With S1ip }\end{array}$ & $\%$ \\
\hline 8 Panel & & & & & & \\
\hline $\begin{array}{l}00 \mathrm{TC} 11 \\
12 \mathrm{TC} 12 \\
33 \mathrm{TC} 11\end{array}$ & $\begin{array}{r}1.57 \\
9.13 \\
15.67\end{array}$ & $\begin{array}{l}1.06 \\
5.27 \\
8.37\end{array}$ & $\begin{array}{l}67.5 \\
57.7 \\
53.4\end{array}$ & $\begin{array}{r}8.02 \\
11.99 \\
5.98\end{array}$ & $\begin{array}{l}4.76 \\
5.42 \\
3.33\end{array}$ & $\begin{array}{l}59.4 \\
45.2 \\
55.7\end{array}$ \\
\hline 10 Pane1 & & & & & & \\
\hline $\begin{array}{l}\text { 00TC11 } \\
\text { 03TC11 } \\
\text { 30TC11 } \\
\text { 33TC11 }\end{array}$ & $\begin{array}{r}1.93 \\
23.98 \\
1.42 \\
17.79\end{array}$ & $\begin{array}{r}1.31 \\
11.37 \\
0.85 \\
6.92\end{array}$ & $\begin{array}{l}67.9 \\
47.4 \\
59.9 \\
38.9\end{array}$ & $\begin{array}{l}7.87 \\
6.60 \\
6.22 \\
5.32\end{array}$ & $\begin{array}{l}4.17 \\
3.22 \\
2.79 \\
2.18\end{array}$ & $\begin{array}{l}53.0 \\
48.8 \\
44.9 \\
41.0\end{array}$ \\
\hline
\end{tabular}

\subsection{HEEL FIXITY}

If the heel column connection is such that any degree of fixity is imposed on the bottom chord, significant moments will be introduced 
into the bottom chord. The heel design shown in Figure 2.7, which has had considerable usage, has the potential for this problem when the column is large.

The moment at the end of the truss might be computed simplistically as $R x$ where $e$ is the eccentricity based on member center lines. In reality, however, the probable stress distribution shown in Figure 8.1 would result in a moment of $R \times e^{\prime}$ where $e^{\prime}$ is the more probable eccentricity based on reaction force lines.

Regardless of the actual moment, it will affect the bottom chord as shown in Figure 8.2. The moment transfered to the first joint will be additive with the deflection induced moment based on a pinned heel joint. This increase in moment can be seen in Figure 8.3 where the moment in the bottom chord based on output from computer analysis of the 8 panel truss is plotted. The conditions shown represent the boundarles i.e., fully fixed versus a purely pinned connection.

In the actual structure, complete fixity is highly unlikely. The maximum moment achievable would be equal to $R \times e^{\prime}$, which would most likely be less than the "fixed" moment.

The amplification of the moment at the first joint, which is a1ready the critical point, suggests that care should be taken to avoid eccentric heel connections in these trusses. The connection detail of Figure 2.7 should therefore be avoided in favor of a detail similar to that shown in Figure 2.6.

\subsection{BOLT SLIPPAGE IN THE HEEL CONNECTION}

As discussed in section 3.2.5.2, bolt slippage was simulated by 


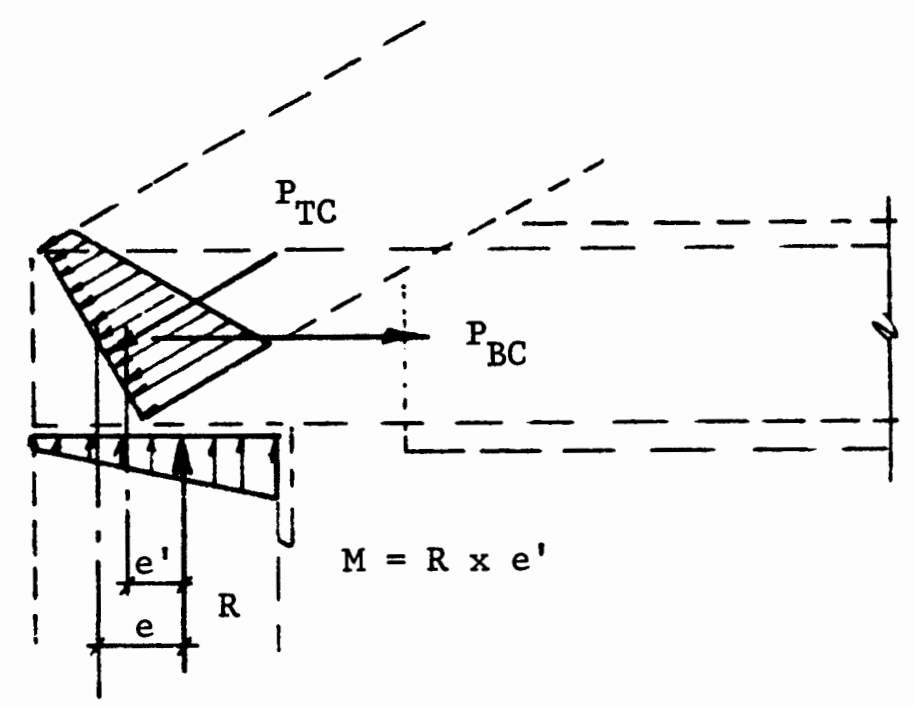

Figure 8.1 Probable stress distribution in an eccentric hee1.

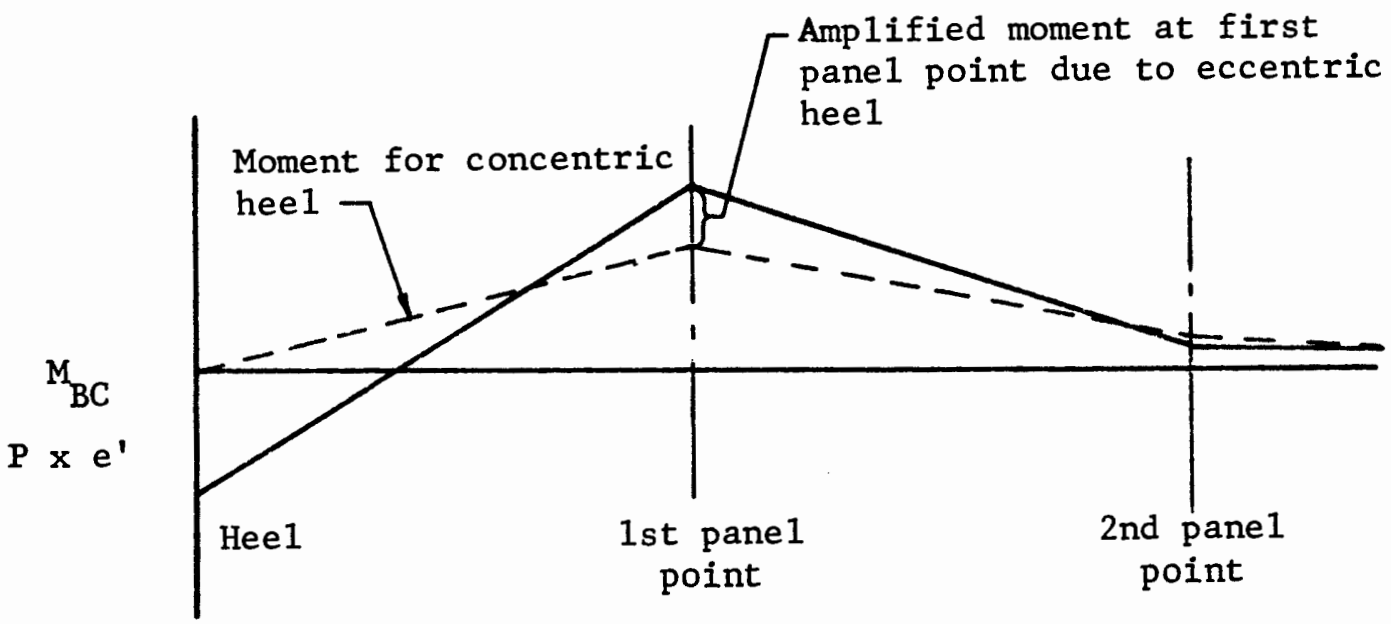

Figure 8.2 Amplification of moment in the bottom chord due to an eccentric heel. 


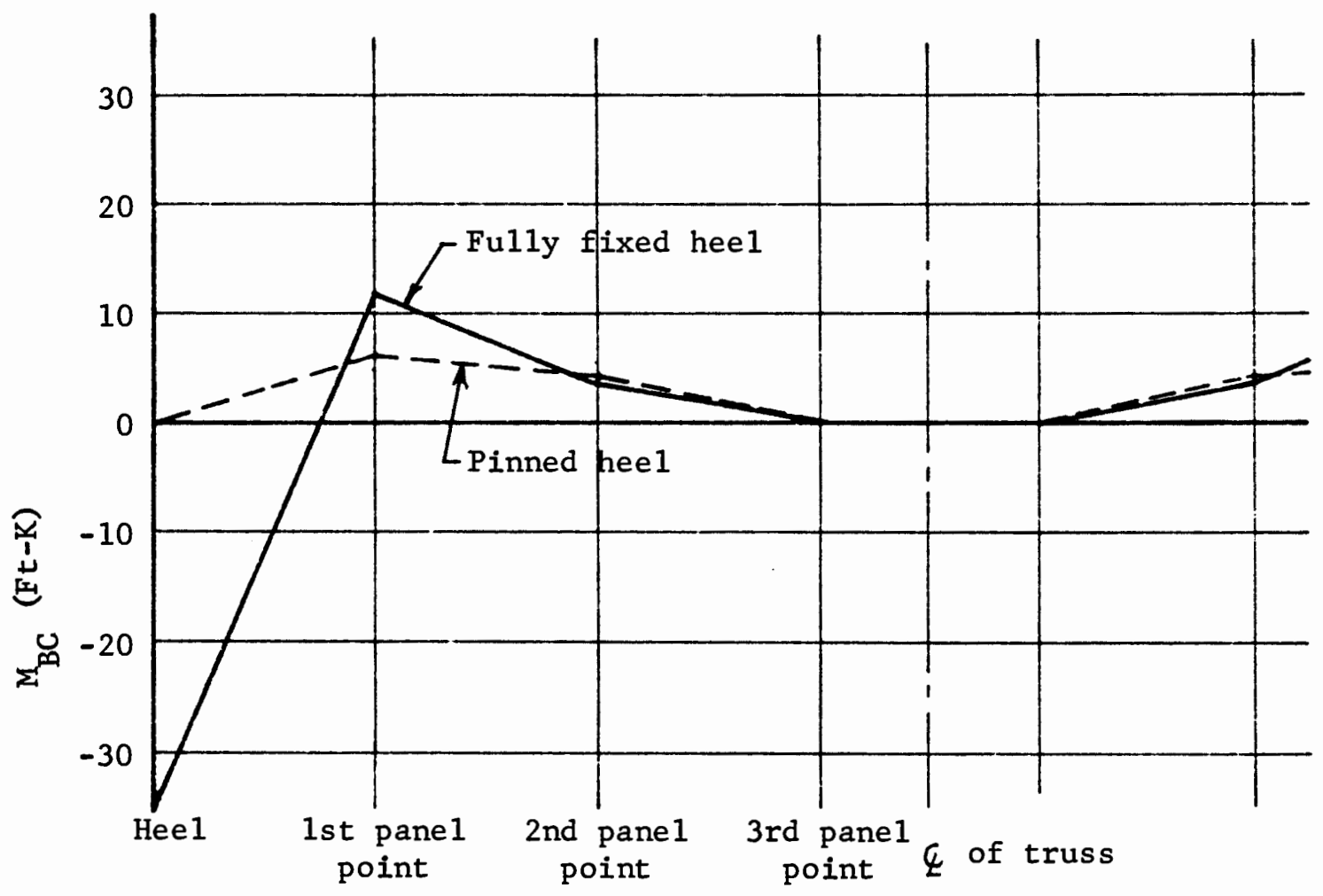

Figure 8.3 Effect of a fully fixed heel on the bottom chord moment in an 8 panel truss with bolt slippage permitted in the web connections. 
reducing the area of the "rigid" link that was modeled into the heel of the truss (see Figure 3.1). The area was reduced an amount necessary to increase the axial deformation of that element by $1 / 8 \mathrm{in}$.

In most cases, several bolts are required in this connection. The change of slippage occurring is therefore thought to be small. In a design that contains only a few bolts or otherwise allows for significant movement in the joint, consideration should be given to the effects of this possibility.

Bolt slippage in this connection has the adverse effect of increasing the secondary moment in both top and bottom chords by a significant amount. The brief study made in this investigation indicates that a $1 / 16$ in. joint slip will increase the moments by an amount equal to approximately

$$
M=\frac{.16 E I}{\ell^{2}}
$$

where $l$ is the length of the end bottom chord panel (i.e., $l=L / 7$ for an 8 panel truss).

Translated into bending stress, for a rectangular section, this becomes

$$
\mathrm{fb}=\frac{.08 \mathrm{Ed}}{\ell^{2}}
$$

For a $100 \mathrm{ft}$. truss with a 13-1/2 in. deep chord, a 1/16 in. joint slip will induce approximately $70 \mathrm{psi}$ of additional bending into the chord. This represents an approximate $16 \%$ increase in bending stress for this case. 


\subsection{BOTTOM CHORD SPLICE}

The effect of joint fixity and joint slippage in the center line splice is negligible. The effect at the end panel joint, which has been shown in Chapters V and VI to be the critical location on the chord, is nominal and appears to be of little concern in terms of induced stresses.

\subsection{TERTIARY $(\mathrm{P}-\triangle)$ MOMENTS}

If the bottom chord is fabricated nearly straight, it will be forced into a slightly curved shape when the truss is loaded. Tertiary, or P- $\Delta$, moments will result from the tension acting on the curved member.

This possibility was considered briefly in order to determine if this was of serious concern in the design of the trusses.

For the cases considered, the moment in the bottom chord was found to be amplified by $2 \%$ to $9 \%$, which represents less than a $1 \%$ change in the unity equation.

This does not appear to be of enough significance to be of concern in the design. This is especially true when considering the fact that the truss is normally fabricated with a camber in it. Under maximum loading, the bottom chord is expected to be nearly straight. For these reasons, no further consideration has been given to the tertiary moments in the bottom chord.

When considering tertiary moments in the upper chord, we are dealing with the P- $\Delta$ moments resulting from the axial load acting 
through the change of curvature of the chord. The moment resulting from the original eccentricity of the chord has been accounted for in the primary moment analysis (see Chapter IV).

Tertiary moment in the upper chord would only be considered critical if the curvature increased under load, thus amplifying the origina1 eccentricity. As was made clear in Chapter VI, however, the upper chord, due to secondary moment (i.e., support settlement type moments caused by the downward joint deflections) is subject to positive moment (compression on top) along its entire length. Therefore the curvature will be decreased slightly which will result in the tertiary moments tending to decrease the total moment. This slight advantage should conservatively be neglected in the author's opinion.

In light of the above discussion, tertiary moments were not studied any further. 


\section{CHAPTER IX}

\section{DEVELOPMENT OF A SYSTEMATIC APPROACH TO THE DESIGN OF STANDARD STRUCTURES}

\subsection{INTRODUCTION}

To this point our approach has been to start with a mass of data and proceed to develop a series of characteristic equations from that data by which to design a structure. The complexity and tediousness of the ensuing equations with their multitude of variables and coefficients cry for a systematic approach which can be applied to a structure in a productive way.

This chapter will attempt to develop such a method. In developing and implementing such a method, three questions must be considered.

1. What degree of accuracy is required or desired?

2. What analytic tools are available to the analyst/designer?

3. Is the problem being considered a single use design case or is it a standard structural configuration being developed?

A general method will be outlined here which can be applied to a range of situations for structures of varying types. From that point, a specific approach will be developed for the design of timber trusses, with emphasis being placed on the design of continuous glu-lam chords of bowstring trusses.

\subsection{GENERAL CHARACTERISTIC EQUATION CONCEPT}

The design of a statically indeterminate structure using a 
computer for analysis normally proceeds in an iterative method. A structural configuration is developed for which initial trial sections are chosen for the members. The structure is then modeled and the required input data entered into the computer.

At this point an analysis is made of the trial design using a standard analysis program. The computed forces and moments are used to check the chosen members for adequacy or oversizing. This may be done by hand, or by the computer if a more extensive design program is available. New sizes are then selected and the process repeated until a satisfactory design is obtained.

This basic iterative technique is certainly valid and indeed desirable when good engineering judgment is incorporated into the process. No proposal is made here to change the iterative process.

The most serious drawback to the iterative process is the expense and time requirement for running many analysis iterations, particularly for standard structures such as trusses. The use of inhouse terminals and an interactive program such as GTSTRUDL ${ }^{(6)}$ or the availability of an inhouse computer with interactive capabilities goes a long way to reduce the extensive time periods associated with overnight batch processing. The cost of working interactively is expensive, however.

This is of particular concern when dealing with "standard" structures because the client, such as a truss manufacturer, may need the design "that afternoon" to prepare a bid. Even with single use problems, the number of iterations is often kept smal1 in order to save cost and time. A "that is good enough" design is used rather than trying a few more refinements or alternatives in an effort to optimize the 
structure.

The attempt then, will be to reduce the number of analyses required. A specific set of analysis runs will be made, from which "characteristic equations" of the structure can be developed. Sufficient runs must be made in order to provide the data required for developing the equations. Thus, the use of the large computer is not eliminated. For a single use project, the development of the characteristic equations may not be justified, since nearly as many iterations may be required in many cases. For the standard structure, or for a structure in which many iterations are desired for optimization, the use of the characteristic equations can be of significant usefulness.

A proposed procedure would be to use a large computer, such as through a service bureau, to analyze a specific set of "designs" to provide a data base. The section properties need not represent any actual member sizes and therefore eliminate the need for an "initial" design. The data base can then be transfered to a small microcomputer, or even a programmable calculator, for the development of the characteristic equations.

An iterative technique can then be performed using the "characteristic equations" to develop the design or designs. Note that structural dimensions can be included as a parameter in the development of the equations. This would be quite useful for "standard structures", such as trusses, in which span and loading intensity may vary over a wide range.

One must begin then, by selecting the parameters that are to be varied. This will be a judgment decision based on many factors which 
will be tempered by the answers to the three questions asked earlier. In addition, the type of structure will have a marked influence on the decision. For example, a low rise moment frame with no bracing will be only marginally affected by axial deformations. Therefore, one may wish to vary the I values only and not refine the equations to account for varying the areas. In multistory frame, one may choose to have all beams of the same section for fabrication economy. Therefore, the beam I's do not need to be varied individually, but as a whole. Similar reasoning is usually applied to the design of columns in buildings. One would most likely consider changing section at every two floors for example.

In truss designs, both area and moment of inertia have a significant impact on the induced moments. Therefore, both $A$ and I should be varied. However, the chord dimensions would most likely remain constant throughout the truss, so once again only a few parameters must be varied.

The desired degree of accuracy will also affect the decision. For example, if a particular parameter is expected to only affect the results by $4 \%$ or $5 \%$, it may not be worth the effort to include that parameter in the equations.

The availability and cost of the computer will also have an impact on the number of parameters to be varied and the number of points to be used to develop the equations. In general, the more parameters to be varied, the more computer runs necessary.

It should be noted that the "characteristic equations" need not be "exact" equations, and in many cases would not be. Their function 
is to provide numbers which can be used as a guide in designing the structure. Once developed, the equations should be back checked to test their reliability. For a single use problem, this would entail making a final frame analysis computer run using the proposed final design as a check on the design. For a standard structure, a typical design or even arbitrary properties could be used in a few runs to check the results.

Once the parameters to be studied are chosen, the input for the computer runs must be logically selected to provide a usable data base. The following procedure is proposed.

1. Select a "base" value for each parameter.

2. One run should be made with all "base" values.

3. All runs should utilize the "base" parameters except for the particular parameter being varied.

Three points are required to establish a curve which will reasonably represent the structure. The "base" run will provide one of these points for each parameter. For many parameters, one of the points can be determined inductively from an understanding of structural behavior. Specifically, often one can determine if the function will approach zero or infinity as the value of the parameter goes to zero. If this is the case, then two of the three points are established and only one additional run need be made. If the limit is not zero or infinity, an additional run must be made in order to describe the curve.

\subsection{PARAMETERS TO BE VARIED}

The possible parameters to be varied can be more than just the area or moment of inertia of a member. The span or other dimensions, 
modulus of elasticity, Poisson's ratio, temperature effects, web stiffness (which would allow for the inclusion of joint slippage), and nearly any other quantity that is part of the model input data might be varied. For each parameter selected to be varied, two computer runs will be required. Thus, the importance of a parameter should be considered carefully before selecting it as a variable.

It was shown in Chapter $\mathrm{V}$ that it is possible to correlate the effect of the number of webs in the truss ( 8 pane1, 10 pane1, 12 panel, etc). Thus, to an extent, even the structural configuration itself can be varied.

\subsection{DEVELOPMENT OF A GENERAL CHARACTERISTIC EQUATION}

In general, it has been found that an equation of the form

$$
y=\frac{k}{x+g}+c
$$

can be used to describe the variation of a variable $(y)$, such as the moment at a specific point, with respect to the variation of a specific parameter $(x)$.

In Equation 9.1 ,

$$
\begin{aligned}
& \mathrm{y}=\text { variable being considered } \\
& \mathrm{x}=\text { the parameter being varied (such as the area of } \\
& \text { the top chord, for example) } \\
& \mathrm{k}, \mathrm{g} \text { and C are constants which define the curve for } \\
& \text { the specific parameter. }
\end{aligned}
$$

Since there are three unknown constants involved, three data points (or "boundary conditions") are required to determine them, as discussed previously.

Three data points, to be obtained from the computer runs, may be 
defined as follows:

$$
\begin{aligned}
& x_{1}=\text { lower limit of the parameter } \\
& x_{2}=\text { base value of the parameter } \\
& x_{3}=\text { upper } 1 \text { imit of the parameter }
\end{aligned}
$$

$y_{1} y_{2} \& y_{3}=\begin{aligned} & \text { the value of the variable obtained from the } \\ & \text { computer run associated with } x_{1}, x_{2} \text { and } x_{3}\end{aligned}$ cases.

Thus, Equation 9.1 may be written as

$$
\begin{aligned}
& y_{1}=\frac{k}{x_{1}+g}+c \\
& y_{2}=\frac{k}{x_{2}+g}+c \\
& y_{3}=\frac{k}{x_{3}+g}+c
\end{aligned}
$$

Combining Equations 9.2 and 9.3,

therefore,

$$
y_{2}-y_{3}=\frac{k}{x_{2}+g}-\frac{k}{x_{3}+g}
$$

$$
k=\left[\frac{y_{2}-y_{3}}{\frac{1}{\left(x_{2}+g\right)}-\frac{1}{\left(x_{3}+g\right)}}\right]
$$

or,

$$
k=\left(\frac{y_{2}-y_{3}}{x_{3}-x_{2}}\right)\left(x_{2}+g\right)\left(x_{3}+g\right)
$$

Similarly, combining Equations 9.3 and 9.4,

$$
k=\left(\frac{y_{1}-y_{2}}{x_{2}-x_{1}}\right)\left(x_{1}+g\right)\left(x_{2}+g\right)
$$

Combining Equations 9.5 and 9.6 ,

$$
\frac{\left(y_{2}-y_{3}\right)}{\left(x_{3}-x_{2}\right)}\left(x_{2}+g\right)\left(x_{3}+g\right)=\frac{\left(y_{1}-y_{2}\right)}{\left(x_{2}-x_{1}\right)}\left(x_{1}+g\right)\left(x_{2}+g\right)
$$




$$
\text { or, } \begin{array}{r}
\left(\frac{x_{2}-x_{1}}{x_{3}-x_{2}}\right)\left(\frac{y_{2}-y_{3}}{y_{1}-y_{2}}\right)=\left(\frac{x_{1}+g}{x_{3}+g}\right) \\
\text { Let } B=\left(\frac{x_{2}-x_{1}}{x_{3}-x_{2}}\right)\left(\frac{y_{2}-y_{3}}{y_{1}-y_{2}}\right)
\end{array}
$$

then

$$
\begin{aligned}
& \qquad \begin{array}{l}
\left(x_{3}+g\right) B=x_{1}+g \\
x_{3} B-x_{1}=g-B g
\end{array} \\
& g=\frac{x_{3} B-x_{1}}{1-B} \\
& \text { or } g=\frac{x_{3}-x_{1} / B}{1 / B-1} \\
& C \text { can be written as }
\end{aligned}
$$

$$
c=y_{2}-\frac{k}{\left(x_{2}+g\right)}
$$

In general

$$
y_{2}=f\left(x_{i}\right)
$$
where all $x \neq x_{i}$ are constants taken as their respective "base"
values.

This equation can be normalized by dividing $y^{B}$ (the value of $y$ for the case where all $\mathrm{x}=$ base values). Thus, a coefficient

$$
\mathrm{K}_{i}=\frac{\mathrm{y}_{i}}{\mathrm{y}^{\mathrm{B}}}=\frac{\mathrm{f}\left(\mathrm{x}_{i}\right)}{\mathrm{y}^{\mathrm{B}}}
$$

is obtained.

A separate coefficient is obtained for each parameter, $x_{1}$. We can now write

$$
\mathrm{Y}_{j}=\mathrm{y}^{\mathrm{B}} \prod_{i=1}^{\mathrm{n}}\left(\mathrm{k}_{i}\right)
$$


where $\prod_{i=1}^{n}$ represents the cumulative product of $k_{1}$ through $k_{n}$. An equation such as 9.13 will be obtained for each variable, $y$. Thus, by denoting $y$ as subscripted $y_{j}$, and defining the "base" value of $y_{j}$ as $Y_{j}^{B}$, we obtain

$$
Y_{j}=\left(Y_{j}^{B}\right) \prod_{i=1}^{n} K_{i j}
$$

Using Equation 9.1 for $f(x)$, we obtain

$$
\left.\begin{array}{rl}
Y_{j}=\left(Y_{j}^{B}\right) \prod_{i=1}^{n}\left\{\frac{\frac{k_{i j}}{x_{i}+g_{i j}}+c_{i j}}{Y_{j}^{B}}\right. & Y_{j}=\left(Y _ { j } ^ { B } \{ 1 - n ) \prod _ { i = 1 } ^ { n } \left(\frac{k_{i j}}{x_{i}+g_{i j}}+C_{i j}\right.\right.
\end{array}\right\}
$$

It must be noted at this point that Equation 9.15 is not an exact equation. It assumes that all of the data curves are of the form of Equation 9.1 which in some cases will be inaccurate. In most cases, the error is believed to be small for values of $x$ between $x_{1}$ and $x_{3}$. The error may become appreciable, however, if the curves are extrapolated beyond the limits of $x_{1}$ and $x_{3}$. It is therefore important to choose $x_{1}$ and $x_{3}$ as expected minimum and maximum values for the parameter.

If more than one loading pattern is to be analyzed, a set of equations for $\mathrm{Y}_{j}$ will be obtained, with one equation for each loading pattern. The further subscript $l$ will be added to $y, Y, k, g$, and $C$, with $\&$ going from 1 to $p$, therefore

$$
Y_{j \ell}=\left(Y_{j \ell}^{B} \prod_{i=1}^{1-n}\right)\left(\frac{k_{i j l}}{x_{i}+g_{i j l}}+C_{i j l}\right)
$$


9.4.1 Summary

The implementation of the method is summarized below.

I. DATA BASE PREPARATION

1. Select the structural configuration.

2. Select all parameters $\left(x_{i}\right)$ to be varied (e.g. area of top chord of a truss).

3. Select "base" values for each parameter $\left(x_{i 2}\right)$. The base values should preferably be a medium value from the expected range of possible values for the parameter.

4. Select minimum and maximum expected values for each parameter $\left(x_{i 1}\right.$ and $x_{i 3}$ respectively).

5. Using base values for all parameters, analyze the structure for each loading case utilizing a standard frame analysis computer program.

6. Two additional computer runs will be required for each parameter for each loading case as follows: For each loading case:

For $i=1$ to $n$

a. All "base" values except change $x_{i}$ to $x_{i 1}$. b. A11 "base" values except change $x_{i}$ to $x_{i 3^{\circ}}$.

II. DEVELOPMENT OF CHARACTERISTIC EQUATIONS

1. Study the results from the frame analysis made in part I. Determine the location of the critical points in the structure which will or potentially can govern the design of the members and/or 
connections, such as the point of maximum moment.

2. With the information above, select the "variables" $\left(y_{i j l}\right)$ to be studied. These might be the moment at the critical location, axial loads, shear, reactions, deflections or other results which are of concern to the designer. Results which are not affected by varying any of the parameters need not be included at this point.

3. Obtain the values of the variables from the output files of the frame analysis made in part I, $\left(y_{i j l}^{B}, y_{i j 1 l}\right.$, and $\left.y_{i j 3 l}\right)$.

4. Compute the constants of Eq. 9.16 for each variable (j) for each parameter ( $i$ ) for each load case (l). The constants are $k_{i j \ell}$ (from Eq. 9.5), $g_{i j \ell}$ (from Eq. 9.9) and $C_{i j l}$ (from Eq. 9.10).

5. Save the values of the constants for use in the design process.

III. VERIFICATION OF EQUATIONS AND THE DESIGN PROCEDURE A. VERIFICATION OF EQUATIONS

1. Once the constants for Eq. 9.16 are computed, Eq. 9.16 can be used to compute the values of the variables (i.e., maximum moment, etc.) for any combination of parameter values (e.g., A, I, etc.) the designer selects for the specific design.

2. If design data for a standard structure is 
being developed, such as for a specific truss type, the characteristic equations should be checked by running a complete frame analysis for a few typical designs until the designer is confident that the equations predict the values of variables within acceptable precision. Once the equations are verified, step III.B. 1 can be used repeatedly by simply entering the values of the parameters into Eq. 9.16 for each variable and checking the design in the usual iterative process.

3. If the problem is a one time solution situation, the final design obtained from step III.B. 1 can be checked by a complete frame analysis using the final design values of the parameters.

B. DESIGN PROCEDURE

1. The traditional iterative design process is used, except Eq. 9.16 is used in place of running a complete frame analysis for each iteration. Trial values of each parameter are selected and the values of the variables (i.e., moment in bottom chord, etc.) are computed using Eq. 9.16. The adequacy of the members as well as other considerations such as deflections are checked and adjustments made to 
the trial sizes. This procedure is repeated until a satisfactory design is obtained.

\subsection{COMPUTER IMPLEMENTATION OF THE PROCEDURE}

This procedure can be easily programmed into a microcomputer to make the process nearly completely automatic. The procedure is highly interactive, quick and inexpensive, which allows the designer to try several combinations of parameter values in developing the design.

To demonstrate and test the procedure, a program was written for use on a microcomputer. The program is written in the MicrosoftBasic language and is 1isted in Appendix 4. The program actually consists of three programs, corresponding to the three sections of the summary. The first program enters the parameter and variable names and the base and extreme values of the parameters, corresponding to steps I.2,3 and 4. The program then sets up combinations of parameters to use in the frame analysis, according to steps I.5 and I.6 of the summary. At this point, the structure would be modeled for the frame analysis and the runs would be batch processed (steps I.5 and 6). Once the data is obtained from the series of frame analyses, a second program develops the characteristic equations and automatically saves the constants on disc files.

This data is then available for use by program number three which uses the characteristic equations (i.e., Eq. 9.16) to compute the value of each variable $\left(M_{B C}, M_{T C}\right.$, etc.) for the set of parameter values specified by the designer during the interactive process of using program three. This corresponds to step III.B.1 of the summary. Program 
three is the only one needed during the design process.

\subsection{EXAMPLE PROBLEM}

The three truss configurations studied in the previous chapters (i.e., the 8, 10 and 12 panel trusses shown in Figure 2.1) will be used to examplify the procedure and to verify that the procedure produces acceptable results.

\subsubsection{Data Base Preparation}

Step 1. The truss configuration of Figure 2.1 will be used. This will be considered as a single configuration with the number of panels to be taken as one of the "parameters". The geometry for the trusses is shown in Figures 2.3 through 2.5 .

Step 2. The parameters to be varied are the area and moment of inertia of the top and bottom chords and the number of panel points, as listed in Table 9.1.

Steps 3 and 4. The base values for each parameter as we11 as the minimum and maximum expected values are listed in Table 9.1.

TABLE 9.1

PARAMETER DATA FOR EXAMPLE PROBLEM

\begin{tabular}{|c|l|r|r|r|}
\hline Parameter & \multicolumn{1}{|c|}{ Name } & $\mathrm{x}_{\mathrm{i} 1}$ & $\begin{array}{r}\text { Base Value } \\
\left(\mathrm{x}_{\mathrm{i} 2}\right)\end{array}$ & $\mathrm{x}_{\mathrm{i3}}$ \\
\hline $\mathrm{x}_{1}$ & $\mathrm{~A}_{\mathrm{BC}}\left(\mathrm{in}^{2}\right)$ & 50 & 75 & 125 \\
$\mathrm{x}_{2}$ & $\mathrm{I}_{\mathrm{BC}}\left(\mathrm{in}^{4}\right)$ & 250 & 1800 & 3600 \\
$\mathrm{x}_{3}$ & $\mathrm{~A}_{\mathrm{TC}}\left(\mathrm{in}^{2}\right)$ & 50 & 75 & 125 \\
$\mathrm{x}_{4}$ & $\mathrm{I}_{\mathrm{TC}}\left(\mathrm{in}^{4}\right)$ & 250 & 1800 & 3600 \\
$\mathrm{x}_{5}$ & NP (no. of pane1s) & 10 & 8 & 12 \\
\hline
\end{tabular}


Step 5. At this point a computer frame analysis would be run using "base" values for all parameters. For this example, data already obtained in previous work will be utilized. Since the values of the parameters used in this earlier work (i.e., Chapters V and VI) were not selected using the structured format that this procedure utilizes, appropriate values will be computed using the characteristic equations developed in Chapters V and VI.

Step 6. Two additional computer runs would be made for each parameter. In our case, having five parameters, ten additional runs are required. Each run will utilize "base" values for all parameters except for the specific parameter being studied which will be changed to $x_{i l}$ or $x_{i 3}$. As mentioned in step five, however, previously acquired data will be used in this example.

Program number one (see Appendix A4) is designed primarily to interactively enter the parameter data (Table 9.1) into the computer for use by the second and third programs. In addition, it produces an organized list of required combinations of computer runs to be made in steps I.5 and I.6.

The second program is now used to compute the constants $(k, g$ and C) for the characteristic equations.

\subsubsection{Development of the Characteristic Equations}

Step 1. The output from the frame analysis computer runs are now studied in order to determine the critical points in the structure. As was found in previous chapters, the critical point for designing the top and bottom chords occurs at the first panel point in from the end 
of the truss.

Step 2. We will therefore select the moment at the top chord at the critical location $\left(M_{T C}=Y_{2}\right)$ and the critical moment in the bottom chord $\left(M_{B C}=Y_{1}\right)$ as our variables. The axial load has only minor variation and therefore will not be considered a variable in this example.

Step 3. The values of the variables (i.e., $\mathrm{M}_{\mathrm{BC}}$ and $\mathrm{M}_{\mathrm{TC}}$ ) are now extracted from the frame analysis output 1istings. In our case, as mentioned before, the data is obtained from the characteristic equations of Chapters V and VI. This data is 1isted in Table 9.2. It should be noted that this data is not truly accurate since it is obtained from the approximate characteristic equations. For this reason,

TABLE 9.2

OUTPUT DATA FOR THE CHOSEN VARIABLES

(OBTAINED FROM COMPUTER FRAME ANALYSIS)

\begin{tabular}{|l|c|c|}
\hline Case & $\mathrm{Y}_{1}=\mathrm{M}_{\mathrm{BC}}(\mathrm{Ft}-\mathrm{K})$ & $\mathrm{Y}_{2}=\mathrm{M}_{\mathrm{TC}}(\mathrm{Ft}-\mathrm{K})$ \\
\hline Base* & 9.13 & 9.78 \\
$\mathrm{~A}_{\mathrm{BC} 1}{ }^{*}$ & 10.64 & 11.00 \\
$\mathrm{~A}_{\mathrm{BC} 3}$ & 7.58 & 8.50 \\
$\mathrm{I}_{\mathrm{BC} 1}$ & 1.35 & 10.42 \\
$\mathrm{I}_{\mathrm{BC} 3}$ & 17.60 & 8.83 \\
$\mathrm{~A}_{\mathrm{TC} 1}$ & 11.94 & 12.80 \\
$\mathrm{~A}_{\mathrm{TC} 3}$ & 6.57 & 7.20 \\
$\mathrm{I}_{\mathrm{TC} 1}$ & 9.41 & 1.65 \\
$\mathrm{I}_{\mathrm{TC} 3}$ & 8.68 & 18.20 \\
$\mathrm{NP}_{1}$ & 10.63 & 10.34 \\
$\mathrm{NP}_{3}$ & 12.08 & 12.15 \\
\hline
\end{tabular}

*Computer run using all parameter "base values. equal to $A_{B C 1}(=50$ in in this case). 
this example problem will produce less accurate results than would otherwise be obtained. The equations of Chapters V and VI are accurate enough, however, that the results should be reasonable.

Step 4. Compute the constants $k_{i j}$ (Eq. 9.5), $g_{i j}$ (Eq. 9.9) and $\mathrm{C}_{i j}(\mathrm{Eq} \cdot 9.10)$.

$$
\text { Effects of } A_{B C}(i=1) \text { on } M_{B C}(j=1) \text { for Load Case } 1(=1) \text {. }
$$

From Table 9.1,

$$
x_{1}=50, x_{2}=75, x_{3}=125
$$

from Table 9.2 ,

$$
\mathrm{y}_{1}=10.64, \mathrm{y}_{2}=9.13, \mathrm{y}_{3}=7.58
$$

using Eq. 9.9,

$$
g_{111}=\frac{x_{3}-x_{1 / B}}{1 / B-1}
$$

where

$$
\begin{gathered}
B_{111}=\left(\frac{x_{2}-x_{1}}{x_{3}-x_{2}}\right)\left(\frac{y_{2}-y_{3}}{y_{1}-y_{2}}\right)=\left(\frac{75-50}{125-75}\right)\left(\frac{9.13-7.58}{10.64-9.13}\right) \\
=0.513245
\end{gathered}
$$

therefore

$$
g_{111}=\left(\frac{125-50 / .513245}{1 / .513245-1}\right)=29.0816
$$

using Eq. 9.5

$$
\begin{aligned}
& k_{111}=\left(\frac{y_{1}-y_{2}}{x_{2}-x_{1}}\right)\left(x_{1}+g_{111}\right)\left(x_{2}+g_{111}\right) \\
= & \left(\frac{10.64-9.13}{75-50}\right)(50+29.0816)(75+29.0816)
\end{aligned}
$$

therefore

$$
k_{111}=497.149
$$


Using Eq. 9.10

$$
\begin{gathered}
c_{111}=y_{2}-\frac{k_{111}}{\left(x_{2}+g_{111}\right)} \\
=9.13-\left(\frac{497.149}{75+29.0816}\right)=4.35347
\end{gathered}
$$

The constants for all other combinations of $i, j$ and $l$ are computed in the same fashion. This is done automatically by the second computer program (see Appendix A4). The computed values of $k_{i j l}, g_{i j l}$ and $\mathrm{C}_{i j \ell}$ for this example are listed in Table 9.3.

Step 5. The constants computed in the previous step are saved for use in the design process using Eq. 9.16.

\subsubsection{III.A. Verification of Equations}

At this point, in a typical situation, a few frame analyses would be run using an actual loading and typical member sizes. Actually, these runs could be made at the same time as the other cases were run. The characteristic equations (Eq. 9.16) are used to compute the values of each variable using the same parameter values of the test case. If satisfied that the computed values are within acceptable accuracy, the equations can now be used to design structures.

In our example, all of the computer runs used in Chapters $\mathrm{V}$ and VI will be used to test the results of the equations. The computed values are listed along with the actual (as computed by the frame analysis program) values in Table 9.4.

Program three computes $\mathrm{M}_{\mathrm{BC}}$ and $\mathrm{M}_{\mathrm{TC}}$ using Eq. 9.16. $\mathrm{M}_{\mathrm{BC}}$ for case "00TC11" (See 3.2.6 for explanation of the case designation.) will be calculated by hand to demonstrate the procedure. A11 other cases are 
TABLE 9.3

CONSTANTS FOR THE "GENERAL CHARACTERISTIC

EQUATIONS" FOR THE BOWSTRING

TRUSS EXAMPLE PROBLEM

\begin{tabular}{|c|c|c|}
\hline Input Data & Cor & nstants \\
\hline 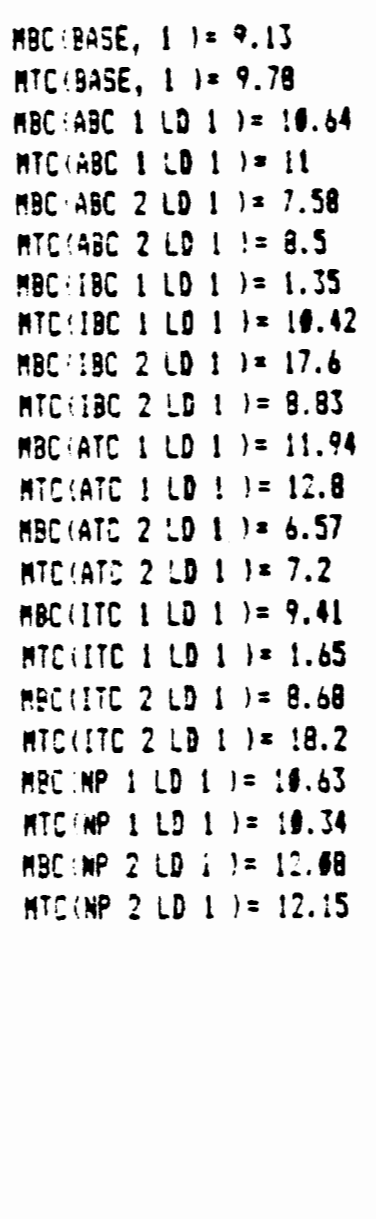 & 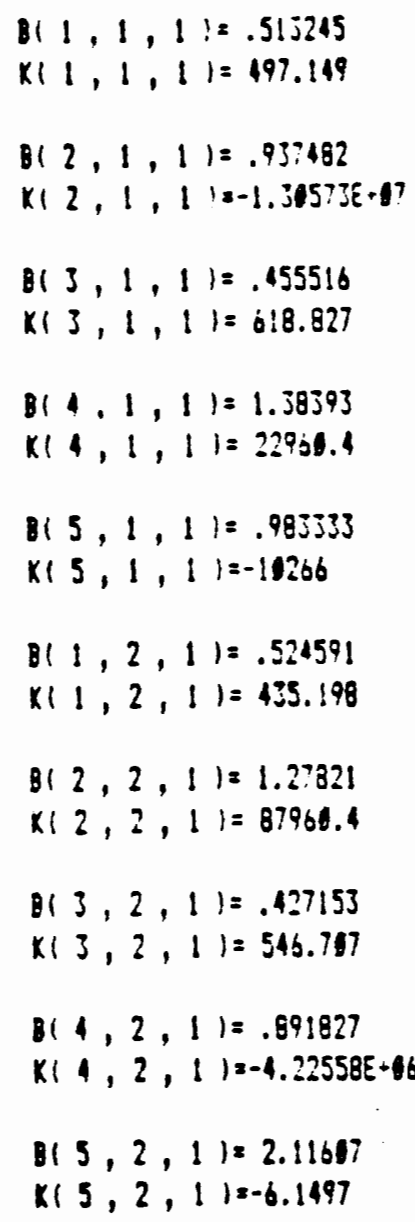 & 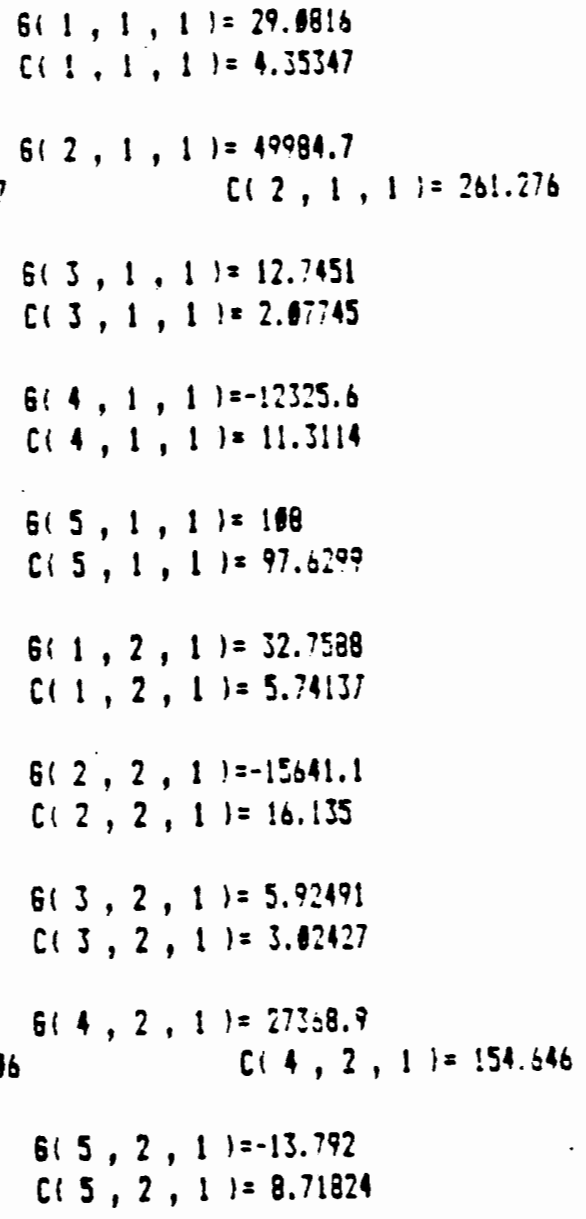 \\
\hline
\end{tabular}


computed using program three.

$$
\begin{gathered}
\text { Case 00TC11 } \quad A_{B C}\left(X_{1}\right)=50 i n^{2} \quad I_{B C}\left(X_{2}\right)=250 i n^{4} \\
N P\left(X_{5}\right)=8 \quad A_{T C}\left(X_{3}\right)=75 i n^{2} \quad I_{T C}\left(X_{4}\right)=800 i n^{4} \\
\text { Load case 1 }(l=1) \quad M_{B C}(j=1) \quad n=5 \\
Y_{j l}=\left(y_{j l}^{B}\right)(1-n) \prod_{i=1}^{n}\left(\frac{k_{i j l}}{x_{i}+g_{i j l}}+C_{i j l}\right) \\
y_{j l}^{B}=y_{11}^{B}=9.13 \quad(\text { see Table 9.2) }
\end{gathered}
$$

See Table 9.3 for values of $k, g$ and $C$.

Thus

$$
\begin{aligned}
M_{B C}\left(Y_{11}\right) & =9.13^{(1-5)}\left(\frac{497.149}{50+29.0816}+4.35347\right) \\
\times & \left(\frac{-1.30573(E+07)}{250+49984.7}+261.276\right) \\
\times & \left(\frac{618.827}{75.0+12.7451}+2.07745\right) \\
& \times\left(\frac{22,960.4}{800-12,325.6}+11.3114\right) \\
& \times\left(\frac{-10,266.0}{8+108.0}+97.6299\right) \\
=9.13^{(-4)}(10.64)(1.350)(9.13)(9.319)(9.13) & \Rightarrow M_{B C}=1.606 \mathrm{Ft}-\mathrm{K}
\end{aligned}
$$

This compares quite we 11 with the 1.57 value computed by the frame analysis program.

As shown in Table 9.4, the results compare favorably. Seventy percent of the cases are within $3 \%$ and nearly $90 \%$ of the cases are within $5 \%$. It should be kept in mind that the data used to develop the equations was approximated to begin with using the equations de- 
veloped in Chapters V and VI. The original data did not bound the range of parameter values in all cases. Thus, some of the data was based on extrapolation. It would be expected then that the use of original, accurate data to develop the characteristic equations would produce very reliable results. The results should be more than accurate enough in light of the discussions in Chapter VIII.

TABLE 9.4

GENERAL CHARECTERISTIC EQUATION VERIFICATION DATA

\begin{tabular}{|l|r|r|r|r|r|l|}
\hline 8 Pane1 & M $_{\text {BC }}^{*}$ & $\begin{array}{r}\text { Actua1 } \\
M_{\text {BC }}\end{array}$ & Ratio & M TC $^{*}$ & $\begin{array}{c}\text { Actual } \\
M_{\text {TC }}\end{array}$ & Ratio \\
\hline 00TC11 & 1.606 & 1.57 & 1.02 & 5.557 & 5.81 & 0.96 \\
20TC11 & 1.239 & 1.23 & 1.01 & 4.557 & 4.64 & 0.98 \\
30TC11 & 1.144 & 1.16 & 0.99 & 4.294 & 4.40 & 0.98 \\
01TC11 & 4.955 & 4.97 & 1.00 & 5.444 & 5.65 & 0.96 \\
02TC11 & 10.860 & 10.94 & 0.99 & 5.216 & 5.38 & 0.97 \\
03TC11 & 20.937 & 21.07 & 0.99 & 4.709 & 4.93 & 0.96 \\
33TC11 & 14.916 & 15.67 & 0.95 & 3.639 & 3.77 & 0.97 \\
11TC11 & 4.252 & 4.26 & 1.00 & 4.840 & 4.90 & 0.99 \\
12TC00 & 12.306 & 12.88 & 0.96 & 2.160 & 2.10 & 1.03 \\
12TC01 & 12.188 & 12.46 & 0.98 & 6.069 & 6.02 & 1.01 \\
12TC02 & 11.940 & 12.12 & 0.99 & 12.800 & 12.80 & 1.00 \\
12TC12 & 9.130 & 9.13 & 1.00 & 9.780 & 9.78 & 1.00 \\
12TC23 & 7.193 & 7.36 & 0.98 & 15.233 & 15.40 & 0.99 \\
\hline 10 Pane1 & & & & & & \\
00TC11 & 1.865 & 1.93 & 0.97 & 5.876 & 6.16 & 0.95 \\
10TC11 & 1.600 & 1.65 & 0.97 & 5.224 & 5.25 & 1.00 \\
20TC11 & 1.438 & 1.51 & 0.95 & 4.817 & 4.79 & 1.01 \\
30TC11 & 1.328 & 1.42 & 0.94 & 4.540 & 4.51 & 1.01 \\
01TC11 & 5.753 & 6.01 & 0.96 & 5.756 & 5.91 & 0.97 \\
02TC11 & 12.645 & 12.91 & 0.98 & 5.514 & 5.51 & 1.00 \\
03TC11 & 24.308 & 23.98 & 1.01 & 4.979 & 4.89 & 1.02 \\
33TC11 & 17.317 & 17.79 & 0.97 & 3.847 & 3.61 & 1.07 \\
12TC02 & 13.901 & 14.20 & 0.98 & 13.533 & 13.82 & 0.98 \\
12TC12 & 10.630 & 10.63 & 1.00 & 10.340 & 10.34 & 1.00 \\
12TC20 & 9.079 & 9.39 & 0.97 & 1.460 & 1.13 & 1.29 \\
12TC21 & 8.992 & 9.13 & 0.98 & 4.104 & 3.89 & 1.06 \\
12TC22 & 8.809 & 8.80 & 1.00 & 8.654 & 8.56 & 1.01 \\
12TC23 & 8.375 & 8.30 & 1.01 & 16.106 & 16.06 & 1.00 \\
\hline
\end{tabular}


TABLE 9.4 continued

\begin{tabular}{|l|r|r|l|l|r|l|}
\hline 12 Pane1 & \multicolumn{1}{|c|}{$\mathrm{M}_{\mathrm{BC}}$} & $\begin{array}{c}\text { Actual } \\
\mathrm{M}_{\mathrm{BC}}\end{array}$ & Ratio & $\mathrm{M}_{\mathrm{TC}}$ & $\begin{array}{c}\text { Actual } \\
\text { M }\end{array}$ & Ratio \\
\hline 00TC12 & 2.082 & 2.13 & 0.98 & 14.56 & 15.47 & 0.94 \\
30TC12 & 1.483 & 1.61 & 0.92 & 11.251 & 11.67 & 0.96 \\
03TC12 & 27.139 & 25.43 & 1.07 & 12.338 & 12.70 & 0.97 \\
12TC12 & 12.080 & 12.08 & 1.00 & 12.150 & 12.15 & 1.00 \\
31TC12 & 4.575 & 4.96 & 0.92 & 11.022 & 11.27 & 0.98 \\
32TC12 & 10.029 & 10.54 & 0.95 & 10.560 & 10.63 & 0.99 \\
33TC12 & 19.334 & 19.25 & 1.00 & 9.534 & 10.08 & 0.95 \\
12TC00 & 16.282 & 17.68 & 0.92 & 2.683 & 2.61 & 1.03 \\
12TC03 & 15.019 & 14.68 & 1.02 & 29.592 & 28.46 & 1.04 \\
12TC11 & 12.330 & 12.74 & 0.97 & 5.761 & 5.90 & 0.98 \\
12TC12 & 12.080 & 12.08 & 1.00 & 12.150 & 12.15 & 1.00 \\
12TC30 & 8.959 & 9.55 & 0.90 & 1.509 & 1.63 & 0.93 \\
12TC31 & 8.873 & 9.22 & 0.96 & 4.241 & 4.40 & 0.96 \\
12TC32 & 8.693 & 8.78 & 0.99 & 8.945 & 8.97 & 1.00 \\
12TC33 & 8.264 & 8.14 & 1.02 & 16.646 & 16.07 & 1.04 \\
\hline
\end{tabular}

* As computed from Eq. 9.16 using the computer program of Appendix 4.

† From frame analysis.

* Frame analysis computer run designation (see section 3.2.6 for description).

\subsubsection{III.B. Design Procedure}

The equations are now ready to be used to aid in the design of a structure. The traditional iterative procedure is used, using the characteristic equations to compute the values of the variables rather than running full frame analyses.

For our example, a $100 \mathrm{ft.,} 8$ panel truss with the configuration shown in Figure 2.3 will be designed to carry $930 \mathrm{lb} / \mathrm{ft}$. on the top chord using AITC-117-79 ${ }^{(5)}$ and the 1982 NDS specifications.

Use 5-1/8 in. wide, combination number 3 glu-lam for the chords. 
Top Chord: From Figures 4.4 and 4.5,

$$
P_{\max }=96.79\left(\frac{100 \mathrm{ft}}{100 \mathrm{ft}}\right)\left(\frac{9301 \mathrm{~b} / \mathrm{ft}}{10001 \mathrm{~b} / \mathrm{ft}}\right)=90.0 \mathrm{~K}
$$

and

$$
\mathrm{M}_{\mathrm{TC}} \text { (primary) }=2.21\left(\frac{930}{1000}\right)=2.06 \mathrm{Ft}-\mathrm{K} \text { (at first joint from the end) }
$$

Bottom Chord: The tension in the bottom chord can be obtained from a stress diagram or from the computer frame analysis runs. For our example, $\mathrm{T}=84.4 \mathrm{~K}$ at the first joint.

Initial trial,

$$
\begin{aligned}
& 5-1 / 8 \times 12 \text { bottom chord } \\
& 5-1 / 8 \times 10-1 / 2 \text { top chord }
\end{aligned}
$$

Program three is executed. The following parameter values are entered when requested:

$$
\begin{aligned}
& A_{B C}=61.5 \text { in }^{2} \quad I_{B C}=738 \text { in }^{4} \\
& A_{\mathrm{TC}}=53.8 \mathrm{in}^{2} \quad \mathrm{I}_{\mathrm{TC}}=494.4 \mathrm{in}^{4} \quad \mathrm{NP}=8
\end{aligned}
$$

The following results are obtained from the program:

$$
\begin{aligned}
M_{B C} & =4.94 \mathrm{Ft}-\mathrm{K} \\
M_{\mathrm{TC}} & =3.84+2.06=5.90 \mathrm{Ft}-\mathrm{K}
\end{aligned}
$$

Allowable stresses for combination number 3 (from AITC 117-79, Table 2):

$$
\begin{array}{ll}
E=1.8\left(10^{6}\right) \text { psi } & F t=1450 \text { psi } \quad F c=2300 \text { psi } \\
F b_{X X}=2000 \text { psi } & 15 \% \text { increase for snow load }
\end{array}
$$

The members will be checked against the "unity" equations of the NDS, ${ }^{(7)}$ section 3.10 , for combined flexural and axial loading. 
Top Chord:

NDS Ref Section

$$
\begin{aligned}
& (x-x \text { axis }) l_{e} / d=(13.1 \mathrm{ft})(12 \mathrm{in} / \mathrm{ft}) /(10.5 \mathrm{in}) \\
& =14.97>11 \\
& K_{\left(x-x_{\text {axis }}\right)}=0.671 \sqrt{\frac{E}{F c}}=0.671 \sqrt{\frac{1800}{(2.3)(1.15)}} \\
& =17.50
\end{aligned}
$$

$11<\ell / d<17.5$, therefore

use intermediate column equation

$$
\begin{gathered}
F_{(x-x)}^{\prime}=F c\left[1-1 / 3\left(\frac{\ell_{e} / d}{k}\right)^{4}\right] \\
=2.3(1.15)\left[1-1 / 3\left(\frac{14.97}{17.50}\right) 4\right] \\
=2.173 \mathrm{Ksi} \\
J_{x}=\frac{\ell / d-11}{K-11} \\
=\frac{14.97-11}{17.50-11} \\
=0.611
\end{gathered}
$$

$3.7 .3 .1(b)$

$3.7 .3 .1(b)$

3.10 .2 .1

$3.3 \cdot 3 \cdot 4$

$$
\begin{aligned}
c_{s} & =\sqrt{\frac{\left(l_{e}\right) d}{b^{2}}} \\
l_{e}=1.92 l_{u} & =1.92(2.0 \mathrm{ft})(12 \mathrm{in} / \mathrm{ft}) \\
& =46.1 \mathrm{in}
\end{aligned}
$$

Determine allowable bending stress:

therefore,

$$
C_{S}=\sqrt{\frac{46.1(10.5)}{(5.125)^{2}}}=4.292<10
$$

therefore,

$$
F b^{\prime}=F b_{x x}=2.0(1.15)=2.30 \mathrm{Ksi}
$$




$$
C_{F}=\left(\frac{12}{d}\right)^{1 / 9} \leq 1
$$

therefore,

$$
\begin{gathered}
C_{F}=1.0 \\
f c=90.0 \mathrm{~K} / 53.8 \mathrm{in}^{2}=1.673 \mathrm{Ksi} \\
\mathrm{fb}=(5.90 \mathrm{ft}-\mathrm{K})(12 \mathrm{in} / \mathrm{ft}) /\left(94.17 \mathrm{in}^{3}\right)=0.752 \mathrm{Ksi} \\
\text { Unity equation }(\mathrm{x}-\mathrm{x} \text { axis }) \\
\frac{\mathrm{fc}}{\mathrm{Fc}}+\frac{\mathrm{fb}}{\mathrm{Fb}-\mathrm{J}_{\mathrm{x}} \mathrm{fc}} \leq 1 \\
\frac{1.673}{2.173}+\frac{0.752}{(2.30-(0.611)(1.673))} \\
=0.770+0.589=1.36 \gg 1.0 \text { No Good }
\end{gathered}
$$

3.10 .2 .1

Although this member is not adequate, we will also check the unity equation considering buckling about the $y-y$ axis in order to demonstrate the method used in subsequent calculations which are computed using a documented programmable calculator program. (8)

$\ell_{(y-y)} / d=(2.0 \mathrm{ft})(12 \mathrm{in} / \mathrm{ft}) / 5.125 \mathrm{in}=4.68<11$ therefore,

$$
\mathrm{FC}_{\mathrm{yy}}^{\prime}=\mathrm{Fc}=2.30(1.15)=2.65 \mathrm{Ksi}
$$

therefore, the unity equation becomes:

$$
\begin{aligned}
& \frac{f a}{F c_{y y}}+\frac{f b}{F b} \leq 1 \\
& =\frac{1.673}{2.65}+\frac{0.752}{2.3}
\end{aligned}
$$




$$
=0.63+0.33=0.960 \mathrm{k}
$$

For the second iteration, try a $5-1 / 8 \times 13-1 / 2$ $\mathrm{BC}$ and a 5-1/8 $\times 12 \mathrm{TC}$.

The following parameters are now used in the characteristic equations (we will use the computer program) :

$$
\begin{array}{ll}
A_{B C}=69.2 \mathrm{in}^{2} & I_{B C}=1050.8 \mathrm{in}^{4} \\
A_{T C}=61.5 \mathrm{in}^{2} & I_{T C}=738 \mathrm{in}^{4} \quad \mathrm{NP}=8
\end{array}
$$

The following results are obtained:

$$
\begin{gathered}
M_{B C}=6.07 \mathrm{Ft}-\mathrm{K} \\
M_{T C}=4.82+2.06=6.88 \mathrm{Ft}-\mathrm{K}
\end{gathered}
$$

The calculator program yields the following results for the top chord:

$(x-x$ axis $): 0.62($ axial $)+0.37$ (bending) $=0.99<1.0$

$(y-y$ axis $): 0.55+0.29=0.85<1.0$ ok

Now check the bottom chord.

Assume a connector at the joint to consist of a 3/4 in. diameter bolt with two 4 in. shear plates. Ac (= Projected Area of the connector) $=8.29 \mathrm{in}^{2}$ therefore,

$$
\begin{gathered}
\text { Net Area }=69.2-8.29=60.9 \mathrm{in}^{2} \\
\mathrm{ft}=\frac{84.4 \mathrm{~K}}{60.9 \mathrm{in}^{2}}=1.386 \mathrm{Ksi}
\end{gathered}
$$




$$
\mathrm{fb}=\frac{(6.88 \mathrm{Ft}-\mathrm{K})(12 \mathrm{in} / \mathrm{ft})}{155.7 \mathrm{in}^{3}}=0.530 \mathrm{Ksi}
$$

Since $\mathrm{ft}$ is much larger than $\mathrm{fb}$, only the bottom face of the member will be checked. The top face will not be subjected to bending compression buckling, which can occur if the bending stress dominates.

Thus, the unity equation becomes:

$$
\begin{aligned}
& \frac{\text { ft (net) }}{\mathrm{Ft}}+\frac{\mathrm{fb}}{\mathrm{Fb}} \leq 1 \\
= & \frac{1.386}{1.45(1.15)}+\frac{0.530}{2.0(1.15)} \\
= & 0.83+0.23=1.06>1.0
\end{aligned}
$$

3.10 .1

The next trial will use a 5-1/8 $\times 12 \mathrm{TC}$ and a $5-1 / 8 \times 15 \mathrm{BC}$.

$$
\begin{array}{ll}
A_{B C}=76.88 \mathrm{in}^{2} & I_{B C}=1441.4 \mathrm{in}^{4} \\
A_{T C}=61.50 \mathrm{in}^{2} & I_{T C}=738.0 \mathrm{in}^{4} \quad \mathrm{NP}=8
\end{array}
$$

The computer program yields the following results:

$$
\begin{gathered}
M_{B C}=7.916 \mathrm{Ft}-\mathrm{K} \\
M_{T C}=4.60+2.06=6.06 \mathrm{Ft}-\mathrm{K}
\end{gathered}
$$

Using the calculator program,

Bottom chord: $0.74+0.21=0.96<1.0$ Ok

Top chord: $0.62+0.32=0.94<1.0$ Ok 
Therefore, a 5-1/8 $\times 12 \mathrm{TC}$ and a 5-1/8 $\times 15 \mathrm{BC}$ would provide an adequate structure. Referring to Chapter VIII, however, it was suggested that a $30 \%$ reduction in bending moments caused by secondary effects would be reasonable due to bolt slippage in the web connection. If the designer chooses to take this into account, the second trial, using a $5-1 / 8 \times 13-1 / 2$ BC and a 5-1/8 $\times 12$ TC could be considered an acceptable design. The unity equation for the bottom chord would become:

$$
0.83+(.7)(0.23)=0.99<1.0 \quad 0 \mathrm{k}
$$

Additional trials using other member sizing such as a 6-3/4 in. wide truss could easily be tried in a matter of minutes. Changing the number of panels could be done just as easily.

The method as presented in this chapter used an equation for $f(x)$ having the form of Equation 9.1 to describe the variation of $y$ with respect to $x$. The method would be equally valid for most any other form of equation. Equation 9.1 works well for most applications. It should be noted however, that this equation becomes undefined if the relationship is a linear function. For this reason, the computer program in Appendix 4 has included a check for linearity and provides a Inear equation for $f(x)$ in that instance. Other equation types could be Included just as easily if the user desires.

The design program as it stands now is in a primitive state, providing only the minimum data. This program could easily be combined into a larger program which would provide automatic code check for the type of member involved, thus making the design procedure even simpler. 


\section{CHAPTER $X$}

\section{OBSERVATIONS}

Several observations can be made from the information in the previous chapters. The most important item to note is that the "secondary" moments in both the top and bottom chords can be substantial. These moments have been assumed small in the past and have traditionally been neglected. The following example compares the "traditional" design neglecting secondary moments with a design which includes these moments.

This example is for the same conditions used in the example presented in the previous chapter, except a 10 panel truss configuration will be used instead of the 8 panel used before.

\subsection{EXAMPLE PROBLEM}

\section{Given:}

$100 \mathrm{ft}$. span truss, $R=\mathrm{L}$ (see Figure 2.4)

$\mathrm{w}=930 \mathrm{lb} / \mathrm{ft}$. on top chord

No bottom chord load

Use 5-1/8 in. wide, combination number $3 \mathrm{glu}-1$ am chords

$15 \%$ stress increases a11owed for snow load.

a.) Design the top and bottom chords for the given truss. Use a 10 panel configuration and neglect secondary moments. Consider balanced load condition only. 
b.) Design the chords again, except this time include secondary moments. Check the degree of overstress in solution "a.)".

c.) Compare the 10 panel design to the 8 panel truss designed in Chapter IX.

\section{Solution:}

The compression and tension forces in the top and bottom chords are obtained from a conventional "pin-jointed" truss analysis. For our case, these are found to be

$$
\begin{gathered}
\mathrm{C}=92.3 \mathrm{~K} \text { (at end pane } 1 \text { ) } \\
\mathrm{T}=87.5 \mathrm{~K} \text { (max at center of truss) }
\end{gathered}
$$

Top Chord:

As mentioned in Chapter IV, the AITC manual simply approximates the primary moment in the top chord by assuming a continuous beam with (in the case of a 10 panel truss) 5 equal spans equal to the horizontal projection of the end panel. For a 5 span beam with uniform load on all spans, the moment at the first support can be found from standard beam tables to be

$$
M_{\text {beam }}=-.1053 w^{2}
$$

which is $84.24 \%$ of the simple beam moment. Using this formula,

$$
M_{\text {beam }}=-.1053(.93)(9.77)^{2}=-9.35 \mathrm{Ft}-\mathrm{K}
$$

The AITC manual recommends assuming that the ' $\mathrm{Pe}$ ' moments (moment resulting from the axial force acting on the curved member) be distributed in the same manner as the beam moments. 
From Figure 2.4,

$$
\begin{gathered}
e=0.00137 \mathrm{R} \\
=0.00137(100)=0.137 \mathrm{ft} .
\end{gathered}
$$

therefore,

$$
(\mathrm{P} \times \mathrm{e})_{(\mathrm{simple})}=92.3(.137)=12.65 \mathrm{Ft}-\mathrm{K}
$$

Taking the same percentage of the simple moment as used for the beam moment (i.e., 84.24\%) we obtain

$$
(\mathrm{P} \times)_{(\text {dist })}=.8424(12.65)=10.66 \mathrm{Ft}-\mathrm{K}
$$

The final moment is, therefore

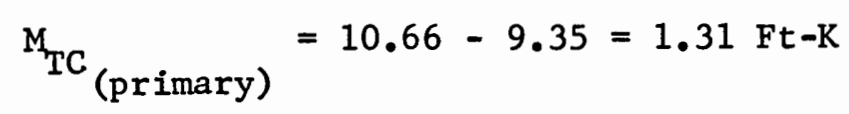

\section{Trial Design:}

Try a 5-1/8 in. $x 9$ in. top chord.

Using the calculator program to solve the unity equation for combined stress as was done in Chapter IX, we obtain (using $l_{e}=10.1^{\prime}$ ) $\mathrm{x}-\mathrm{x}$ axis: $0.86+0.15=1.00 \mathrm{Ok}$

Bottom Chord:

The maximum tension occurs at the center panel of the bottom chord. Assume the bottom chord splice will consist of 1 in. diameter bolts, with a maximum two bolts at one section (see Figure 2.9). Thus the connectors will reduce the area of the chord by

$$
(1.0625 \text { in. })(5.125 \text { in. })(2 \text { bolts })=10.89 \text { in }^{2}
$$

Therefore, the gross area of the chord required will be

$$
\frac{\mathrm{P}}{\mathrm{Ft}}+10.89 \mathrm{in}^{2}
$$




$$
=\frac{87.5 \mathrm{~K}}{1.45(1.15)}+10.89=63.36 \mathrm{in}^{2}
$$

A $5-1 / 8 \times 13-1 / 2\left(A=69.2\right.$ in $\left.^{2}\right)$ would be selected. Therefore,

use

$$
5-1 / 8 \times 9 \text { Top Chord (at 100\%) }
$$

$$
5-1 / 8 \times 13-1 / 2 \text { Bottom Chord (at } 90 \% \text { ) }
$$

Using the procedure developed and demonstrated in Chapter IX, the truss chords will be redesigned including the secondary moments.

First, check the design produced in part a:

$$
\begin{array}{lll}
5-1 / 8 \times 9 \mathrm{TC} & \mathrm{A}_{\mathrm{TC}}=46.13 \mathrm{in}^{2} & \mathrm{I}_{\mathrm{TC}}=311.3 \mathrm{in}^{4} \\
5-1 / 8 \times 13-1 / 2 \mathrm{BC} & \mathrm{A}_{\mathrm{BC}}=69.19 \mathrm{in}^{2} & I_{\mathrm{BC}}=1050.8 \mathrm{in}^{4}
\end{array}
$$

As shown in Chapter VI, when considering secondary moments, the critical location for combined stresses occurs at the first web joint from the end. At this point, the axial tension is found to be $85.0 \mathrm{~K}$ for our case.

Entering the parameter data into the computer program (Program III, Design), we obtain

$$
\begin{gathered}
\mathrm{M}_{\mathrm{BC}}=8.60 \mathrm{Ft}-\mathrm{K} \\
\mathrm{M}_{\mathrm{TC}}=2.86 \mathrm{Ft}-\mathrm{K}
\end{gathered}
$$

From Figure 4.7 , the primary moment equals

$$
1.71(.93)=1.59 \mathrm{Ft}-\mathrm{K}
$$

thus

$$
\mathrm{M}_{\mathrm{TC}}=2.86+1.59=4.45 \mathrm{Ft}-\mathrm{K}
$$

Using the calculator program, the unity equation becomes:

Top Chord: $x-x$ axis : $0.86+0.50=1.36>>1.0$ 
Bottom Chord: (Use Area of connector - 8.29 in. at the first panel point - 1-3/4 in. diameter bolt with 2 4-in diameter shear plates)

$$
0.84+0.29=1.13>1.0
$$

Note that under the previous design, the bottom chord was only stressed to $90 \%$ of capacity. Had it been stressed to $100 \%$, it would actually be $26 \%$ overstressed when considering secondary moments. As can be seen, a truss designed neglecting the secondary moments can be significantly overstressed ( $36 \%$ in this case). Even if bolt slippage is accounted for, the top chord could be $20 \%$ overstressed.

Try a 5-1/8 $\times 10-1 / 2$ top chord and a 5-1/8 $\times 15$ bottom chord. The computer program yields

$$
\begin{gathered}
M_{B C}=10.09 \mathrm{Ft}-\mathrm{K} \\
M_{T C}=3.70+1.59=5.29 \mathrm{Ft}-\mathrm{K}
\end{gathered}
$$

check TC:

$$
\mathrm{x}-\mathrm{x} \quad 0.70+0.33=1.03 \text { Say } \mathrm{Ok}^{*}
$$

check BC:

$$
0.74+0.27=1.02 \text { Say } \mathrm{Ok}^{*}
$$

*The small overstress is considered acceptable since we have neglected the effect of joint slip in the web/chord connection.

\section{Summary:}

Use $5-1 / 8 \times 10-1 / 2 \mathrm{TC}$ and $5-1 / 8 \times 15 \mathrm{BC}$.

The final design of the 8 panel truss done in the example of Chapter IX consisted of a 5-1/8 × 12 TC and 5-1/8 × 13-1/2 BC when joint slippage was considered. As can be seen, the 8 panel and 10 
panel use essentially the same amount of chord material. The 8 pane1 truss reduces the bottom chord size by one lamination and increases the top chord by one lamination as opposed to the 10 panel design.

The 8 panel truss is preferred over the 10 panel for at least three reasons, however. First, the two chords are better balanced (i.e., nearly the same size). Second, the 8 panel truss will be more economical due to the reduced cost in the webs. And third, the larger top chord will provide increased stability during erection.

\subsection{DESIGN OPTIMIZATION}

It should also be noted from Figures 5.3 and 6.3 , that the bending stress in the chords increases as the depth increases. This would suggest that the use of wide, shallow members will result in greater economy than narrow deep members. In terms of chord material, this is true, however wider web members and longer bolts will be required which may cancel any savings. In addition, the $\mathrm{L} / \mathrm{d}$ ratio of the top chord will influence the top chord depth. Shallower chords will reduce the size of web strap plates required, thus improving economy. As a result, no general statement can be made as to the optimum width. This will vary with the specific situation with time and with the individual fabricator.

The more striking impact on economy is the effect of varying the number of panels in the truss. Increasing the number of panels results in greatly increasing the secondary moments (see Figures 5.10 and 6.5). The primary moment in the top chord decreases as the number of panels is increased. The secondary moments, however, are generally much more 
significant. The economy of decreasing the number of panels is significant. Not only are the sizes of the chords possibly reduced, but the savings in material and labor in the web members and connections is substantial.

Informal studies by this author suggest that the 8 panel truss may be the optimum configuration in terms of fabrication cost for trusses ranging from $60 \mathrm{ft}$. to $150 \mathrm{ft}$. The exception might be 1ightly loaded trusses, which may be more economical with 10 panels since the buckling length of the top chord may become a controlling factor. There is also concern, however, that 8 panel trusses greater than 120 ft. may be difficult to "tilt" up from flat on the ground to an upright position during construction.

\subsection{THE EFFECT OF THE SECONDARY MOMENTS ON THE WEBS}

The last item to be discussed briefly is the influence of the secondary moments in the chords on the two webs at the end of the trusses. A traditional "pin-jointed" analysis results in very small forces in these webs. The secondary moments in the chords increase the forces substantially, however. Figure 5.7 shows how these moments force loads into these members. The forces in these members would be recommended "variables" to be included in the systematic design procedure discussed in Chapter IX. 


\section{CHAPTER XI}

\section{SUMMARY, CONCLUSIONS AND RECOMMENDATIONS}

\subsection{SUMMARY}

This study has focused on three major factors influencing the design of bowstring trusses with continuous glue-laminated timber chords. These are:

1) the primary moments in the top chord, resulting from the applied member loads and the axial force acting at the ends of a curved member. Chapter IV presented a rational technique using the moment distribution method. An equation was derived for computing the FEM's resulting from the axial forces.

2) The major effort was spent on developing a relationship between the member properties (area and moment of inertia) and the secondary moments induced into the top and bottom chords as the truss deflects under loads. These moments, which in the past have normally been assumed negligible, are found to be quite significant. Trusses designed neglecting these moments may actually be as much as $50 \%$ overstressed. In reality, due to bolt slippage in the web connections, the overstress probably does not exceed 30\%. However, this is still of great concern.

Charts and tables have been proposed in Chapters V and VI for use in determining these moments for the specific type of trusses con- 
sidered in this report.

3) In order to provide a useful, less tedious method for developing such design charts for other parameters or other structural configurations, a method for easily generating characteristic equations for a structure was developed. This method is easily adapted to a sma11 microcomputer which makes the procedure very easy to use. A primitive program has been provided in Appendix 4 for this purpose. Other factors which affect these moments and other elements of the truss were briefly discussed, such as joint slippage, eccentricity in the heel to column connection and tertiary $(\mathrm{P}-\Delta)$ moments.

\subsection{CONCLUSIONS}

This study makes it clear that special attention should be given to the "secondary" moments which can be present in bowstring trusses. Other truss types may have the same concern, although in most other types of trusses the problem will only involve the bottom chord. In most truss types the secondary moment will "help" the top chord since they act opposite to the primary moment. As was shown, this is not true in the bowstring.

Fortunately, in bowstring trusses, any bolt slippage that may occur in the web connections will relieve at least a part of the moments, which may account for the fact that few if any failures have resulted from this situation.

The "Genera1 Characteristic Equation" method would appear to be very useful to the designer for designing standard structures. This method allows secondary stresses and other internal force redistribu- 
tion resulting from static indeterminancy of the structure to be included in the analysis without having to model and analyze every condition with a frame or finite element analysis program. Once the initial data is developed and entered into the program, the design/analysis process becomes very simple using this method.

\subsection{RECOMMENDATIONS}

Further work would be helpful to determine to what extent the bolt slippage of the web connections can be relied upon to reduce the secondary moments. Additional computer modeling, possibly using the "generalized characteristic equations" approach, together with some physical testing would be useful.

Additional work should be done on the "general characteristic equation" method to determine its reliability and usefulness to a variety of structures. The method has the potential for being useful for structures of most any configuration and of any material. It is not limited to timber trusses. The possibility of extending the program to allow automatic data transfer from the analysis files to the program files would be very helpful, if possible. 


\section{APPENDIX 1 \\ DERIVATION AND JUSTIFICATION OF THE FIXED \\ END MOMENT EQUATIONS USED TO \\ COMPUTE THE PRIMARY MOMENTS \\ IN THE TOP CHORD}

\section{A1.1 DERIVATION OF FEM(Pe)}

The fixed end moments at the ends of a curved top chord segment resulting from the axial load acting on the curved member was given in Chapter IV as

$$
\mathrm{FEM}_{A}=\mathrm{P}_{A^{R}} \mathrm{R}\left(\frac{\tan \theta}{\theta}-1\right)
$$

The following assumptions were made:

1. Both ends are fixed against rotation;

2. Both ends are restrained from translation in the radial direction;

3. The upper end is free to translate tangentially;

4. Axial deformations are neglected; and

5. Shear deformations are neglected.

Equation 4.1 can be derived by referring to Figure A1.1. Taking moments about point ' $O$ ', we obtain

$$
\sum M_{0}=0=F E M_{A}+F E M_{B}+P_{A} R-P_{B} R
$$

From Figure Al.2, taking moments about point ' $i$ ',

$$
\sum M_{i}=0=F E M_{A}+M_{i}+P_{A} R(1-\cos \emptyset)+V_{A} R \sin \emptyset
$$




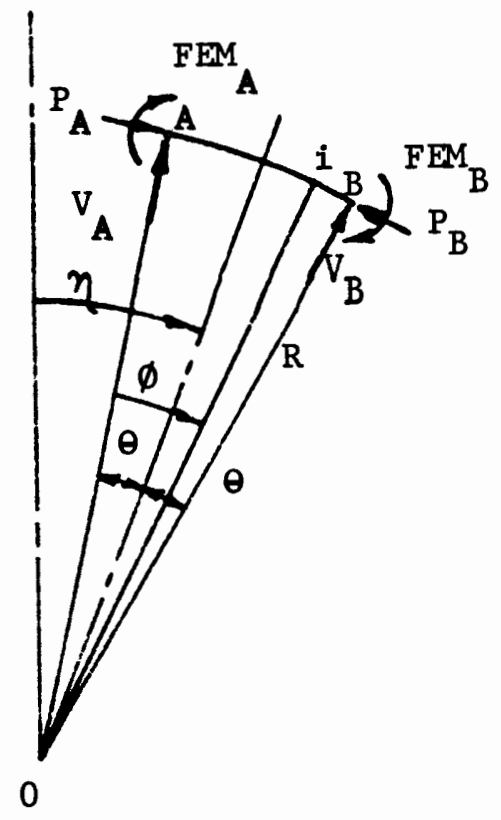

Figure A1.1 Fixed end forces in a top chord panel.

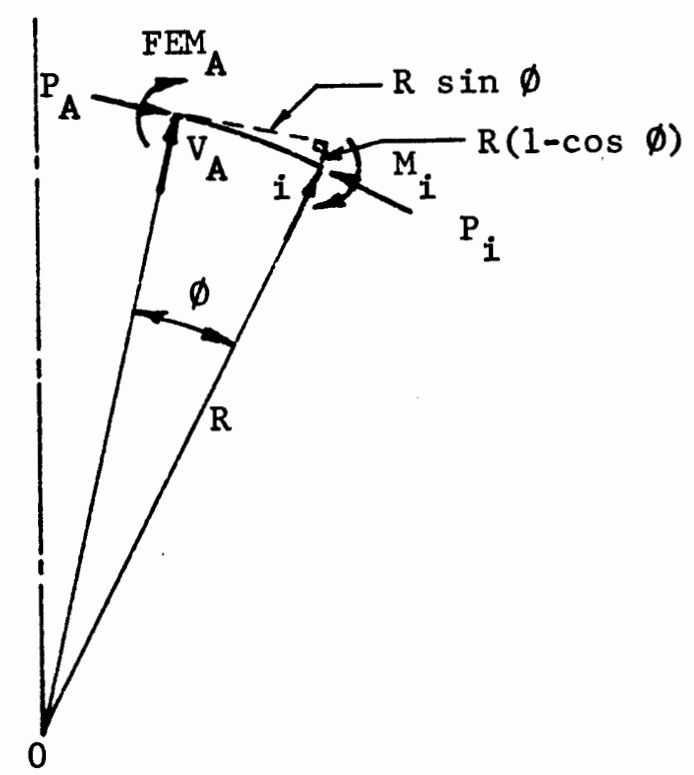

Figure Al.2 Freebody forces on a top chord segment under fixed end conditions. 
Rearranging, we obtain

$$
M_{i}=-F E M_{A}-P_{A} R(1-\cos \emptyset)-V_{A} R \sin \emptyset
$$

Summing moments about point ' $B$ ' on Figure $A 1.1$,

$$
\sum \mathrm{M}_{B}=0=\mathrm{FEM}_{A}+\mathrm{FEM}_{B}+\mathrm{P}_{A} \mathrm{R}(1-\cos 2 \theta)+\mathrm{V}_{A} \mathrm{R} \sin 2 \theta
$$

or

$$
\mathrm{V}_{\mathrm{A}}=-\left[\frac{\mathrm{FEM}_{A}+\mathrm{FEM}_{\mathrm{B}}}{\mathrm{R} \sin 2 \theta}+\frac{\mathrm{P}_{\mathrm{A}}(1-\cos 2 \theta)}{\sin 2 \theta}\right]
$$

Substituting Equation A1.4 into Equation A1.3, we obtain

$M_{i}=-F E M_{A}-P_{A} R(1-\cos \emptyset)+\left[\frac{F_{A}+F E M_{B}}{\sin 2 \theta}\right](\sin \emptyset)+\frac{P_{A}(1-\cos 2 \theta)}{\sin 2 \theta(A 1.5)} \sin \emptyset$

In order for the change in slope of the member at point ' $A$ ' to be equal to zero (fixed),

$$
\int_{0}^{2 \theta} \frac{M}{E I} d \emptyset=0
$$

For a constant EI,

$$
\int_{0}^{2 \theta} M_{i} d \emptyset=0
$$

Inserting Equation A1.5 into Equation A1.6, we have

$$
0=-\mathrm{FEM}_{A} \int_{0}^{2 \theta} \mathrm{d} \emptyset+\frac{\mathrm{FEM}_{A}}{\sin 2 \theta} \int_{0}^{2 \theta} \sin \emptyset \mathrm{d} \emptyset+\frac{\mathrm{FEM}_{B}}{\sin 2 \theta} \int_{0}^{2 \theta} \sin \emptyset \mathrm{d} \emptyset
$$

$-P_{A} R \int_{0}^{2 \theta} d \phi+P_{A} R \int_{0}^{2 \theta} \cos \phi d \emptyset+\frac{P_{A} R}{\sin 2 \theta}(1-\cos 2 \theta) \int_{0}^{2 \theta} \sin \phi d \phi$ 
By observation of symetry, it can be seen that

$$
\mathrm{FEM}_{A}=-\mathrm{FEM}_{\mathrm{B}}
$$

Therefore,

$\left.\operatorname{FEM}_{A}(\phi)\right|_{0} ^{2 \theta}=-\left.P_{A} R(\phi)\right|_{0} ^{2 \theta}+\left.P_{A} R \sin \phi\right|_{0} ^{2 \theta}-\left.\left(\frac{P_{A} R}{\sin 2 \theta}\right)(1-\cos 2 \theta) \cos \phi\right|_{0} ^{2 \theta}$ which becomes

$$
\mathrm{FEM}_{A}=\frac{1}{2 \theta}\left[-\mathrm{P}_{A} R(2 \theta)+\mathrm{P}_{A} \mathrm{R} \sin 2 \theta-\left(\frac{\mathrm{P}_{A} R}{\sin 2 \theta}\right)(1-\cos 2 \theta)(\cos 2 \theta-1)\right]
$$

or

$$
\mathrm{FEM}_{A}=-\mathrm{P}_{A} \mathrm{R}+\mathrm{P}_{A} \mathrm{R}\left(\frac{\sin 2 \theta}{2 \theta}\right)+\mathrm{P}_{A} \mathrm{R}\left(\frac{\sin 2 \theta}{2 \theta}\right)\left(\frac{1-\cos 2 \theta}{\sin 2 \theta}\right)^{2}(\mathrm{~A} 1.8)
$$

Further reduction yields

$$
\begin{aligned}
\text { FEM }_{A} & =P_{A} R\left(-1+\frac{\sin 2 \theta}{2 \theta}+\frac{\sin 2 \theta}{2 \theta}\left(\tan ^{2} \theta\right)\right) \\
& =P_{A} R\left(\frac{\sin 2 \theta}{2 \theta}\left(\tan ^{2} \theta+1\right)-1\right) \\
& =P_{A} R\left[\left(\frac{2 \sin \theta \cos \theta}{2 \theta}\right)\left(\frac{1}{\cos ^{2} \theta}\right)-1\right]
\end{aligned}
$$

or

$$
\mathrm{FEM}_{A}=\mathrm{P}_{A} R\left(\frac{\tan \theta}{\theta}-1\right)
$$

which is the desired result.

\section{A1.2 JUSTIFICATION OF THE EXTERNAL LOAD INDUCED FEM's}

In order to handle the case of the external member loads (which may be unsymmetrical), we must satisfy the following three equations: 


$$
\begin{aligned}
& \int_{A}^{B} \frac{M y d y}{E I}=\delta_{I} \cos \theta \\
& \int_{A}^{B} \frac{M x d x}{E I}=-\delta_{I} \sin \theta \\
& \int_{0}^{2 \theta} \frac{M}{E I} d \emptyset=0
\end{aligned}
$$

The notation and tabular format used by Roark and Young in their book Formulas for Stress and Strain, fifth edition ${ }^{(9)}$ will be used to organize the complex equations involved and to allow unusual loading conditions to be considered. A few variables will be redefined as noted below in order to facilitate the special case being considered here.

The case being considered is described by reference number 13 of Table 18 in Roark and Young.

Referring to Figure A1.3, the normal force at point ' $A$ ' has been defined as $V_{A}$ and the tangential force as $P_{A}$. The angle $\zeta$, as defined by Roark and Young, will be equal to $-\theta$ in this case. Thus, the equations given in Table 18, item 13 of Roark and Young become

$$
\begin{gathered}
\delta_{I}\left(\frac{E I(c)}{R^{3}}\right)=V_{A}\left(B_{H V}(c)+B_{H H}(s)\right)+B_{H M}\left(\frac{M}{R}\right)-I F_{H} \\
\delta_{I}\left(\frac{E I(-s)}{R^{3}}\right)=V_{A}\left(B_{V V}(c)+B_{V H}(s)\right)+B_{V M}\left(\frac{M}{R}\right)-L F_{V} \\
0=V_{A}\left(B_{M V}(c)+B_{M H}(s)\right)+B_{M M}\left(\frac{A}{R}\right)-L F_{M}
\end{gathered}
$$




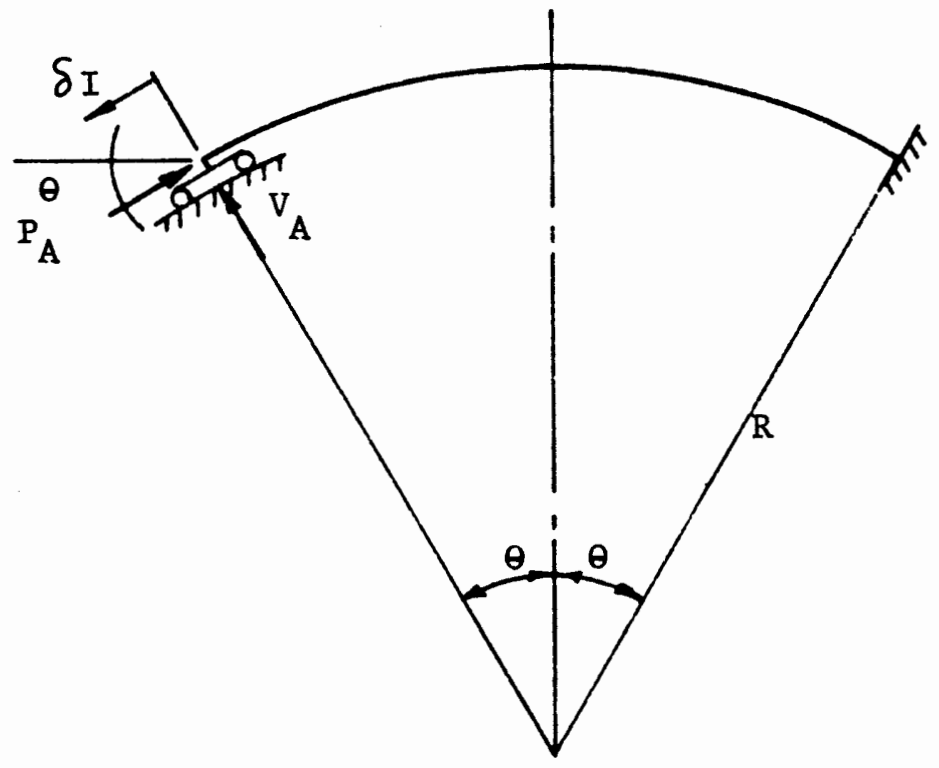

Figure Al.3 Model and nomenclature used by Roark and Young. 
where

$$
\begin{aligned}
& \mathrm{s}=\sin \theta \\
& \mathrm{c}=\cos \theta \\
& \mathrm{E}=\text { Modulus of Elasticity } \\
& \mathrm{I}=\text { Moment of Inertia } \\
& \mathrm{R}=\text { Radius of Arch } \\
& \mathrm{B}_{\mathrm{HH}}=\theta+2 \theta \mathrm{c}^{2}-3 \mathrm{sc} \\
& \mathrm{B}_{\mathrm{HV}}=\mathrm{B}_{\mathrm{VH}}=2 \mathrm{~s}^{2}-2 \theta \mathrm{sc} \\
& \mathrm{B}_{\mathrm{HM}}=\mathrm{B}_{\mathrm{MH}}=2 \mathrm{~s}-2 \theta \mathrm{c} \\
& \mathrm{B}_{\mathrm{VV}}=\theta+2 \theta \mathrm{s}^{2}-\mathrm{sc} \\
& \mathrm{B}_{\mathrm{VM}}=\mathrm{B}_{\mathrm{MV}}=2 \theta \mathrm{s} \\
& \mathrm{B}_{\mathrm{MM}}=2 \theta
\end{aligned}
$$

$L F_{H}, L F V$ and $L F M$ are load factors which are defined for specific load cases in Roark and Young, Table 18, ref. 5a through 5n. a1so let,

$$
\begin{aligned}
& \mathrm{B}_{1}=\mathrm{B}_{\mathrm{HV}}(\mathrm{c})+\mathrm{B}_{\mathrm{HH}}(\mathrm{s})=\theta s-\mathrm{s}^{2} \mathrm{c} \\
& \mathrm{B}_{2}=\mathrm{B}_{\mathrm{VV}}(\mathrm{c})+\mathrm{B}_{\mathrm{VH}}(\mathrm{s})=\theta c-s c^{2}+2 \mathrm{~s}^{3} \\
& \mathrm{~B}_{3}=\mathrm{B}_{\mathrm{MV}}(\mathrm{c})+\mathrm{B}_{\mathrm{MH}}(\mathrm{s})=2 \mathrm{~s}^{2} \\
& \mathrm{a}^{\prime}=\left(\frac{\mathrm{EI}}{\mathrm{R}^{3}}\right)(\mathrm{c}) \\
& \mathrm{b}^{\prime}=\left(\frac{\mathrm{EI}}{\mathrm{R}^{3}}\right)(\mathrm{s})
\end{aligned}
$$

We can therefore write,

1)

$$
-\delta_{I}(a)+B_{1} V_{A}+\left(\frac{B_{H M}}{R}\right) M_{A}=L F_{H}
$$

$$
\delta_{I}{ }^{\left(b^{\prime}\right)}+B_{2} V_{A}+\left(\frac{B_{V M}}{R}\right) M_{A}=L F_{V}
$$


3)

$$
0+B_{3} V_{A}+\left(\frac{B_{M M}}{R}\right) M_{A}=L F_{M}
$$

After performing Gaussian elimination on this set of equations, we obtain

$$
M_{A}=\frac{\left[\frac{\left(\frac{L F_{H}}{a}+\frac{L F V}{b}\right)}{\left(\frac{B_{1}}{a^{\prime}}+\frac{B_{2}}{b^{\prime}}\right)}-\left(\frac{L F_{M}}{B_{3}}\right)\right]}{\left[\frac{\left(\frac{B_{M M}}{R a^{\prime}}+\frac{B_{V M}}{R b^{\prime}}\right)}{\left(\frac{B_{1}}{a^{\prime}}+\frac{B_{2}}{b^{\prime}}\right)}-\left(\frac{B_{M M}}{B_{3} R}\right)\right]}
$$

which can be rewritten as,

$$
M_{A}=\left[\frac{\left(\frac{L F_{H}}{a^{\prime}}+\frac{L F V}{b^{\prime}}\right)-\left(\frac{B_{1}}{a^{\prime}}+\frac{B_{2}}{b^{\prime}}\right)\left(\frac{L F}{B_{3}}\right)}{\left(\frac{B_{H M}}{R a^{\prime}}+\frac{B_{V M}}{R b^{\prime}}\right)-\left(\frac{B_{1}}{a^{\prime}}+\frac{B_{2}}{b^{\prime}}\right)\left(\frac{B_{M M}}{B_{3} R}\right)}\right]
$$

further manipulation yields,

$$
M_{A}=R\left\{\frac{s L F_{H}+c L F_{V}-\left[s_{1}\left(B_{1} / B_{3}\right)+c\left(B_{2} / B_{3}\right)\right] L F_{M}}{{ }_{\mathrm{HM}}+c B_{V M}-\left[s\left(B_{1} / B_{3}\right)+c\left(B_{2} / B_{3}\right)\right]{ }_{M M}}\right\}
$$

Defining the denominator as $Q_{2}$, we have, after algebraic manipulation,

$$
Q_{2}=2 s^{2}-\left(\frac{\theta}{s}\right)^{2}+\theta\left(\frac{c}{s}-2 s c\right)
$$

Also, defining

$$
Q_{1}=s\left(B_{1} / B_{3}\right)+c\left(B_{2} / B_{3}\right)=\frac{1}{2}\left(\frac{\theta}{s^{2}}+c s-\frac{c^{3}}{s}\right)
$$

We thus have

$$
M_{A}=\frac{R}{Q_{2}}\left[(s) L F_{H}+(c) L F_{V}-\left(Q_{1}\right) L F_{M}\right]
$$


Similarly, we can write,

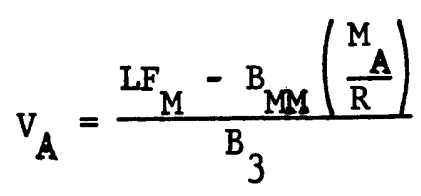

and

$$
\delta_{I}=-\frac{1}{b}\left[\left(V_{A}\right) B_{2}+B_{V M}\left(\frac{M_{A}}{R}\right)-L F_{V}\right]
$$

Letting

$$
Q_{5}=\left(\frac{c^{2}}{2 s^{2}}-1-\frac{\theta c}{2 s^{3}}\right)
$$

and

$$
Q_{6}=\left(\frac{\theta^{2} c}{s^{3}}-\frac{\theta c^{2}}{s^{2}}\right)
$$

we then obtain,

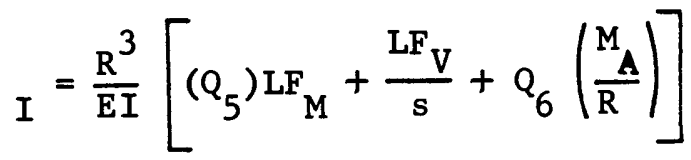

Now, knowing $M_{A}$ and $V_{A}$, and assuming $P_{A}=0$, we can obtain an equation for $M_{B}$ by summing moments about point ' $B$ '. Thus,

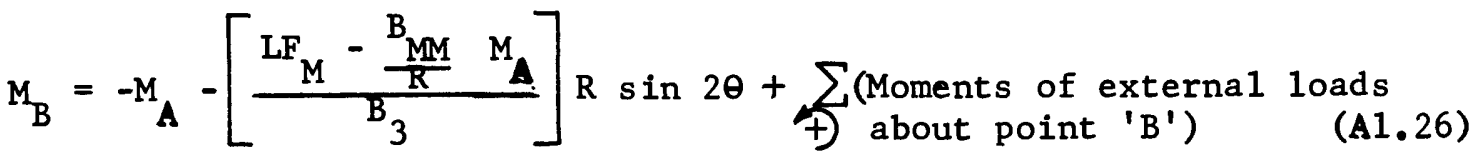

which reduces to

$$
M_{B}=M_{A}\left(\frac{\theta \sin 2 \theta}{s^{2}}-1\right)-\left(\frac{R \sin 2 \theta}{2 s^{2}}\right) L F_{M}+\sum_{7)}\left(M_{B}\right. \text { of external loads) }
$$

Let ting

$$
Q_{3}=\frac{\theta \sin 2 \theta}{s^{2}}-1=\frac{2 \theta}{\tan \theta}-1 \text { and }
$$




$$
Q_{4}=\frac{R \sin 2 \theta}{2 s^{2}}=\frac{R}{\tan \theta}
$$

we can then write,

$$
M_{B}=\left[Q_{3} M_{A}-Q_{4}\left(L F_{M}\right)+\sum_{\oplus}\left(M_{B} \text { of loads }\right)\right]
$$

Since we are dealing with elastic deformations, we add loadings by the theory of superposition.

We therefore have, in summary,

$$
\begin{gathered}
\text { FEM }_{A}=\frac{R}{Q_{2}}\left[s \sum_{i=1}^{n} L F_{H i}+c \sum_{i=1}^{n} L F_{V i}-Q_{1} \sum_{i=1}^{n} L F_{M i}\right] \\
F_{B}=Q_{3}{ }^{F E M} M_{A}-Q_{4} \sum_{i=1}^{n} L F_{M}+\sum_{\dagger} M_{B} \text { of loads } \\
\delta_{I}=\frac{R^{3}}{E I}\left[Q_{5} \sum_{i=1}^{n} L F_{M}+\frac{1}{s} \sum_{i=1}^{n} L F_{V}+Q_{6}\left(\frac{F E M}{R}\right)\right]
\end{gathered}
$$

where,

$$
\begin{aligned}
& s=\sin \theta \\
& c=\cos \theta \\
& R=\text { Radius of the Chord } \\
& Q_{1}=\frac{1}{2}\left(\frac{\theta}{s^{2}}+c s-c^{3} / s\right) \\
& Q_{2}=2 s^{2}-(\theta / s)^{2}+\theta(c / s-2 s c) \\
& Q_{3}=\frac{2 \theta}{\tan \theta}-1 \\
& Q_{4}=R / \tan \theta \\
& Q_{5}=\frac{c^{2}}{2 s^{2}}-1-\frac{\theta c}{2 s^{3}}
\end{aligned}
$$


$Q_{6}=\frac{\theta^{2} c}{s^{3}}-\frac{\theta c^{2}}{s^{2}}$

$L F_{H}, L F V$ and $L F_{M}$ are load factors obtained from Table 18, cases 5a through $5 \mathrm{n}$ of Roark and Young, Formulas for Stress and Strain,

5 th edition.

Now, consider a specific case in order to demonstrate that Equations Al.29 and A1.30 give the same answers as simply assuming the number to be a straight sloped beam, with the 'Pe' moment given from Eq. 4.1 .

\section{A1.2.1 Example Problem}

The member shown in Fig. Al.4 is subject to a uniform vertical load of 1 kip per foot.

Since Table 18 of Roark and Young does not cover the specific case loading shown, we must obtain the answers by superposition of load cases $5 \mathrm{~d}, 5 \mathrm{e}$ and $5 \mathrm{f}$.

Case $5 \mathrm{~d}$ is a concentrated tangential load applied at an angle $\emptyset$ from the center axis. In our case, $\phi=0$, therefore, the equations for. $L F_{H}, L F V$ and $L F_{M}$ as stated in Roark and Young become,

$$
\begin{gathered}
L F_{H 1}=P_{A}\left(3 c \theta-s-\frac{s c^{2}}{2}-s-\frac{c^{2} s}{2}\right) \\
L F_{H 1}=P_{A}\left(3 c \theta-2 s-s c^{2}\right)
\end{gathered}
$$

similarly,

$$
\mathrm{LF}_{\mathrm{V} 1}=\mathrm{P}_{\mathrm{A}}\left(\mathrm{c}-3 \mathrm{~s} \theta+(3 / 2) \mathrm{c}\left(\mathrm{s}^{2}-\mathrm{c}^{2}\right)+\mathrm{c} / 2\right)=\mathrm{P}_{\mathrm{A}}(3)\left(\mathrm{cs} \mathrm{s}^{2}-\mathrm{s} \theta\right)
$$

and

$$
\mathrm{LF}_{\mathrm{M} 1}=\mathrm{P}_{\mathrm{A}}(\mathrm{cs}+\mathrm{cs}-2 \theta)=2 \mathrm{P}_{\mathrm{A}}(\mathrm{cs}-\theta)
$$


The uniform load can be broken into its normal and tangential components as shown in Figure A1.5; for the normal loading, from $5 \mathrm{e}$ of Table 18, Roark and Young,

$$
\begin{aligned}
\mathrm{LF}_{\mathrm{H} 2}= & \mathrm{WR}\left[\frac{\mathrm{s}}{2}+(5 / 6) \mathrm{s}^{3}-(3 / 2) \theta c+\theta c^{3}\right] \\
\mathrm{LF} & =\mathrm{WR}\left[2 \theta s-(3 / 2) \mathrm{s}^{2} \mathrm{c}+\frac{\theta \mathrm{s}}{2}\left(\mathrm{~s}^{2}-\mathrm{c}^{2}\right)\right] \\
& \mathrm{LF} \mathrm{M}_{2}=\mathrm{WR}\left[\frac{\theta}{2}+\theta \mathrm{s}^{2}-\frac{\mathrm{sc}}{2}\right]
\end{aligned}
$$

For the tangential loading, from $5 f$ of Roark and Young, Table 18 ,

$$
\begin{gathered}
\mathrm{LF} F_{\mathrm{H} 3}=\mathrm{WR}\left[\frac{\theta}{2}-3 / 4 \theta c-\theta c^{3}+(7 / 4) s-\frac{23}{12} s^{3}-\frac{\mathrm{sc}}{2}\right] \\
\mathrm{LF}{ }_{\mathrm{V} 3}=\mathrm{WR}\left[5 / 6-(3 / 2) c^{2}-(5 / 4) c+(3 / 4) \theta s-\theta \mathrm{s}^{3}+\frac{23}{12} c^{3}\right]
\end{gathered}
$$

and

$$
L F_{M 3}=W R\left[s-(7 / 4) s c+(3 / 4) \theta-\theta s^{2}\right]
$$

Substituting the values for this specific case into Eq. A1.32 and $A 1.40$, we have

$$
\begin{array}{rlrl}
L F_{H 1} & =-1.4770\left(10^{-5}\right) & L F_{V 1}=-1.4110\left(10^{-3}\right) \\
L F_{H 2}=1.3710\left(10^{-5}\right) & L F_{V 2}=1.3090\left(10^{-3}\right) \\
L F_{H 3}=\frac{1.0220\left(10^{-7}\right)}{L F} & \sum_{V 3}=\frac{3.3180\left(10^{-6}\right)}{L F_{V}=-9.8680\left(10^{-5}\right)} \\
\sum_{L F_{H}}=-9.6780\left(10^{-7}\right) & \\
L F_{M 1}=-1.7970\left(10^{-2}\right) & \\
L F_{M 2}=1.6680\left(10^{-2}\right) & \\
L F_{M 3}=\frac{1.0880\left(10^{-4}\right)}{L L F}=-1.1810\left(10^{-3}\right) &
\end{array}
$$


Given:

$$
\begin{aligned}
\mathbf{P}_{A} & =93.95 \mathrm{~K} \\
\mathbf{W} & =1 \mathrm{k} / \mathrm{ft} . \\
\eta & =21^{\circ} \\
\theta & =3^{\circ} \\
\mathbf{R} & =100 \mathrm{ft} .
\end{aligned}
$$

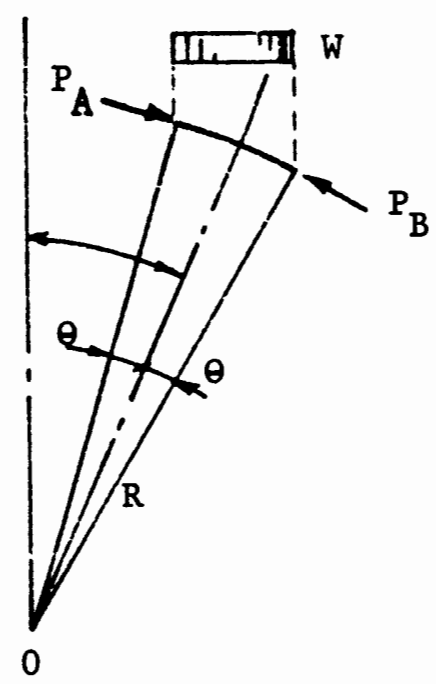

Figure A1.4 Data for Example Al.1.

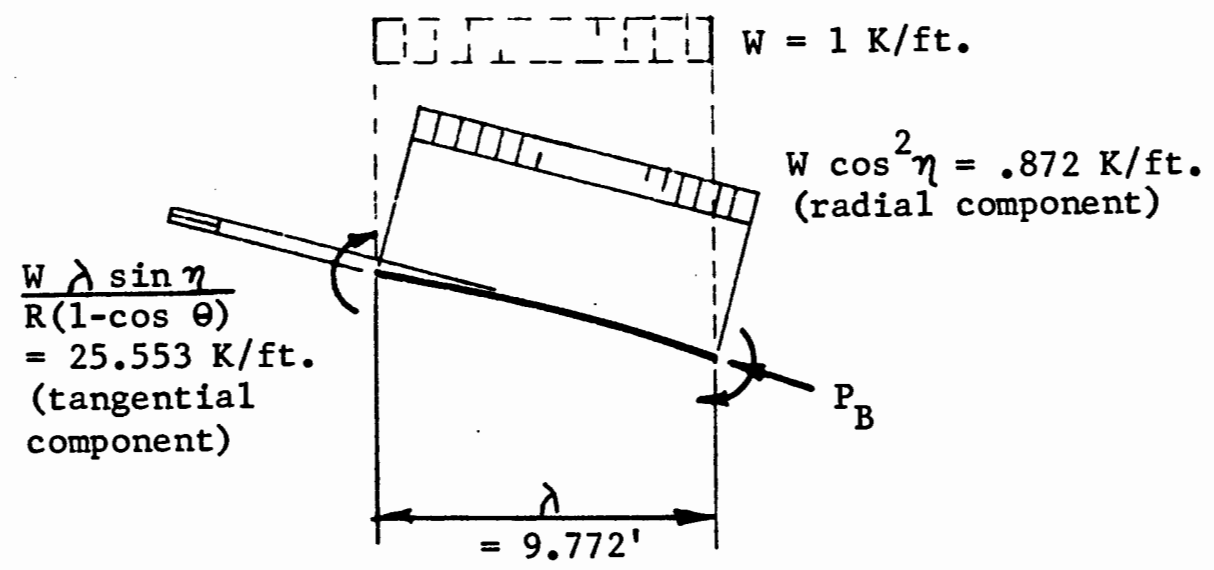

Figure A1.5 Load components for Example A1.1 
now computing the $Q$ factors,

$$
\begin{aligned}
& Q_{1}=6.9724\left(10^{-2}\right) \\
& Q_{2}=-1.8234\left(10^{-3}\right) \\
& Q_{3}=9.982\left(10^{-1}\right) \\
& Q_{4}=1.908\left(10^{3}\right) \\
& Q_{5}=-1.3322 \\
& Q_{6}=3.4887\left(10^{-2}\right)
\end{aligned}
$$

substituting these values and the values of LF into Eq. A1.29 and A1.30, we obtain the following moments:

For ' $\mathrm{Pe}$ ' only,

$$
\begin{aligned}
& \mathrm{FEM}_{A}=8.5904^{1-k} \\
& \text { FEM }_{B}=-8.5998^{1-k}
\end{aligned}
$$

For the uniform load only,

$$
\begin{aligned}
& \mathrm{FEM}_{A}=-7.692 \\
& \mathrm{FEM}_{B}=8.032
\end{aligned}
$$

Using Eq. 4.1 for the 'Pe' moment, we obtain

$$
\begin{aligned}
& \text { FEM }_{A}=8.5951^{1-k} \\
& \text { FEM }_{B}=-8.5951^{1-k}
\end{aligned}
$$

The fact that $\mathrm{FEM}_{A} \neq-\mathrm{FEM}_{\mathrm{B}}$ when computed using the Roark and Young method is attributed to round-off error resulting from the numerous cal culations required. The average value of these moments is

$$
\mathrm{FEM}_{\text {average }}=\frac{8.5904+8.5998}{2}=8.5951
$$


which is precisely the value obtained using the simplified method of Eq. 4.1. Thus Eq. 4.1 appears valid for the assumptions made.

Computing the fixed end moments for a beam using the standard

formula for straight, sloped beams gives,

$$
\mathrm{FEM}_{A}=-\mathrm{FEM}_{B}=-\frac{w \lambda^{2}}{12}=-\frac{w(9.772)^{2}}{12}=-7.958^{1-k}
$$

which is within $3 \%$ of the answer obtained using the Roark and Young formulas. Thus, we conclude that the simplified method is sufficiently accurate.

Actually, the fixed end moments for the member loads will not be precisely of equal magnitude. The tangential component of the load wi11 produce an unbalanced condition. This can be considered negligible in the geometries used in bowstring trusses as can be seen by the relative magnitude of the LF factors of case 3 versus 1 and 2. The net influence on the total unity equation for the member will be on the order of $0.1 \%$.

The curvature was found to have a small effect on the carry over factor (CO) used in the moment distribution. The $C O$ was computed to be .5061 for an eight panel truss rather than the .50 which applies to a straight beam. This is not considered to be of enough significance to be considered and will be neglected. It should also be noted that the chord is unrestrained against axial deformations and thus fixed end axial forces do not affect the moments in the chord. 
APPENDIX 2

SUMMARY OF THE

FRAME ANALYSIS COMPUTER DATA 
TABLE A2.1

DATA FOR FIGURE 5.1

\begin{tabular}{|l|rrrrr|rrrr|}
\hline Designation & $A_{\mathrm{BC}}$ & $\mathrm{I}_{\mathrm{BC}}$ & $\mathrm{A}_{\mathrm{TC}}$ & $\mathrm{I}_{\mathrm{TC}}$ & $\mathrm{NP}$ & \multicolumn{1}{|c|}{$\mathrm{M}_{1}$} & $\mathrm{M}_{2}$ & $\mathrm{M}_{3}$ & $\mathrm{M}_{4}$ \\
\hline 20TC11 & 100 & 250 & 75 & 800 & 8 & 1.23 & 0.23 & 0.0 & \\
02TC11 & 50 & 1800 & 75 & 800 & 8 & 10.94 & 2.92 & 0.0 & \\
12TC12 & 75 & 1800 & 75 & 1800 & 8 & 9.13 & 2.27 & 0.0 & \\
12TC00 & 75 & 1800 & 50 & 250 & 8 & 12.88 & 2.26 & 0.0 & \\
12TC23 & 75 & 1800 & 100 & 3600 & 8 & 7.36 & 2.23 & 0.0 & \\
33TC11 & 125 & 3600 & 75 & 800 & 8 & 15.67 & 3.37 & 0.0 & \\
& & & & & & & & & \\
20TC11 & 100 & 250 & 75 & 800 & 10 & 1.51 & 0.19 & 0.45 & 0.0 \\
02TC11 & 50 & 1800 & 75 & 800 & 10 & 12.91 & 2.93 & 4.31 & 0.0 \\
12TC12 & 75 & 1800 & 75 & 1800 & 10 & 10.63 & 2.42 & 3.40 & 0.0 \\
12TC20 & 75 & 1800 & 100 & 250 & 10 & 9.39 & 1.94 & 3.09 & 0.0 \\
12TC23 & 75 & 1800 & 100 & 3600 & 10 & 8.30 & 2.50 & 2.92 & 0.0 \\
33TC11 & 125 & 3600 & 75 & 800 & 10 & 17.79 & 4.00 & 5.30 & 0.0 \\
& & & & & & & & & \\
31TC12 & 125 & 800 & 75 & 1800 & 12 & 4.96 & 0.91 & 1.06 & 1.09 \\
03TC12 & 50 & 3600 & 75 & 1800 & 12 & 25.43 & 9.25 & 7.08 & 7.40 \\
12TC12 & 75 & 1800 & 75 & 1800 & 12 & 12.08 & 3.15 & 2.89 & 3.04 \\
12TC00 & 75 & 1800 & 50 & 250 & 12 & 17.68 & 3.00 & 3.78 & 3.73 \\
12TC32 & 75 & 1800 & 125 & 1800 & 12 & 8.78 & 2.68 & 2.30 & 2.48 \\
33TC12 & 125 & 3600 & 75 & 1800 & 12 & 19.25 & 5.71 & 4.50 & 4.74 \\
& & & & & & & & & \\
\hline
\end{tabular}


TABLE A2.2

COMPUTER FRAME ANALYSIS DATA

\begin{tabular}{|c|c|c|c|c|c|}
\hline & $A_{B C}$ & $I_{B C}$ & $\mathrm{M}_{\mathrm{BC}}$ & ${ }_{\text {Tota }}^{\mathrm{M}_{1}}$ & $\begin{array}{c}\mathrm{M}_{\mathrm{TC}}^{*} \\
\text { Secondary }\end{array}$ \\
\hline \multicolumn{6}{|l|}{8 Pane 1} \\
\hline $00 \mathrm{TC} 11$ & 50 & 250 & 1.57 & 8.02 & 5.81 \\
\hline $20 \mathrm{TC} 11$ & 100 & 250 & 1.23 & 6.85 & 4.64 \\
\hline 30TC 11 & 125 & 250 & 1.16 & 6.61 & 4.40 \\
\hline $01 \mathrm{TC} 11$ & 50 & 800 & 4.97 & 7.86 & 5.65 \\
\hline $02 \mathrm{TC} 11$ & 50 & 1800 & 10.94 & 7.59 & 5.38 \\
\hline $03 \mathrm{TC} 11$ & 50 & 3600 & 21.07 & 7.14 & 4.93 \\
\hline $33 \mathrm{TC} 1 \mathrm{I}$ & 125 & 3600 & 15.67 & 5.98 & 3.77 \\
\hline $11 \mathrm{TC} 11$ & 75 & 800 & 4.26 & 7.11 & 4.90 \\
\hline $12 \mathrm{TC} 00$ & 50 & 250 & 12.88 & 4.31 & 2.10 \\
\hline $12 \mathrm{TC} 01$ & 50 & 800 & 12.46 & 8.23 & 6.02 \\
\hline $12 \mathrm{TCO} 2$ & 50 & 1800 & 12.12 & 15.01 & 12.80 \\
\hline $12 \mathrm{TC} 12$ & 75 & 1800 & 9.13 & 11.99 & 9.78 \\
\hline $12 \mathrm{TC} 23$ & 100 & 3600 & 7.36 & 17.61 & 15.40 \\
\hline \multicolumn{6}{|l|}{10 Panel } \\
\hline $00 \mathrm{TC} 11$ & 50 & 250 & 1.93 & 7.87 & 6.16 \\
\hline 10TC11 & 75 & 250 & 1.65 & 6.96 & 5.25 \\
\hline $20 \mathrm{TC} 11$ & 100 & 250 & 1.51 & 6.50 & 4.79 \\
\hline $30 \mathrm{TC} 11$ & 125 & 250 & 1.42 & 6.22 & 4.51 \\
\hline $01 \mathrm{TC} 11$ & 50 & 800 & 6.01 & 7.62 & 5.91 \\
\hline $02 \mathrm{TC} 11$ & 50 & 1800 & 12.91 & 7.22 & 5.51 \\
\hline $03 \mathrm{TC} 11$ & 50 & 3600 & 23.98 & 6.60 & 4.89 \\
\hline $33 \mathrm{TC} 11$ & 125 & 3600 & 17.79 & 5.32 & 3.61 \\
\hline $12 \mathrm{TCO}$ & 50 & 1800 & 14.20 & 15.53 & 13.82 \\
\hline $12 \mathrm{TC} 12$ & 75 & 1800 & 10.63 & 12.05 & 10.34 \\
\hline $12 \mathrm{TC} 20$ & 100 & 250 & 9.39 & 2.84 & 1.13 \\
\hline $12 \mathrm{TC} 21$ & 100 & 800 & 9.13 & 5.60 & 3.89 \\
\hline $12 \mathrm{TC} 22$ & 100 & 1800 & 8.80 & 10.27 & 8.56 \\
\hline $12 \mathrm{TC} 23$ & 100 & 3600 & 8.30 & 17.77 & 16.06 \\
\hline \multicolumn{6}{|l|}{12 Pane1 } \\
\hline 00ТC12 & 50 & 250 & 2.13 & 16.32 & 15.467 \\
\hline $30 \mathrm{TC} 12$ & 125 & 250 & 1.61 & 12.52 & 11.67 \\
\hline $03 \mathrm{TC} 12$ & 50 & 3600 & 25.43 & 13.55 & 12.70 \\
\hline $12 \mathrm{TC} 12$ & 75 & 1800 & 12.08 & 13.00 & 12.15 \\
\hline $31 \mathrm{TC} 12$ & 125 & 800 & 4.96 & 12.12 & 11.27 \\
\hline $32 \mathrm{TC} 12$ & 125 & 1800 & 10.54 & 11.48 & 10.63 \\
\hline 33TC12 & 125 & 3600 & 19.25 & 10.93 & 10.08 \\
\hline $12 \mathrm{TC} 00$ & 50 & 250 & 17.68 & 3.46 & 2.61 \\
\hline
\end{tabular}


TABLE A2.2 continued

\begin{tabular}{|c|c|c|c|c|c|}
\hline & $\hat{A}_{B C}$ & $I_{B C}$ & $\mathrm{M}_{\mathrm{BC}}$ & ${ }_{\text {Total }}^{\mathrm{M}_{1}}$ & Secondary $^{*}{ }^{*}$ \\
\hline $\begin{array}{l}12 \mathrm{TC} 03 \\
12 \mathrm{TC} 11 \\
12 \mathrm{TC} 12 \\
12 \mathrm{TC} 30 \\
12 \mathrm{TC} 31 \\
12 \mathrm{TC} 32 \\
12 \mathrm{TC} 33\end{array}$ & $\begin{array}{r}50 \\
75 \\
75 \\
125 \\
125 \\
125 \\
125\end{array}$ & $\begin{array}{r}3600 \\
800 \\
1800 \\
250 \\
800 \\
1800 \\
3600\end{array}$ & $\begin{array}{r}14.68 \\
12.74 \\
12.08 \\
9.55 \\
9.22 \\
8.78 \\
8.14\end{array}$ & $\begin{array}{r}29.31 \\
6.75 \\
13.00 \\
2.48 \\
5.25 \\
9.82 \\
16.92\end{array}$ & $\begin{array}{r}28.46 \\
5.90 \\
12.15 \\
1.63 \\
4.40 \\
8.97 \\
16.07\end{array}$ \\
\hline
\end{tabular}

* $\mathrm{M}_{\mathrm{TC}}($ Secondary $)=\mathrm{M}_{\mathrm{TC}}($ Tota 1$)-\mathrm{M}_{\mathrm{TC}}$ (Primary) where

$\mathrm{M}_{\mathrm{TC}}$ (Primary) (found from Figures $4.5,4.7$ and 4.9)

for each truss is as follows:

$$
\begin{aligned}
& 8 \text { Panel - } \mathrm{M}_{\mathrm{TC}} \text { (Primary) }=2.21 \mathrm{Ft}-\mathrm{K} \\
& 10 \text { Panel " }=1.71 \mathrm{Ft}-\mathrm{K} \\
& 12 \text { Panel " }=0.85 \mathrm{Ft}-\mathrm{K}
\end{aligned}
$$


TABIE A2.3a

COMPUTER FRAME ANALYSIS DATA * USED TO PLOT FIGURE $6.1 \mathrm{a}$

8 PANEL TRUSS

\begin{tabular}{|c|c|c|c|c|c|}
\hline \multirow[b]{2}{*}{ Location } & \multirow{2}{*}{$\begin{array}{l}\text { Primary } \\
\text { Moment }\end{array}$} & \multicolumn{2}{|c|}{$12 \mathrm{TC} 12$} & \multicolumn{2}{|c|}{$12 \mathrm{TC} 23$} \\
\hline & & Tot Mom & Sec Mom & Tot Mom & Sec Mom \\
\hline $\begin{array}{l}\text { J } 23 \\
\text { J } 25 \\
\text { J26 } \\
\text { J } 27 \\
\text { J } 28 \\
\text { J } 31 \\
\text { J } 32 \\
\text { J33 } \\
\text { J } 34 \\
\text { J37 } \\
\text { J } 38 \\
\text { J } 39 \\
\text { J40 } \\
\text { J41 } \\
\text { J42 } \\
\text { J } 43 \\
\text { J44 }\end{array}$ & $\begin{array}{r}0.00 \\
1.01 \\
-1.09 \\
-0.10 \\
-0.32 \\
-0.11 \\
2.21 \\
-2.95 \\
0.00\end{array}$ & $\begin{array}{r}0.00 \\
1.80 \\
2.73 \\
2.77 \\
2.10 \\
2.53 \\
2.44 \\
1.96 \\
1.32 \\
3.68 \\
5.90 \\
8.25 \\
11.19 \\
6.13 \\
2.27 \\
0.06 \\
0.00\end{array}$ & $\begin{array}{l}0.00 \\
1.72 \\
3.19 \\
2.54 \\
1.64 \\
6.01 \\
8.98 \\
5.22 \\
0.00\end{array}$ & $\begin{array}{r}0.00 \\
2.37 \\
3.87 \\
4.46 \\
4.34 \\
4.74 \\
4.61 \\
4.07 \\
3.34 \\
6.61 \\
9.67 \\
12.82 \\
16.50 \\
10.20 \\
5.04 \\
1.47 \\
0.00\end{array}$ & $\begin{array}{l}0.00 \\
2.86 \\
5.43 \\
4.71 \\
3.66 \\
9.78 \\
14.29 \\
7.99 \\
0.00\end{array}$ \\
\hline
\end{tabular}

*Data from Model III, Fu11 Truss 
TABLE A2.3b

COMPUTER FRAME ANALYSIS DATA

USED TO PLOT FIGURE $6.1 \mathrm{~b}$

12 PANEL TRUSS

\begin{tabular}{|l|r|r|r|r|r|}
\hline \multirow{2}{*}{ Location } & \multirow{2}{*}{$\begin{array}{c}\text { Primary } \\
\text { Moment }\end{array}$} & \multicolumn{2}{|c|}{$12 \mathrm{TC12}$} & \multicolumn{2}{|c|}{$12 \mathrm{TC} 33$} \\
\cline { 3 - 6 } & & Tot Mom & Sec Mom & Tot Mom & Sec Mom \\
\hline J1 & 0.00 & 0.00 & 0.00 & 0.00 & 0.00 \\
J2 & 0.35 & 1.09 & 0.74 & 1.52 & 1.17 \\
J3 & 0.37 & 1.81 & 1.44 & 2.66 & 2.29 \\
J4 & 0.08 & 2.25 & 2.17 & 3.52 & 3.46 \\
J5 & -0.50 & 2.35 & 2.85 & 4.03 & 4.53 \\
J10 & -0.06 & 2.69 & 2.75 & 4.36 & 4.42 \\
J11 & 0.10 & 2.72 & 2.62 & 4.37 & 4.27 \\
J12 & 0.02 & 2.48 & 2.46 & 4.11 & 4.09 \\
J13 & -0.25 & 2.05 & 2.30 & 3.65 & 3.90 \\
J16 & -0.04 & 2.46 & 2.50 & 4.07 & 4.11 \\
J17 & 0.04 & 2.75 & 2.71 & 4.37 & 4.33 \\
J18 & 0.05 & 2.91 & 2.86 & 4.54 & 4.49 \\
J19 & 0.06 & 3.15 & 3.09 & 4.78 & 4.72 \\
J22 & -0.15 & 3.01 & 3.16 & 5.02 & 5.17 \\
J23 & -0.28 & 2.87 & 3.14 & 5.24 & 5.52 \\
J24 & -0.22 & 2.96 & 3.18 & 5.69 & 5.91 \\
J25 & 0.09 & 3.30 & 3.21 & 6.35 & 6.26 \\
J28 & -0.06 & 5.38 & 5.46 & 8.65 & 8.71 \\
J29 & -0.05 & 7.64 & 7.69 & 11.12 & 11.17 \\
J30 & 0.21 & 10.17 & 9.96 & 13.87 & 13.66 \\
J31 & 0.85 & 13.00 & 12.15 & 16.92 & 16.07 \\
J33 & -0.43 & 8.75 & 9.18 & 11.69 & 12.12 \\
J34 & -1.09 & 5.06 & 6.15 & 7.01 & 8.10 \\
J35 & -0.99 & 2.08 & 3.07 & 3.05 & 4.04 \\
J36 & 0.00 & 0.00 & 0.00 & 0.00 & 0.00 \\
& & & & & \\
\hline
\end{tabular}




\section{APPENDIX 3 \\ "PINNED MEMBER" DESIGN METHOD}

The classical method of considering secondary stresses in trusses consists of computing the joint deflections based on a pinjointed truss analysis. These deflections are then used as support settlements for the continuous chord which allows the moments to be computed. This method is only approximate, but is reasonably accurate for most design work. It should be noted that the deflection perpendicular to the top chord should be used when computing top chord moments.

The slight error in this method stems from the fact that the secondary moments cause some redistribution of axial forces in the members which will affect deflections. In bowstring trusses, an additional error is introduced by the fact curved top chord changes length not only due to the axial stress deformation, but also as a result of the bending moments $\left(\delta_{I}\right.$, derived in appendix 1$)$.

The $\delta_{I}$ value for primary moments is generally small compared to the axial deformation. However, as was shown, the secondary moments may be much larger than the primary moments. These moments will be positive moments (tending to decrease curvature) and as a result will tend to lengthen the member.

The redistribution of forces in the end two webs is also significant which tends to smooth the deflected shape. 
These two factors result in deflections computed assuming straight pinned end members being greater than will actually occur. Thus, the secondary moments computed by this technique will be conservative. In most cases, however they will represent the actual stresses accurately enough for design purposes.

Joint slippage can be introduced in this method in any of the conventional ways, normally by including a fixed internal deflection component into the virtual work summation process, or if a matrix analysis is used, the member areas can be artificially modified to affect a larger member deformation. 
APPENDIX 4

"GENERAL CHARACTERISTIC EQUATION" METHOD

COMPUTER PROGRAMS 
PROGRAM I. DATA BASE PREPARATION

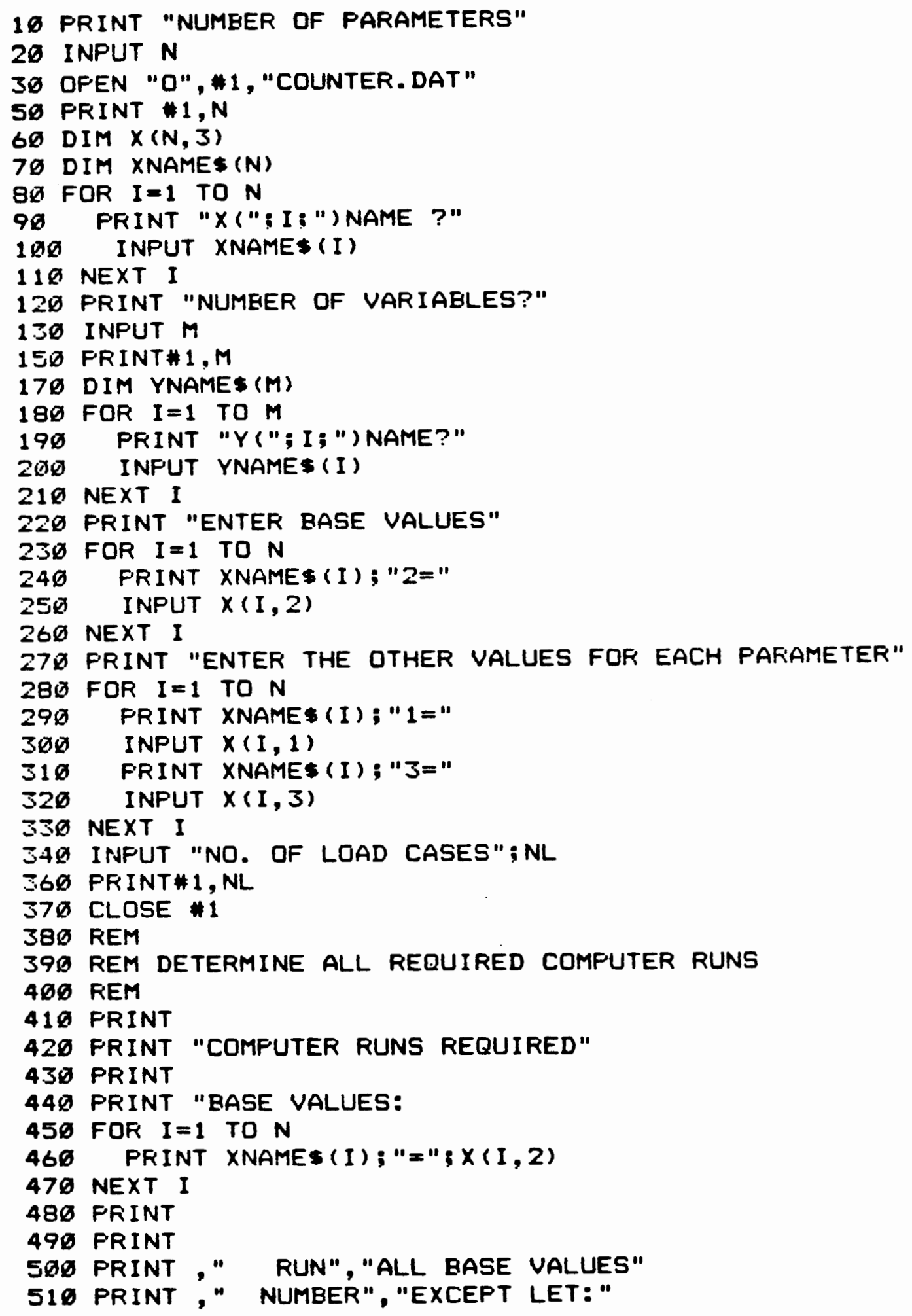




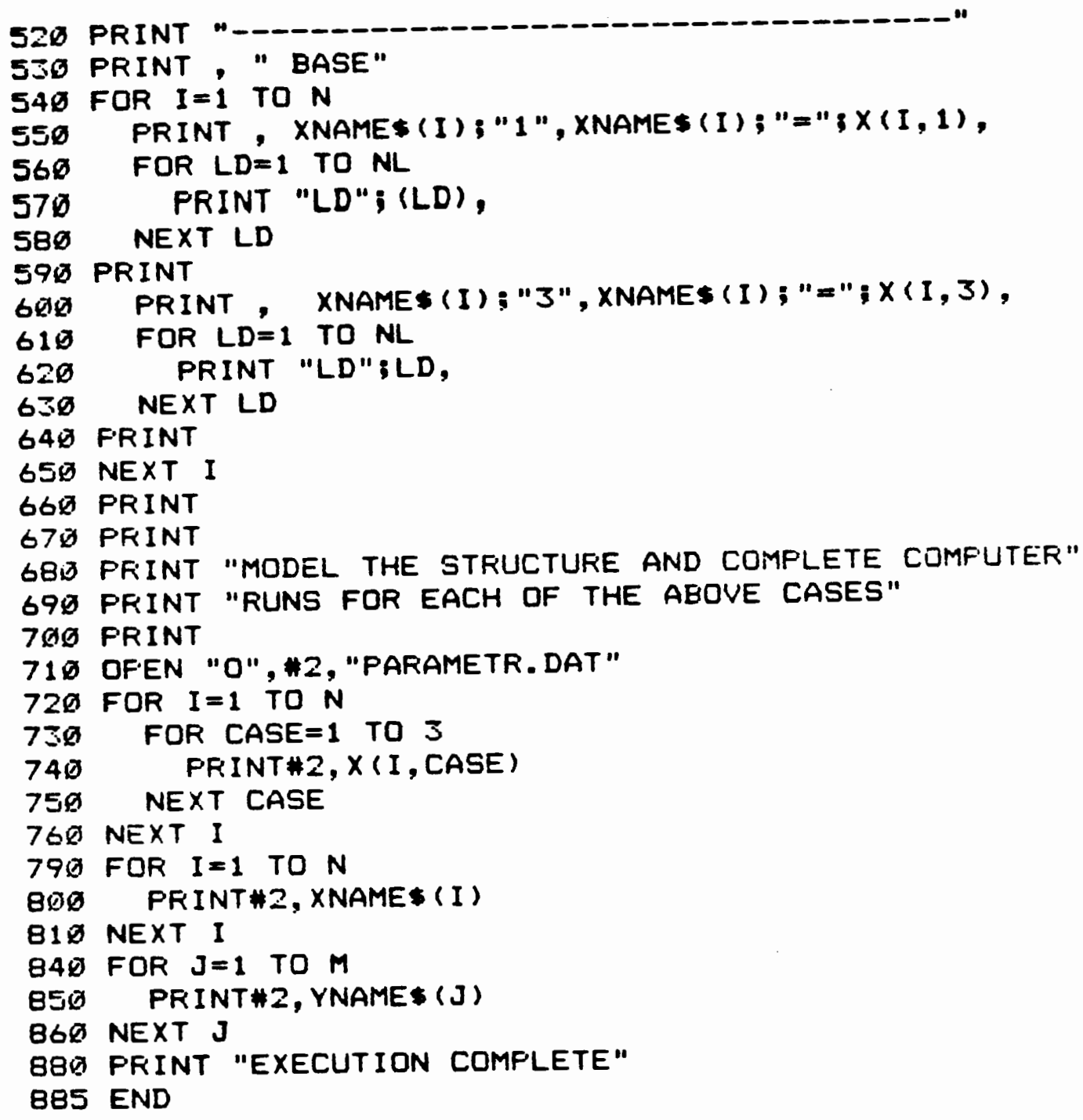


PROCRAM II. DEVELUPMENT OF CHARACTERISTIC EQUATIONS

8Qत FEM THIS FFOGFAM DE!'ELIJFES THE CONSTANT FOR THE

381 FEM CHARACTEFISTIC EQUATIONS

995 INFLT "FFINTER CONNECTED ( 1 OF $Y=Y E S) "$ :FF:

896 OFEN "I". \#1. "COUNTEF.DAT"

(7) INFUT $1 . \mathrm{N}$

920 INIFUT $\$ 1, M$

940) INFUT \#1.NL

950 DFEN "I", \#2. "FAFAMETR. DAT"

$97 \%$ FOF $\mathrm{I}=1$ TO $\mathrm{N}$

975 FOF $C A S E=1$ TO :

PBS IIFUT \#Z,X (I.CASE)

1 (Q)G NEXT CASE

1) 15 NEXYT I

1.1) D(1) FOR $\mathrm{I}=1$ TO $\mathrm{N}$

$1 \%$ IOI INFUT \#2, XPAME\$(I)

10)40I NEXT I

$106 \%$ FOF $J=1$ TO $M$

$197 \%$ INFUT \#2, VNAME (J)

1 1\%8G NEXT J

$109)$ DIM E (N, M,NL)

11 DIM $G(N, M, N L)$

1110 DIM $R$ (N,M,NL)

11200 DIM C(N,M,NL)

1130 DIM YE(M.NL)

1135 DIM $Y(N, 2, M, N L)$

1140 DIM TY (M,NL)

$115 \%$ IIM TOTY (M)

1160 DIM TX(N)

117 13 OFEN "O", \#Z, "EQUATION. DAT"

$113 \ddot{3}) \mathrm{FOF} \quad L D=1$ TO $\mathrm{NL}$

1206 FOF $J=1$ TO $M$

1210 FFINT YNAME (J);"(EASE, " LD;") =?"

12239 INFUT YE(J,LD)

12F⿻ FFINT\#S,YE(J,LD): IF FF $=" 1 "$ OR FF $\$=" Y "$ THEN LFFINT YNAME (J):"(EASE, "LD:" )="; YE(J,LD)

$124 \%$ NEXT $J$

1241 NEXT LD

1243 FOR $L D=1$ TO NL

1245 FOR $I=1$ TO $N$

1247 FOF CASE $=1$ TO 2

1249 FOF $J=1$ TO $M$

1251

FFINT YNAMEO(J):" " : XNAME (I) : CASE: "LD":LD:")?"

;

125: INFUT Y (I, CASE, J,LD)

1254 IF FF: $\$=" 1 "$ OR FF: "Y" THEN LFFINT YNAME $(J): "$ "

"; XNAME (I) : CASE: "LD"; LD") =" : Y I , CASE, J, LD )

1255 NEXT J

1257 RHEXT CASE 


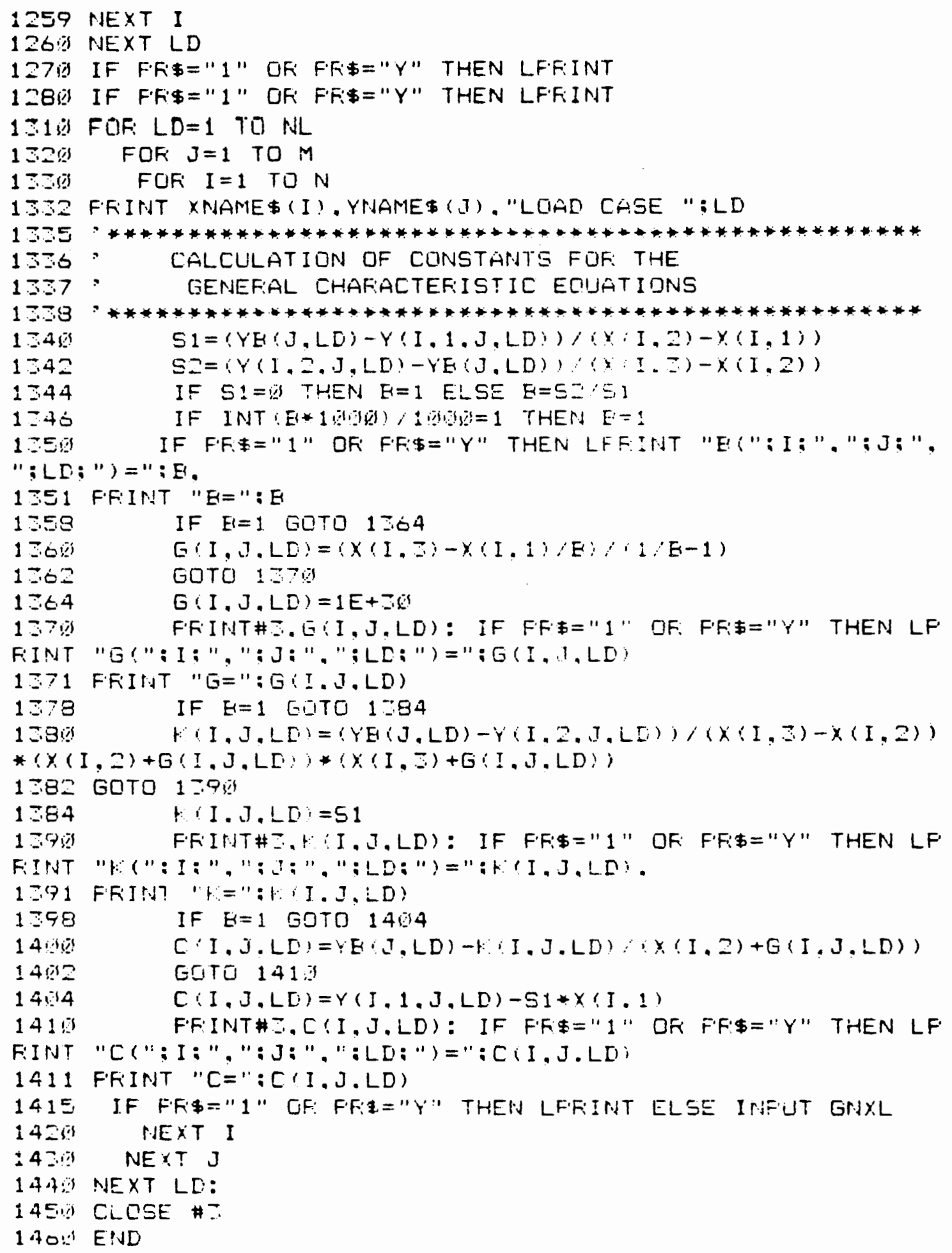




\section{PROCRAM III. DESIGN PROCEDURE}

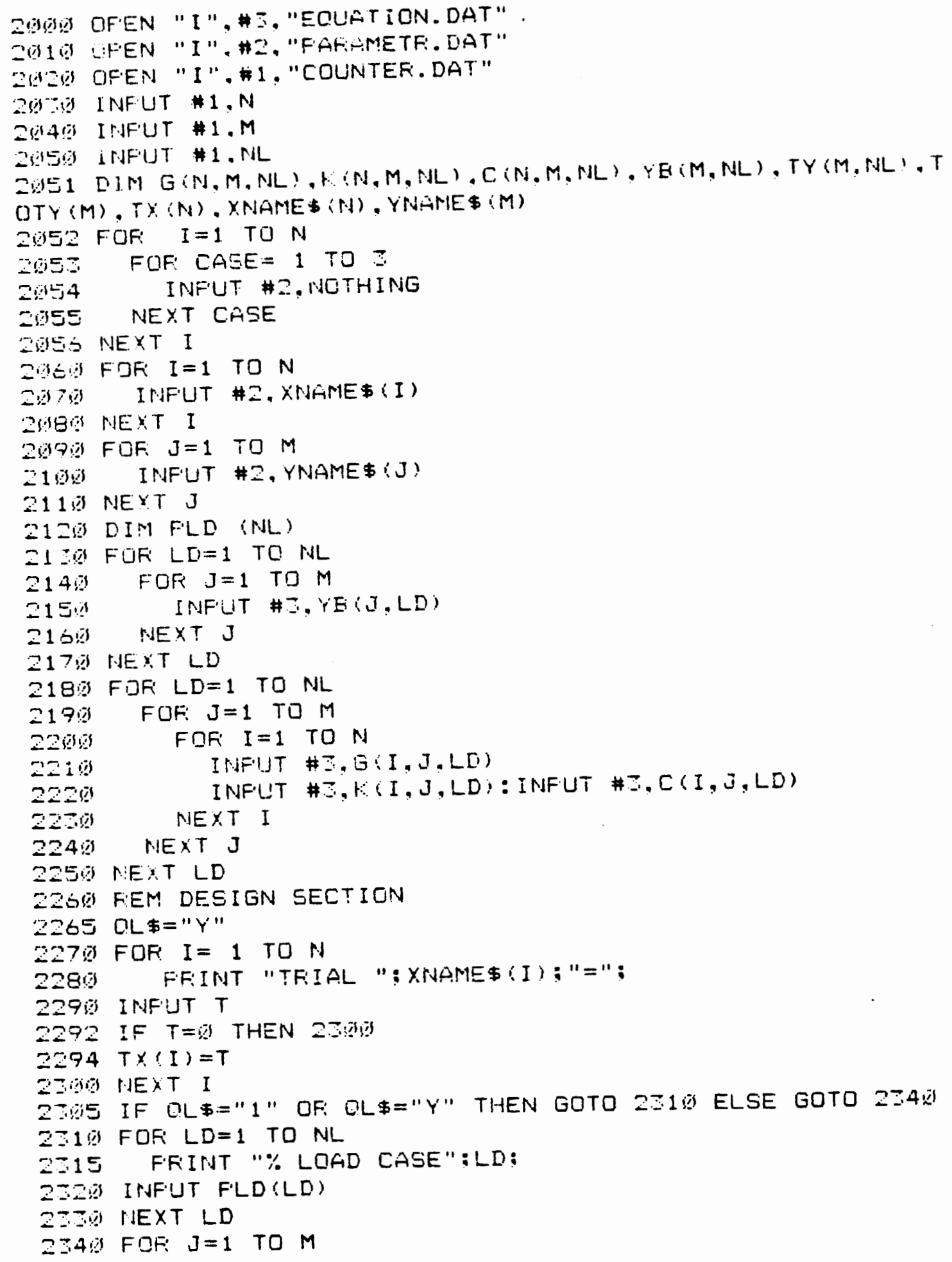




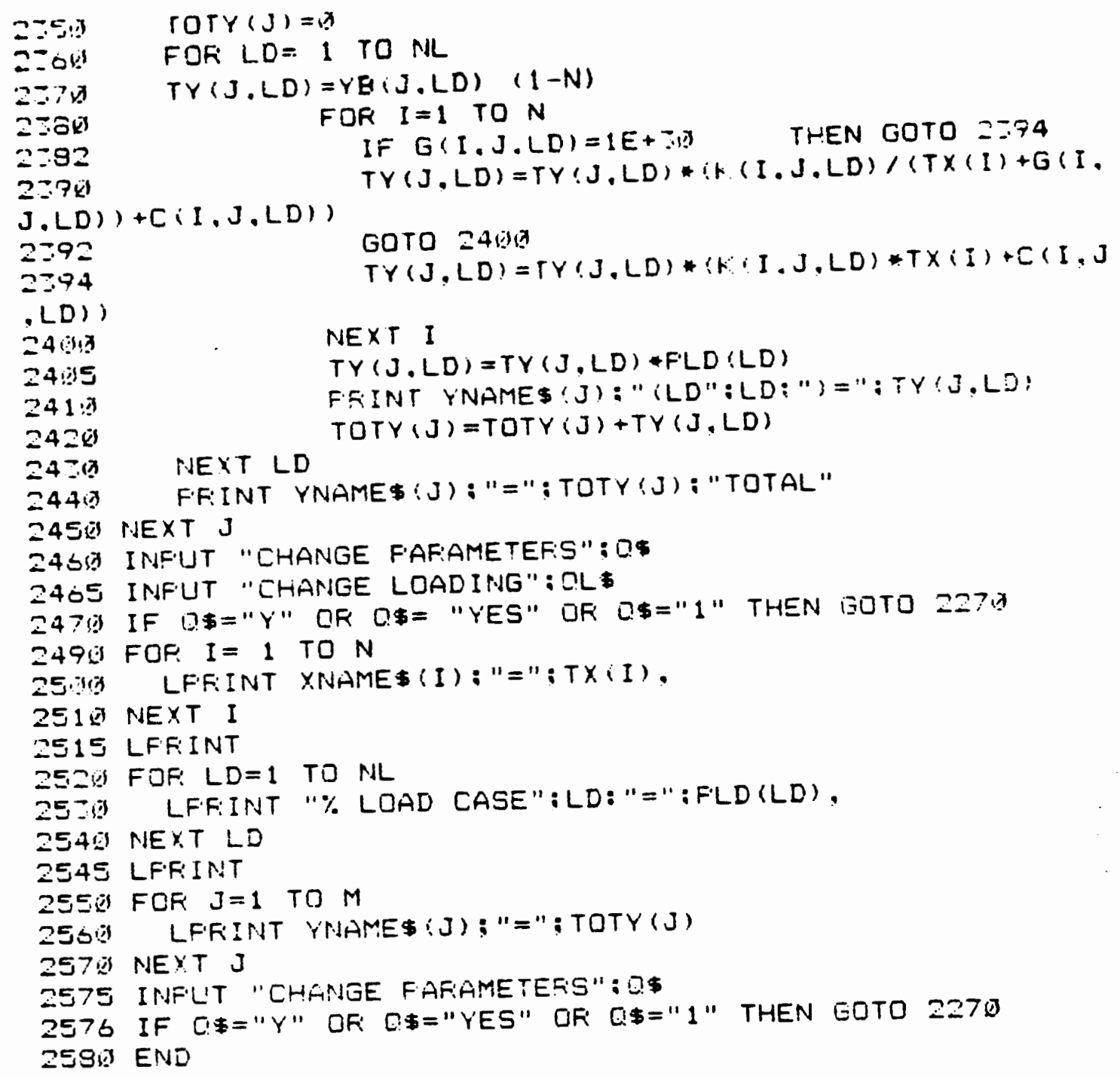




\section{REFERENCES}

1. Laursen, H.I. 1969. Structural Analysis, McGraw-Hill Book Company.

2. The American Institute of Timber Construction, 1974. Timber Construction Manual, Second Edition, John Wiley and Sons, Inc.

3. Mueller, W.H. III. RIGID, A Frame and Truss Analysis Program, Civil-Structural Engineering, Portland State University.

4. Bathe, K.J., Wilson, E.L., and Peterson, F.E. SAP IV, A Structura1 Analysis Program for Static and Dynamic Response of Linear Systems, June 1973, Revised April 1974, College of Engineering, University of California, Berkeley, California.

5. The American Institute of Timber Construction. AITC 117-79-Design Standard Specifications for Structural Glued Laminated Timber of Softwood Species, Adopted as Recommendations June 27, 1979.

6. GTICES Systems Laboratory. GTSTRUDL, School of Civil Engineering, Georgia Institute of Technology, Atlanta, Georgia.

7. National Forest Products Association. National Design Specification for Wood Construction, 1982 Edition, National Forest Products Association, Washington, D.C.

8. Bradford, J.F. Timber Design - 1982 NDS, Dick W. Ebeling, Inc., Portland, Oregon.

9. Roark, R.J. and Young, W.C. 1975. Formulas for Stress and Strain, Fifth Edition, McGraw Hill Book Company. 